Florida International University

FIU Digital Commons

FIU Electronic Theses and Dissertations

University Graduate School

10-28-2019

\title{
Democracy and Bureaucracy of Smart Place: Coral Gables, FL and the Role of Aspirational Content in Local Governance
}

\author{
Ramon Trias \\ rtria003@fiu.edu
}

Follow this and additional works at: https://digitalcommons.fiu.edu/etd

Part of the Architectural History and Criticism Commons, Environmental Design Commons, Historic Preservation and Conservation Commons, Policy History, Theory, and Methods Commons, Public Administration Commons, Public Policy Commons, Urban, Community and Regional Planning Commons, and the Urban Studies Commons

\section{Recommended Citation}

Trias, Ramon, "Democracy and Bureaucracy of Smart Place: Coral Gables, FL and the Role of Aspirational Content in Local Governance" (2019). FIU Electronic Theses and Dissertations. 4283.

https://digitalcommons.fiu.edu/etd/4283

This work is brought to you for free and open access by the University Graduate School at FIU Digital Commons. It has been accepted for inclusion in FIU Electronic Theses and Dissertations by an authorized administrator of FIU Digital Commons. For more information, please contact dcc@fiu.edu. 


\section{FLORIDA INTERNATIONAL UNIVERSITY}

Miami, Florida

\section{DEMOCRACY AND BUREAUCRACY OF SMART PLACE:}

CORAL GABLES, FL AND THE ROLE OF ASPIRATIONAL CONTENT IN LOCAL GOVERNANCE

A dissertation submitted in partial fulfillment of the requirements for the degree of DOCTOR OF PHILOSOPHY

in

PUBLIC AFFAIRS

by

Ramon Trias 
To: Dean John F. Stack, Jr.

Steven J. Green School of International and Public Affairs

This dissertation, written by Ramon Trias, and entitled Democracy and Bureaucracy of Smart Place: Coral Gables, FL and the Role of Aspirational Content in Local Governance, having been approved in respect to style and intellectual content, is referred to you for judgement.

We have read this dissertation and recommend that it be approved.

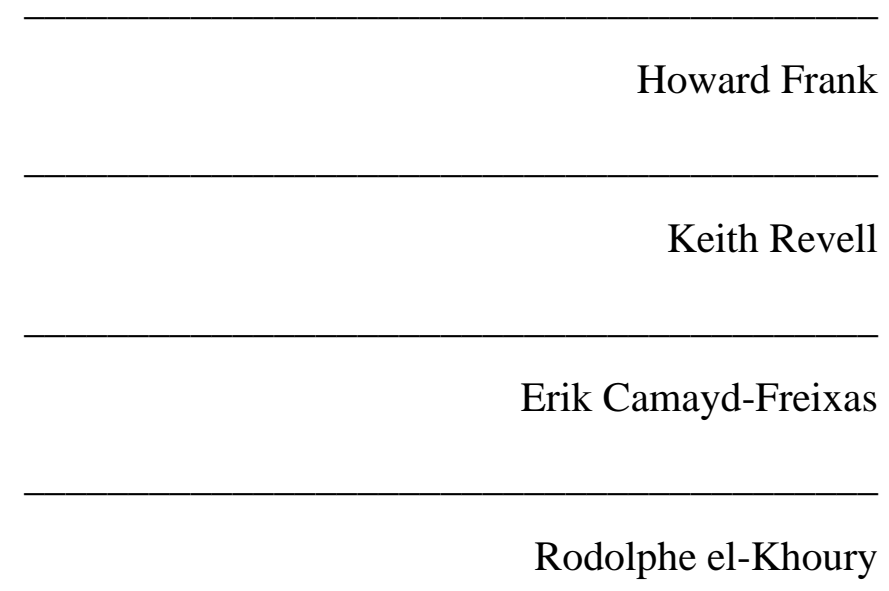

Jean-Claude Garcia-Zamor, Major Professor

Date of Defense: October 28, 2019

The dissertation of Ramon Trias is approved.

Dean John F. Stack, Jr. Steven J. Green School of International and Public Affairs

Andres G. Gil

Vice President of Research and Economic Development and Dean of the University Graduate School

Florida International University, 2019 
(C) Copyright 2019 by Ramon Trias

All rights reserved. 


\section{DEDICATION}

I dedicate this dissertation to the memory of my father, Ramon Trias Baez, and the patience of my mother, Maria del Carmen Rodriguez Ferrando. 


\section{ACKNOWLEDGMENTS}

I want to thank the dissertation committee of outstanding scholars from Florida

International University and the University of Miami who assisted me with this dissertation.

Professors Jean-Claude Garcia-Zamor, Chair of the Committee, Howard Frank, Chair of the FIU Public Administration Department, Keith Revell, associate professor of public administration, Erick Camayd-Freixas, professor of Spanish, and Rodolphe elKhoury, Dean of the University of Miami’s School of Architecture.

Their criticism and vision are appreciated. Comments from the dissertation defense were incorporated in the final manuscript. 


\author{
ABSTRACT OF THE DISSERTATION \\ DEMOCRACY AND BUREAUCRACY OF SMART PLACE: \\ CORAL GABLES, FL AND THE ROLE OF ASPIRATIONAL CONTENT \\ IN LOCAL GOVERNANCE \\ by \\ Ramon Trias
}

Florida International University, 2019

Miami, Florida

Professor Jean-Claude Garcia-Zamor, Major Professor

This dissertation explores the role aspirational content on democracy and bureaucracy for governance of place in the United States. Place is a fundamental concept for municipal democracy and bureaucracy, as it defines the physical qualities of a community and their effect on people and quality of life. Smart Place would update theory and practices for local governance. Research reviewed process and content for the implementation of place, a gap in public administration theory. Literature review, historical research on $20^{\text {th }}$ century planning and zoning, research on 1920 's best practices on architecture and archival, qualitative findings and quantitative data on Coral Gables, Florida provided evidence for theory and practice recommendations related to timeless qualities of place and innovative smart strategies. Analysis of findings led to the following generalized conclusions:

1. Aspirational content should guide best practices for local democracy and bureaucracy on issues related to place.

2. Governance of smart place should replace conventional planning and zoning. 


\section{TABLE OF CONTENTS}

CHAPTER

PAGE

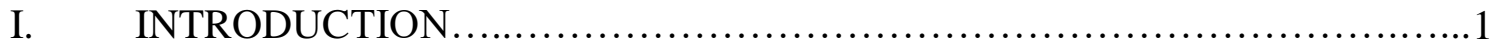

Personal Preface................................................... 2

Introduction to the Administration of Place..................................

Coral Gables: The Administration of Form..............................23

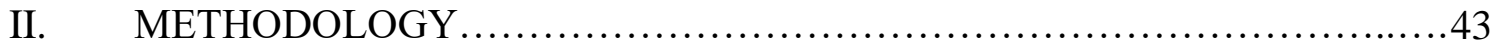

Research Methods and Questions...................................44

Scope and Limitations of the Study ..................................56

III. LITERATURE REVIEW ....................................................65

In Search of a Language for Place....................................66

Towards a Literature of Place: Coral Gables, FL.........................89

Architecture Reference Books from the Early $20^{\text {th }}$ Century ..............106

George Merrick's Narrative of Place.................................126

Data for Smart Place..............................................152

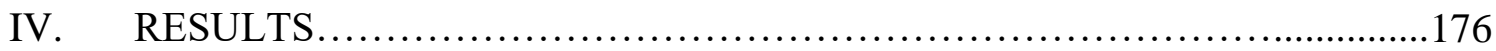

Qualitative Interviews on Place...................................177

Zoning the City Beautiful........................................ 186

The Coral Gables Mediterranean Bonus Program..................... 200

Coral Gables Board of Architects................................... 223

Quantitative Data on Content and Process for Coral Gables............ 235

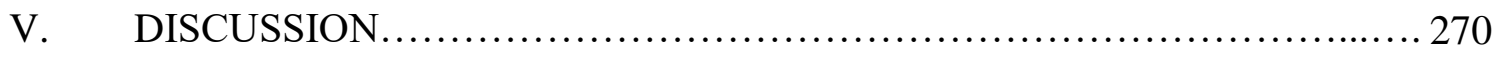

Aspirational Content............................................. 271

Governance of Smart Place......................................2277

From the Administrative City to Smart Place............................ 285

Best Practices for Democracy of Smart Place:

Education, Participation, Decision................................... 297

Best Practices for Bureaucracy of Smart Place:

Data, Language, Manuals, Procedures................................. 323

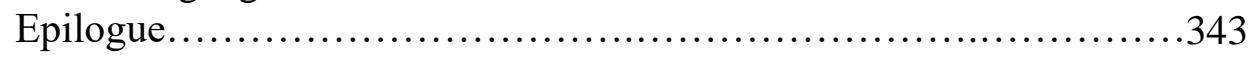

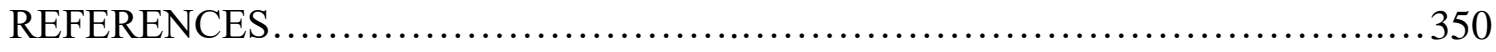

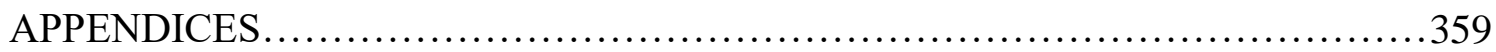

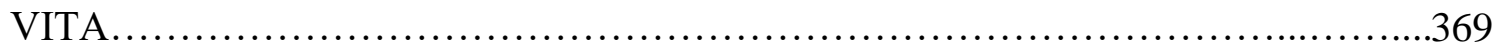




\section{LIST OF TABLES}

TABLE

PAGE

1. Coral Gables demographic data. Source: United States Census Bureau............. 25

2. Coral Gables employment data. Source: United States Census Bureau.............26

3. Persons interviewed by Ramon Trias.....................................178

4. List of Coral Gables zoning ordinances. Source: City of Coral Gables.............193

5. Evolution of zoning language.

Source: Coral Gables Zoning Codes 1930 - 2007............................198

6. List of regulations related to the Mediterranean bonus program.

Source: City of Coral Gables................................................ 206

7. Mediterranean bonus program, standards of review.

Source: Coral Gables Zoning Code...............................................207

8. List of exemplary buildings for Coral Gables Mediterranean style.

Source: Coral Gables Zoning Code...................................... 208

9. Evolution of Coral Gables Board of Architects.

Source: City of Coral Gables...............................................230 


\section{LIST OF FIGURES}

FIGURE

PAGE

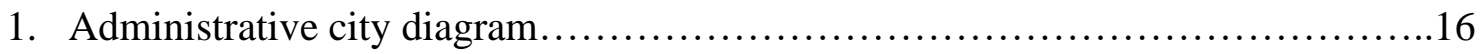

2. Smart Place diagram.................................................. 16

3. Zoning Process diagram. Source: Coral Gables Zoning Code, 2007...............38

4. Quality of life in Coral Gables statistics.

Source: City of Coral Gables website....................................... 240

5. Quality of life in Miami-Dade County statistics.

Source: City of Coral Gables website..................................... 242

6. Word cloud from Community Engagement survey write-in comments.

Source: Ramon Trias.................................................243

7. Word cloud from Board of Architects survey write-in comments.

Source: Ramon Trias................................................. 261 


\section{LIST OF PLATES}

PLATE

PAGE

1. Administration Building, Coral Gables, architect Walter de Garmo, 1924.

Source: HistoryMiami Archive. xiv

2. South Elevation, City Hall, Coral Gables, architect Phineas Paist, 1927, Source: City of Coral Gables..... 1

3. Marina Square, Fort Pierce, FL. Photograph by Ramon Trias.

4. Map of South Florida, 1914. Source: HistoryMiami Archive.....................28

5. Coral Gables Plat, 1921. Source: HistoryMiami Archive......................30

6. Diagram of Coral Gables street layout. Source: City of Coral Gables.............. 32

7. Map of Coral Gables and vicinity. Source: City of Coral Gables...................33

8. Diagram of Coral Gables master plan. Source: City of Coral Gables.............. 35

9. Douglas Entrance rendering, by Walter de Garmo, Denman Fink and Phineas Paist, Associate Architects. Source: HistoryMiami Archive.

10. Comparison of Coral Gables marketing rendering and painting by Martin Rico. Sources: Rendering: Coral Gables publication, painting: Prado Museum

11. Entrance, Biltmore Hotel, Coral Gables, architect Schultze and Weaver, 1926. Source: Coral Gables Historic Preservation office.

12. Cover, Lesser Known Architecture of Spain, 1925.

Source: Ramon Trias

13. Original 1809 edition of J. N. Durand's Precis de lecons d'architecture dones 1'Ecole Royale Polytechnique. Photograph: Ramon Trias.......................108

14. Folio book illustration. Source: Ramon Trias

15. Folio book illustration. Source: Ramon Trias.

16. Pencil Point, PDF version. Source: HathiTrust website

17. Smart City portal, 2019. Source: Coral Gables website. 154 
18. East Giralda, pedestrian counts. Source: Coral Gables website. 160

19. Fink Studio, Ponce de Leon boulevard façade.

Source: Coral Gables website... 163

20. Fink Studio, details. Source: Coral Gables website .164

21. Coral Gables magazine article. Photograph: Ramon Trias .166

22. Coral Gables main menu. Source: Coral Gables website 167

23. Traffic information. Source: Coral Gables website 168

24. Parking information. Source: Coral Gables website .169

25. Bicycle and pedestrian incidents. Source: Coral Gables website 169

26. Sanitation information. Source: Coral Gables website 170

27. Electronic vehicle charging station locations. Source: Coral Gables website......171

28. Historic preservation page. Source: Coral Gables website 172

29. Current development projects. Source: Coral Gables website .173

30. Parks page. Source: Coral Gables website 174

31. Coral Gables development, existing conditions, 2016.

Source: City of Gables 176

32. 2020 Salzedo. Photograph: Ramon Trias. 211

33. Diagram of buildings which received Mediterranean bonus, highlighted in red. Source: City of Coral Gables 212

34. Summary of topics, ZenCity. Source: City of Coral Gables 263

35. Social media comments, ZenCity. Source: City of Coral Gables 264

36. Coral Gables City Hall, South Facade, 2016. Photograph: Ramon Trias. 270

37. ZenCity information ion I-Phone display. Source: City of Coral Gables 304

38. Flagler Section page. Source: Coral Gables website 305 
39. Coral Gables interactive zoning map.

Source: Coral Gables website

40. Coral Gables City Hall, South Elevation.

Source: Coral Gables website

41. Coral Gables Mediterranean Architecture page.

Source: Coral Gables website

42. Coral Gables planning initiatives page.

Source: Coral Gables website.

43. Social media comments. Source: ZenCity

44. Neighborhood presentation page. Source: Coral Gables website

45. Neighborhood workshop. Photograph: Ramon Trias

46. Neighborhood walk. Photograph: Ramon Trias.....

47. Coral Gables Board of Architects meeting. Photograph: Ramon Trias 316

48. Coral Gables Commission Workshop. Photograph: Ramon Trias.

49. Report on workshop. Source: Coral Gables website. 318

50. Coral Gables Commission Meeting. Source: City of Coral Gables.

51. Tree Keeper page. Source: Coral Gables website. 320

52. Community engagement page. Source: Coral Gables website.

53. Coral Gables City Commission meeting on television.

Photograph: Ramon Trias.

54. Above, Nolli map of Rome, 1748. Below, map of Coral Gables, after Nolli map technique, 2019. Source: City of Coral Gables.

55. Zoning map, with volumetric data and existing conditions photograph.

Source: City of Coral Gables. 328

56. Zoning Code illustration. Source: Coral Gables website

57. Community intelligence page. Source: Coral Gables website. 300 
58. Control office, smart video information. Photograph: Ramon Trias .331

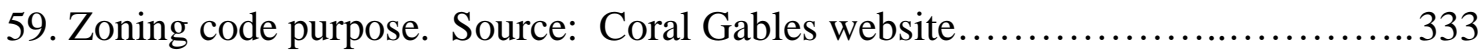

60. Best Practices Manual, Coral Gables Board of Architects. Source: Coral Gables website............................................. 336

61. North Ponce capital projects page. Source: Coral Gables website..................337

62. Giralda Plaza pedestrian counts. Source: Coral Gables website.................. 338

63. Coral Gables zoning code, Mediterranean architecture.

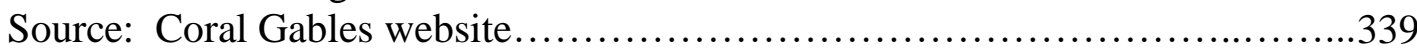

64. Board of Architects meeting. Photograph: Ramon Trias.........................341

65. Permit page. Source: Coral Gables website.................................342

66. Brochure cover. Source: City of Coral Gables............................. 333

67. Brochure text. Source: City of Coral Gables.................................... 344

68. 307 Orange Avenue, Fort Pierce, FL. Photograph: Ramon Trias................. 345 


\section{GLOSARY FOR THEORY DEVELOPMENT}

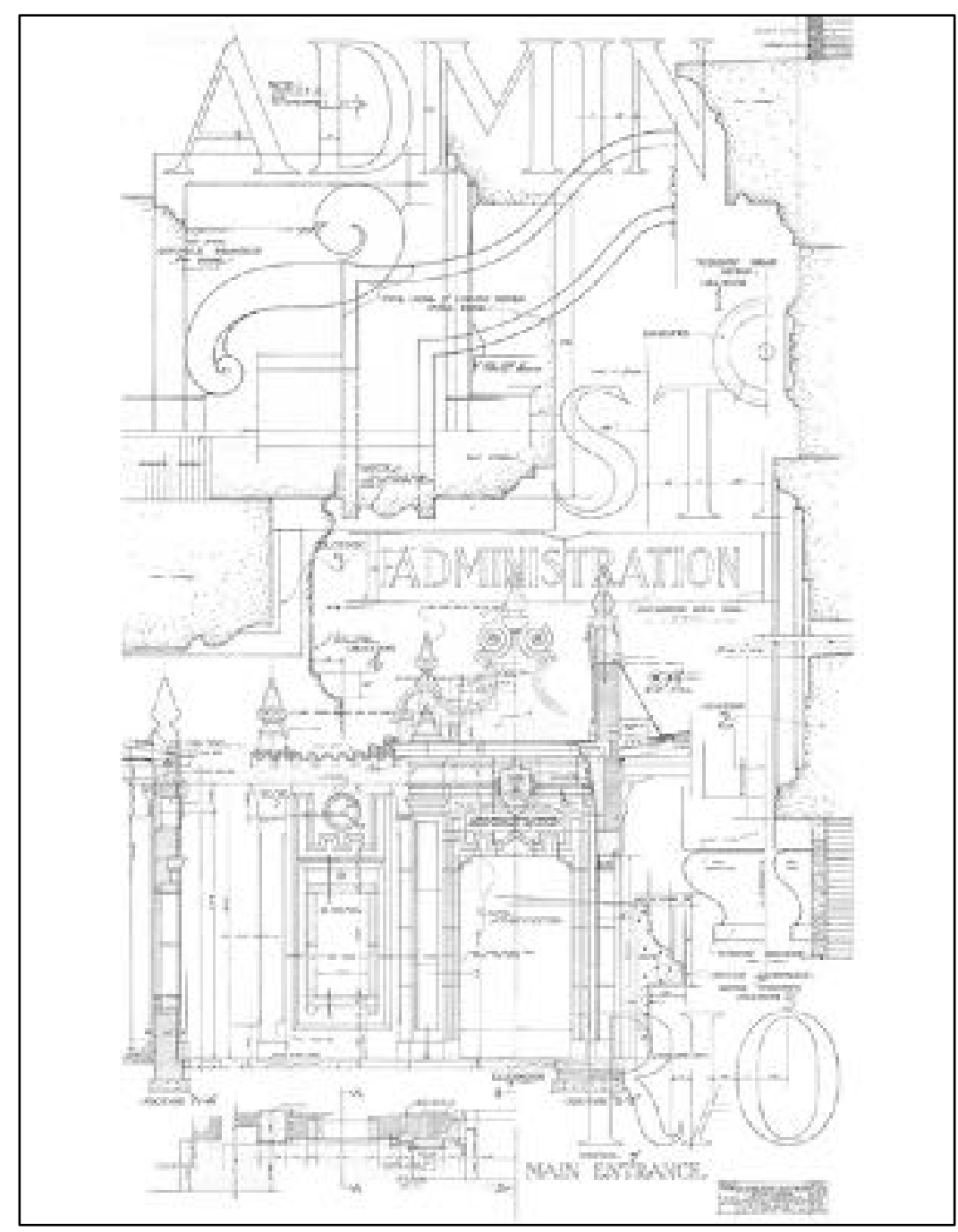

Plate 1. Administration Building, Coral Gables, architect Walter de Garmo, 1924. Source: HistoryMiami Archive.

The analytique drawing technique was a best practice of the 1920's inspired by Beaux Arts training, where technical details of construction in multiple views and scales were incorporated into an artistic composition intended to convey content. The city administration building, designed in the Mediterranean style, would house staff who implemented Coral Gables local governance until demolition in 1950. A two-story MIMO building replaced it. The new building was remodeled with Mediterranean features in the 1980's. In 2019 a seven-story hotel was proposed for the site. 
The following terms, concepts and names propose updated theory for Public Administration, explain Coral Gables terminology, identify key people mentioned in the text of the study or provide context for use in this dissertation. One of the goals of the study was to expand the language of place. The glossary reflects conclusions and should contribute to future discussion. It may be read independently from the rest of the text.

Administration of place: Planning and zoning processes and additional local government activities related to the physical environment of community.

Administrative city, the (related to place): Bureaucratic organization for local governance mandated, but not designed, by state legislation based on the zoning enabling act. The specific structure of bureaucracy is determined by each local government, in public hearings and administrative decisions, and may change through time. General theory and best practices would enhance administration.

Aspirational content: Principal subject matter of governance of place. Content is the general term for characteristics of place and is derived from a narrative of place and provides objective standards for quality, meaning and significance to place. "Aspirational" referrers to a democratic process used to develop content.

Autonomy of place: Discussion of place is about data and should be independent from social policy, historical methods or demographic information.

Best practices for building design from the early $20^{\text {th }}$ century: Tools and techniques used by American architects in the 1910's and 1920's inspired by the methods developed in the Ecole des Beaux Arts in the $19^{\text {th }}$ century. Reference folio books, 
typology, precedent and aesthetic style were among the practices. Such practices can be updated through Smart Place strategies.

Board of Architects (Coral Gables): Volunteer committee of professional architects, established by the Zoning Code of Coral Gables, Florida. The Board meets every Thursday and it is tasked with the aesthetic review of all exterior building permits, which range from new multistory mixed-used buildings to replacement of residential windows.

Cerda, Ildefons: (1815-1876) Spanish civil engineer and town planning innovator. He coined the term urbanization, pioneered the use of data for long range planning, and suggested the term "content" in General Theory of Urbanization (1867).

Comprehensive plan: A plan for the future development of a community, often mandated by state law. Notwithstanding contemporary legal meaning, the early intent was comparable to the first Coral Gables master plan. Thus, early $20^{\text {th }}$ century zoning and early comprehensive plans provide contrasts of best practices with early $21^{\text {st }}$ century planning and zoning.

Conceptual theory sketch: A preliminary abstract theory framework that provides generalized guidance for best practices on a subject of research and establishes a foundation and suggests direction for theory development.

Content and process: The two major components of administration of place. Process tends to prevail over content in conventional planning and zoning. Governance of place provides an equitable balance between content and process.

Conventional planning and zoning: Administrative tools and processes, based on Euclidian zoning principles from 1926, which were generally adopted by 
American local governments throughout the $20^{\text {th }}$ century. Process was the focus. Typical bureaucratic tools included setbacks, lot coverage, Floor Area Ratio (FAR), density and maximum height. Typical democratic activities included volunteer boards, such as Planning and Zoning and Board of Adjustment, and public hearing before a Commission.

Chronology bias (related to place): The understanding and analysis of place guided by historic time and predicted obsolescence. This was a fundamental principle of Modern architecture theory, which rejected historic place as not relevant to current times. This view contrasts with the understanding of place as data.

Customer satisfaction (Board of Architects): Quantitative measurement of the implementation of place through the democratic process of Board review and the bureaucratic processes of a building permit.

Democracy and bureaucracy of place: All public and administrative activities established by a local government to implement and enhance the physical characteristics of community. This term includes general and structured public input, volunteer board review, formal discussion and decision-making, regulatory processes, staff review, permits and enforcement.

Durand, J. N.: (1760-1834) Author of early $19^{\text {th }}$ century textbooks based on analysis of precedent and typology. His work provided the framework for best practices for building design of the early $20^{\text {th }}$ century, which can be adapted to contemporary practices of smart place.

Dynamic content (for place): Qualities of place understood and applied with smart strategies. 
Dynamic design critique: Staff and public input about project design, as coordinated sequentially by a public platform for electronic plan review.

Equity of place: Cumulative goal of decision processes for governance of place.

Folio books: Large format publications from the early $20^{\text {th }}$ century which reproduced line drawings and black and white photographs of exemplary buildings, usually organized by architectural style. The images were intended to be used by architects as references and precedents, to assist with contemporary designs. Limited descriptive text was included. Content for place prior to the 1930's was often based on these books.

Governance of Smart Place: Administrative activities that develop and implement aspirational content of place, through multiple democratic processes at various scales and flexible bureaucratic procedures informed by dynamic data.

Conventional planning and zoning should transition to governance of place.

Law of the Indies, the: Spanish legislation, adopted in several versions, that guided the form and function of settlements in the New World. The Laws were an early effective use of content and process for regulation of cities, towns and villages. The Laws were an early example of bureaucracy of place. The "bureaucratic city" has been used in academic literature to describe outcomes.

Mediterranean architecture (Coral Gables): Coral Gables zoning term which refers to the local interpretation in the 1920's of aesthetic features of vernacular Spanish and Italian architecture. Some examples from major buildings of the renaissance and baroque periods are also used as reference, such as La Giralda in Seville. Eight exemplary local buildings are listed in the zoning code for design reference and 
for definition of the term. Mediterranean architecture is a best practice of the Coral Gables zoning code and an example of the use of content for governance of place.

Mediterranean bonus: Coral Gables zoning process, established in 1989 and modified several times, that provides additional height and area to buildings which comply with aesthetic standards inspired by Mediterranean architecture, as defined in the zoning code and approved by the Board of Architects. Most large buildings constructed since the late 1980's have participated in the process.

Merrick, George: (1886-1942) Founder of Coral Gables, Florida. Founder of the University of Miami, in Coral Gables. Pioneer on the use of content for place.

New Urbanism: Planning and zoning reform movement of the late $20^{\text {th }}$ century. It was first conceptualized as "neo traditional movement" at the University of Miami's School of Architecture in the 1980's, a theory strand partially inspired by the content of Coral Gables, FL, and the role of founder George Merrick and his team of professionals. In the 1990's discussion generated a national critique of conventional planning and zoning, which led to form-based codes as an alternative to Euclidian zoning regulation.

Narrative of place: Methodical investigation and discussion of the physical characteristics of a unique community, which may lead to aspirational content for public administration.

Place: The physical qualities and characteristics of community. 
Place as data: The understanding of the physical aspects of community in objective and measurable terms, which are cumulative, interchangeable and timeless, and build content for public administration. This view prevents chronology bias.

Precedent (Building): Exemplary building from the past used as reference for contemporary design. The Coral Gables zoning code lists eight buildings as precedents for Mediterranean architecture, a best practice for administration of place.

Smart Place: Community informed and managed with aspirational content and smart processes for place supported by dynamic data.

Taxonomy of opportunity: Spectrum of participation techniques, at various stages and scales.

Typology: Study of generalized characteristics of buildings, in terms of data for best fit for place, as a best practice for conceptual architectural design.

Zoning language deconstruction: Analytical tool for place which traces the evolution of zoning language and internal consistency with aspirational content through time. 


\section{CHAPTER I}

\section{INTRODUCTION}

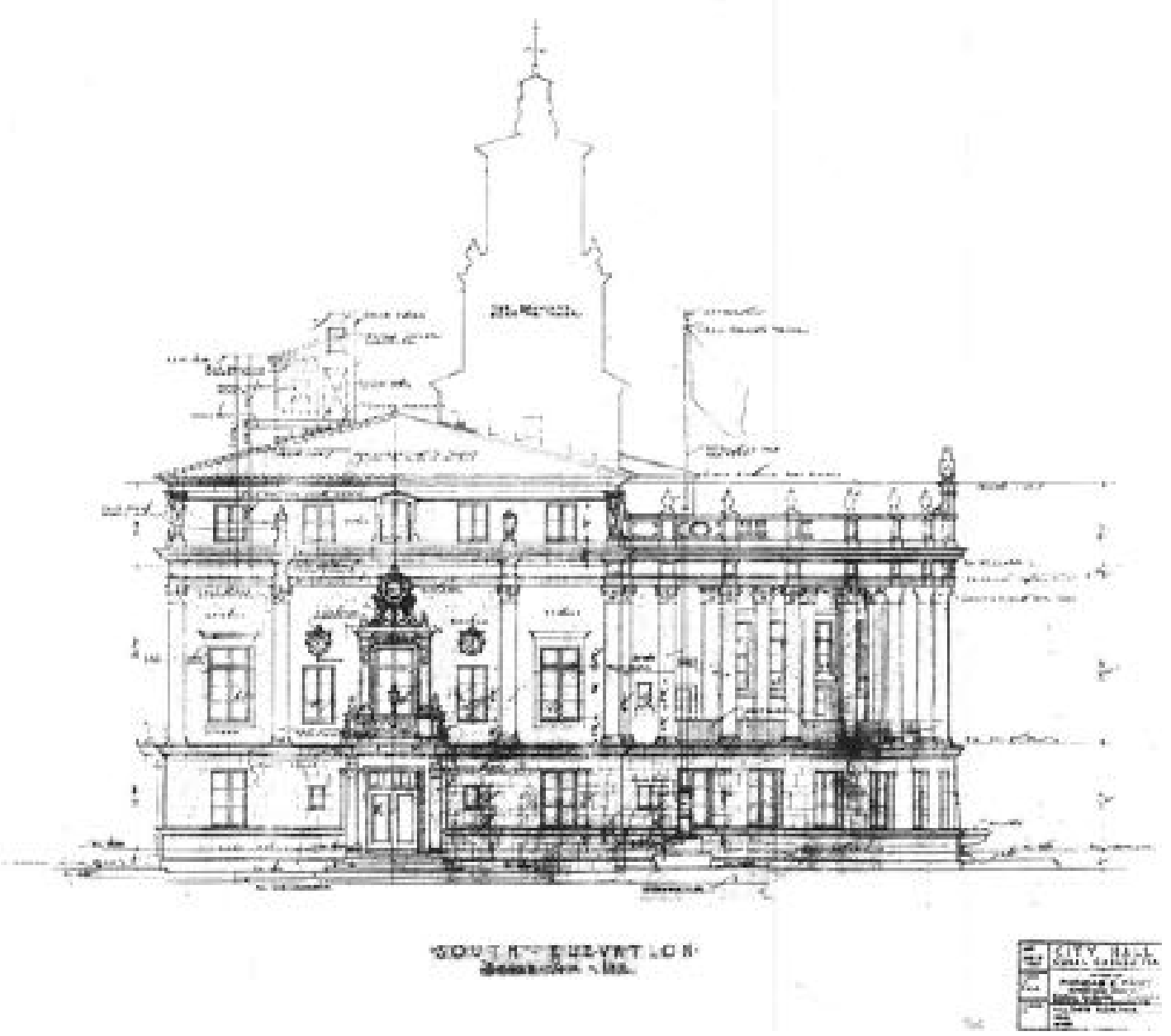

Plate 2. South Elevation, City Hall, Coral Gables, architect Phineas Paist, 1927. Source: City of Coral Gables.

The original construction drawing is a sketch, with sufficient detail for builders of the 1920's. Aesthetic choices were carefully researched for stylistic accuracy, consistent with the overall vision of the community. City Hall is listed in the Coral Gables zoning code as a model for Coral Gables Mediterranean architecture. 


\section{Personal Preface}

In 1998 I received a box full of picture books published in the 1910's and 1920's, from an elderly resident of Fort Pierce, Florida. At the time I worked as Director of Planning for the City. As I looked through the books, I saw many drawings and black and white photographs that resembled iconic downtown buildings.

The most emblematic title was Lesser known architecture of Spain, published in 1925. Author and photographer Francis Yerbury proposed a coherent narrative of place scaled for small towns that aspired to quality. The book described with pictures and very few words, as the title promised, specific building types and a preferred language of aesthetics.

The fact that the architecture was "lesser known" suggested an emphasis on vernacular competence. In the 1920's the title was trendy. A strong interest in rustic aesthetics guided the work of many artists and architects of the time, perhaps still following Ruskin in the years that predated the Modern movement. For example, the aesthetic choices of painter Martin Rico towards the end of the nineteenth century promoted a taste for small towns in Castile and for the informal facades along the canals of Venice, with their muted and modest classical proportions. His townscapes were wellknown in Paris, where many architects went to school, and also in the United States. Years later, the style that would blend rural Spain and Venice, and other occasional examples from southern Europe, would be rebranded as Mediterranean. But the specific sources for content were yet to be researched. The built outcomes, on the other hand, were all around Fort Pierce, Coral Gables and many other Florida towns, now historic landmarks which enhanced quality of life. 
Content was neutral and plural in the 1920's among scholars and practitioners of traditional design. There was no preference for Spanish architecture as a universal choice, as Yerbury also published books on the architecture of Holland and on Georgian details for domestic buildings. However, there was interest in precise research and nuanced taxonomy. For example, a book on Dutch South African architecture would inspire a village of unique aesthetics in Coral Gables. Content was an informed choice, as an appropriate narrative was expected to create long-term value. The economic success of Coral Gables offered evidence to support this claim.

The books I received had belonged to William Hatcher, an architect who worked in Fort Pierce from the 1920's to the end of his career in the 1970's. He used them for reference. I found a pencil drawing on yellow trash paper and contemporary catalogue advertisements, used as page markers among the bound volumes.

At first Hatcher's buildings were Mediterranean, indistinguishable from contemporaneous Coral Gables architecture. In the 1930's he designed several Georgian houses. By the end of his career he was influenced by MiMo. I never met him.

In 1999, soon after I read the Hatcher's folio books, I met Tony Hiss, who had recently published The Experience of Place. The book provided a different perspective and expanded discussions of town planning and design. In the folio books of the 1920's, towns were shaped by beautiful buildings, even when the structures were modest and utilitarian. But they also created places experienced by people. The term "place" was insightful, as it expressed an outcome, and implied a process of administration and implementation. The idea of place was worth exploring further, from the point of view of local governance. Plate 3 depicts Marina Square, a project I created at that time, which 
illustrates the concept of place, in this case a civic space for public use, with a clearly defined identity.

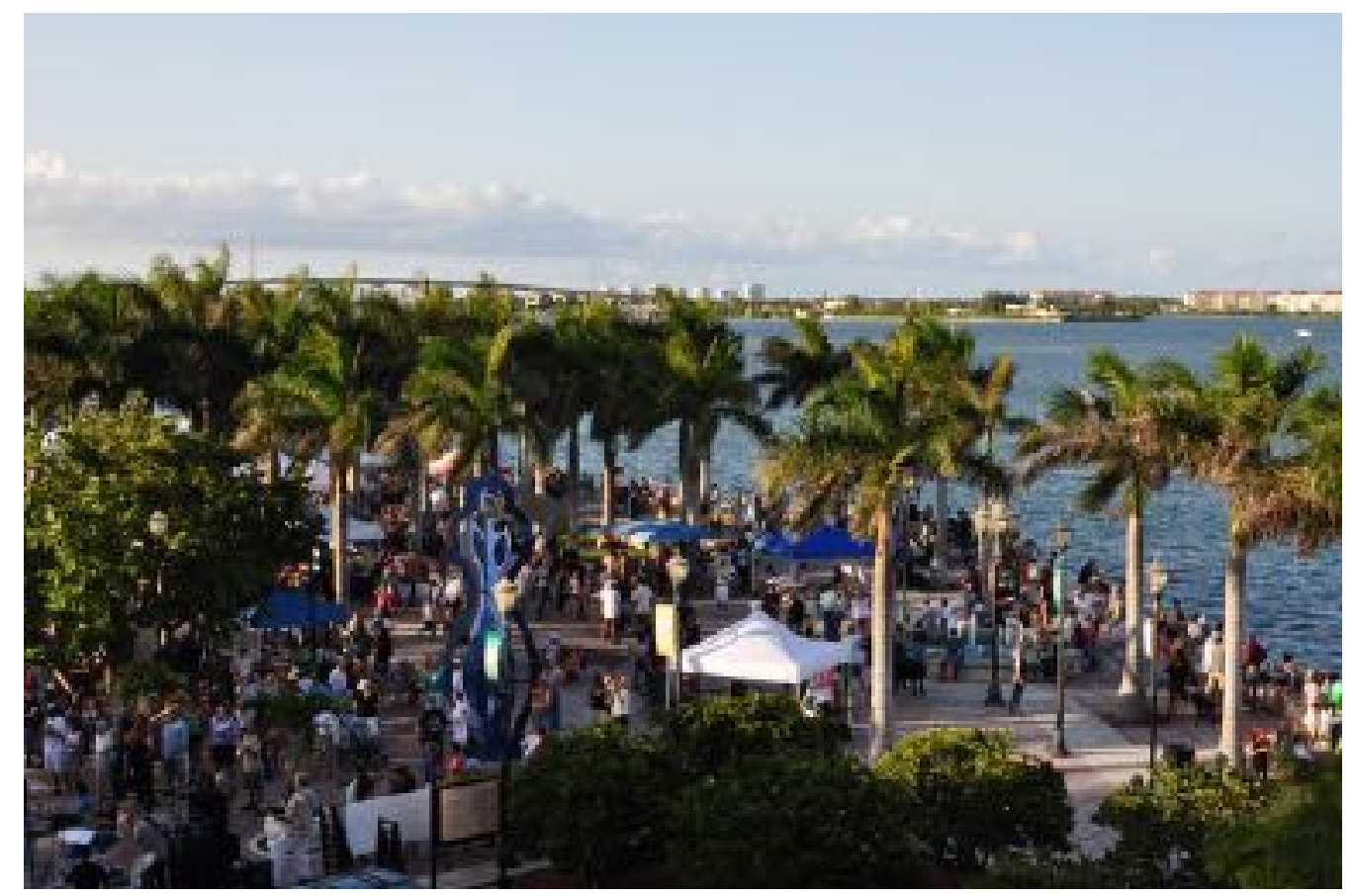

Plate 3. Marina Square, Fort Pierce, FL. Photograph by Ramon Trias.

After I left Fort Pierce City Hall, I moved my practice across Orange Avenue to an office in one of the buildings designed by Hatcher, built in 1926 and inspired by one of the reference books. I had helped with the restoration, which included the reconstruction of ornate Corinthian capitals that had been damaged and concealed in an unsensitive renovation during the 1960's. I worked there seven years.

Architect Water De Garmo, a contemporary of Hatcher who worked in South Florida, owned two volumes of Lesser known architecture of Spain, preserved at the Special Collections of the University of Miami. This was not a coincidence. It was evidence of the methodology based on precedents commonly used by design professionals in the 1920's. The fact that the same books had inspired architecture in Fort 
Pierce and Coral Gables at the same time suggested general methods and theory that could enhance all cities.

Old content had contemporary value. Coral Gables had preserved the quality of its original vision with administrative tools, implemented through the zoning code. Fort Pierce had been redeveloped through historic preservation strategies, which started with the restoration of one of Hatcher's best buildings, the historic City Hall on Avenue A. Review of the role of content could lead to best practices.

The text and illustrations of the picture books of the early $20^{\text {th }}$ century were effective tools for practice, through the of display of content to be copied and emulated. A best practice was the study of precedent. This approach had been prevalent throughout the nineteenth century, promoted mainly by the Ecole des Beaux Arts, its graduates and many followers. In early twentieth century America, the method was applied to city planning, as "the City Beautiful movement." However, by the third decade of the twentieth century, these ideas were fading from professional practice.

George Merrick's Coral Gables may have marked the end of an era of informed choice about the aspiration of place, as a best practice for the implementation of place. This was the precise moment when American zoning was invented. The early $20^{\text {th }}$ century was a time of creativity in the administration of cities, as zoning was conceptualized and quickly adopted in most of local governments. It was also a time when Modern theory transformed design and town Planning. This chronology is one of the reasons that Coral Gables is of interest as a case-study.

By the time I received William Hatcher's books, I had guided a public input process and capital project program that would transform downtown Fort Pierce. 
Hatcher's professional library helped explain the exceptional quality of the architecture from the 1920's in a small town in the Treasure Coast of Florida. The architecture from buildings from time had been helpful during public charrettes of the 1990`s and early 2000's, as it provided content for contemporary aspirations. The books supported the methodology that helped achieve aesthetic excellence. They also provided support for a new historic preservation program established in the late 1990's.

In 2012 I had a chance to revisit the same issues, as Director of Planning and Zoning in Coral Gables. By then, I was aware that the same picture books had being used in early Coral Gables. However, the methodology had been forgotten in contemporary practice. Moreover, original ink on vellum drawings of the Biltmore had been misplaced. There were no design manuals for the Mediterranean bonus program. Residential architecture lacked models for neighborhood compatibility. There was little guidance from theory for best practices related to content of place.

The role of content from the books used in Coral Gables and Fort Pierce led to the proposed investigation on planning and zoning administration in local government. Public administration research seldom focused on place. In-depth research about place represented a gap in the literature of public administration and would lead to new knowledge.

In 2012, professor Rocco Ceo of the University of Miami came to my office on a bicycle and gave me two three-inch-thick binders with the background material for the only academic book about Coral Gables. The Coral Gables story could be revisited as an example for generalized theory, with an emerging understanding of its influence on contemporary planning and zoning practice. In addition, the pencil corrections form 
Elizabeth Plater-Zyberk recorded theory innovation at the origin of the New Urbanism in 1991, a year before the first Congress. Coral Gables, an American garden city reconnected with the folio books of the 1920's and argued for the reform of planning and zoning. Within a few years after publication, as a result in part of creative work inspired by Coral Gables, form-based codes, design review, charrettes and the administration of vision would become tools for local government administration. All were first proposed as critiques of conventional zoning, and shared history, precedents and theory context that would enrich academic literature. The influence of Coral Gables on late $20^{\text {th }}$ century zoning reform was significant.

The urban planning work associated with many participants on the Coral Gables book, at the turn of the twentieth century, transformed the concept of place in America local governments in terms of democracy and bureaucracy, with innovative participation processes and administrative techniques rooted in the successful ideas from the 1920's. A review of Coral Gables data, from the point of view of almost a century of administration, would provide a new perspective on conventional planning and zoning and suggest best practices for governance of place.

There may be many alternative explanations for the data, as conflict, tension, controversy and disagreements also had major roles in Coral Gables governance. Aspirational content was fragile at times and completely forgotten during several decades of the mid-twentieth century. But this dissertation is about smart place, not Coral Gables. Data and evidence from Coral Gables were available, convenient and timely, and the city implemented classic best practices that may be of contemporary interest. Although Coral Gables presents a successful illustration of theory and best practices for place, further 
research could explore the reasons in greater depth. This study attempted a rough sketch at theory, which was intended to be incomplete.

The following chapters should not be read as a history of Coral Gables, nor as a deterministic description of utopian urbanism. History has been discussed elsewhere, and some publications were mentioned in the Literature Review. Moreover, it is well-known that utopian ideas about town planning inform the literature of the discipline. However, Coral Gables was first a business venture and, later, it became a local government. Theory in this context had a very practical focus.

Coral Gables was a practical and respected source of generalizable ideas for timeless place and smart strategies. Some ideas about town planning were anticipated prior to the study and had been discussed in the literature. Ideas about smart strategies were understood during the process of research. Future research should explore other places and compare and contrast diverse content and processes. Notions about Coral Gables should not distract the reader from the innovative opportunities for smart place which resulted from an objective consideration of the findings from this study. 


\section{Introduction to the Administration of Place}

\section{General Ideas}

This dissertation reviews and proposes theory and best practices on aspirational content for place, for local governance in the United States. Place is a fundamental concept for municipal practice, as it describes the physical qualities of a community, which affect people and quality of life. Place is an outcome of governance. All American municipalities invest public resources to maintain and enhance community assets, measured in terms of quantifiable planning goals, design features and contribution to economic development.

Place is the practical outcome of the future vision of a community. Thus, quality of place, and quality of life, depend on the effective understanding and implementation of a shared public vision, which should be inclusive and diverse. First, a democratic vision needs to be defined, in terms of aspirational content. Afterwards, it must be implemented, with the administrative tools of bureaucracy. Democracy and bureaucracy of place require robust theory to coordinate process and content effectively. Examples and data from this study offer only initial ideas to be developed in the future, and there is no implied sense of inevitability about the conclusions.

Discussion on the cumulative impact of the administration of the content of place on cities, towns and villages presents a gap in the literature. Literature review provided context for discussion and data for professional practice. Expert interviews contributed theory and professional experience. Archival and quantitative survey research were performed on Coral Gables, Florida for a detailed review and critique of the implementation of place. Coral Gables had a history of effective implementation of best 
practices for administration since it was founded in the 1920's. Moreover, in recent years city staff had started the application of many innovative smart city strategies, which enhanced democracy, bureaucracy and governance.

Coral Gables was studied as one example of the application of democratic and bureaucratic activities for implementation of place. Town planning and architecture tools, such as zoning and graphics, provide examples of administrative practices. Some tools should be generalizable as best practices for theory development of democracy and bureaucracy of place. Coral Gables, FL was a source of data, to measure concepts for theory and test ideas for best practices.

Discussion on design and governance cover some topics that are understudied by public administration literature and were highlighted to explore new ideas for theory and best practices. Future discussion may explore other aspects of research, such as social or economic questions. Current research does not dismiss such topics. It simply provides a targeted perspective designed to enrich discussion of public administration. In addition, future research should also explore other examples of local governance and test proposed ideas.

Data about Coral Gables was collected according to specific research questions. Findings do not attempt to provide a comprehensive historical analysis nor imply a sense of inevitability of outcomes. In fact, qualitative interviews revealed conflict had a significant role in the administration of Coral Gables in the past century. Regardless of the merits of early concepts and contemporary satisfaction with the community expressed in survey data, a variety of opinions have informed democratic processes since incorporation. Thus, in addition to narratives and bureaucratic tools, debate has shaped 
implementation. Future research could focus on that aspect of administration and enhance the nuances of proposed theory on democracy of place.

Moreover, robust content in isolation does not predict long-term outcomes. For instance, Merrick's foundational narrative was practically forgotten in the 1960's and 1970`s (Parks, 2016). Administrative tools were required for effective governance. Many contemporary administrative tools date from the 1980's, with more recent amendments, such as the Mediterranean bonus process. The project of the restoration of the Biltmore Hotel also dates from the 1980's, but at the time its success was uncertain (Doheny, 2017). Thus, discussion about the administration of place should be expected to develop further. Nevertheless, research findings offered practical guidance for governance of place, and also outlined the crucial role of aspirational content for local democracy and bureaucracy.

\section{Organization of Data}

Dissertations, as a genre of academic literature, follow a rigorous structure. This study was generally organized following the standard outline of the Florida International University Graduate School. However, the chapter on methodology was placed before the chapter on literature review at the request of the dissertation committee, as the content of literature review proposed arguments for theory development.

A fundamental assumption of the study was that place is autonomous, in the sense that social, economic or demographic considerations do not directly or necessarily affect physical design or qualitative considerations of administrative policy outcomes related to smart strategies for implementation. Thus, this study did not review certain topics that may be common to public administration literature. Limited discussion about social 
policy and its intended or unintended impacts, debates and conflict during a century of implementation, or evaluation of the reasons for success or failure of certain aspects of democracy or bureaucracy, resulted from research design. It is also acknowledged that arguments would be strengthened with robust discussions of related topics and proposed conceptual ideas from this study should be tested more extensively in the future. However, practical constraints of time and data led to the proposed framework, which should be sufficient to sketch effective best practices. Recommendations would be narrowly targeted to gaps in the literature of design review and administration of governance.

A summary of the intent and role of certain aspects of the manuscript may clarify the order and intent of the data presented in the text:

1. Literature Review. Coral Gables and prior theory of place. Literature on Coral Gables provided one concrete example for narratives of place and implementation. Literature on select topics from the history of planning and zoning framed initial theory ideas, in terms of provenance and emphasis. Literature on best practices of the 1920's discussed evidence that could inform contemporary practice. This chapter provided background for multiples arguments for theory. Although literature on Coral Gables was reviewed, general literature about place provided the majority of the information for theory and best practices.

2. Results chapter. Qualitative input on place.

In-depth interviews with experts informed in general terms theory arguments and best practices. Comprehensive review of the input guided 
hypotheses and conclusions. Although most experts were knowledgeable about Coral Gables, their input addressed general topics.

3. Results chapter. Data on Coral Gables.

Coral Gables was selected as a research subject because of historical chronology with respect to the development of conventional planning and zoning, availability of recent survey data, and availability of experts with opinions that would be valuable for theory development. However, this study was not about Coral Gables. It was about the generalization of theory and best practices about democracy and bureaucracy of place, from in-depth research and analysis of data from an exemplary local government.

\section{Statement of the Problem}

Conventional planning and zoning regulated place in American local governments throughout the $20^{\text {th }}$ century, with uneven results. The root of the problem was incomplete theory about place, which should include guidance for local democracy and bureaucracy.

Democracy and bureaucracy of place were fundamentally misunderstood by applicants, neighbors, professionals and officials who participated in local government practice. Democracy was believed to be adversarial politics and unfiltered resident input. Bureaucracy was misconstrued as casual conversation open to boundless discretion. Neither view led to quality place. Frustration and disbelief were common in many interactions at any City Hall. At the start of the $21^{\text {st }}$ century, effective governance of place for local governments was yet to be designed. 
Place was often regulated indirectly, without regard for aspirational content. Regulation, or process, appeared to be the main goal of administration, which led to considerable public confusion and arbitrary decisions. Routine administration with limited or negligible content would lead to ineffective governance.

Zoning regulation started with the $20^{\text {th }}$ century and was formalized in 1926.

Afterwards, bureaucracy and democracy shaped the administration of place within a very narrow regulatory framework. Cities adopted standard language for regulation and established volunteer boards for public discussion, as required by state laws which followed federal guidelines. Coincidentally, during the time that conventional planning and zoning was first established, George Merrick developed Coral Gables, with a strong sense of content of place. Study of early Coral Gables provided insight into the administration of place in local governments.

By the end of the $20^{\text {th }}$ century, the planning and design of Coral Gables were among the sources of inspiration for the planning and zoning reform movement that would be known as New Urbanism (Plater-Zyberk, 2018). Late $20^{\text {th }}$ century critiques of conventional planning and zoning identified many deficiencies in administrative procedures and one significant oversight. As processes for regulation had increased in complexity and precision, the role of content was neglected. In the 1990's, New Urbanism theory rediscovered the tools and techniques used at the inception of Coral Gables and other contemporaneous communities, and proposed new tools for regulation and participation, such as form-based codes and charrettes, which reconnected current administrative practice to best practices of town planning with a focus on design and place. 
As the $21^{\text {th }}$ century developed, local governments rapidly adopted new technologies for data collection for enhanced management of services. The term "Smart City" summarized these efforts. Current literature has discussed the opportunities of smart technology for routine city services. Nevertheless, discussion of theory best practices for the implementation of place has been limited.

Regulation and participation, however, often failed to adapt to new administrative opportunities. Public administration theory should be updated on issues related to the content and process of place, as new technologies provide renewed opportunities to continue the long-term project of building sustainable cities, towns and villages which enhance quality of life. Coral Gables was an early adopted of Smart City strategies.

The two major topics influenced content of place would be local government bureaucracy and democracy. Bureaucracy appears complex but the challenge is that is often misunderstood (Goodsell, 2015). Zoning may rank among the least understood bureaucratic processes and the most public, as it is at the core of democracy at the local level. Discussions related to place generate public debate, conflict and confusion in otherwise routine municipal meetings. Moreover, bureaucracy implements democracy and place should be the outcome of democratic discussion.

Democratic aspirations for place should form the core content of planning activities which lead to zoning regulations. However, local government democracy may be as misunderstood as bureaucracy, as public participation may be highly structured and deliberate. However, bureaucracy is a type of organization, and it may be adopted in the private and public sectors. All public activities in American local governments are 
fundamentally democratic. Thus, democracy is the key distinction between public and private activities.

\section{Democracy and Bureaucracy Shape Place}

Local governments regulate place. Local governments also decide what type of place should be implemented, in a democratic format. Administration of place is a core mission of the administrative city, a bureaucratic organization for local governance led with structured democratic processes for policy direction and administered with inflexible procedures for routine decisions.

Conventional planning and zoning lead to the administrative city. The following diagram summarizes conventional administration:

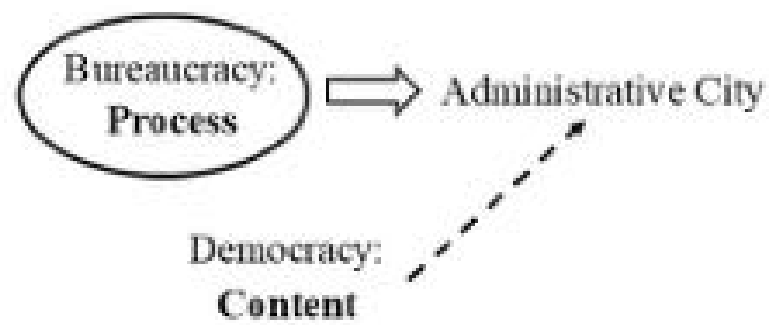

Figure 1. Administrative city diagram.

On the other hand, Smart Place is the outcome of a proposed theory and practice framework, based on enhanced integration of content and best practices related to place

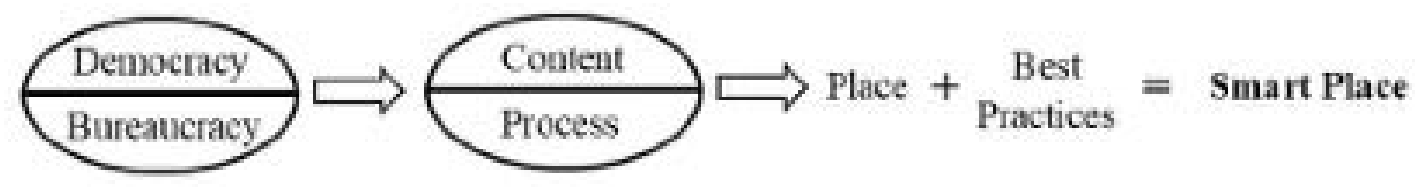

Figure 2. Smart Place diagram. 
Democracy and bureaucracy are in competition in the administrative city. This type of organization follows Wilson's classic, and critiqued, separation of policy and administration more strictly than public entities at other levels of government. However, as it is the case with the Federal administration, which is vaguely and briefly mentioned under article one of the Constitution, the structure of bureaucracy was not designed by enabling laws or state constitutions. Thus, the specific details of the organization of each local government vary and are determined locally by elected officials or administrators. Moreover, as each community is unique, the role of content would vary. Finally, democracy is often understood only as politics, perhaps following up on Wilson's seminal article on administration, and thus overlooked by some administrators.

Theory should guide calibration for content and best practices and should facilitate the implementation of Smart Place. Theory should also clarify that residents of local government are not customers, but citizens engaged in democratic civic life. Moreover, local government bureaucracy is not a sequence of isolated transactions, but a coherent effort to implement place. Definition, calibration, facilitation and implementation of content are gaps in the literature. Figure 2 outlines a framework for theory, where the goal is Smart Place, the result from synergy of democracy and bureaucracy through the integration of process and content.

From visioning to code enforcement, the range and scope of parallel tasks related to place at multiple scales is extensive and may change through time to follow the priorities of elected officials. These administrative activities affect daily life directly. Whether a house can be enlarged, a new school may be located, or mobility improved in a neighborhood, are regulated at the local level with development standards, levels of 
service and building permits. The implied outcome of the separate administrative decisions should be a quality place, but this goal is seldom expressed directly. Nevertheless, coordination of governance and bureaucracy related to development may by a goal expressed on Comprehensive Plans or political speeches during a campaign or from the dais, but it is seldom achieved with conventional administrative tools.

\section{Content and Process}

As democracy and bureaucracy have been generally explained in terms of process in administration literature, the content of place has not received adequate attention. This is a weakness of theory. On the other hand, place is often conceptualized in terms of design and function, by related disciplines. A review of the role of content should provide effective ideas for the administration of place.

Public activities related to place are often guided by aspirational statements, applied in many formal and informal settings which collectively attempted to provide governance for a community. Some activities are mandated by law, such as the preparation of Comprehensive Plans or the adoption of zoning codes. Other activities provide regular public input, such as committees and volunteer task forces. Some activities allow occasional public discussion on specific topics, such a charrettes and workshops, beyond the scope of conventional planning and zoning. The overall effect on place is poorly understood, as the process of implementation of place does not follow a clear structure. Best practices which optimize results should be developed.

The following research explores "smart place" as a preferred outcome of public administration at the local level, guided by democratic aspirational objectives and implemented through effective bureaucratic professional practices. Governance of place 
should organize regulations, public hearings, workshops and discussion that conceptualize and implement the physical aspects of community. These two theory ideas form the core of the research, findings and conclusions which follow.

\section{Conventional Planning and Zoning}

American local governments are very consistent on processes for the administration of place, although they may vary in emphasis and the use of content. Since the 1920's, the legal framework has been "planning and zoning" (Burke, 2002). In particular, the Supreme Court decision in the Village of Euclid vs. Ambler Realty Co. of 1926 has been accepted as the start of generalized American zoning. Coincidentally, 1926 was the year of the Great Miami hurricane which provoked the collapse of the Florida boom and of the first phase of development of Coral Gables. This date is significant for the current research project because George Merrick master planned Coral Gables prior to the use of zoning regulations, but with strict reliance on aspirational content.

After the damage of the hurricane of 1926 and the Great depression of 1929, Coral Gables adopted a zoning code in 1930. The Coral Gables zoning coded would be amended extensively through the decades and would be a source of pride and debate for residents, developers and candidates in countless political campaigns. This chronology made Coral Gables valuable for research, as it provided an unbroken timeline of zoning decisions since the inception of the process, guided by consistent content.

Conventional planning and zoning addressed democracy and bureaucracy of community, but it neglected place. Administration of democracy would take place through volunteer boards and public hearings. Administration of bureaucracy followed 
regulations in zoning codes. Although there have been attempts at reform in the past century, planning and zoning have provided a coherent set of processes throughout the United States.

\section{Planning and Zoning Reform in the Late $20^{\text {th }}$ Century}

In the late $20^{\text {th }}$ century, New Urbanism theory critiqued conventional planning and zoning (Duany, Plater-Zyberk, Speck, 2000). Arguments for reform were based on an evaluation of late $20^{\text {th }}$ century development and growth management outcomes, which followed strictly conventional planning and zoning processes. Local disinvestment, support of suburban sprawl and insensitive redevelopment were listed on the Charter of the New Urbanism as poor outcomes caused by the administrative failure of conventional planning and zoning (Charter, 1994). Thus, American communities increasingly lacked a "sense of place." This result would have been predictable, as place was seldom discussed by administrators. If neighbors or elected officials attempted to approach the subject of place at a public hearing, conventional processes lacked an effective language for constructive debate. Thus, the term NIMBY (Not in my backyard) was coined to describe neighbor frustration with conventional planning and zoning and general opposition to change. NIMBY was caused by a misunderstanding of democracy and bureaucracy by most participants in conventional planning and zoning. As an alternative, proposed governance of place would provide a productive path for democratic discussion and bureaucratic implementation with less structured activities along a spectrum of participation.

New urbanism theory proposed innovative democratic tools, centered on the charrette. Proposed bureaucratic reform focused on form-based codes and long-range 
planning based on a transect of development. These ideas set a new direction towards outcomes, and away from procedures. Aspects of new urbanism were implemented by many local governments throughout the United States and have been discussed (Fraga, 2014). Once reforms were tested in practice, such as Miami21 form-based zoning reform, some significant improvements were observed (Cejas, 2019). In spite of regular zoning reform efforts and occasional planning mandates, the outcome of place has not been the focus conventional administrative practice.

\section{Towards Theory and Practice for Smart Place}

Place is the physical expression of the future vision of a community, and a core component of public administration at the local level. Thus, vision should be understood as content for administrative processes within the field of public administration. Administrative practices that guide vision in terms of place, generally related to design goals and public participation which result in aspirational content, have been overlooked by prior literature. Research data, findings and conclusions expand ideas about democracy and bureaucracy from the perspective of planning and zoning administration of smart place.

New knowledge should enhance the administration of local governments and provide historical and theoretical context for planning policy on smart initiatives. Recommendations are provided in two general topics:

1. Theory recommendations for the role of aspirational content in local government planning bureaucratic processes. 
2. Best practices for the application of administrative creativity to local government planning activities, including new tools for public participation, zoning regulation and project review, for use in administrative processes.

Conclusions present a conceptual critique of conventional planning and zoning process through the introduction of three theory concepts. First, smart place is the desired outcome of local governance, and preferred to the administrative city. Second, governance of place is the enhanced process of local administration, which is proposed as an update of conventional planning and zoning activities in the administrative city.

Third, aspirational content is conceptualized as the language for place developed from local democracy and implemented through bureaucracy.

Theory is presented as a rough sketch to be further developed by future research. Recommendations for best practices provide general direction and select specific ideas for implementation of smart place, in terms of public administration. Coral Gables was a valid source of qualitative and quantitative data, but proposed theory ideas should be tested in other locations, with varied conditions and diverse aspirations. Further research would also enrich the range of best practices. 


\section{Coral Gables:}

\section{The Administration of Form}

\section{Coral Gables, Florida}

When an anonymous survey asked residents of Coral Gables to rank their quality of life, results were very positive:

- sum qualityoflifeCoralG

\begin{tabular}{r|rrrrr} 
Variable & Obs & Mean & Std. Dev. & Min & Max \\
\hline qualityofl G & 894 & 1.558166 & .5953115 & 1 & 4
\end{tabular}

A value of 1 was "excellent" and the mean result was 1.5. This positive outcome was expected, as Coral Gables was recognized as a very desirable place in South Florida. Additional discussion on the data and its context follows in the results chapter.

The story of Coral Gables had been told many times, most recently and comprehensively by Arva Moore Parks (2015). However, Parks and other authors told the story from the perspective of founder George Merrick's biography and explored Coral Gables in terms of people and historic events. The perspective of this study is place.

Merrick's foundation story, as summarized by Parks and others since the 1980's, belonged to the folklore of South Florida. Merrick moved to Miami as a child and transformed his family grove into an ideal city, with the assistance of talented relatives and experienced professionals. Thus, he pioneered the real estate industry in the region and set a high standard for future developers.

Merrick was the only real estate developer with a solid reputation and a statue at City Hall. However, a foundation story was an insufficient explanation for the success of 
Coral Gables. Moreover, there were some negative overtones related to the social history and public policy of the southern United States from the early $20^{\text {th }}$ century (Mohl, 2001).

Culot and Behar (1991) and Millas and Uguccione (2005) expanded discussion and described Coral Gables principally in terms of planning, design and preservation. Those strands of research were explored by the current study to inform theory implications for the administration of place, a subject overlooked, with the exception of Poole (1987).

Under conventional economic development metrics, Coral Gables was considered a success. However, from other points of view Coral Gables had been critiqued in the past. Current research was performed on place, which is autonomous from social or political theory. The following information provides census data, as an introduction to the context of historic and contemporary policy choices. Household incomes, education, property values and retail sales suggested a robust economy (Roberts, 2016), as may be verified in the following chart:

\begin{tabular}{|l|l|}
\hline Coral Gables & Florida \\
\hline $\begin{array}{l}\text { Median household income (2013) } \\
\$ 90,649\end{array}$ & $\$ 46,956$ \\
\hline $\begin{array}{l}\text { Median value of owner-occupied } \\
\text { residences (2013) } \\
\$ 617,300\end{array}$ & $\$ 160,200$ \\
\hline $\begin{array}{l}\text { Bachelor's degree, over 25 (2013) } \\
63.5 \%\end{array}$ & $26.4 \%$ \\
\hline
\end{tabular}




\begin{tabular}{|l|l|}
\hline $\begin{array}{l}\text { Hispanic or Latino (2010) } \\
53.2 \%\end{array}$ & $22.5 \%$ \\
\hline $\begin{array}{l}\text { Persons below poverty level (2013) } \\
7.6 \%\end{array}$ & $16.3 \%$ \\
\hline Retail sales per capita (2007) & $\$ 14,353$ \\
\hline 33,309 & \\
\hline
\end{tabular}

Table 1. Coral Gables demographic data. Source: United States Census Bureau.

The Coral Gables census estimate of population for 2014 was 51,227. In 2010

there were 20,266 housing units. In addition of well-established neighborhoods, the city included a downtown of approximately 11 million square feet of commercial real estate. Vacancy rates were $8.9 \%$ in 2015, a good rate according to economic development professionals (Roberts, 2016). In the $21^{\text {st }}$ century, Coral Gables had become a complete community, consistent with the founder's vision, and according to the Community Engagement Survey of 2018, consistent with the expectations of its residents.

An analysis of employment census data for the first decade of the $21^{\text {st }}$ century shows a stable community. For example, the great recession of 2007, which affected Florida cities disproportionally due to their reliance on real estate for economic activity, had a lesser effect on Coral Gables. Economic data provided general context to this study, but it should be reviewed in depth by future research.

Development activity increased after 2012. Employment data reflected a full recovery by 2012, as shown by census data on table 2 : 


\begin{tabular}{|c|c|c|c|c|c|c|}
\hline & $\begin{array}{l}2002 \\
\text { Empl. }\end{array}$ & $\begin{array}{l}2002 \\
\text { Revenue } \\
(\$ 1,000)\end{array}$ & $\begin{array}{l}2007 \\
\text { Employees }\end{array}$ & $\begin{array}{l}2007 \\
\text { Revenue } \\
(\$ 1,000)\end{array}$ & $\begin{array}{l}2012 \\
\text { Employees }\end{array}$ & $\begin{array}{l}2012 \\
\text { Revenue } \\
(\$ 1,000)\end{array}$ \\
\hline $\begin{array}{l}\text { Wholesale } \\
\text { trade }\end{array}$ & 1,731 & $2,481,148$ & 1,124 & $7,011,739$ & 1,575 & $9,264,116$ \\
\hline Retail & 2,945 & $1,018,113$ & 4,545 & $1,436,412$ & 4,154 & $1,556,562$ \\
\hline Real Estate & 1,246 & 219,816 & 2,418 & 403,887 & 1,144 & 331,674 \\
\hline Professional & 1,263 & 920,917 & 1,429 & $1,387,861$ & 1,506 & $1,544,536$ \\
\hline
\end{tabular}

Table 2. Coral Gables employment data. Source: United States Census Bureau.

Superior property values, high levels of education, stable economic activity along several major sector all pointed towards a successful community with an outstanding quality of life. Nevertheless, when compared to its neighbor Miami, or even most coastal Florida towns, Coral Gables had an unremarkable location. But Coral Gables was a very desirable place. Part of the reason was the role content played in early development and current branding. Aspirational content contributed to the creation of value and to satisfaction about quality of life.

Coral Gables lacked many physical features commonly associated with desirable Florida real estate, such as beaches, lake frontage or low-density suburban development. In fact, there was no unique quality that could be traced to geography, or even investment of infrastructure. Moreover, Coral Gables, centrally located in South Florida, endured negative impacts from neighboring communities, such as 270,000 automobile trips per day that traveled through city streets on the way to other destinations. Under conventional real estate criteria, Coral Gables would not stand out. 


\section{A Place Known as Coral Gables, FL}

Frank Button prepared the master plan of Coral Gables, under a one-page contract with George Merrick. Button (1921) proposed to plan 1000 acres at $\$ 1.00$ per acre, to be completed in two months. Button would continue his work in Coral Gables until his untimely death in 1938, as he directed the planting of trees in the median of Bird road (Parks, 2015).

The land was owned by Merrick, originally acquired by his father and expanded through the years (Parks, 2015). Some acres were planted with grapefruit. The natural landscape was pine flatwoods. In the context of South Florida, Coral Gables land was sufficiently high and dry for urban development.

Plate 4 is a map of the existing conditions of South Florida prior to the development of Coral Gables, printed commercially in 1914. The map depicts the extent of urban development and natural features. It is of interest in the $21^{\text {st }}$ century because most wetlands and natural shorelines have disappeared during the past century, as cities expanded. This information has become increasingly valuable as the effects of climate change have affected the region, as the original topography will impact future drainage patterns and salt water intrusion.

The original map was colorized for this study, with light green color added for wetlands and flow ways and dark green for mangroves. The resulting graphic records natural features that were altered by urban development in the $20^{\text {th }}$ century. The street grid of Coral Gables superimposed on the original map, and it was colored red: 


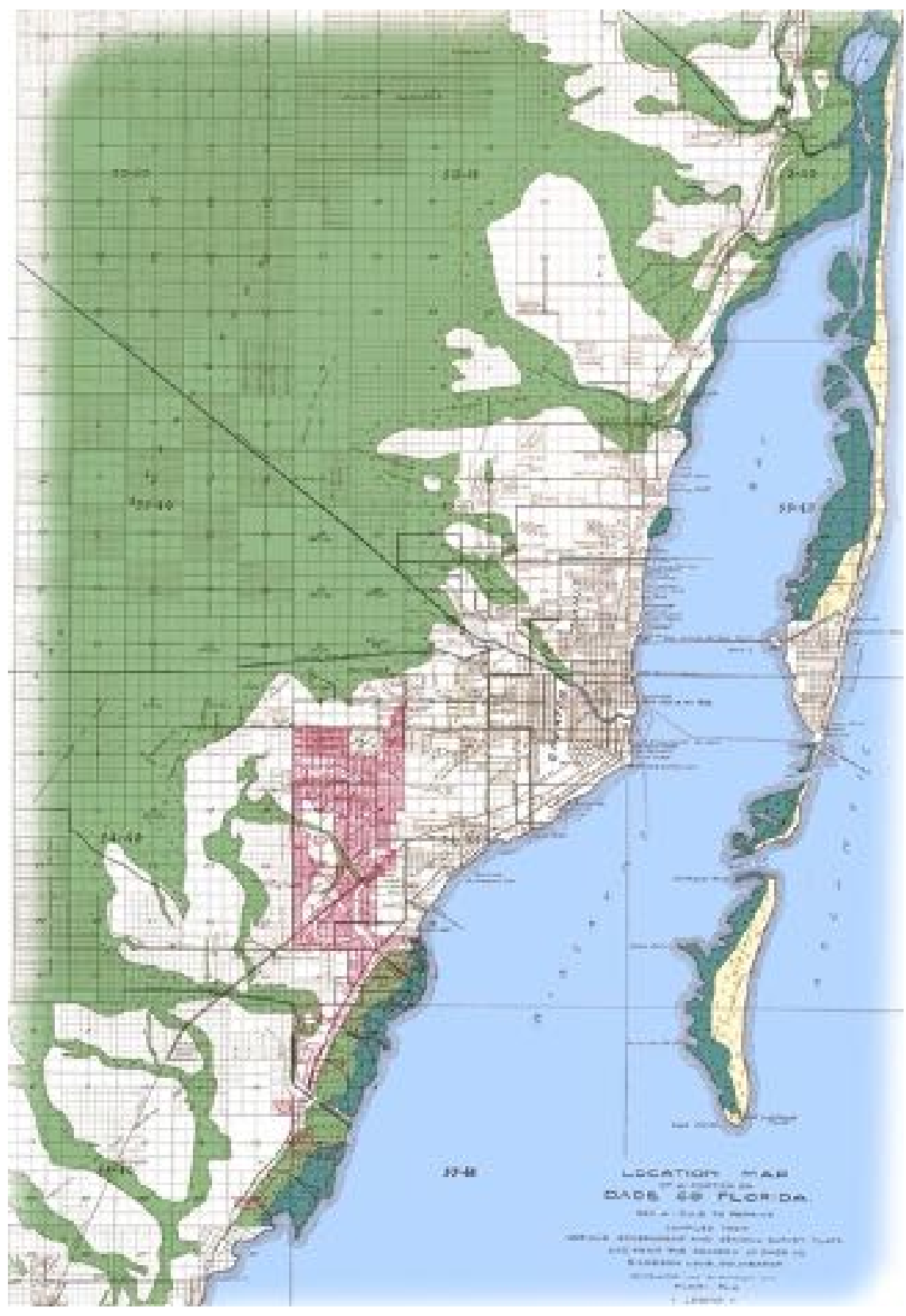

Plate 4. Map of South Florida, 1914. Source: HistoryMiami Archive.

As the map illustrates, development of South Florida through the 1920's was located in a narrow strip of land along Biscayne Bay, east of the regional wetland known as the Everglades. Throughout the $20^{\text {th }}$ century, most of the land depicted as wetlands and mangroves was drained and filled. Local governments approved countless 
subdivisions, with minimal considerations for long-term planning. Aspirational content was forgotten as the driver of development by the 1930's. Mid-century planning theory supported limited real estate objectives and governance was regulated by conventional zoning. As a result of the impacts of traffic, destruction of the environment and poor urban form, late $20^{\text {th }}$ century local policy discussions focused on planning and zoning reform, often inspired by Coral Gables. Such was the case of early New Urbanism. Button stated that a "general plan" would include blocks, parkways, parks and other necessary details. As the 1914 map shows, natural systems were incorporated into the plan on the north half of the city. City neighborhoods south of Sunset Drive, built on former Mangrove marshes, were not developed by Merrick. In 2019, nothing remained of the natural environment of 1900, except in large county parks. Every tree had been planted, every canal had been dug. Some old sloughs had become golf courses.

Plate 5 is a preliminary plan prepared by Frank Button, which matched the deliverable contemplated by the one-page agreement. This map preserved corrections in red ink, as it was a working document. "Redlining" was a conventional practice for manual drafting corrections. Coincidentally, the term would be used in the $20^{\text {th }}$ century as a metaphor for discriminatory housing practices. Deed restrictions, a common practice at the time, sometimes promoted exclusion.

The design of Coral Gables was constantly refined, as the development team attempted to enhance the aesthetic content of the master plan. A close reading of Plate 5 demonstrates great care in the design of public space and landscaped greens. 


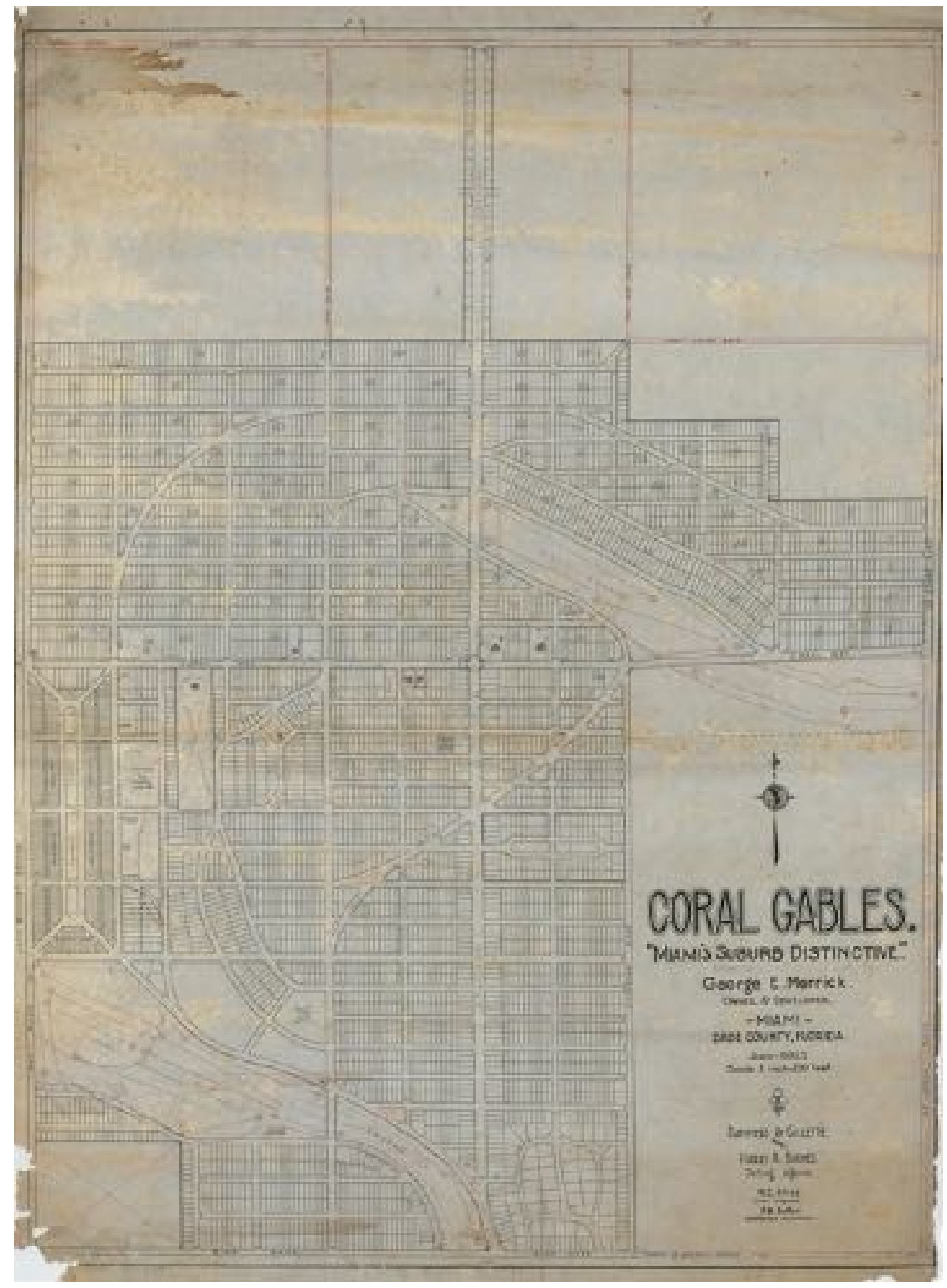

Plate 5. Coral Gables Plat, 1921. Source: HistoryMiami Archive.

Revisions were probably by Button or Merrick, the only two individuals that should be credited with the master plan (Parks, 2016). The streets and blocks were implemented in the form of multiple coordinated plats, consistent with the comprehensive 
plan. The sequence of plats, preserved in the website of the Miami-Dade Clerk of the courts, provided a record of an effective administrative tool. Each plat, often a quarter section in size, would be filed individually. All plats would be aligned to continue rightsof-way and complement neighboring development. Once filed the geometry of the plat would bound the parameters of development for a long time. A majority of the plats filed under Merrick's direction in the 1920's was unchanged almost 100 years later. This was not unusual, and it underscores the importance of early decisions about urban form. Content, once platted and codified, tended to last.

The overall master plan was implemented incrementally, as land was sold. The sale of real estate was George Merrick's core business. Aspirational content and related administrative procedures were tools to find customers. Then, buildings were constructed individually, through time.

Some content was recorded as deed restrictions that addressed specific style. Moreover, civic projects, such as entrances and plazas, also promoted the overall vision. Every building fit well at the end, not because Coral Gables was a utopian community, but as a result of the best practices of the time.

A century after initial development, the original plan was generally unchanged. Two important features of the plan should be noted:

1. It was comprehensive and aspirational.

2. It was designed to evolve, within the parameters defined by content.

Plate 6 is a diagram of existing conditions in 1922, with the first six houses depicted in black, developed from research published by Millas, Uguccione (2002). 


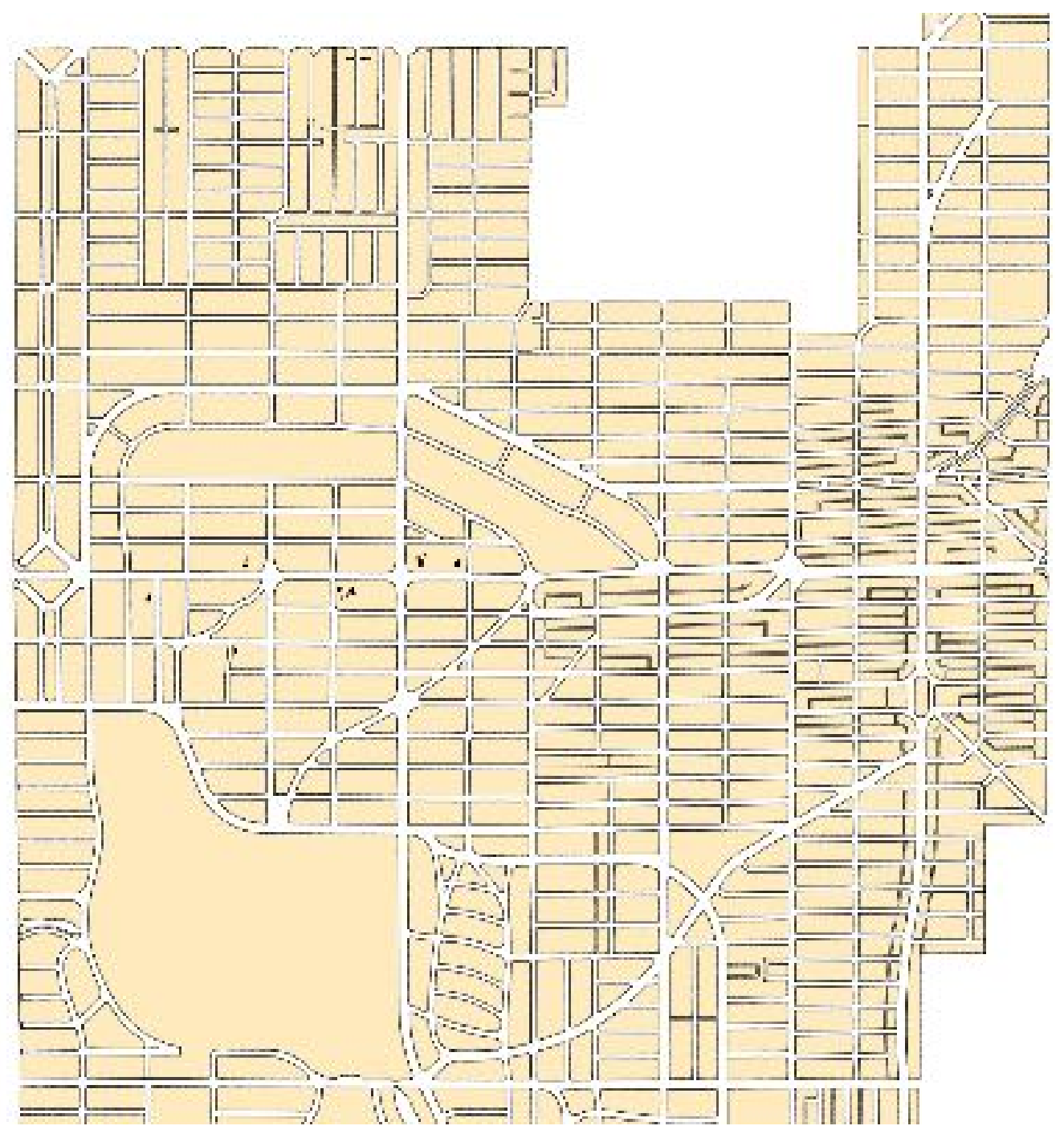

Plate 6. Diagram of Coral Gables street layout. Source: City of Coral Gables.

The layout of the city was well-integrated internally and in the overall street layout of South Florida. However, Coral Gables included more than a basic grid of streets. A general plat of Miami from 1918 predated Coral Gables and reflected a less picturesque street layout. Pate 7 is a map of existing conditions in 2019, which demonstrates the resiliency of the form of the city, whether it was platted by Henry Flagler in Miami or Merrick in Coral Gables: 


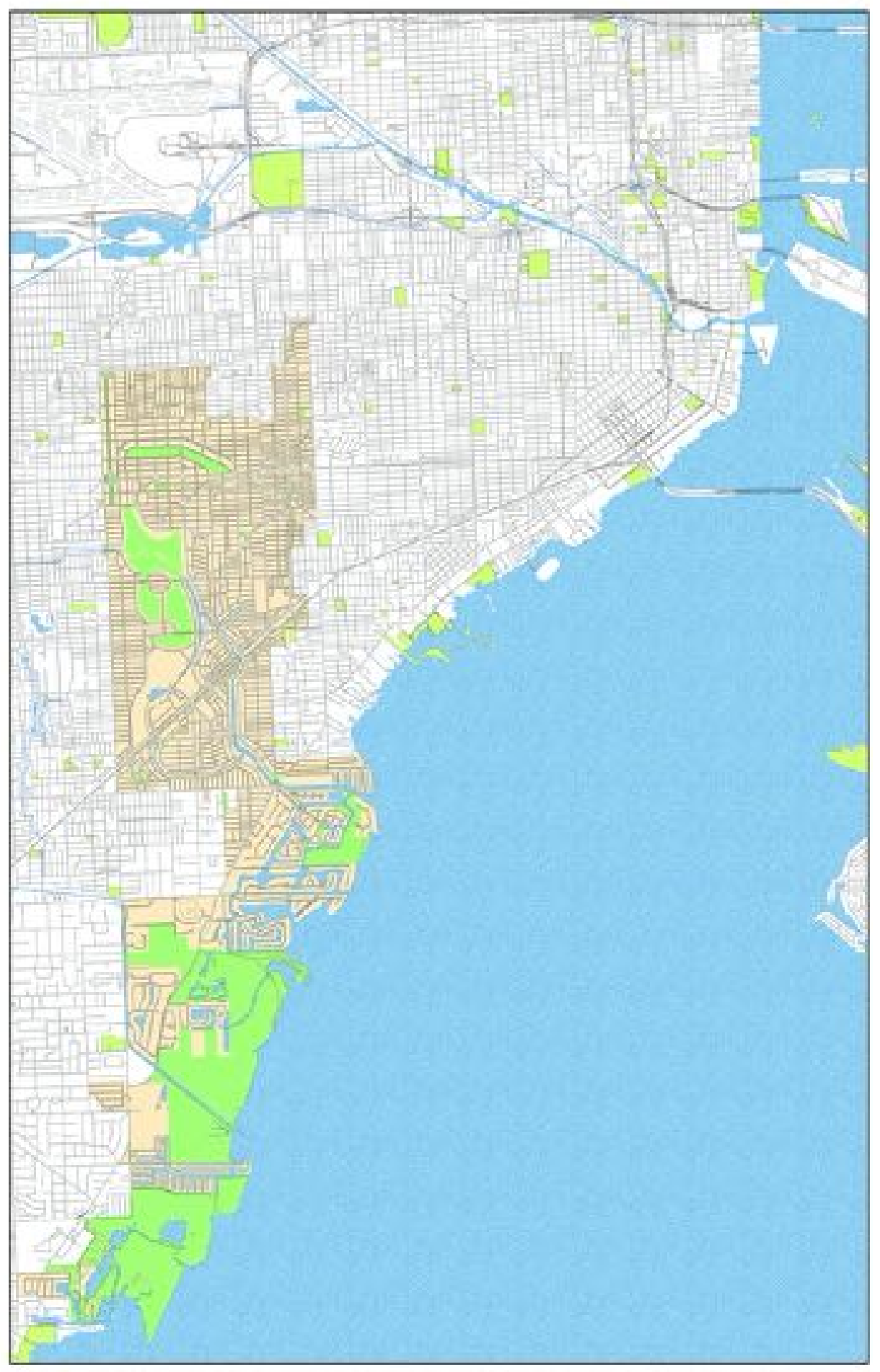

Plate 7. Map of Coral Gables and vicinity. Source: City of Coral Gables. 
There was a distinction between early Miami and early Coral Gables. Early Miami was developed with relatively simple plats, which optimized the engineering of lots and rights-of-way. On the other hand, Button organized Coral Gables along strategically planned diagonal avenues and a few curving streets. This was a nuanced enhancement of prior platting practice, which focused on surveying and engineering.

Button was a landscape architect from Brandon, Vermont. Landscape architects of the period had expanded professional practice to town planning, after the example of Frederick Law Olmsted in the late $19^{\text {th }}$ century, and in the 1920 's the work of the Olsmted Brothers, John Nolen (Venice, FL, ) and others. Frank Button planned Coral Gables with more complex aesthetic standards than prior conventional practice, but which had become best practices in the 1920's.

Artistic considerations, in particular terminated vistas, guided form. Design according to artistic principles was a fundamental subject for best practices of the 1920's. Many reference books proposed parallel methods of design based on content. For instance, the strategy of terminated vistas highlighted landmarks intended to convey a sense of quality and permanence. However, none of these issues were central to the development of zoning after 1926. By the mid-century other priorities would prevail over quality design in South Florida local governments including Coral Gables, such as traffic management and maintenance of traffic signals. Coral Gables would be seen as exceptional in the $21^{\text {st }}$ century and perceived as an enclave of wealth, when it had been nothing more than the expected outcome of standard best practices of town planning in the 1920's, built by a real estate developer. 
Plate 8 is a diagram that illustrates the role of the Biltmore Hotel in the composition of streets.

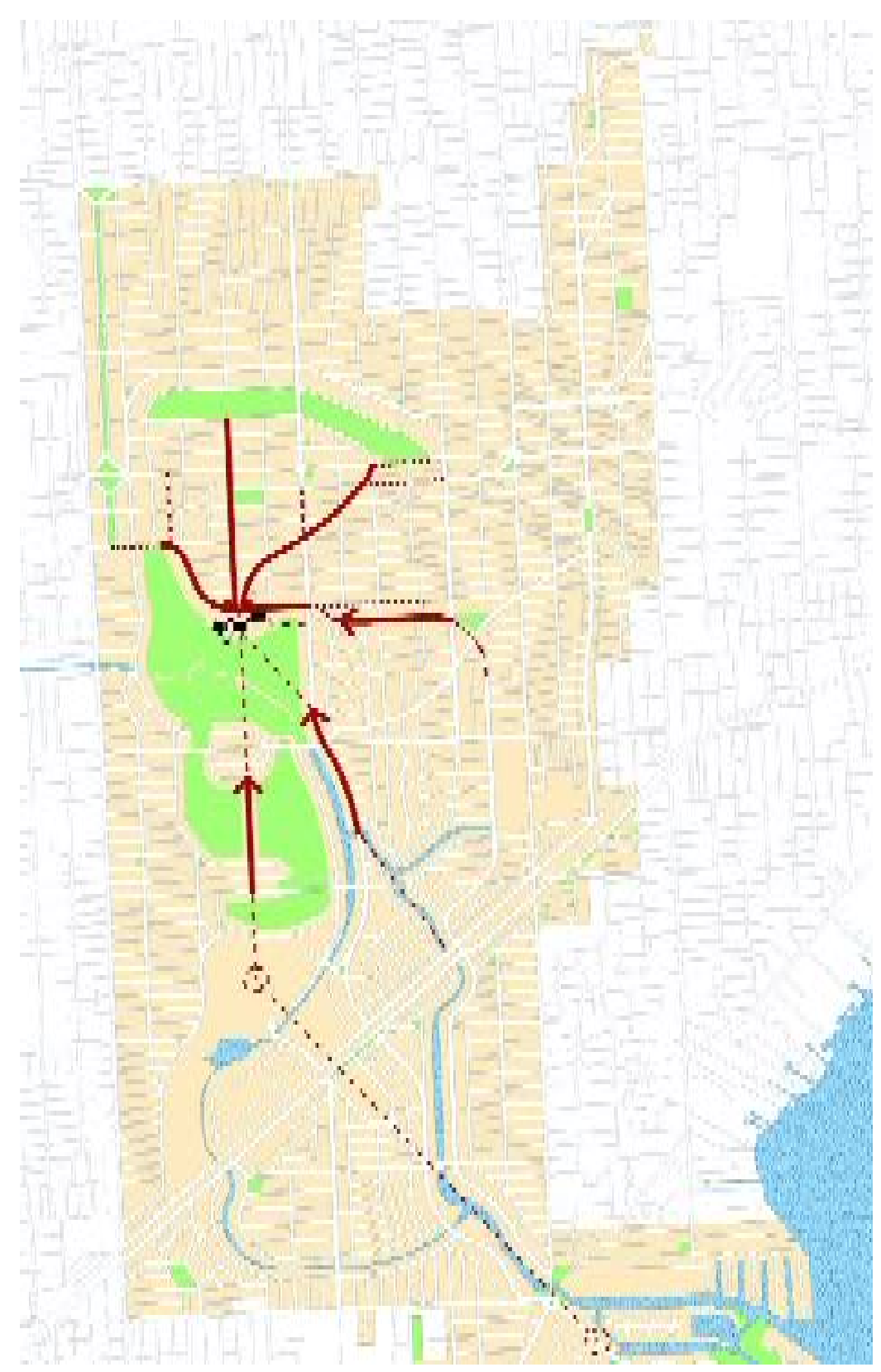

Plate 8. Diagram of Coral Gables master plan. Source: City of Coral Gables.

Coral Gables was also planned in terms architectural style. Such content was influential in the implementation of place and the regulation of development through the 
decades. Pate 9 reproduces a conceptual rendering of Douglas Entrance, which was built as intended. In the 1980's, however, larger buildings located in the plaza areas changed the proportions of the district.

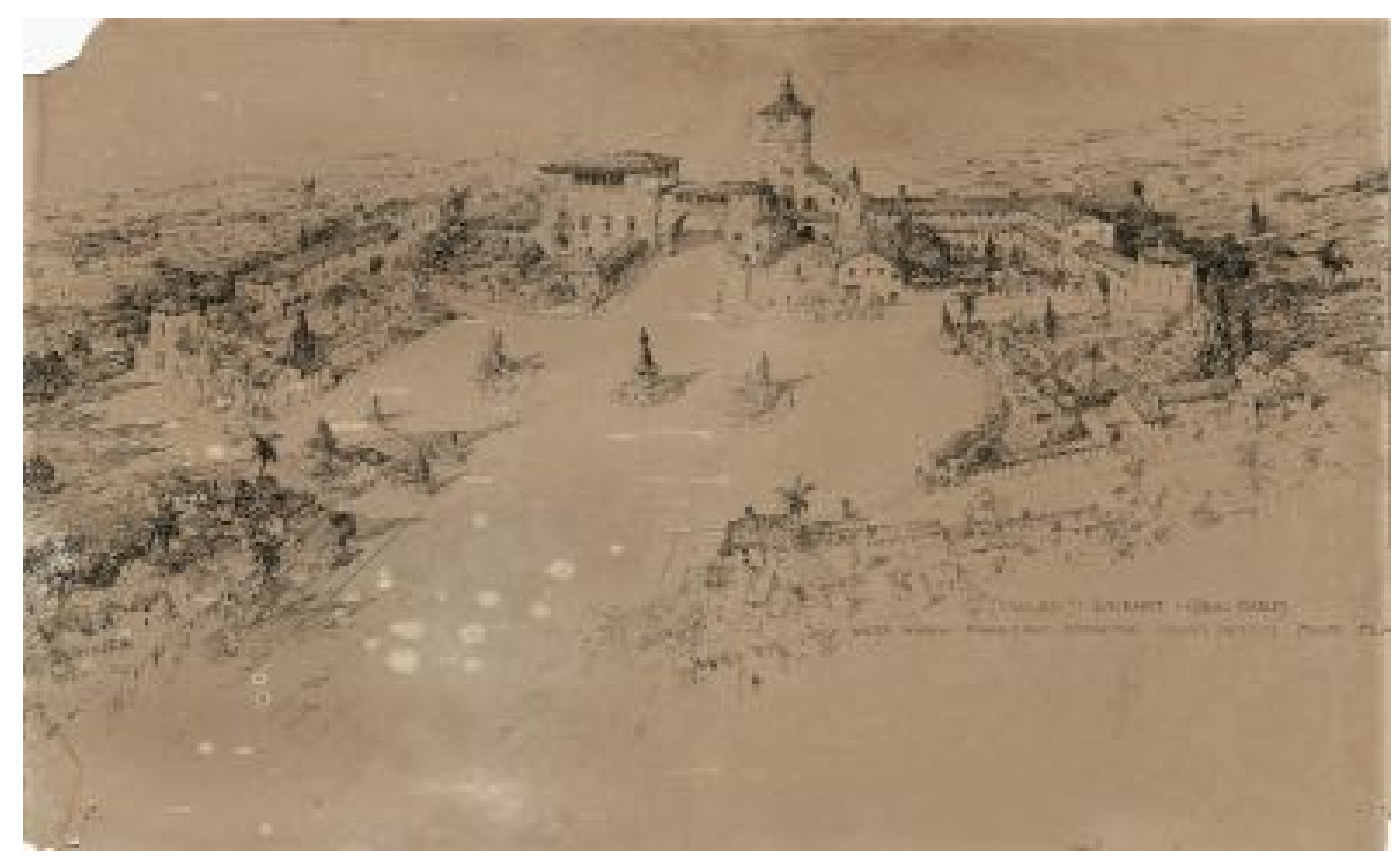

Plate 9. Douglas Entrance rendering, by Walter de Garmo, Denman Fink and Phineas Paist, Associate Architects. Source: HistoryMiami Archive.

Even through the Coral Gables zoning code emphasized aesthetics and had robust standards for design features, planning and zoning processes were conventional. The administrative features of the zoning code followed the outline provided by the Zoning Primer of 1926 and had incorporated many procedures developed in the past century. The Coral Gables zoning code was generally understood as a particularly complex regulatory document for a local government. In addition, it was also full of clear content. The contradiction between complex process and clear content created successful outcomes, but at a great investment of time and expertise, and the standard of review was not "excellence," but compliance with the adpted rules. 

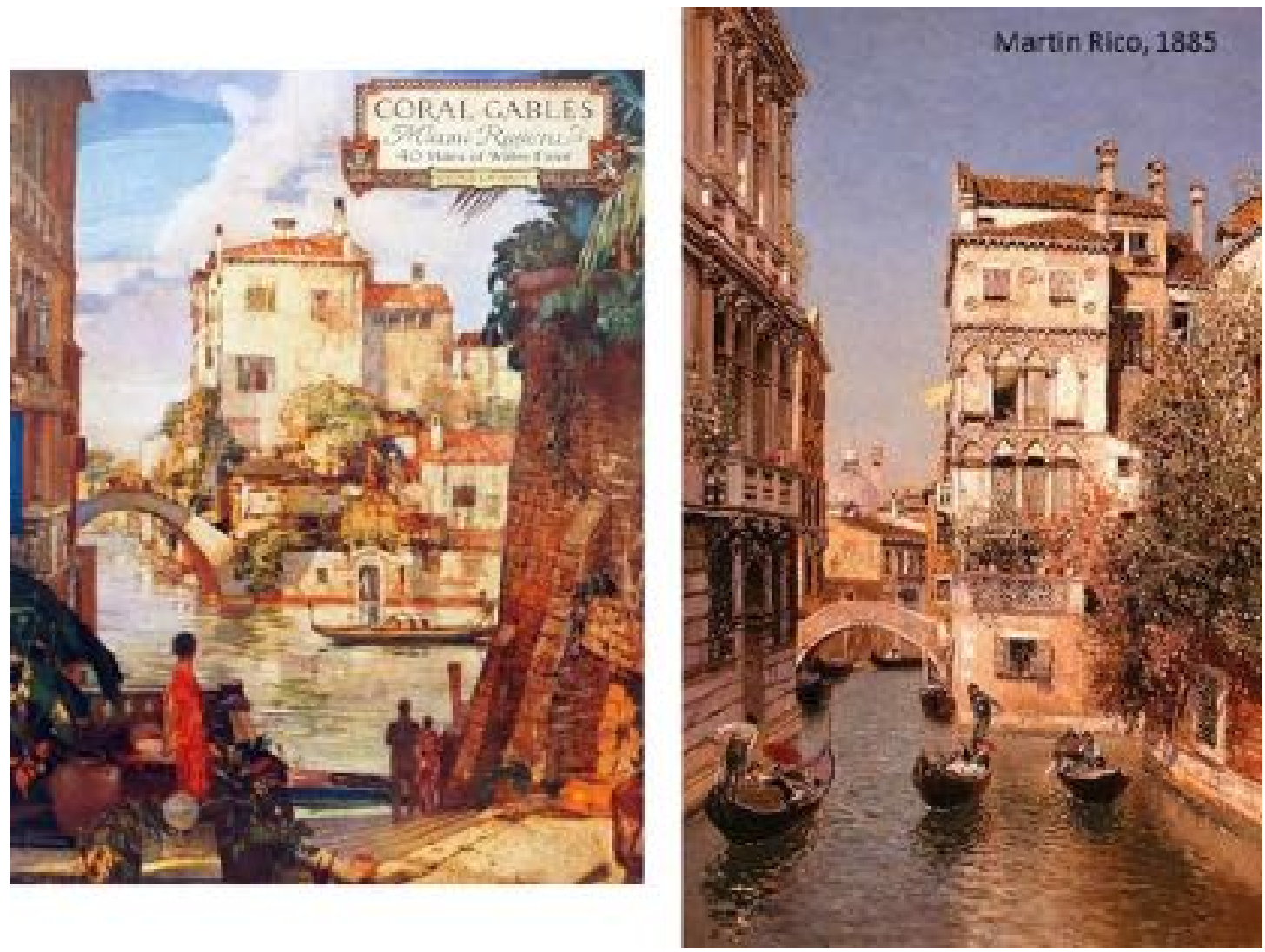

Plate 10. Comparison of Coral Gables marketing rendering and painting by Martin Rico. Sources: Rendering: Coral Gables publication, painting: Prado Museum.

\section{Conventional Planning and Zoning + Robust Design Review $=$ Place}

Coral Gables began with content, as depicted in multiple renderings, which were typical of contemporary best practices in architecture and the arts. However, development throughout the $20^{\text {th }}$ century was implemented with conventional planning and zoning. Only one administrative process would be considered exceptional: design review by the Board of Architects.

Figure 3 is a typical flow chart of the development process, included in the zoning code of 2007. The chart maps a thorough process for bureaucracy of place, within the expected framework of conventional zoning. Democracy of place is implemented by the Board of Architects step, where volunteer members review projects in a public meeting. 


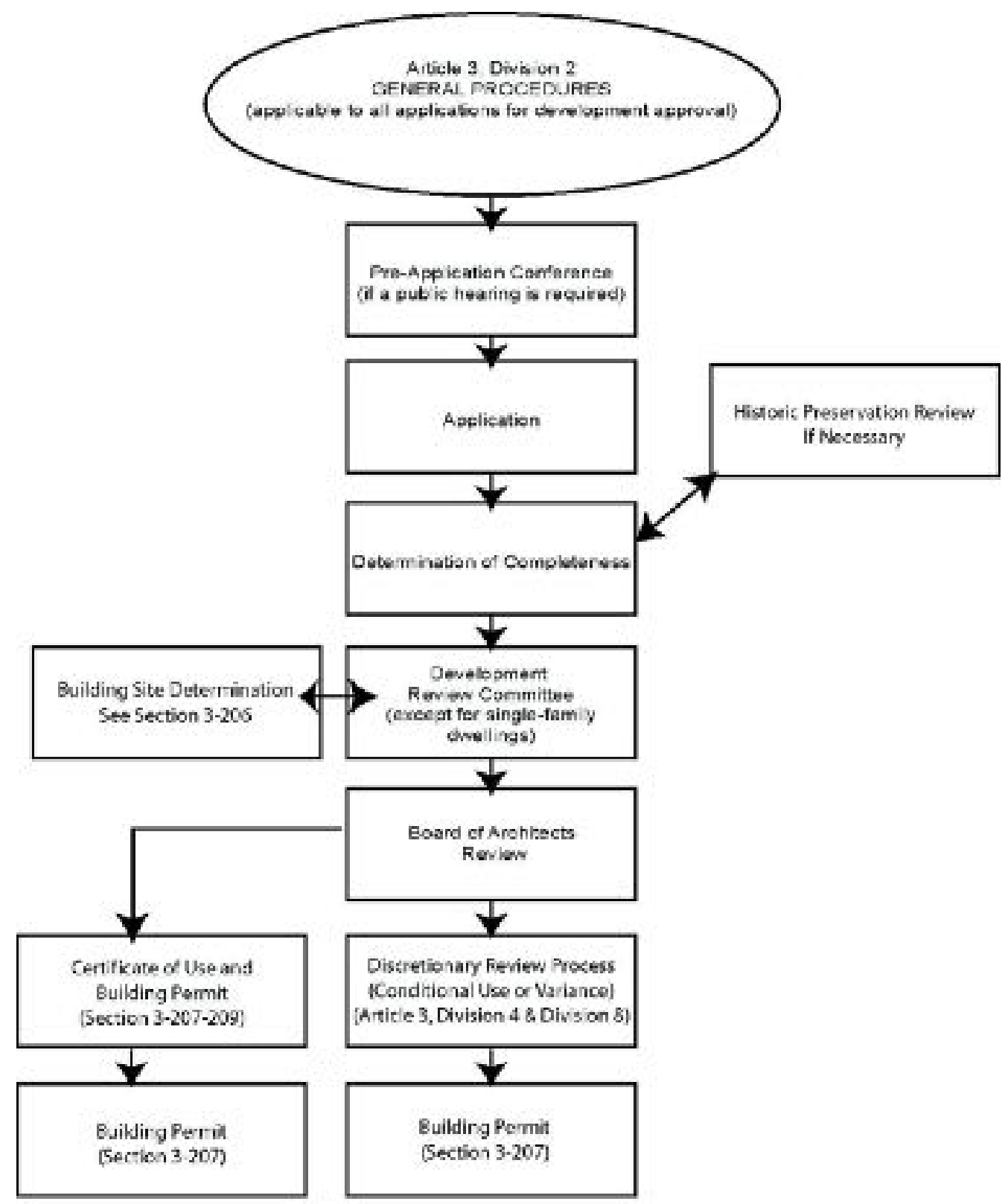

Figure 3. Zoning Process diagram. Source: Coral Gables Zoning Code, 2007.

Many cities adopted some type of design review, but Coral Gables' process was uniquely robust. It had professional staff, a board of professionals, and strong support from language in the zoning code. Although the process has been modified periodically, it predated incorporation and had been consistently applied for the past century in lively public meetings, where debate and disagreement were common. 


\section{Lessons from Coral Gables}

Coral Gables is a recognizable place because of a continued interest in the implementation of content. Administrators applied zoning as originally intended in 1926, with deliberate coordination between a comprehensive plan and regulations.

Surprisingly, strict interpretation of the initial potential of zoning makes Coral Gables an exception, and additional research should explore this finding. In contrast, many local governments tended to implement abstract regulations with cursory attention to comprehensive planning.

New Urbanism theory has critiqued typical zoning practices and proposed "formbased code" as an alternative (Duany et al, 2010). This approached suggested that conventional planning and zoning had ineffective best practices, for democracy and bureaucracy. Enhanced practices for democracy, such as charrettes and workshops, and improved tools for bureaucracy, centered on "form-based codes" were offered as solutions. But a more nuanced review of place would also emphasize governance and administration. Conventional zoning of the early $21^{\text {st }}$ century could be understood as a poor application of the original intent, which is well illustrated in early Coral Gables.

Moreover, focus of the New Urbanism was content for the private sector. Coral Gables was originally implemented as a private project and the developer would be remembered as “town founder" (Duany et al., 2000). For example, the University of Miami’s Master's program on real estate development and urbanism, which emerged from early new urbanism theory discussions, prepared students for careers in the private sector (Bohl, 2019). 
As Coral Gables played a seminal role in New Urbanism theory for content but a less prominent role for process, a more nuanced understanding should inform future theory related to conventional zoning and the administration of design. Conventional zoning can lead to a focus on design and high-quality aesthetic outcomes. However, although conventional zoning may be different from Euclidian zoning, theory and best practices tend to privilege legal arguments over design considerations. Thus, content and process were unlikely to develop as they did in Coral Gables, under current practice.

Merrick's master plan was an effective "comprehensive plan”, as such plans would be understood in the 1920's (Plater-Zyberk, 2018). The 1930 zoning code followed the Euclidian structure, but attempted to expand zoning to its aspirational potential, with emphasis on design parameters and review. By 1930 Coral Gables had become a model for the administration of building and development in local government.

The merits of the Coral Gables zoning code appear to be clear to professionals who apply it to projects, or who are responsible for implementation of its provisions. A common frustration was that the professional knowledge that shaped early Coral Gables as a quality place had been lost (Poole, 2018) (Dover, 2018) (Plater-Zyberk, 2018). A specific example was the use of reference books on architectural style as a best practice of 1920's architects, which promoted superior quality in design with a simple methodology that could be applied routinely. Each book provided practical models of a style of building, which could be imitated or modified competently by professional architects. Although the Coral Gables zoning code reflected this practice with the Coral Gables Mediterranean style bonus program's exemplary buildings, architects of the $21^{\text {st }}$ century did not enjoy adequate support from theory and best practices on aesthetics, and 
some misconstrued the intent of the code. Theory construction through public administration methods of data and analysis, which lead to concepts and categories, may eliminate this gap in the literature of allied design professions.

Data from the research questions supports the hypothesis that an early vision of place can be implemented and preserved through administrative tools of zoning and design review. This conclusion was expected and confirms typical goals for local government administration of growth and development. However, data and analysis from Coral Gables illustrate the complexity of design review and the commitment of time and resources needed for the effective implementation of aspirational ideas about place by a local government. Academic literature is limited on the topic, but findings suggest that effective design review sustained consistently through several decades at the local government level is rare.

Survey data from Coral Gables confirm design review can be implemented successfully if conventional zoning regulation is supported with effective aspirational content and adequate processes. Coral Gables provides superior examples for content and process for communities interested in high quality architecture. Future research should explore additional examples with a range of best practices, calibrated to their needs and expectations of each community. Although aesthetic considerations tend to be the focus of design regulation, content should reflect local goals. For instance, best practices on sustainability or climate change could be researched.

\section{Findings}

1. Place will be resilient, as the early layout of streets and blocks will last into the future, regardless of content or process. 
2. Quality will endure when content guides form.

3. A general plan prepared in two months may be developed incrementally for a century and beyond. However, each incremental step should be consistent with the content of the plan.

4. Coral Gables was the expected outcome of standard best practices of the 1920's. There is nothing utopian about the community. In fact, it was created as a private development.

5. Conventional planning and zoning may implement content through robust design review. However, content will always be debated, as different opinions may prevail at various times. Design review should be understood as a creative process and would require supportive democratic and bureaucratic practices to be effective for the long term.

6. Coral Gables may appear exceptionally successful only because other communities did not consistently implement comparable planning and administrative strategies. Data on Coral Gables explained the role of aspirational content and its practical application for local governance. 


\section{CHAPTER II}

\section{METHODOLOGY}

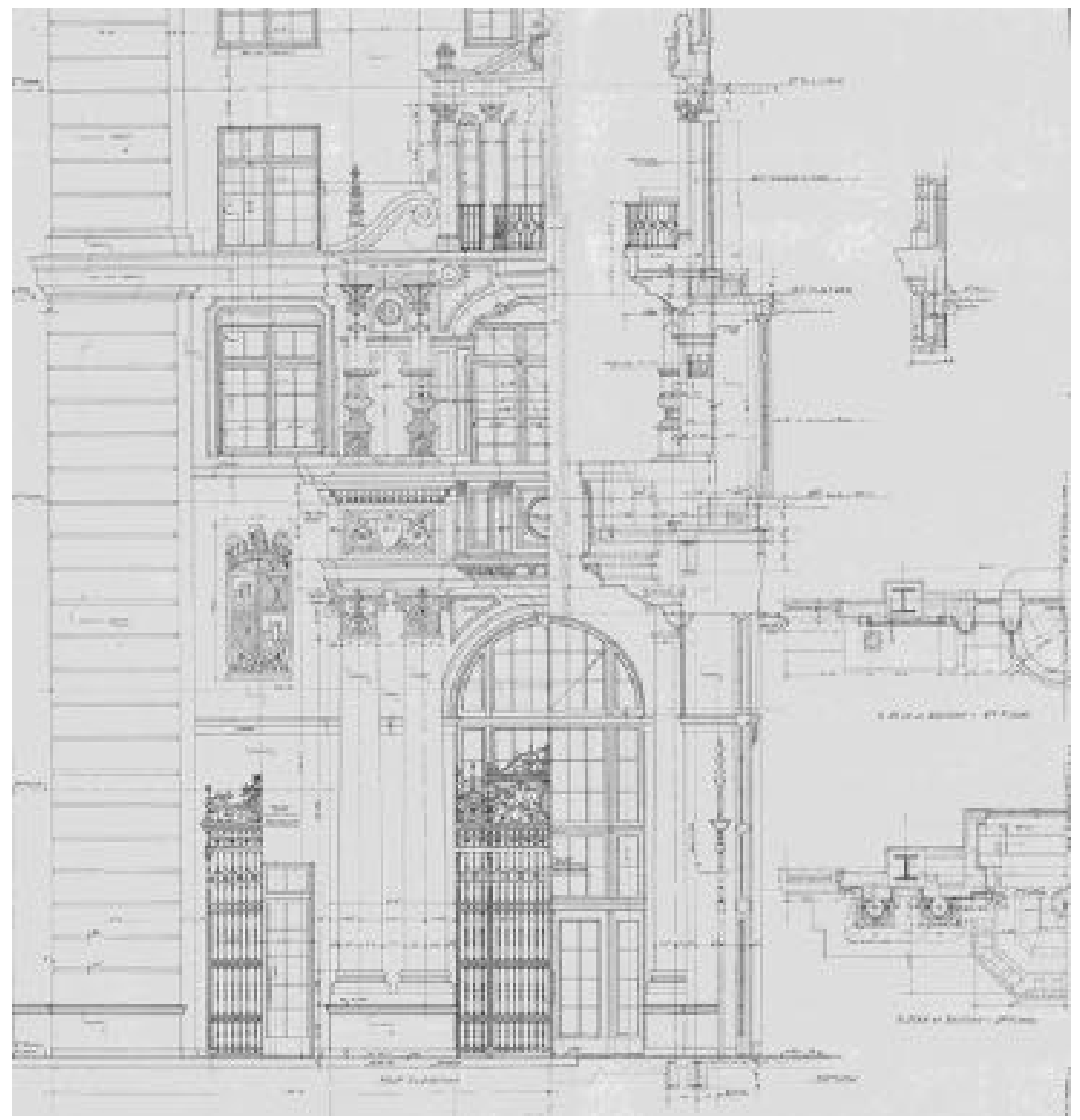

Plate 11. Entrance, Biltmore Hotel, Coral Gables, architect Schultze and Weaver, 1926. Source: Coral Gables Historic Preservation office.

Hotel design was inspired by Seville's Giralda tower and renaissance and baroque details. 


\section{Research Methods and Questions}

\section{Objective of the Study}

The study was designed to initiate discussions about the administration of content for place in local government. Democracy and bureaucracy of place were researched in terms of theory of public administration and best practices. The goal was guidance for governance of place at the local level.

The administration of place is a principal activity of local governments. Effective democratic discussion of place requires a language for aspirational content. Efficient implementation of place will result from best practices which update bureaucracy with smart tools. These are core topics of public administration and research was designed to establish a framework for theory development and innovation in practice.

The role of aspirational content in democracy and bureaucracy of place was explored, from the point of view of late $20^{\text {th }}$ century planning reform ideas and theory, and through in-depth review of one city which was at the forefront of early zoning and developed nuanced administrative tools. The objective was a rough sketch of theory concepts and best practices, which would introduce new knowledge to the literature of public administration. Qualitative interviews and archival research provided direction for theory and existing survey data measured hypotheses.

Physical development of neighborhoods and districts promotes extensive public discussion and specialized professional processes. However, place is seldom discussed directly, although development proposals and capital projects often generate controversy. Public administrators have limited tools for public input and review, and tend to undervalue place within narrow disciplines, such as transportation, land-use, code 
enforcement or economic development. Moreover, common procedures such as planning, and zoning have not adapted to contemporary opportunities of technology and innovation and have been implemented largely unchanged for a century.

Late $20^{\text {th }}$ century reform movements, such as New Urbanism, proposed alternate regulatory frameworks and design techniques, but public administration was never the central topic of research. Public administration analysis of place should review process and content, and democracy and bureaucracy.

This study was not a history of Coral Gables, or even a comprehensive analysis of the administration of Coral Gables. Coral Gables was a practical source of data on topics that should inform public administration literature. Coral Gables, like any American local government, can by researched from many points of view. This study only reviewed the research questions that follow in the results chapter. Data on social and economic issues was not part of research design.

\section{The Gap of the Literature:}

\section{Democracy + Bureaucracy $\rightarrow$ Place + Smart City $=$ Smart Place}

Democracy and bureaucracy of place in the age of Smart City represented a gap in the literature of public administration which could be remedied with discussion, theory and best practices about Smart Place.

Related disciplines reviewed place from the point of view of design or use. However, data on the long-term administration of place and its impact on quality of life were limited and theory for public administration was not established. Furthermore, trendy commentary on Smart City initiatives could obscure the radical transformation of 
place into data, without chronology bias, which would be implemented by smart place theory and best practices.

Research was performed on planning literature, literature and data on design and development of Coral Gables and anonymous surveys on customer satisfaction and quality of life in the city. Although in-depth research was performed one local government, the project was not a case study. Coral Gables provided focus for the general topic of "place," but multiple strands of research were performed. New qualitative and quantitative data were reviewed, on various aspects of content and process. Findings from all data provided support for a generalized theory sketch and recommendations for best practices.

The analogy of the sketch, borrowed from design disciplines typically concerned with place, was appropriate for the current research scope. A sketch provides sufficient direction to understand basic issues, acknowledges present limits of understanding of the subject, it is a preliminary tool for implementation and deliberately suggests further development towards a finished design. Discussion of data and prior ideas attempted to establish broad strokes for theory and best practices. Qualitative and quantitative findings led to a proposed conceptual theory sketch for the role of aspirational content on the democracy and bureaucracy of place.

\section{Research Design and Methods}

At the start of the project it became evident that the study of place required mixed methods.

Prior literature tended to emphasize either qualitative or quantitative research, but findings were not robust. For instance, Measuring urban design (Ewin, Clemente, 2013) 
an attempted an explanation of place with regression analysis of visual data. This effort followed less methodical attempts to measure visual preference developed by Anton Tony Nelessen (Nelessen, 1993) after the 1970's. However, the understanding of place in terms of data was rudimentary and findings did not review administrative practices. Such research led to interesting discussion, but limited theory. When questioned in 2019, one of the original participants confirmed the limitations of the research (Dover, 2019).

On the other hand, a classic publication on late $20^{\text {th }}$ century polemics about place, Suburban nation (Duany, Plater-Zyberk, Speck, 2000), did not follow social science methods but provided classic qualitative arguments for place and against poor planning practice of the second half of the $20^{\text {th }}$ century, based on expertise and interviews. The authors lectured persuasively and promoted zoning reform in the 1990's and 2000's. Additional publications by the authors would follow and expand aspects of discussion (Speck, 2012). However, many arguments lacked the support of data and could be critiqued from the point of view of research design and methods.

Neither approach proved to be sufficient for theory development on its own, although both had invaluable impact on contemporary practice. Review of past qualitative and quantitative data and discussion on place and zoning reform led to the new theory idea of "narrative of place," as an administrative tool that would promote quality development. This idea structured in-depth review of Coral Gables, FL, as a successful example of long-term implementation, and to qualitative and quantitative analysis of data from interviews and anonymous surveys.

Research questions included theory considerations for a definition of narrative of place and analysis of the experience in in a successful location, with emphasis on 
generalizable conclusions. The goal was to initiate a systematic study of tools for the implementation of place for use by local governments, which may lead to better practices for public administration and governance.

Research was divided in to qualitative and quantitative strands:

A. Qualitative research explored and developed general ideas for theory. Some topics were directly related to Coral Gables. Other topics were informed by contemporary theory discussions.

B. Quantitative research measured satisfaction with Coral Gables practices and resident awareness of the role of content in local governance. Findings from qualitative and quantitative data led to conclusions about theory and best practices.

The study was structured along five phases:

Phase 1. Review of theory concepts from prior literature.

- Literature on place.

General background information established limits to the study.

- Literature on Coral Gables.

Although academic literature of Coral Gables was limited, several influential publications were reviewed.

- Best practices for architecture from the 1920's.

Reference folio books published at the start of the $20^{\text {th }}$ century had a fundamental role in town planning in the United States and in Coral Gables. Content and explanatory tools were research from an extensive library of original publications. 
Phase 2. Research on content and process, from study of Coral Gables regulations.

- Narrative of place.

Merrick explained Coral Gables and the explanation was used for decades to implement place. His approach created value and can be preserved and expanded with smart administrative tools. The concept of aspirational content was developed from the example of Merrick's narrative. Aspects of the narrative were transformed into administrative processes, especially in the zoning code.

- Deconstruction of Coral Gables zoning language.

A zoning code can exist without content. However, content may be introduced incrementally to conventional planning and zoning. Coral Gables provided a nuanced example of the practice of zoning. Zoning amendments refined aspirational content sequentially. Analysis of the regulatory tools used in Coral Gables informed recommendations for best practices.

- Aspirational content and a language for place, for public administration. Content and process for the implementation of place can be discussed in theory and with best practices. An effective language for place had not been established. The distinction and coordination between process and content was not understood in depth. The role of content, or aspirational ideas about design outcomes, in zoning practice was unexplored. Moreover, the evolution of zoning regulatory language about design, from inception in 1926 through the reform movement of the new urbanism, also presented gaps in the literature. 
Phase 3. Qualitative interviews for theory development.

- Interviews with experts.

Research design and research questions emerged from planning and zoning reform ideas from the late $20^{\text {th }}$ century, and from qualitative interviews with experts through the use of grounded theory methods

Phase 4. Quantitative testing of hypothesis.

- Regression analysis of survey data.

Two data sets from anonymous random surveys were reviewed to measure the role of aspirational content and governance in quality of life and customer satisfaction with bureaucratic processes.

Phase 5. Proposed theory and best practices.

- Smart Place

Smart City has been a popular term in literature and academic conferences. Although literature on Smart City was in its early stages when this study was performed, research revealed opportunities to link smart strategies to place. Smart City typically refers to technology solutions for municipal services. Smart Place is more descriptive of the goals of public administration and more useful for practice.

Findings informed recommendations on best practices for democracy and bureaucracy of place. In the most general sense of theory, place should the outcome of the implementation content through public process. Content would be developed with democratic activities. Process would be implemented through bureaucracy. 
- Democracy and bureaucracy

Public administration would have a role in content and process, as democracy and bureaucracy are best implemented by professional administrators. An understanding of the preferred qualities place would enrich public administration theory.

\section{Qualitative Research Questions}

The following questions were researched with archival resources and literature review and expert interviews. The initial question led to topics that required further research:

1. What is the role of content and best practices for design and smart place in contemporary practice and local governance?

Qualitative findings about topics and priorities informed targeted questions, which were explored with literature review:

2. What were best practices for architecture in the 1920's?

3. What was the content of George Merrick's narrative of place for Coral Gables? How was content adapted to governance?

The Coral Gables Mediterranean narrative was investigated as it evolved from inception in the early 1920's to its application in 2016. Literature research was conducted on the administrative documents defined the narrative. In addition, in-depth qualitative interviews were performed with individuals who crafted the contemporary interpretations of this narrative, from the 1970's to the present. Most participants had not previously shared their views and opinions on the topic. 
The role of design in zoning practice in Coral Gables was reviewed, as a model for local government regulation of aesthetics and community aspirations. The evolution of zoning regulations was documented, and qualitative research was performed on application and effectiveness through in depth-interviews with experts on the subject.

4. What was the evolution of the zoning language related to content in Coral Gables?

A close reading of the evolution of the Coral Gables code provided the opportunity to deconstruct zoning language and analyze it as content, in terms of meaning and assumptions.

5. How did the Mediterranean bonus program in Coral Gables implement content of place?

The Mediterranean bonus program was one of the most direct expressions of content in a municipal zoning code. Findings provided information to discuss and evaluate the role of content.

The following questions were researched with in-depth qualitative interviews of selected experts:

6. What is the role of content and best practices for design and smart place in contemporary practice and local governance?

7. Were the administrative tools of conventional planning and zoning adapted to aspirational content?

\section{Quantitative Data: Citizen Engagement and Customer Satisfaction Surveys}

The City of Coral Gables sponsored two anonymous random surveys in 2018. The surveys were conducted by the Baldrige Group, LLC. Raw data was publicly 
available at the City Manager's website. Naomi Levi-Garcia, staff coordinator of the survey, was interviewed in 2019 and provide information on context and intent.

This study used existing excel files prepared by the consultant, and adpted the data for the clarity, based on the following research questions:

1. What was the role of content in community satisfaction?

A general community survey provided quantitative data on the role of content in resident satisfaction.

2. What was the level of customer satisfaction with the implementation of content through the Coral Gables Board of Architects process?

Data form a survey of Board of Architects customers measured awareness of content and satisfaction with the design review process.

\section{Hypotheses}

Prior theory discussion and literature review led to the following hypotheses, which were researched with questions developed from qualitative data, and measured with quantitative survey data:

H1: Aspirational content of place enhanced local governance in Coral Gables through resident and customer satisfaction.

H2: Democracy and bureaucracy informed by aspirational content in Coral Gables lead to generalizable strategies for the implementation of Smart Place.

\section{Deliverables}

Findings led to specific recommendations, described as deliverables because they can be read independently. Proposed ideas developed theory and practice, but anticipated future research. 
Theory:

1. Glossary of proposed theory concepts.

The proposed terms should lead to an expanded discussion on place, calibrated for local conditions. The glossary is a first attempt at theory development. Future research should refine language and lead to direct and accurate discussion on place, for administrative activities related to democracy and bureaucracy.

2. Aspirational content and narrative of place.

These are two fundamental ideas for public administration, which have an effect on quality of life and customer satisfaction. Research on Coral Gables demonstrated the value of content of place, expressed in the form of a coherent narrative. An assumption of the study was that the concepts are generalizable. Future research should test this assumption.

3. Governance of Smart Place.

Proposed best practices would lead to a transition from the administrative city regulated by conventional planning and zoning to a framework for governance of place. Principles of governance would guide democracy and bureaucracy of place. This theory concept should provide guidance for professional practice.

Best Practices:

1. Democracy: Education, participation, decision American local government's principal role is the implementation of democracy. At times, democracy and bureaucracy may be confused because 
of conventional practices. Local government democratic activities related to place should be significantly enhanced. Three topics were identified. Education requires effective content and delivery methods. Participation should be structured within a spectrum of options, from informal discussions to public hearings. Decision should be transparent and participatory.

2. Bureaucracy: Data, language, procedures Place should be understood in terms of data and discussed directly. The language of place should be about place. Procedures should lead bureaucracy towards governance and away from arbitrary regulations.

A precise understanding of democratic and bureaucratic activities would enhance in local governance. Often, democratic processes, such as notice requirements, multiple public meetings or posting of properties, are misunderstood as bureaucratic. Although professional staff may assist in these activities, they are intended to enhance public participation and engagement. Thus, a fundamental distinction between the private and the public sectors is that in the public sector a principal role of bureaucracy in the implementation of democracy. 


\section{Scope and Limitations of the Study}

\section{General Observations}

The study was designed to develop recommendations for theory and practice related to the administration of place. Place had been regulated with the administrative tools of planning and zoning in American local governments for almost a century. However, standardized democratic and bureaucratic practices had proved inadequate at the implementation of civic aspirations and often led to ineffective governance. Frustration with conventional planning ang zoning had led to reform efforts in recent decades.

Coordination between regulatory language and a physical plan for the future was the original intent of zoning (Zoning Primer, 1926), a goal seldom realized. Nevertheless, this original objective was achieved to a great extent in Coral Gables since the 1920's, through coherent administration of aspirational content and innovative bureaucratic processes. Thus, research qualitative and quantitative research performed on Coral Gables would inform theory and practice.

The fundamental constraint of present research was its targeted focus. This was a deliberate choice of research design, as the topic required detailed understanding of data to develop theory. Findings supported hypotheses and provided new knowledge. Some analysis was anticipated at the start of the study, such as the value of Merrick's narrative of place and the analysis of zoning tools based on content. Some conclusions were unexpected, such as the current role of Smart City initiatives in the implementation of place. In the end, the scope of the project fulfilled the objectives of new theory and best practices. 
Conclusions were considered generalizable, as data form Coral Gables was consistent with conventional practice at each period of history under review. Investigation may have uncovered some instances of exceptional implementation or content in terms of quality, but always within the bounds of accepted practice. Nevertheless, additional research on other local governments would confirm or reject proposed interpretations of data and may contribute enhanced practices for a transition from conventional planning and zoning to governance of place. Such an effort would be beyond the scope of the project, but opportunities for future research can continue along strands revealed by the current study.

\section{Research Limitations}

The study had the following limitations:

1. Conceptual ideas are new and require future testing and refinement.

The intent of the study was to develop theory and practice. Proposed ideas are a work in progress and future refinement is expected.

2. Coral Gables informed theory development and best practices, but the assumption that local findings are generalizable throughout the United States would require further research and other examples.

The scope of the study was designed to be limited. This choice was deliberate, for practical concerns of time constraints and also as a critique of research that amalgamates data from multiple sources to the detriment of local calibration. Future research should build on current findings and expand theory and refine best practices.

3. Coral Gables may be critiqued as exceptional and not exemplary, because of demographics and census data. 
Prior literature critiques Coral Gables occasionally from points of view beyond the scope of place. This critique would be an error of theory. Place is autonomous. A discussion of place about issues not related to place undermines theory on democracy and bureaucracy. In other words, a critique along social or economic issues would not lead to theory development on place. However, such research would provide independent perspectives that could enrich discussion about a particular place.

Nevertheless, research design underestimated the influence of preconceived perceptions about Coral Gables. Some readers who critiqued the manuscript were at times skeptical about the generalized value of the data, as personal ideas about Coral Gables interfered with an objective reading of the text. Prior narratives about Coral Gables, supportive or critical, impacted perceptions about theory recommendations. As the study was not about Coral Gables but about theory and best practices for public administration, the remedy would be future research from multiple locations. Such a project would be beyond the scope of the current study but could be designed to expand and test proposed theory.

4. Best practices for governance of place are not fully tested.

This concern would result from innovation related to smart strategies. Time and experience would refine practices and lead to enhance bureaucracy of place. Recommendations are not intended to be comprehensive, as practices should be calibrated to the needs of each community.

\section{Scope of Recommendations}

Recommendations based on findings from the study were intended to start a wider discussion on place. Therefore, proposed ideas acknowledge the need for future research. 
The following comments reflect the bounds of the study and the scope of recommendations.

\section{Theory:}

1. Planning and zoning of the administrative city should transition to governance of smart place.

Since 1926, conventional planning and zoning has been the typical process for the administration of place in local governments in the United States. Reform efforts have led to innovations in the past century, but the fundamental regulatory framework has been consistent.

Planning and zoning provided inflexible processes for democracy and bureaucracy, where content was addressed indirectly. Residents and elected officials were often interested in content, and conventional administration lacked effective tools or language to facilitate democratic discussion or bureaucratic processes. In an effort to enhance governance, local governments often perform additional meetings and prepare reports and regulations beyond the scope of adopted planning and zoning regulations and with negligible guidance from theory.

The term governance of place is proposed for public administration theory. This conceptual framework reflects many new and old aspects of current and historic practice and encourages enhanced coordination of administrative activities, which span democracy and bureaucracy. Planning and zoning should not be abandoned but would be transformed with the introduction of smart tools. Additional public input processes and flexible regulations should calibrate the administration, towards the objective of smart 
place. Public administration of smart place should reflect historic conditions and future aspirations.

Governance would promote enhanced participation in the democratic development of content and flexibility about bureaucratic creativity in processes. Planning and zoning was a static proposition of the $20^{\text {th }}$ century. Governance is a dynamic framework for smart place. Best practices for democracy and bureaucracy should be guided by aspirational content and lead to smart place, which are new terms for public administration theory.

2. Place should be understood as data, to eliminate chronology bias and promote smart strategies.

Place is a complex challenge for theory, as the practical implementation of aspirations requires an extensive frame of reference. Social science methods privilege a narrow understanding of data. For instance, research on local governments may measure customer satisfaction, demographics, real estate values, or similar quantitative data. Qualitative data may be more comprehensive, but it may be difficult to measure accurately.

Place requires an expanded understanding of data. Data must be defined and collected, and the type of data selected would condition the scope of future research. Thus, literature research and data in the study may exceed conventional public administration methods in an effort to develop new theory.

For example, zoning language should be understood as qualitative and quantitative data. Quantitative data emerged from analysis of the text of adopted or proposed ordinances. Qualitative input on Coral Gables zoning (Gelabert-Navia, 2016), 
(Parks, 2016) provided insight on the process of translating place into regulatory language.

When place is analized as data, an objective evaluation without bias from time, personal preference or professional specialization would lead to enhanced governance. Prior literature assigned too much relevance to historical time or personal aesthetic choice when discussing place. This study proposes the elimination of chronology bias and arbitrary choice.

3. Aspirational content: A democratic language for administration of quality. Language about urban development has a long history of innovation (Cerda, 1867) (Lynch, 1960) (Jacobs, 1961) (Duany et al, 2010). The proposed language about place is a contribution to discussion about place in public administration. Two main ideas are aspirational content and governance of smart place. Additional terms are listed in the glossary.

\section{Practice:}

1. Qualitative and quantitative data provide a dynamic ecosystem for locally calibrated governance.

Contemporary Smart City literature describes the framework of theory and practice as an "ecosystem." This analogy is comparable to the "transect" proposed by New Urbanism theory in the 1990's. Both metaphors imply study of the administration of a complete community, to measure distinctions and identify synergies. An ecosystem or a transect represent reality with tools that are generalizable and linked to practice.

"Ecosystem" and "transect" can be understood as theory models which rely on data that is detailed, local, quantitative and qualitative, to shape a generalizable 
framework for practice. Coral Gables zoning language was documented, best practices of the 1920`s were researched and evaluated, qualitative policy issues were discussed with experts, and processes were measured for customer satisfaction. This comprehensive analysis provided a general view of the ecosystem of governance, with opportunities for enhancement.

Qualitative and quantitative data provide insufficient explanations of place in isolation, and best practices should apply findings from all types of data. Qualitative and quantitative data must inform an ecosystem for governance that leads to quality place. Public administration procedures must be flexible, as dynamic data provides unprecedented opportunities for local calibration.

2. Education about content implements democracy of place.

Coral Gables data on the Board of Architects process and public participation efforts revealed a need for effective information about content. Democratic discussion about place would be enhanced with coherent content. Although research analyzed the constructive use of content in the Coral Gables zoning code, effective implementation required additional information. Best practices manuals would educate professionals. Public discussion of aspirational content in a spectrum of formats, supported by education about examples and practices, would facilitate democratic activities.

3. Bureaucracy tasked for dynamic calibration and adjustment of content. Smart initiatives transform processes, as they provide the opportunity to adapt to new conditions. Prior bureaucratic practices on the administration of planning and zoning have addressed place indirectly. Smart data collection and use should have a direct focus on place. 
Moreover, conventional planning and zoning bureaucracy was static because it lacked smart tools. The task of bureaucracy should shift to implementation of smart place. This conceptual distinction requires best practices, as conventional planning and zoning procedures interfere with dynamic creativity.

Aspirational content should guide regulation, and content should be calibrated based on dynamic data. This proposed framework is the exact opposite of a conventional zoning process, where a code is interpreted by a zoning official, and amendments are incorporated incrementally, as policy priorities shift. Conventional tools were not tested by data and were not conceptualized in terms of data. Thus, a conventional zoning code would tend to collect decades of isolated decisions, unsupported by theory. Governance of place, on the other hand, would promote dynamic calibration of aspirational content.

\section{Future Research}

The goal of the study was to initiate discussions about democracy and bureaucracy of place. The role of aspirational content and the goal of governance of place were identified and measured with data from Coral Gables. The following chapters provide data an analysis consistent with the stated objectives. However, current research questions provide a limited review of the full theory implications of the proposed arguments.

Future research should expand the topics that have a role in the administration of place, and measure generalizability with data from multiple local governments throughout the United States. The study used Coral Gables data, as a method to develop generalizable ideas about democracy and bureaucracy of place. Research revealed that place had been discussed and regulated indirectly in past administrative practice. 
Proposed theory ideas, including a glossary of terms and concepts for best practices, should be explored further, with a direct focus on the practice of democracy and bureaucracy of place, in diverse locations with varied histories and contrasting long-term visions. A goal of the current study was to elevate place in terms of theory, by emphasizing its autonomy. Future research may recontextualize place within a wider discussion on urban studies and evaluate its role in overall quality of life. 


\section{LITERATURE REVIEW}

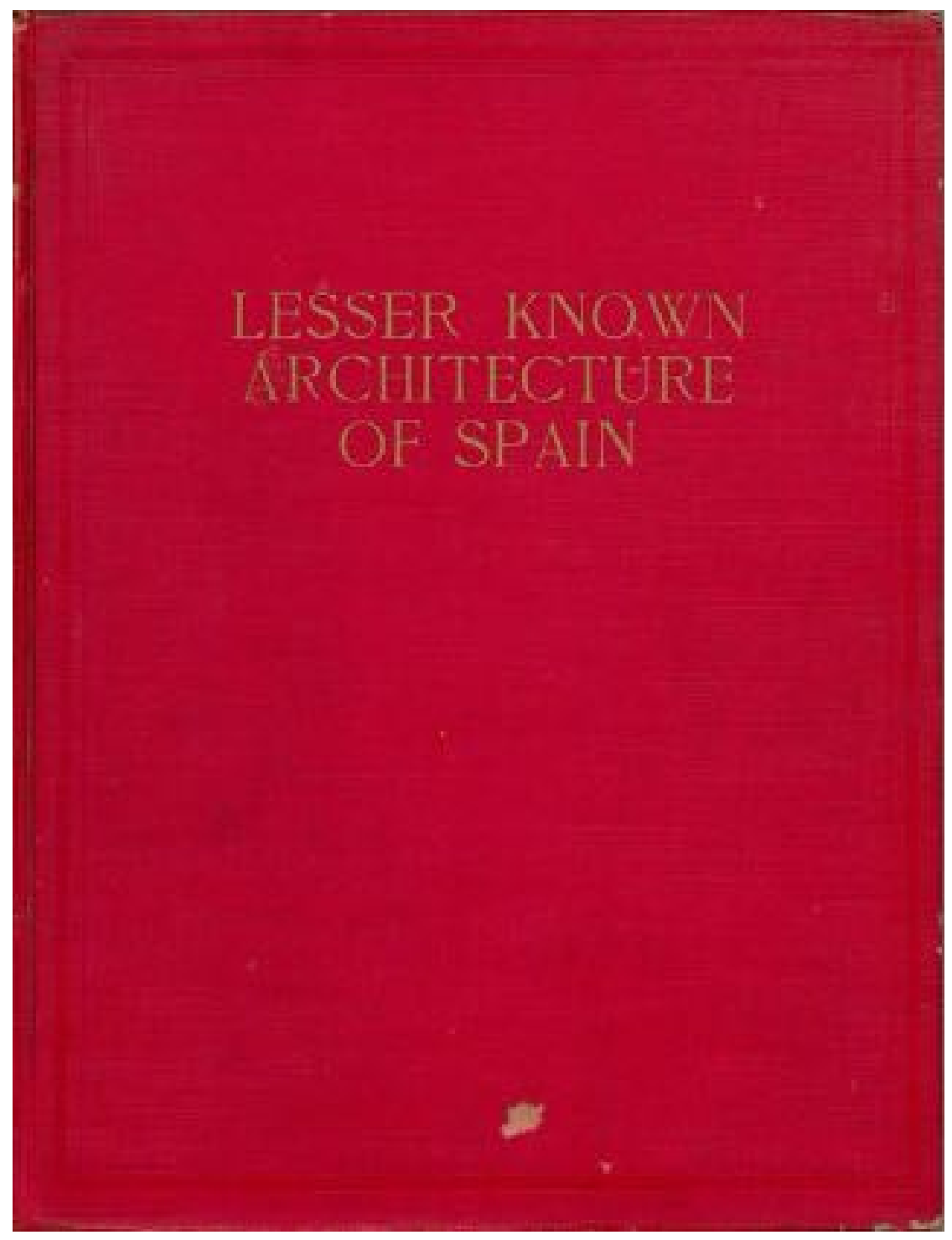

Plate 12. Cover, Lesser Known Architecture of Spain, 1925. Source: Ramon Trias.

The book was owned by Fort Pierce architect William Hatcher and was used for reference on design aesthetics in the 1920's. 


\section{In Search of a Language for Place}

\section{Place for Public Administration}

Place is an outcome of local bureaucracy and democracy and should have an effective language for public administration. However, administrators who manage bureaucratic processes seldom speak in terms of place. Public hearing participants, where local democracy thrives, generally discuss place indirectly. Professionals who discuss place deliberately, such as architects and planners, have limited roles in public administration. Thus, conventional bureaucracy and democracy on issues related to place often lead to unpredictable outcomes based on inferior information. A more effective language for place is needed.

Administration of place is performed with bureaucratic processes which require some type of content. Quality of place depends on content. Thus, content informs bureaucracy and democracy, and effective content should lead to superior outcomes. The administrative city privileged process over democracy, and democracy is the source of effective content.

\section{Content of Place}

Content of place has become a topic of concern in the last 20 years, and it has been discussed indirectly and without effective terminology. For instance, discussions about New Urbanism in the late twentieth century and smart cities in the early $21^{\text {st }}$ century have resulted in a wide spectrum of recommendations about the administration of place. Conventional zoning and abstract data have been critiqued as insufficient for effective implementation of a community's vision of the future. Recent discussions about Smart City initiatives have expanded opportunities for best practices. 
Aspirational content requires new theory because is not a common topic for bureaucracy. Weber $(1922,2011)$ was silent on the general topic of content. Hummel (2008) proposed a critique which reintroduced politics and expertise to bureaucracy, on issues other than process. Miller (2012) recognized the value of content as the story in governing narratives, but he did not focus on place. Place was generally overlooked by public administration theory about bureaucracy, even though planning and zoning became a major aspect of local administration.

Among canonical public administration authors of the past century, Follet (1923, 2016) stressed the neighborhood roots of community and governance, which shape the core of contemporary public participation theory and aspirational content for town planning. Her work was published at the time that George Merrick developed Coral Gables along comparable ideas. More recently, Florida (2012) measured the effect of local narratives of quality and openness as a competitive economic tool that attracted and retained talent at a national scale, although in his latest book (Florida, 2017) revisited early assumptions on the characteristics place.

Recent literature on municipalities emphasizes collection and use of data for enhanced governance, under the general topic of Smart Cities (Meijer, Rodriguez, 2016). The authors reviewed 80 academic articles and concluded that the separation between research on technology and government provided an opportunity for synergies. Moreover, literature on zoning reform has an extensive history in the past two decades, under the general topic of New Urbanism (Duany et all, 2010).

New Urbanism theory proposed administrative tools that regulated place and form, as alternatives to conventional zoning. In addition, content would be developed 
through robust public participation processes, such as charrettes and workshops. In the 1990's and early 2000's many professionals developed and refined innovative best practices for content and process (Lennertz, Lutzenheiser, 2018).

A common admonition of public administration is that data without theory does

not lead to quality outcomes. Similarly, zoning reformers stressed the need to articulate a clear vision that would guide effective regulation. These shortcomings are understandable, as administration theory has focused on bureaucratic process (Weber, 1922, 2011) or critiques of processes (Goodsell, 2015). Content, in contrast with process, has been understudied. The gap in the literature can be addressed with an understanding of the role of civic aspirations for the implementation of place, collection and analysis of appropriate types of data for evaluation of design and use, and best practices that directly address quality of life in terms of place.

\section{Smart Place}

Design and use, in the context of public discussion, define place. The implementation of design and use, through planning and zoning practice, forms the core of local government bureaucracy. Democracy and bureaucracy require aspirational content to be effective. Innovative technologies, media and civic discourse provide opportunities for effective public participation, an in-depth understanding of historical trends and development and effective tools for planning and testing future scenarios.

Data could make a city smart. Aspirational content for smart place would be dynamic and build a community over time. This study discusses new theory and best practices on the aspirational content for smart place, to enhance democracy and bureaucracy at the local level. 
Practices related to Smart City initiatives could be enhanced with complete understanding of place. Recent literature emphasizes innovation. The approach may be timely, but it is also fractured and may underestimate the evolution of place.

Smart place integrates smart city processes with long-term aspirational content for democracy and bureaucracy, to update theory about local governance. The conventional planning process has been understood for a century. First, the vision needs to be defined, in terms of content. Afterwards, it must be implemented, with effective administrative tools for the bureaucratic process, such as a zoning code. Such objectives shape democracy and bureaucracy at the local government level and should be understood with public administration theory and implemented through best practices. However, literature on evaluation of the relative success of the planning process or its implications for public administration theory is limited.

\section{A Select History of City Form and Language for Administration}

During the 1990's, literature that influenced New Urbanism zoning reform presented a cursory review of administration and a more extensive discussion of design and planning policy (Duany et al, 2002). Research revisited theory and history topics which guided zoning innovation in the late $20^{\text {th }}$ century, and at times compared to the experience of Coral Gables by academic and practitioners in South Florida.

A theory idea that informed research was the need to develop a language for the administration of place. The starting point was prior literature on topics related to city planning and development which led to New Urbanism theory and current discussion about democracy and bureaucracy of place. The set of ideas which were reviewed and interpreted by scholars and practitioners from design and administrative disciplines at the 
turn of the $21^{\text {st }}$ century a foundation for research targeted to the needs of public administration.

The following topics established a general theory context for zoning reform. This framework generalized local findings from research on Coral Gables and other $20^{\text {th }}$ century cities.

1. The Law of the Indies

Bureaucracy for the implementation of place was discussed directly, in terms of an early visions and a consistent implementation through time. Gasparini (1991) equated the particular urban form of the Spanish colonial grid with bureaucracy and contributed to the discussion about the administration of cities from the point of view of content. Moreover, Rojas and Rexach (1973) had published a folio book in the manner of the renaissance treatise with reproductions of the original watercolor plans of colonial Spanish cities from the 1500's and 1600's, preserved at the Archivo de Indias in Seville, Spain. Suisman (1993) reviewed implementation in Mexico during colonial postcolonial times and proposed some outcomes as models for town planning content for the United States.

2. Ildefons Cerda

Cerda (1867) introduced the terms "urbanization" and "content." He also pioneered data-based research on urban form. Moreover, he implemented the Barcelona Plan of 1859, with considerable political effectiveness. Although he influenced theory, his success as a practitioner also provided insight on the role of public administration. 


\section{The Village of Euclid vs Ambler Realty}

Conventional American zoning began in the Village Euclid in 1926. Original documents provide insight on conventional zoning through the $20^{\text {th }}$ century, Data from Coral Gables early zoning tools provide a nuanced understanding of the origins of the administration of place.

4. New Urbanism theory

Duany et al (2010) refocused discussion of planning and zoning towards form and propose administrative reform. Their groundbreaking ideas have matured and can be critiqued (Fraga, 2015).

\section{Bureaucratic City of the Americas}

Research on the Laws of the Indies during the 1990's revealed the connection between form and regulation. The New City, a journal of the University of Miami, published in 1991 the original text of the Law and several articles that provided a scholarly critique of its application (Gasparini, 1991). The cover reproduced an exemplary city plan: compact and surrounded by the countryside, gridded and centered on a rectangular plaza.

The concept of place promoted and regulated by the Law of the Indies was unambiguous. A town was to the "ordered", a term that could be interpreted to recommend the orthogonal grid of streets that became prevalent. Law 112 illustrates the focus on place:

"The main plaza is to be the starting point of the town."

The principal civil, religious and commercial buildings would be located at the plaza. Moreover, the distribution of land would include an urban lot and an agricultural 
parcel. This important link would promote compact towns and discourage sprawl. Thus, the bureaucratic understanding of place had local and regional scales.

The effectiveness of this process is demonstrated by the resilience of colonial building types and public spaces into the present in the historic core of large cities in the Americas, such as Mexico and Lima, and smaller provincial towns, such as Granada in and Leon in Nicaragua. Aesthetic features, such as barrel tile roofs, ornate entrances and window surrounds, and a preference for classical orders in public buildings and public spaces, would inspire revivals and reinterpretations, even in the United States in the early twentieth century. Similar aesthetic choices were incorporated in the 1920's to the architecture of towns in Florida. Although the use of certain architecture could be interpreted from many points of view, from the perspective of design practice and administration a coherent architectural style provided a practical best practice for efficient construction.

Bureaucratic tools calibrated by content present a clear contrast with bureaucratic tools centered on process. Moreover, the administrative process itself has also been discussed. Rojas and Rexach (1973) reproduced a selection of the fundamental tool of implementation, the town plan. The graphic tool should be considered a best practice, then and now, as it provided a coherent method to display quantitative data to achieve a qualitative outcome.

The size and edges of the town, dimensions of blocks, and the relationship between building type and quality of place are easily understood. The illustrations of urban development are comparable in detail to Button's plan of Coral Gables, and supplemented by architectural character sketches, similar to the renderings prepared by 
Merrick's team. Although the Laws are strictly followed, details of implementation provide ample variety, which outcomes calibrated to local conditions.

\section{Data on Urbanization as a Method of Research}

Ildefons Cerda is recognized as the founder of rational town planning based on quantitative data and research (Neuman, 2011). His work was discussed in the late 1980's and 1990's by a few American scholars interested in place from the perspectives of planning and implementation. Although his impact in theory development outside of the Spanish language world is debatable, his understanding of public administration as politics has been explored as controversial and effective.

Teoría general de la urbanización (Cerda, 1867) proposed a new discipline for the study of cities and provided data to support theory. Cerda's term "urbanization" led to the discipline of "urbanism," which became part the American lexicon more than a century after publication, especially through New Urbanism theory. An important distinction is that Cerda's use of the term assumed a focus on public sector implementation. On the other hand, American use of the term urbanism in the late twentieth century was principally related to the private sector.

Cerda collected data systematically, but he lacked statistical methods that would become prevalent in the $21^{\text {st }}$ century. His theory work must be evaluated in the context of a pioneering discipline.

Cerda is best remembered for implementing the 1856 plan for the expansion of Barcelona. The Barcelona plan is a classic model of town planning, known for an orthogonal grid of chamfered blocks, with strategically located wide boulevards. To this day, this area of the city is informally known as "Cerda's expansion," ensanche or 
eixample in Spanish or Catalan. Cerda's personal commitment to the project was well documented (Estape, 2001). As a result, literature on Cerda tends to praise or critique the Barcelona plan and overlook his contribution to theory.

Discussion about Cerda's original intent of the Barcelona plan, in contrast with actual implementation, has been be the topic of many scholarly articles (Aibar, 1997). For example, major works of architecture, such as Antoni Gaudi’s Sagrada Familia basilica and the mixed-use infill project Casa Mila were regulated by Cerda's plan. It can be argued Gaudi was at his best within the limits of Cerda's rigorous grid. On the other hand, the typical residential block of Barcelona has less open space than originally conceptualized by Cerda. The shortcomings of the plan may be due to Cerda's failure to propose tools for administration. An illustrative example is that the Sagrada Familia did not have a valid building permit for 136 years, until 2018 (Meixler, 2018).

Cerda's theory work has gone through several periods of rehabilitation. Fabian Estape, a professor of economics from the University of Barcelona, republished Cerda's work in 1967, in the format of a facsimile. Although the publication rescued Cerda's reputation for the history of planning, academic literature has discussed Cerda's ideas generally in the limited context of $19^{\text {th }}$ century political debates.

From the perspective of $21^{\text {st }}$ century theory, Cerda's major contribution was the understanding of a city through discrete and measurable data. He dedicated volume two of the three volume set to raw data. Prior theory had analized cities qualitatively from the point of view of design, an approach that continued into the $20^{\text {th }}$ century, or in terms of bureaucracy. The qualitative approach was best exemplified by Raymond Unwin, whose work influenced Coral Gables. Town planning in practice originally published in 1909 
(Unwin, 1994). Unwin discussed place from a qualitative perspective, an approach later followed by Lynch and others. His book was extensively illustrated with perspective drawings of preferred examples for practice.

One conceptual idea from Teoría General has been reframed in the present research. Cerda divided data into two main chapters: container and content. By container he meant the physical city. For instance, he tabulated the dimensions of all streets and recorded building types and uses block by block. Content referred to social data. For example, he provided detailed information on employment, linked epidemic statistics to geography and compared census data through several centuries. The idea of content was new then, and it is expanded and redirected in the following chapters.

As town planning developed as a discipline, professional specialization would take hold. For example, Cerda's book emphasized street planning, with special care given to pedestrian circulation, as old Barcelona was very crowded. However, his wider streets and rational grid would be later adapted to automobiles. Transportation planning became one of the disciplines that would rely on data for specialized policy direction. Results from specialization did not lead to overall quality development. Thus, an expansion of the meaning and the role of content would lead to enhanced theory and practices.

\section{American Zoning: The Abstraction of Place}

In 2016 a historical marker was installed in Ohio to commemorate inception of zoning as a standard administrative tool for American local governments (Felton, 2016). It memorialized the location where a dispute about development rights legitimized zoning. The basic facts from the 1920's were generally known among practitioners and 
academics. The American Planning Association considered the Supreme Court decision of Euclid vs. Ambler Realty from 1926 the inaugural event of the planning profession (APA website). Professional planners were likely to answer questions about the case in the AICP exam, usually framed in terms of role of police power in local government practice. However, a review of the facts from the point of view of content and process revealed new insight into the role of zoning in the administration of place.

Euclid, Ohio, was an incorporated village adjacent to Cleveland. It was comparable to Coral Gables in its geographic and urban relationship to Miami. Both developed early in the twentieth century as suburbs in terms of regional geography but were incorporated as local governments for the stated purpose of control over future development.

In 2019 their populations were similar, at approximately 50,000. Euclid became a township in 1809 as one of the first communities in the area and was incorporated as a municipality in 1903. Coral Gables was incorporated in 1926. Both local governments had significant roles in the administration of place through planning and zoning in the twentieth century. Euclid led the process. Coral Gables perfected content.

In 1922 Ambler Realty Company planned to build an industrial development in a 68 -acre parcel bordered by a railroad track, within the village limits. Village leaders opposed the concept. The Village Council rezoned the property to a residential use, to prevent industrial development. Council's decision was challenged in the courts.

In 1926 the Supreme Court ruled that the zoning designation by the village Council was constitutional, as an application of police power. It was a 6-3 decision, which marked the beginning of conventional zoning in the United States. 
Ninety years after the Supreme Court decision, dignitaries present at the dedication of the marker explained that the whole country was transformed by the decision (Felton, 2016). They were correct, as Euclidian zoning became the standardized process to define and administer place throughout America. Although academic literature described the evolution of Euclidian zoning for the past century, by the end of the $20^{\text {th }}$ century the administrative structure of conventional zoning was substantially similar to early Euclidian zoning in terms of the relationship of process to content, with process as the main objective of administration.

Although conventional zoning added complexity to some initial Euclidian bureaucratic concepts the administration of place at the local government level remained fundamentally unchanged. Regulation of use in ever greater detail and regulation of form with blunt tools such as setbacks or FAR were consistent with the approach of Euclidian zoning. The administration of place in America was Euclidian for almost a century, and that meant that process prevailed over content.

The Ambler Realty parcel's story after 1926 was less known, but it contributed context and ambiguity to the foundation story of the planning profession. The historical marker provided a summary of the facts, which was expanded by newspaper reporting from its inauguration. The federal government bought the property during World War II to build a factory. The factory was built. After the war, General Motors acquired the factory and produced automotive parts until 1992 (Felton, 2016). Thus, in the end, the nonconforming industrial use prevailed for most of the century. The content of the dispute, a municipal vision of residential zoning, did not determine the ultimate development of the site. 
Euclid became the symbol of conventional zoning only because the process of judicial review led to the Supreme Court. But the facts after the case were also significant for a complete understanding of zoning in America. Euclid was also an example of the unpredictable consequences of zoning regulations absent of adequate content.

\section{A Zoning Primer, 1926}

In 1926 A Zoning Primer described in ten pages a standardized national structure for democratic participation and bureaucratic administration for the regulation of private real estate. In a conversational style, the Primer called for "common sense and fairness" and for applying different standards for each "particular district" (Primer, 1926). To achieve this, a "zoning commission" would be established, preferable a local planning board, which would take actions with technical advice. "Getting public support (...) by means of full public discussion" would ensure that the regulations contained in the zoning ordinance would be fair (Primer, 1926).

Democratic process recommendations, which would be recognizable to administrators in 2019 , included:

1. Zoning Commission

2. Board of Adjustment

3. Public hearings

4. Remedies for violations

Bureaucratic content suggestions included proper definitions and uniformity, but also "careful preparation of regulations with reference to the character of the district and its peculiar suitability for particular uses" (Primer, 1926). 
Finally, the Primer included a list of all 426 local governments that had adopted zoning as of January 1, 1926. Only four Florida towns were listed, among them St. Augustine. Practically all American local governments would soon follow this structure, including Coral Gables in 1930. Despite several attempts at reform, the fundamental administrative framework has been very consistent through the years in American communities of all scales of development.

\section{Zoning Reform}

The relationship between process and content was recognized early. A zoning primer (1926) stated the need to have a Comprehensive Plan in addition to zoning regulation. The Plan would identify public facilities such as parks and streets, along some logical structure that would lead to a quality place. However, little guidance was provided. The Primer assumed general competence at the local level. This assumption turned out to be insufficient for the implantation of place.

The history of zoning was not a popular topic of research in the $21^{\text {st }}$ century. Literature review revealed. From limited literature, two contradictory conclusions could be proposed:

1. Zoning had changed very little in a century.

2. The democratic and bureaucratic context of zoning had changed significantly. Comprehensive planning and zoning were $20^{\text {th }}$ century American innovations. At

first, most local governments crafted modest plans and followed equally modest "Euclidean" zoning. The 1927 zoning code was proudly displayed in the village of Euclid's website in 2019, as a celebrated historical document. 
Euclid's code was silent on aspirational content, and the Supreme Court did not consider such issues. Thus, this early decision defined the scope of zoning regulation in terms that did not focus on the creation or preservation of place. Rather, typical zoning arguments were based on the negative impact of nuisance on property values. Moreover, Euclid was a suburb of Cleveland, a fact that also played a role on the expectations of zoning regulations in small and suburban communities for the rest of the century.

Prior to Euclid, zoning was a rare administrative tool. A well-known early adopter was New York, to regulate skyscrapers. The Supreme Court decision legitimized the used of zoning for small towns and suburbia, to limit growth and to police relatively minor disputes among neighbors.

The approach proposed by George Merrick had a more constructive goal than early Euclidian zoning. Instead of attempting to prohibit nuisances, Merrick focused on quality: Coral Gables would be a carefully master-planned suburb of Miami. This approach was consistent with the initial idea that zoning would implement a comprehensive plan. Although planning practice continued to promote this goal, zoning became a priority of local administrators.

After an initial acceptance of Euclidian zoning the history of zoning could be summarized as follows:

1. Euclidian zoning, 1920 's. Universally adopted in most jurisdictions in the first half of the twentieth century, and readily expanded and modified in the following decades. It is characterized by a strict segregation of uses and simple development standards, such as required setbacks and maximum building height. However, pure Euclidian zoning was very limited. Codes 
initially based on Euclidian principles can be more accurately described as "conventional zoning" in later decades.

2. Performance zoning, 1970 's. Applied in many local governments in some form to encourage flexibility, often to supplement earlier Euclidian regulations. Tools included FAR (floor area ratio), landscape percentages, building coverage, and similar abstract requirements. Planned unit developments (PUD) are also a tool used for larger projects. Coral Gables adopted all of these zoning tools.

3. Incentive zoning, 1980 's. Used to encourage certain types development in specific districts, typically in the form of overlays. For instance, additional height or FAR may be awarded for mixed-use projects. The Coral Gables Mediterranean bonus was an outstanding example of this zoning tool.

4. Form-based zoning, 2000's. Adopted in some local governments as a method to enhance the predictability of place. Instead of abstract regulations used by performance zoning, form-based regulations are prescriptive. Typically, the building envelope is well-defined, and there is flexibility among uses. Some features of the Coral Gables mixed-use provisions could be considered to be "form-based," and such sections would be considered a hybrid code under New Urbanism theory.

Zoning codes could be classified under alternative taxonomies, but they can be described as the fundamental administrative tool of bureaucracy of place. In-depth analysis of subtle differences or emphasis in regulations would not lead to an enhanced understanding of place. It is true that local government regulation of buildings and uses 
has evolved beyond the rudimentary concepts of early Euclidian codes. But from the point of view of place, most zoning types are fundamentally similar in their indirect approach to design and limited use of aspirational content. The only exception is formbased zoning, when applied correctly and completely.

Form-based codes attempted to address place directly. However, adopted regulations often retained prior Euclidian expectations. Few pure form-base codes have been implemented (Faga, 2014). When compared to early $20^{\text {th }}$ century practice, $21^{\text {st }}$ century revisions of codes tend to result in hybrid regulations, with elements from several categories of zoning, an outcome that tends to add complexity and may or may not enhance predictability.

Strictly Euclidian codes are rare in the $21^{\text {st }}$ century, but updated conventional codes, after decades of amendments, are seldom radically different. Moreover, contemporary codes are certainly more complex than early Euclidian codes and tend to be difficult to administer. Thus, qualitative research is essential for a full understanding of the impact of zoning regulations related to place.

\section{Euclid's Administrative Language for Place}

The language of the administration of place in American local governments is zoning, and as any language, it is arbitrary (Saussure, 1900). This language has a clear beginning, in 1926. It has standard conventions for structure and scope. It also has a long record of evolution and reform. It is commonly used by elected officials, staff and developers to discuss complex design issues with precision. Research concluded that outcomes for place depended on content, which infuses meaning to the language. 
FAR (floor area ratio), density bonus, lot coverage and many other common zoning terms are neutral abstractions. They are neither good nor bad. They may be meaningful or meaningless. Their effectiveness for public administration depends completely on content. Zoning is only a system of signs for classification, for the purpose of communicating content. Zoning without content is insufficient to predict outcomes.

Moreover, the language of zoning was abstract because it was radically different from the tools used by other disciplines. For instance, architecture and related design disciplines used drawings to communicate content of place. Instead, technical words were used to establish rigid rules, to be applied uniformly by administrators.

The administrative state explained Dwight Waldo's observation that bureaucracy had transformed national government and democracy (Waldo, 1948). At the local level, the administrative city may begin with Wilson's emphasis on professional administration in 1887.

One of the most direct expressions of the theory framework that privileges professional administration may be the adoption of zoning codes after 1926, which established rules and procedures for place. After zoning was generally adopted, urban quality of life would be irrevocably linked to bureaucracy. In addition, planning, in imperfect forms, would occasionally contribute democracy to zoning activities.

In the $20^{\text {th }}$ century Zoning became the preferred bureaucratic process for regulation of place in American local governments. Zoning regulated use and general form. It also provided a minimal framework for civic debate. Thus, zoning facilitates local government bureaucracy and allows some democracy related to place. Zoning was 
to be primarily a neutral process which would provide structure to the administration of place. Calibration for local needs was intended, as democracy and bureaucracy could play different roles in a particular community, but proved difficult in practice. For most of the $20^{\text {th }}$ century, the potential of planning and zoning was misunderstood, as the language of regulation became increasingly standardized. Qualitative discussions of place were deemphasized, as administration promoted efficiency.

\section{Administrative Reform from the New Urbanism}

Towards the end of the $20^{\text {th }}$ century, dissatisfaction with conventional planning and zoning centered on lack of predictability, poor public input and excessive red tape. Concerns revolved around fundamental issues of democracy of place, which was the core responsibility of local governments. New Urbanism theory developed reforms for democracy and bureaucracy of place. The charrette would enhance democratic debate and "form-based codes" would transform bureaucracy. Unfortunately, only superficial attention was given to theory implications for public administration, as emphasis was placed on practice and private sector strategies.

New Urbanism theory critiqued conventional planning and zoning because it promoted suburban sprawl and outlawed historic patterns of urban form. New Urbanism solutions included zoning reform, such as codes based on the form and placement of buildings and public participation strategies. Prior conventional zoning practice had emphasized use over form and had minimized public participation.

The main focus of New Urbanism theory was community design. Theory and practice recommendations addressed place directly. However, democracy and bureaucracy were discussed indirectly. As public administration had neglected content in 
the past, reform efforts from New Urbanism underestimated process. The current study attempted to identify opportunities to enhance theory and best practices for both.

The lexicon, a dictionary of preferred concepts for development, and smart codes were some of the early tools prepared in the 1990's that led to generalized adoption of form-based codes in the $21^{\text {st }}$ century. Miami 21 was a noted city-wide form-based code that applied New Urbanism theory to practice and provided a partial solution to the discussion of place.

\section{Content as Vision}

Content could be best described as the physical vision for place. Thus, it requires effective democratic processes at first, and it can only be implemented with targeted bureaucratic procedures. Democracy and bureaucracy of place develop along an expansive spectrum of activities, and together shape local governance. On the other hand, conventional planning and zoning limit input and decisions to a few procedures that are often not calibrated to local needs.

Content becomes aspirational when it has been developed with effective public input. Thus, the role of aspirational content should be explored and tested. The content of zoning regulations shapes quality of life, in terms of physical design and use. The process of zoning allows multiple opportunities and formats for public participation. From the perspective of the early twenty first century public administration theory, zoning implements democracy of place through local government bureaucracy.

The dual objective of democracy and bureaucracy was present in the foundational documents of American zoning: the Zoning Primer (1926). In the past century, zoning practice has tended to overemphasize bureaucracy. Nevertheless, recent practice has 
restored some of the democratic components of place, with renewed emphasis on effective public participation, especially under the guidance of New Urbanism theory (Duany et all, 2010). Planning and zoning activities in American local government have evolved significantly in the last 25 years towards an emphasis on content.

\section{Coral Gables as a Model for Reform}

New Urbanism was conceptualized in the late 1980's and early 1990's, and a fundamental model was Coral Gables (Platter-Zyberk, 2018). The town founder's vision, design features of the city plan and the design review process by a city architect were Coral Gables examples that shaped the direction of early new urbanism theory and practice.

Moreover, the role of reference folio books of the early twentieth century was also recognized in the late 1980's as a timeless educational tool for design professionals (Plater-Zyberk, 2018). Even zoning history of Coral Gables in terms of design review was reviewed in a legal journal (Poole, 1988). A few topics were understudied at the time, and will be discussed in some detail this study, as they are relevant for public administration history and theory:

1. Coral Gables predated zoning and later adopted some of the earliest and insightful zoning codes. Thus, it played an overlooked role in the history of zoning and comprehensive planning.

2. The aspirational narrative of Mediterranean architecture guided zoning reforms in Coral Gables in the late 1980's. This is a clear example of the application of content to local government practice.

3. Best practices of architects from the 1920's. 


\section{Recent Literature on Planning, Zoning and Smart City}

The current state of planning and zoning has been discussed and critiqued extensively (Fraga, 2014, 2006), (Berg, 2010), (Duany et al, 2013), (Garnett, 2013), (Geller, 2010), from the point of view of regulation and public participation. Although perspectives vary, research findings showed a general concern that conventional planning and zoning had not promoted quality development. A focus on place would provide theory direction for enhanced best practices.

Moreover, recent objective criteria for some aspects of content were developed in the LEED-ND process. Miami 21 offers a nearby example where data and experience can be contrasted (Garde, Kim, Tsai, 2015). Thus, Coral Gables zoning can be considered a hybrid code which incorporates notions of form-based theory, where content plays an exceptional role.

Burke (2002) published a textbook on zoning and land use for attorneys that clearly reflects the literature gap about content of place. Aesthetic review is centered on police power. In other words, discussion is not about the nature or type of aesthetics. Thus, from the point of view of the law, content is allowed. Legal reasoning simply estates that aesthetics is a valid topic for discussions about place.

When regulations are drafted and adopted by a local government, most states allow consideration of aesthetics in zoning regulation, even as the only criterion for action. Burke lists some examples of such regulations: historic districts, historic landmarks and billboards. However, there is limited discussion about what would constitute effective regulation, beyond a vague standard of "compatibility." 
Recent literature has discussed the differences between conventional zoning and form-based codes. Fraga (2014) discussed in her dissertation reasons for the shift to the latter. Form-based codes provide a method to customize regulations for the requirements of place. The approach enhances predictability and compatibility.

Some local governments, such as the City of Miami, have adopted citywide formbased codes. However, many local governments had adopted aspects of form-based regulation, often for targeted planning goals as overlay districts. For instance, this study reviewed mixed-use and Mediterranean bonus sections of the Coral Gables zoning code, which could be characterized as hybrid zoning, which retain the format of conventional zoning but introduce precise regulation of physical design. In addition, theory suggested that a thorough public process should inform regulations. Best practices should be incorporated in adopted zoning codes.

Furthermore, robust aesthetic ideas are often discussed but seldom implemented with effective administrative tools. Although the term aspirational content may not be used, many related issues are discussed informally as benefits of form-based codes. Research provided a methodology to organize ideas and evaluate data and contribute new knowledge on practical tools that may fill the gaps in theory and practice. Formal procedures should be part of adopted zoning codes, calibrated to local needs and designed to implement best practices for democracy of place. 


\section{Towards a Literature of Place: \\ Coral Gables, FL}

\section{The Topic of Coral Gables, FL}

Coral Gables, from the point of view of the administration of place, has been the subject of a limited number of publications. Nevertheless, the books reviewed were often found in the office shelves of local administrators, as they provided references on content, especially in terms of historic preservation and design review for neighborhood compatibility. In addition, several publications influenced best practices at the end of the $20^{\text {th }}$ century, as New Urbanism theory was first conceptualized through research on Coral Gables.

\section{2: From Wilderness to Metropolis}

In 1982 Metropolitan Dade County, known now as Miami-Dade County, published an educational book on the development of South Florida, From Wilderness to Metropolis. A second edition was published in 1992. The book presented in text and graphics a comprehensive collection of narratives about South Florida from 1825 to 1940.

The publication was intended to be a textbook for historic preservation. Thus, the authors catalogued and classified buildings according to style, and included personal biographical stories. The text and images were understood as definitive references for the history of architecture and development of South Florida.

From page 106 through 116, Coral Gables was discussed. After a brief introduction to George Merrick, the community was described as a model city with many less successful contemporary imitators (Metropolitan Dade County, 1992). At the time of 
publication postmodern theory of architecture often discussed style. Thus, the "Mediterranean" style was rediscovered and reinterpreted in the 1980's and 1990's, for use in contemporary design.

The publication had an impact on practice. Projects from the late $20^{\text {th }}$ century often attempted an aesthetic association with the narrative of Coral Gables to add real estate value to otherwise mediocre buildings, sometimes even within the city limits and as approved by the Board of Architects. From the point of view of historic preservation replication of old styles was not a best practice. From the perspective of design, style conveyed a set of comprehensive and identifiable visual conventions, which required accurate implementation. Best practices of the 1920's included effective reference materials to ensure quality. However, in the 1980's and 1990's architects lacked much of the information about style that had been generally available in the early $20^{\text {th }}$ century. From Wilderness to Metropolis attempted to fill that void.

The text mentioned, without surprise, that most work was performed in 1924 and 1925, and that after the real estate bust development would progress slowly. The master plan was described, but not reproduced. Urban design features, such as the entrances and landscaping, were highlighted as "key elements." However, other features, such as the interconnected network of streets, the size of blocks and the well-defined neighborhoods were overlooked.

Discussion of Coral Gables planning ideas provided some contrast to less sustainable development patterns of the second half of the $20^{\text {th }}$ century. However, the narrow perspective of historic preservation limited comments to aesthetics. Only years later, as the consequences of sprawl became clear in Miami-Dade county and the nation, 
Merrick and Button's innovative town plan would be recognized as a historical model of sustainability, for New Urbanism theory.

Photographs supported the arguments. One image from the time of publication, the recently completed restoration and addition to the historic colonnade was included, ostensibly as a successful example of historic preservation. This example was also among the first projects that would implement the Coral Gables Mediterranean bonus program. Finally, discussion of residential architecture contrasted Mediterranean houses with the "theme villages."

The rest of the book described in similar detail historic districts throughout South Florida, as if their stories were comparable. From a historic preservation point of view, maybe that would be true. From the point of view of administration, the stories diverged significantly, as most other districts had disappeared in the $21^{\text {st }}$ century as redevelopment altered the scale of growth and the nature of communities.

From Wilderness to Metropolis would be the first and last comprehensive review in the $20^{\text {th }}$ century of the architecture of South Florida. It was an educational document intended for use in practice. Although it proved invaluable for historic preservation professionals, it did not achieve the quality of the folio books of the 1920's.

Nevertheless, the publication became the reference point for discussions about the content of historic preservation in South Florida through the $21^{\text {st }}$ century.

\section{7: The Good, the Bad and the Consensus Ugly}

A few years after the first edition of From Wilderness to Metropolis, Sam Poole (1987) authored an article on the legal aspects of design regulation which influenced 
early New Urbanist practice and revealed opportunities for future research. Poole also discussed Coral Gables regulations.

Architectural appearance review regulations and the first amendment: the good,

the bad and the consensus ugly, proposed a narrow view of design in terms of aesthetics, from the point of view of the citizen and the first amendment. However, the text far exceeded the initial topic and quickly ventured into considerations about the public role of design from multiple perspectives.

Poole at first attempted to narrow discussion with examples of building permit reviews of single-family houses, based on neighborhood compatibility. He suggested that this was a timely concern in the 1980 's, as approximately 500 local governments had established appearance review boards, and of those, about half had done so in the previous ten years. He highlighted that Coral Gables had one of the earliest architectural review processes, established in its first zoning code of 1930. As part of his research, he interviewed Coral Gables planning director for a perspective on the practice of administration.

The article's literature review and case history revealed that several distinct professional fields were considered within the same theory framework. In addition of appearance review for new houses in suburban neighborhoods, Poole also mentioned historic district regulations for the French Quarter in New Orleans, Landmarks Preservation Law in New York, community-wide regulations of Coral Gables, and urban amenities bonus program in New York. This was heterogeneous list of precedents from multiple disciplines. The article discussed historic districts, historic landmark designations, planning bonus programs and overall community vision as a single topic, 
and it implied that neighborhood appearance review was at the core of the discussion. This excessively general view about the role of appearance diminished the nuances of design, which separate good from bad and create community value. Moreover, discussion about first amendment protection of architectural design presented additional challenges, as regulation of artistic content could be unconstitutional, but not all content would be equal for the term of art, "compatibility."

In the end, Poole's broad scope pointed towards the need for enhanced theory guidance about the role of design in the implementation of place. Design was everywhere, and every characteristic of a building or town beyond basic zoning rules could be lumped into “appearance.” However, “consensus ugly" would be a poor standard for public administration. Thus, Poole implied that the law lacked an effective language about design. He recommended an approach similar to Coral Gables, although he did not go into detail about best practices.

Poole (2018) commented on the article 30 years after publication, recently retired from practice as a land use attorney. Poole wrote the article as he was about to finish law school. Immediately afterwards, he collaborated with some of the first New Urbanist practitioners, including Andres Duany, Elizabeth Plater-Zyberk, Victor Dover and Dan Cary, and became a national expert on the legal framework for New Urbanism.

Poole's article was recalled as a source of inspiration, when literature about design review was scarce and New Urbanism theory was developed (Dover, 2018). Throughout a long career, Poole provided professional advice to many development projects, consistent with the ideas proposed in 1987. After retirement, he stressed the 
need for design education for administrators and continued to support an effective legal and regulatory environment for best practices on quality town planning.

\section{9: Coral Gables, a Brief History}

A sixteen-page pamphlet published by the City in 1989 helped established historic preservation as a principal topic of the Coral Gables narrative of place. The publication was an administrative document formatted a tourist guide. It is included in the literature review because it was not an adopted regulatory document. However, it was designed to assist in the implementation of policy, through documentation of precedents.

An uncredited introduction sketched the main components of the narrative: praise for Merrick and his team of professionals, surprise at the speed of implementation from 1923 to 1926, inspiration from Mediterranean buildings and contemporary support by the residents for history and zoning. The core of the publication was an album of black and white photographs from the 1920's and 1930's organized by building type. Institutional and public buildings included city hall and the Coral Gables elementary school. Commercial buildings and hotels reproduced the Fink studio, the Colonnade and the Biltmore. All those buildings would be listed by name in the zoning code, as models for Mediterranean architecture.

The cover was a rendering reproduced on plate 10 , which could only be described as aspirational. It was an image of a canal and several picturesque buildings of a "Mediterranean" style, which had been used as a printed advertisement for real estate in the city in 1926. The composition and aesthetic quality were reminiscent of a painting by Martin Rico from 1885. Thus, Merrick's branding followed contemporary trends, and the historic references were used to sell. 


\section{1: An American Garden City}

Less than a decade after the publication of Poole's article, a comprehensive review of the history of Coral Gables' planning and architecture was published, Coral Gables, an America garden city. This publication was the only rigorous academic review of the content of Coral Gables to date, particularly in terms of the images. The collection of maps and photographs provided extensive data from original sources on design intent and implementation. The text played a subordinate role, with commentary in the manner of the folio books of the early $20^{\text {th }}$ century.

Coral Gables, an American garden city should be considered a "best practice" for the discussion of place. The book was co-edited by Maurice Culot and Roberto Behar, and several scholars associated with the university of Miami wrote chapters.

Elizabeth Plater-Zyberk's introduction proposed that the city is at "a time of suspension between maturity and timelessness." She pointed to early buildings "aging well" and stressed the endurance of landscape on streets and public spaces. She also critiqued the effects of automobiles on street design and "mid-century buildings which rejected their design heritage." As a result of resident concerns, administrative tools were adopted in the zoning code, which are discussed in the Results Chapter of the study.

Vincent Scully authored a chapter titled "a dream of Coral Gables." Scully quoted Merrick’s poetry. He compared Merrick's very real efforts favorably to the contemporaneous fiction of Sinclair Lewis's Babbitt, an observation that contextualized the priorities of the age and removed any sense of utopian motivation. As a top critic of architecture in the twentieth century, and professor at Yale and later on at the University 
of Miami, Scully legitimized the Merrick narrative by restating details of the Coral Gables foundation story.

Review of the files used by the authors in the early 1990's revealed extensive research on the administrative tools used by Merrick. For instance, aspirational content was recorded in routine real estate documents. Deed restrictions determined architectural styles, according to a comprehensive plan. Designated areas of the city were to be developed in the Chinese, Norman, Italian, French, French Country, Dutch South African and other styles, some which were not fully implemented. These areas would be known as the villages and would provide variation to the general Mediterranean character of early residential and commercial buildings. However, the focus of discussion in the book was the Coral Gables narrative of place. Thus, administration was not sufficiently explored in terms of implementation.

Volsky (1994) quoted Culot in a Coral Gables Gazette article, "what is this city doing here?" Culot, an influential academic and practitioner based in Paris who was awarded the Richard H. Driehaus prize in 2019 for lifetime contributions to traditional architecture and urbanism, pointed to the vitality of the city, and the pride of the community as ingredients (Volsky, 1994). In his introduction to the book, Culot restated the Coral Gables narrative of place for the 1990's and expanded its scope. Culot had been tutored by colleagues from the University of Miami School of Architecture.

The text described Merrick as a visionary with a practical approach, as spiritual and commercial goals were skillfully combined in his work (Behar, Culot, 1997). The graphics described the place and needed no additional explanation. The subject of each image, whether it was a site plan or a black and white photograph, was urban design. 
Even the Biltmore Hotel, an object emerging from the landscape, was always depicted in an urban context in conceptual sketches. A classic aspirational rendering records the formal public space from the belfry of the Congregational church to the tower of the hotel, which was long ago transformed into a parking lot for Sunday worshipers. Such images shaped the Coral Gables narrative of place and were collected in a single book. The graphic depiction of aspirational content by Merrick's team was a best practice for the implementation of place.

The early outcome was illustrated with an aerial photograph from 1931, half way through the text. The recently completed Biltmore hotel is at the foreground and a network of well-planned streets with few buildings and many young trees stretches towards the horizon. The buildings would come incrementally, each structure would enhance the value of the community and the vision would be preserved.

Professor Joanna Lombard wrote a chapter titled "Coral Gables: The city as a garden." The landscape plan designed by Frank Button and implemented by Merrick's team was simple and effective. The city would be a garden with buildings in it, Lombard summarized. In reality, street trees were planted along streets, of the same species and on a straight line, a best practice from the early twentieth which made Coral Gables consistently green after several decades of growth.

Two three-inch ring binders preserved the research files for the book and were consulted in the course of the study. The materials summarized documentation on the history of Coral Gables and the evolution of town planning and design ideas. The topic can be best described as the Coral Gables narrative of place, as interpreted by the University founded by Merrick. 


\section{2: Coral Gables Charrette Report}

In 2002 the City and the University of Miami’s School of Architecture collaborated on an ambitious planning project. The principal tool for democracy of place from New Urbanism theory, the charrette, would be used to refine the content of Coral Gables regulations. Residents and officials believed there was a need to update administrative practices.

The report from the charrette summarized information relevant for discussion about content and implementation. It was also a book that reflected the era's aspirations for town planning and city administration, form the point of view of academics and practitioners.

Chuck Bohl (2019) coordinated the events and recalled that when a rendering depicted the transformation of a modern building into the Mediterranean style participants applauded. The existing building and the rendering, a hypothetical before and after illustration, were published in page 88 . The caption read: "responding to popular demand (...) recladding of an existing building.”

At the start of the $21^{\text {st }}$ century charrettes had become effective public input processes through the efforts of practitioners associated with New Urbanism theory. The School of Architecture at the University of Miami had served as an incubator for town planning theory and practice, and the charrette was one of the first projects of a new civic service effort to assist communities (Bohl, 2019).

The soft cover Report read as a faithful record of best practices of New Urbanism from the turn of the century. Included in the final publication were schedules, summaries of meetings, rough sketches, general thoughts, proposed street sections, PowerPoint 
presentations, final recommendations and a transcript of a talk on the history of Coral Gables by Arva Parks were she quoted an article from 1960 which expressed concern about the city's overdevelopment and provided context for the future.

The expansive and ambitious methodology of the charrette blended historical research and practical solutions, in terms of design, management or policy. The outcome would a long-term master plan, which could be implemented incrementally. For several years afterwards, as promised in the Report, planning staff tracked city and private projects for compliance with charrette recommendations.

The first 102 pages of the Report were organized along topics related to place: master plan, public space, streetscape, transportation, downtown and North Ponce de Leon Neighborhood. Most ideas were illustrated with diagrams and conceptual renderings. Also included was a narrative of the public process.

The mission statement read as follows: "To define a community vision that enhances the vitality of downtown and enhances the livability of adjoining neighborhoods." The pre-charrette process lasted six months, with background research, staff meetings and a survey. The charrette lasted four days and was attended by 1500 participants. The professional team included more than 50 designers. New University of Miami President Donna Shalala and new Mayor Don Slesnick introduced the project on opening night.

The last sections of the Report summarized input, findings and listed recommendations. Under the heading of "Day Four" ideas from the professional team were outlined. Faculty associated with the Garden City book from 1991 (Joanna Lombard, Elizabeth Plater-Zyberk and Jean-Francois LeJeune) provided suggestions 
related to aspirations of place about a decade later. More trees, walkability, public spaces, mid-block passage ways, parking management, were mentioned. Engineer Rick Hall recommended slower traffic and more mobility options. On day five, a final presentation by Plater-Zyberk and Bohl was described in the Report as a great plan for the $21^{\text {st }}$ century by elected officials and administrators.

In 2019 four of the five proposed public spaces were still under discussion, in some form or another: Ponce de Leon Park, City Hall Green, Alhambra Rambla and Miracle Square. Only Firehouse Park had been implemented, as the plaza for the Coral Gables Museum. Ideas from the charrette had an effect, but the absence of a comprehensive and creative strategy for administration reduced the impact of public aspirations.

\section{5: Coral Gables Tour}

Millas and Uggucione (2005) published Coral Gables: Miami Riviera, an architectural guide, with a scope and depth of research that exceeded typical tourist brochures. The format was small and handy. The text and graphics provided an in-depth analysis of this history and content of Coral Gables. The publication may be understood as an update of the pamphlet published by the city in 1989, which Uggucione had authored.

The book appeared to be a pamphlet to plan architectural visits, produced in anticipation of a meeting of the Society of Architectural Historians. But the rigorous academic research and wealth of unpublished graphic information continued the path of Coral Gables: An American garden city towards general discussion about town planning and policy for place. Coral Gables was described as the outcome of compelling design 
concepts, with the biographies of the founder and his team of experts. The argument was made with historic photographs and renderings, and contemporary analytical map diagrams, in other words, with content of place. The authors were preservation professionals, and discussion was framed by best practices of the profession.

George Merrick's life and dreams were retold briefly in part one, titled "Coral Gables: A city inspired." Repeating the foundation narrative had become a convention in any discussion of Coral Gables at the turn of the $20^{\text {th }}$ century. The text quickly was refocused towards architecture, in the form of tours organized along notable neighborhoods and districts. One tour covered the business district. Another tour reviewed early homes. The Villages, the University of Miami, the long vistas along roads and community amenities also had tours. The overall visit would display a complete community implemented with a coherent and ambitious vision.

Descriptions of the villages, small neighborhoods designed along thematic styles other than Mediterranean, were insightful. As Coral Gables expanded towards the Riviera section in 1925, Merrick created thematic enclaves, with the tool of deed restrictions. French Normandy, Florida Pioneer, Italian, Chinese, Dutch South African, French Country, French City and MacFarlane Homestead were the implemented villages. Others were never built. The aesthetic content for each style was found in specialized folio books, which were interpreted expertly by architects schooled in the practice of researching precedent.

The fundamental idea behind the book was that early ideas were implemented consistently over time. This was a fundamental theory concept for New Urbanism 
discussed at the time. The publication was a significant contribution to best practices, as an exemplary manual for town planning and preservation.

\section{5: George Merrick, Visionary}

In 2015, Arva Moore Parks published the definitive biography on George Merrick. This was not Park's first book on Coral Gables. Prior publications, such as Castles in Spain, had shaped and refined the Coral Gables narrative of place since the 1980's. George Merrick, son of the south wind: Visionary and creator of Coral Gables, expanded on subjects and themes that had become generally known in south Florida towards the end of the twentieth century because of Park's scholarship.

Merrick was remembered in South Florida because of a persuasive narrative of place recalled by Parks and retold by others, that influenced postmodern architecture of the 1980's in Coral Gables and, to a lesser extent, other municipalities in Florida. Architects found the story relevant to late twentieth century practice. Parks (2016) explained her continuing research of primary sources, and her progressive understanding of the period that would be known as the Florida boom. The definitive story of Coral Gables was summarized in the book.

Parks acknowledged finding new information on Merrick through the years (Parks, 2016) but the content of the book confirmed the well-known account of Coral Gables. Recently found documentation provided details and modified emphasis. The general tone underscored George Merrick's narrative of place. Parks writings always linked Coral Gables and its founder.

In 1970 Parks moved to a house designed by Walter de Garmo and became a scholar of Merrick and his work. When she bought her house Merrick and his legacy had 
been relegated to the past (Parks, 2016). The Biltmore hotel was abandoned. Highrise glass office buildings had transformed the scale and appearance of the business district. Best practices of architecture from the 1920's had been completely forgotten.

Parks would set to correct historical and administrative shortcomings, first through service in the Coral Gables historic preservation board, which would lead to the restoration of the Biltmore and the "Mediterranean ordinance." Her articles and books on local history since the late 1970's explained the story from primary sources to the public at large and played a crucial role in shaping the Merrick narrative in South Florida.

Parks did not write architectural criticism nor urban history. The book was a welldocumented biography where the main character was referred to as "George." Parks never met Merrick, but she interviewed his brother, widow and many residents who know him. She also reviewed Merrick's personal papers, acquired through the years. Some of Parks' papers were preserved at the University of Miami’s Richter Library special collection on Coral Gables.

Parks suggested in the book that Merrick's idea of Coral Gables emerged from visits to Tuxedo Park and Forrest Hills Gardens with his uncle Denman Fink. At the time, upon completion of his studies at Rollins college in Winter Park, Florida, Merrick was a law student in New York. New railroad suburbs, professionally planned and designed as complete communities, were under construction. Other precedents identified by Parks were Shaker Heights. All those examples followed best practices for place of the early $20^{\text {th }}$ century. They remain, for the most part, as originally designed. The main distinction from Merrick's vision was that Coral Gables was designed for place and for future growth. 
About half of Parks book deals with Merrick's life prior to Coral Gables. His experience as a farmer and as a college student provide context to his biography. But his experience as a developer, which followed one term as county commissioner in Dade County (known later as Miami-Dade), would define his approach to place.

Parks reproduced a photograph of Merrick which reveal the source of inspiration for city gates and for the Spanish architecture style that would in time be called "Mediterranean." Merrick and wife Eunice posed in front of the historic gate of St. Augustine. Parks did not elaborate on the significance of the photographs, but it provided evidence for aesthetic features that would be implemented in Coral Gables. This photograph published by Parks merits discussion because it demonstrated the role of content and precedent, and it inspired a best practice of building civic projects at strategic locations to define the aesthetic qualities of Coral Gables.

St. Augustine was well known in the early $20^{\text {th }}$ century to South Florida developers because it was the headquarters of Henry Flagler's railroad company. The town was also a source of contemporary architectural style. Flagler constructed two hotels inspired by Spanish architecture. Moreover, St. Augustine was planned according to the principles of the Law of the Indies. The plaza was located by the water front, as recommended by law 112 . The town plan, and the buildings from the late $19^{\text {th }}$ century, were examples of best practices for place.

Moreover, the St. Augustine gate clearly defined the edge of town and provided a visual separation between town and countryside. It was built by royal engineer Manuel de Hita in 1808 in a severe classical style, according to the historical marker. However, a functional north entrance to town had been at that location since 1739. De Hita's piers, 
constructed of local coquina stone and detailed with elegant moldings, were markers of place. They were a civic project which emphasized aesthetics and place.

The piers at the Prado Entrance to Coral Gables, a failed early business center, would recall the St. Augustine gate, in general appearance, proportion and style. They also marked the edge of Coral Gables, as the gate of St. Augustine. Merrick would also build other entrances along the perimeter of his project. Today the Prado entrance is a passive park, as if designed as a folly of Mediterranean aesthetics. The piers, a fountain and a pergola provide a fantasy setting for photoshoots. They mark the edge of the city, but do not prevent access to anyone.

The Coral Gables piers were only about a century older than the St. Augustine gate at the time of construction. Moreover, the concept of making place with classic tools of urban design, common in Spanish and Mediterranean practice, would be applied throughout Coral Gables, which significant success. Civic projects for entrances, monuments and fountains were the first structures to be constructed.

Parks' book became a reference tool for Coral Gables administration. The original intent of Merrick's narrative of place would be inserted in political debates and public hearings into the $21^{\text {st }}$ century. Coral Gables city manager Peter Iglesias acknowledged that Merrick's legacy was mentioned practically every day in City Hall. On the other hand, at a previous job in as assistant city manager Miami held by Iglesias, a city which was founded by another legendary figure in South Florida history and in St. Augustine, Henry Flagler's name had been practically forgotten (Iglesias, 2018). Although Flagler built memorable buildings and transformational infrastructure, he did not focus on the long-term development of place. 


\section{Architecture Reference Books from the Early 20 ${ }^{\text {th }}$ Century}

\section{From Treatises to Folio Books}

Since the early renaissance, a fundamental best practice of architecture was the treatise. The treatise was a pedagogical publication intended to teach by example. The genre was a best practice from the 1400 's to the 1920 's. In particular, the early $20^{\text {th }}$ century was a prolific time for treatises, with the advent of photography and efficient printing methods. Multiple specialized publications, in the format of large format folio books, reproduced examples of architecture with black and white photographs and measured drawings. Then, In the mid- $20^{\text {th }}$ century, the treatise disappeared as a tool for practice, when Modern architecture theory promoted chronology bias, to the detriment of history and in favor of innovation. Folio books would be rediscovered as a tool for design towards the end of the century, when architects interested in town planning theory and New Urbanism researched Coral Gables.

The genre of the architecture treatise had a long history as a best practice for design. Treatises began as reports of academic research, which presented empirical data. Renaissance scholars studied the ruins of Rome throughout the Italian peninsula and of Italian Greek settlements in Sicily or Naples to extrapolate principles of design. Their conclusions were driven by objective research and were published with the goal of enriching practice. They were an early example of the methodical use of content of place as a best practice for design.

Renaissance scholars also searched for original literature from the classical age. But they found a single book on architecture from classical antiquity, Ten books of architecture by Vitruvius, probably written between 30 and 15 B.C. The publication 
served as a model for the renaissance treatise, particularly Palladio's and Serlio's, and for the folio books of the 1920's.

Vitruvius discussed architecture in terms of content. He stated he wanted to link thought to practice. He offered practical advice within a very coherent theory framework, based on the five orders of Roman architecture: Tuscan, Doric, Ionic, Corinthian and Composite. This taxonomy defined architectural theory for twenty centuries. Discussion centered on the details of each order or the refusal to follow them.

Vitruvius considered a wide range of topics related to place, from town planning to mechanical systems. He also divided buildings between private and public, an early attempt at typology. His formula for effective design, translated as "firmness, commodity and delight," summarized the role of architecture in private and public life, and became a well-known slogan in the neoclassical English-speaking world. Later scholars provided illustrations based on description in the text, as original graphics were not preserved.

The treatises of the renaissance were used for reference. Leon Battista Alberti wrote On the art of building in 1452 and published it in 1485. Filarete completed Architectonic book on around 1464. Sebastiano Serlio used illustrations in Seven books of architecture in 1537. Andrea Palladio published in 1570 Four books of architecture, with illustrations from his own buildings. Notable treatises after the renaissance were authored by Gibbs in 1728 and Laugier in 1753. The common theme is an emphasis on practical content, supported by a coherent theory framework of classical architecture. 


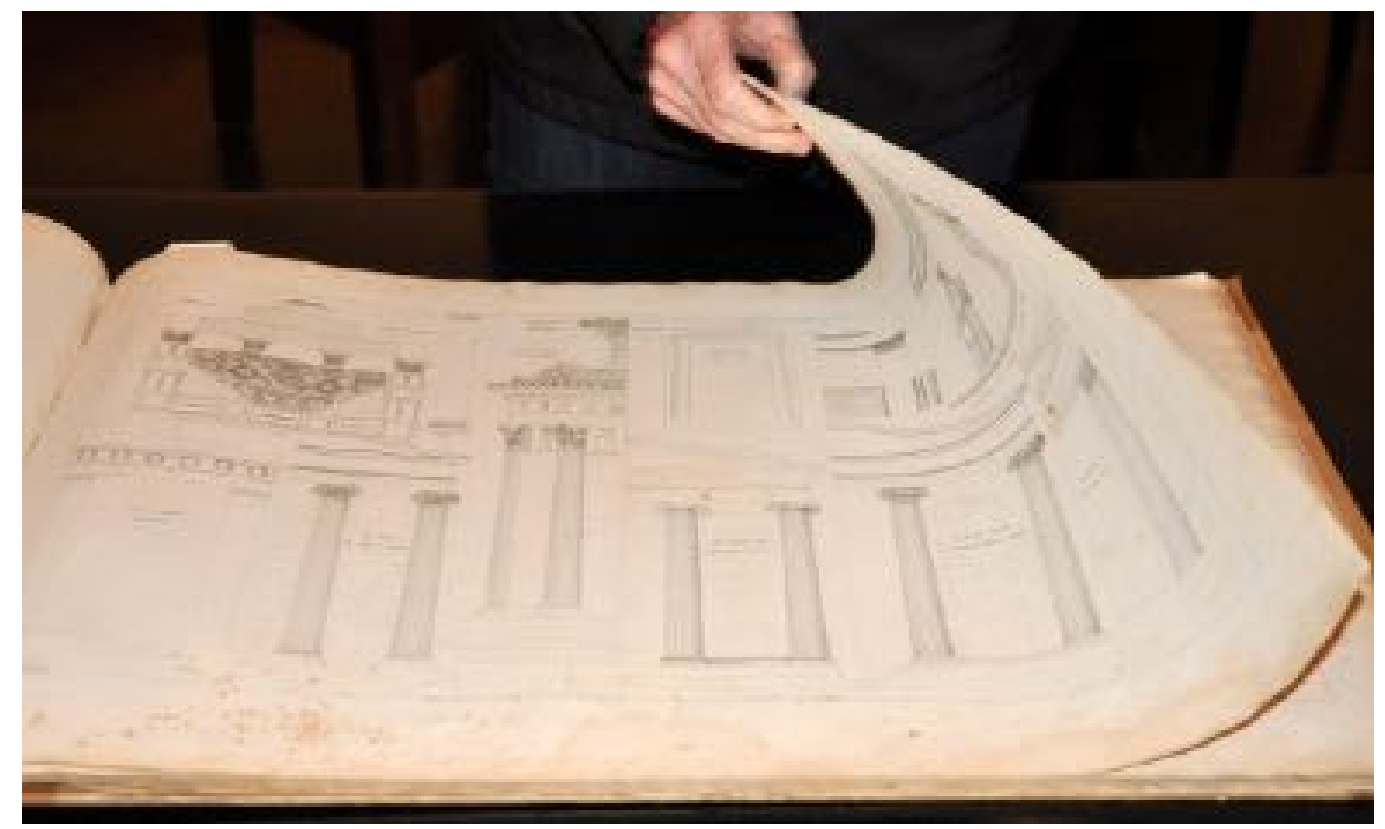

Plate 13. Original 1809 edition of J. N. Durand's Precis de lecons d'architecture dones a l'Ecole Royale Polytechnique. Photograph: Ramon Trias.

Durand transformed the treatise into a textbook and crafted the precedent for early $20^{\text {th }}$ century folio books. Precis de lecons d'architecture dones a l'Ecole Royale Polytechnique (1809) was one direct inspiration for the folio books. The page on plate 13 discussed the Ionic order, by comparing and contrasting five examples from classical antiquity. Each architect of a Greek temple applied a slightly different interpretation of the proportions and conventions of the order. All ionic columns had volute capitals and were fluted, but they were not exactly the same. An observer could see similarities, differences or both.

Durand explained the different versions of the Ionic order in two pages. An interpretation removed from chronology bias would conclude that Durand defined effective content for timeless building techniques. The fact that Durand taught engineers at Napoleon's Polytechnique University, instead of architects or fine artists at the Ecole 
des Beaux Arts, suggested a universal interest in best practices inspired by aesthetic criteria.

Durand's lessons focused on artistic nuance. This is the highest level of discussion of aesthetic content, and it was intended for an audience of engineering students. Durand elevated discussion of content for future professionals whose main expertise was not aesthetics. The textbook was heavy, oversized and the plates were engraved in minute detail. Thus, the original delivery method imparted credibility to the content. Later reproductions of the graphics as small illustrations in obscure history books did not have a comparable instructional effect. Durand's books were relegated in the mid- $20^{\text {th }}$ century to discussions about the past. However, smart technologies of the $21^{\text {st }}$ century may rescue valuable information, as seminal books can be digitized, pictures may be zoomed in, and access may be universal, for reference and on demand.

Analysis of the content of various treatises does not suggest and unbroken strand of writing, through centuries of progress. Instead, content is rediscovered multiple times, in cycles which follow trends of aesthetic preference. As time goes by and printing and photography technology evolve, there are more pictures. At the start of the $20^{\text {th }}$ century technology and theory converge. But the great picture books printed before 1929 may be the best, and could be the last, treatises for architectural practice.

Reference picture books with drawings and photographs became a common tool for designers in the early $20^{\text {th }}$ century. Best practices included review of accurately documented precedents (Pencil Points, 1928). The books in the professional libraries of architects during the 1920's fulfilled the same purpose as the treatises of the renaissance. 
There were many books, from many points of view. Moreover, best practices for graphic representation were developed to standardize information for practice.

\section{Lesser Known Architecture of Spain and Other Books Owned by William Hatcher and Walter de Garmo}

William Hatcher was an architect who moved to Fort Pierce in the 1920's. His professional library was extensive. It was also typical of the times, as contemporaneous architects such as Walter de Garmo owned similar books. Hatcher and other design professionals used the books for reference on style and composition, which was a best practice of the time. Thus, the content from the books enhanced quality of place, for decades into the future. Research was performed on books owned by Hatcher in the 1920's, which are currently in the collection of Ramon Trias.

Yerbury (1925) published the intriguingly titled folio book Lesser known architecture of Spain. The hardcover book bound in red cloth. It was a portfolio of forty-eight black and white plates. The book was printed in France by a publisher with offices in London and New York. The text was limited to an introduction and captions. Yerbury explained in the foreword dated on January of 1925 that the photographs were examples of small buildings from a larger collection taken during visits to Spain. He stated that they should be "a source of inspiration to the architect and designer." Furthermore, he announced that he intended to publish future books of Spanish architecture, on specific subjects and building types.

The title of the book can be understood as a summary of the prevailing architecture theory of the age. It may also be read in the $21^{\text {st }}$ century as an innovative tool for bureaucracy, and a time-tested tool for architectural practice. The architecture 
was "lesser known" and from Spain, a country better known for its past at the time of publication. There was no attempt to depict innovation nor exceptionalism. There was no grand theory proposed, beyond a practical respect for vernacular design in small towns. The pictures spoke for themselves, as the intended audience would be architects who understood the use of precedent as a best practice for design.

Moreover, the book was not a manual for historic preservation. Instead, it was a textbook for design content and, by extension, design review. In contrast, late $20^{\text {th }}$ century architecture theory would overlook the present value of design content as precedent for place, as historic preservation recommended practice prohibited copying and discouraged imitation, as stated in the Secretary of the Interior standards for preservation. The late $20^{\text {th }}$ century official view of preservation was exactly the opposite of the best practices for the implementation of place in the 1920's.

The publication, and countless similar titles, attempted to provide modest and coherent content for architects, for reference in their new projects. The results have been preserved in buildings, such as 307 Orange Avenue in Fort Pierce designed by Hatcher, and drawings, such as the collection of original pencil plans by de Garmo preserved at the HistoryMiami archive. The houses that de Garmo designed in Coral Gables may be modest by the standards of $21^{\text {st }}$ century real estate but achieved remarkable quality in terms of design and sense of place. Best practices were different then, but qualitative input from expert interviews suggested that enhanced understanding of precedents could also inform contemporary design.

The book's graphic content provided effective data for professionals. There are photographs from Córdoba, Toledo, Seville, Burgos, Salamanca, Alcalá de Henares and 
Aranjuez, well-known cities full of recognizable buildings. Tourists of the $20^{\text {th }}$ and $21^{\text {st }}$ centuries visit the Giralda tower in Seville, various cathedrals or the main plaza by Alberto Churriguera in Salamanca but may overlook lesser known architecture. As the title warned, the most memorable landmarks were not included. Instead of the Giralda, there are several neighborhood churches from Seville. Architects who consulted the book would be working on projects of a comparable scale. The opportunity to design a major landmark was rare. Therefore, study of modest precedents of superior aesthetic quality was an effective best practice for the implementation of place.

When a building or site that may be recognizable was photographed, such as the gardens of the Royal Palace of Aranjuez or the Palace of the Duke of Alba, only generic details were shown. There are many two and three-story buildings, with a common Renaissance aesthetic, in dubious states of maintenance. The term "Mediterranean architecture" would emerge from a renewed appreciation of Spanish vernacular interpretation of the classical language of design, in a state of picturesque disrepair. Eventually, aesthetic preferences would become content for administration.

"Coral Gables Mediterranean architecture," from the point of view of bureaucracy of place as expressed in time with zoning language, would be a new style for construction in Florida of the 1920's, and would inspire aesthetic choices through the following century. However, because the style was expressed with words that could be understood outside of the precise bureaucratic framework, "Mediterranean" would be reinterpreted, debated, dismissed, exalted or ignored, for multiple reasons unrelated to content of place. Nevertheless, as long as the folio books of the early $20^{\text {th }}$ century were commonly used as a best practice, discussion would be centered on content. 
There are a few people in the photographs, to provide an occasional sense of scale. The are no cars, of course, but there are a few horse-drawn carriages for deliveries. Most pictures are carefully shot with a tripod. Some are composed genre scenes, in the costumbrista tradition. The author attempted to recreate the weathered old-world ambiance he expected to find. This aesthetic emphasis may not add information about building design, but it does convey a sense of place.

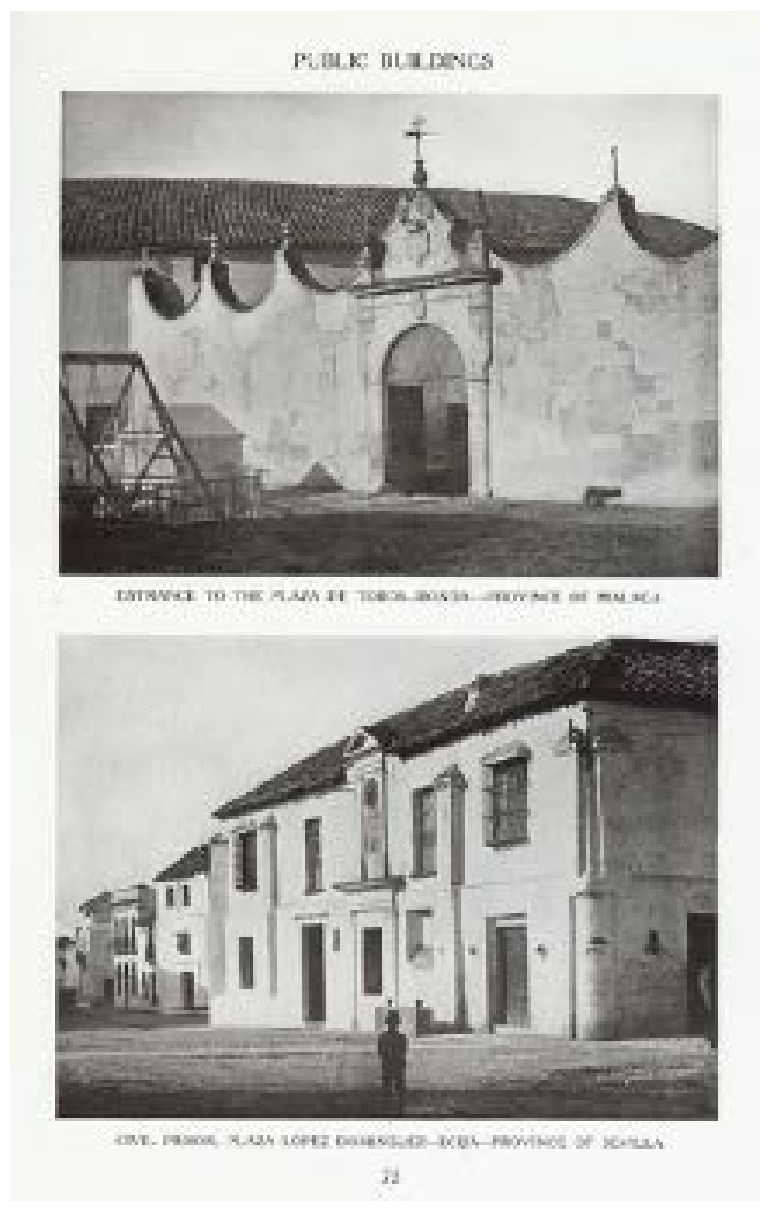

Plate 14. Folio book illustration. Source: Ramon Trias.

The images were intended to be "copied," which more accurately meant interpreted and recomposed. Typical photographs were reproduced on plate 14. For instance, page twelve is a frontal view labeled "An old palace," in Cordoba. It is very 
similar in composition to half of Fink's studio along Ponce de Leon Boulevard. The other half of the building is of venetian inspiration, probably from another source.

Whittlesey (1920) had published a volume that focused on similar content. The renaissance architecture of central and northern Spain was a portfolio of photographs and measured drawings that provided coherent content for architecture. The author and photographer's studies were interrupted by World War I and he produced the book. He observed that northern Spain's plateresque architecture could be a source of precedents distinct from Southern or Mediterranean Spain.

Mayer (1920), professor at the University of Munich, published Architecture and the applied arts in old Spain. The book was a survey of Spanish architecture prepared by an art historian. The introduction was thorough and scholarly. He explained uniquely Spanish terms such as plateresque, derived from the details designed by silversmiths, and churrigueresque, the baroque style modeled after Salamanca architect Churriguera. However, erudition was not needed to appreciate the book, or, more importantly, to use it in professional practice. The text could be omitted, although it was valuable for theory.

The images summarized content for use in practice. Although the book included the Alhambra, several castles and even one photograph of the royal place in Madrid, a baroque complex by Italian architect Juvarra, the general impression of the photographs was similar to the publications that only focus on lesser known buildings. Place was more important than landmarks.

Svole (1924) published Spanish farm houses and minor public buildings. He organized the material along building typology, a theory framework of the Ecole des Beaux Arts, which would be rescued at the end of the twentieth century by New 
Urbanism. Well-known architect Ralph Adams Cram, designer of St. John the Divine and many neogothic American college campuses, wrote the introduction. He suggested that the real Spain "is almost an unknown country." The real Spain was not to be found in the cosmopolitan cities. It was the Spain of "aristocratic democracy," "vast ruined castes," of "caballeros and beggars," outside of the tourist track. Cram clearly stated that "pictures such as these are for students and creators of real architecture." He concluded that "Spain is an exemplar of the saving of real things while unreal pass by," as shown in plate 15. This rhetoric of authenticity and "castles in Spain" will be echoed in George Merrick's promotional materials for Coral Gables.
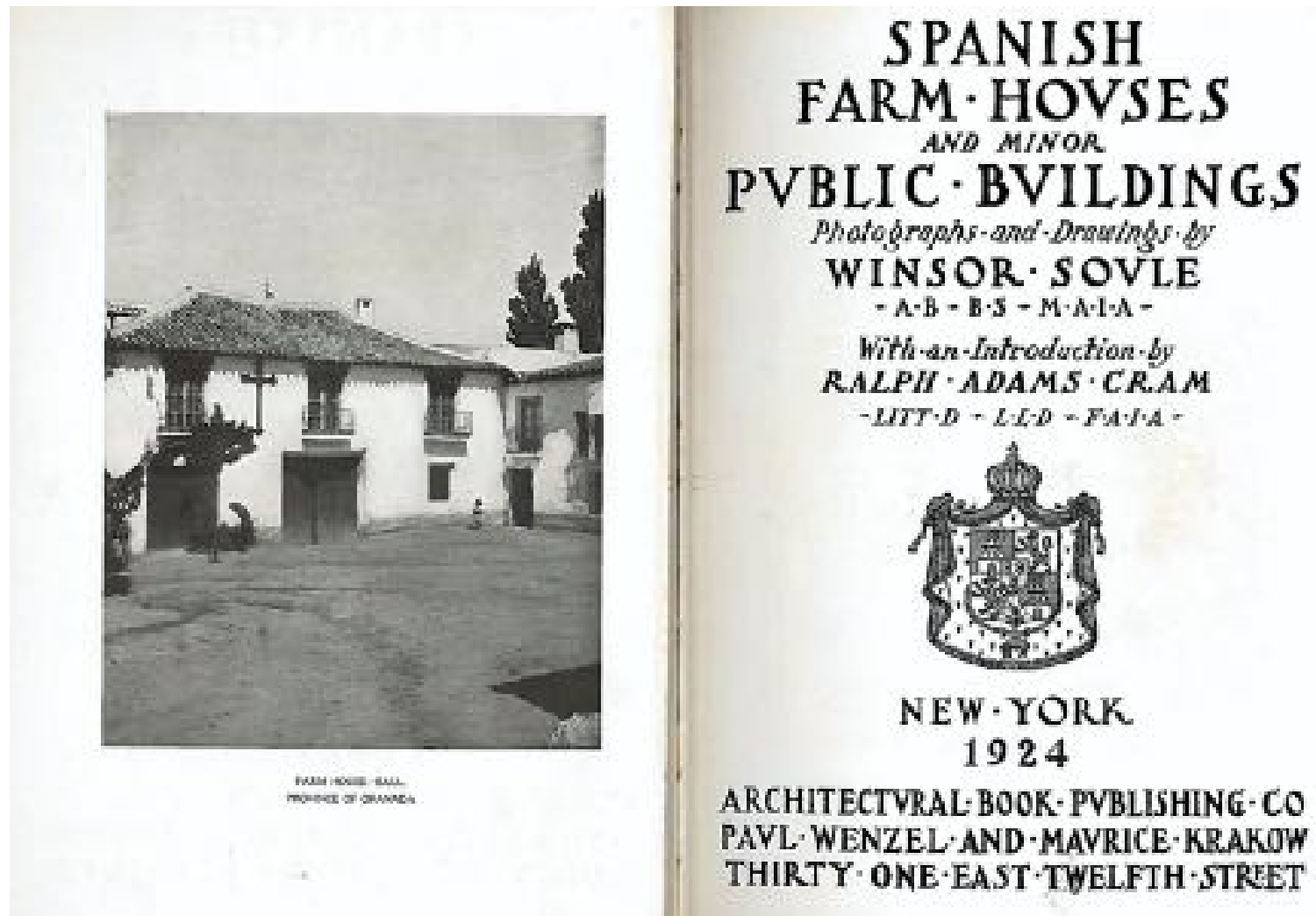

Plate 15. Folio book illustration. Source: Ramon Trias. 
Svole's photographs of farm houses depicted evocative objects in the landscape. These images could easily serve as precedents for single-family houses, which was the typical residential type of the 1920's in America, but rare in small town Spain. Irregular massing and tile roofs would become recognizable features in American "Spanish" architecture.

Part two reproduced city houses. These were generally two- or three-story party wall buildings, which at times concealed interior courtyards. The architecture was refined. Academic features based on classical architecture were always retained. These photographs would serve as precedent for Main Streets and small downtowns.

Part three was titled "Public Buildings." It included photographs of town halls and churches, with a few convents and seminaries and one prison. These buildings had Tuscan columns, ornate belfries and plateresque entryways. The author implied that professional design was reserved for public buildings.

Part four is titled "Details." Close up photographs of doors and balconies, cornices and capitals, window grilles and ornamental fountains were printed in isolation, to be used for reference, as required in varied projects. The back pages advertise related books from the collection. Surprisingly, there were no castles among the photographs.

Van Pelt (1925) appeared to take the opposite research approach with the ambitious title Masterpieces of Spanish architecture, Romanesque and allied styles. The book belonged to a collection published under the general title The library of architectural documents, which included prior publications on Tuscan and French Gothic architecture and promised future volumes on Moorish and Gothic Spanish architecture. 
The cover page credited "one hundred plates from monumentos arquitectónicos de España," the original source of the images.

The "masterpieces" were little known, however, and may be described accurately as vernacular civic buildings. Nevertheless, towards the end of the nineteenth century $\mathrm{H}$. H. Richardson had popularized the Romanesque style in America, as van Pelt explained. Unfortunately, van Pelt continues, Richardson's style had lost quality when lesser architects applied it to unremarkable commercial buildings. Thus, the original sources of Romanesque architecture would be of current interest for architects at the time of publication.

Van Pelt reproduced rigorous academic research performed in the second half of the $19^{\text {th }}$ century, under private sponsorship. The book only included a portfolio of exquisitely detailed copper engravings, as photography was not part of the original research project. The buildings were depicted in elevation and details, rendered with 45degree shadows, with occasional floor plans for reference. Thus, very modest neighborhood churches or old cathedrals had the appearance of timeless masterworks. From the perspective of the author, that was an important message, as quality was found in otherwise minor buildings.

Van Pelt stated that the collection of plates was incomplete as a reference for art history, but that it was useful as a tool for practice. In the introduction he included a section titled "application of the subjects shown to modern uses." It was a clear statement of intent. A source of concern was the "swing of art from impressionism through futurism to symbolism" and a "tendency of tourists after the World War (I) to invade Spain" that have revived an interest in the style, which had declined in quality 
since the work of Richardson (Van Pelt, 1925). Then, the author discussed in detail the design of churches, with precise reference to the plates. Afterwards, van Pelt suggested that "a bank building that needs the suggestion of massive strength, a library that recalls the lore and history of earlier times, such buildings as fraternity houses, lodges and temples" would be compatible with the impressions associated with Romanesque architecture (van Pelt, 1925). Finally, the author highlighted the accurate illustrations of details of iron works and doors as "particularly useful" (van Pelt, 1925). The book was intended fundamentally as a technical tool for use by design professionals, consistent with the best practices of the times.

Walter Thomas and John Fallon (1928) published Northern Italian Details originally in 1916, along a similar theory framework. Their book was scholarly, as it included measured drawings in addition to photographs, which generally depicted the same subject in consecutive pages, first as a photograph and then as a drawing.

The introduction by John Mead Howells, a well-known New York architect who trained at the École de Beaux Arts and collaborated with his fellow student Raymond Hood in the early twentieth century, warned that many books on architecture were not published primarily for architects, as they followed a literary form. That was not the case with this book, as "every plate ought to be useful in the draughting room." There were measured drawings of balustrades, doorways, façade details, woodwork, metal work, fountains, gardens, gateways, all carefully drafted in elevation and section drawings.

Should an architect need to design a gate for a perimeter wall, plate 81 showed the piers and stucco details of the wall in the Palazzo Zamboni in Verona or plate 79 compared similar piers from the Palazzo Bonin in Vicenza and the Palazzo Gallo in 
Brescia. Window surrounds, for example, from the mannerist period from the Palazzo Valsecchi in Milan were drawn in elevation and section, the classic analytique technique of the École, which would also be used in the drawings of the Coral Gables Biltmore Hotel. Although the architecture depicted in the book was of superior professional quality, it could be described as lesser known, as it did not include canonical work by Brunelleschi or Michelangelo. Some of Andrea Palladio's minor work was included, but the architect was not mentioned. Architecture was presented in its own terms, devoid of biography or social context. Discourse of the early twentieth century viewed architectural design as an autonomous discipline. Later in the century, superficial discussion about related issues, such as social trends, would often cloud the role of design in town planning and public administration.

Blakeslee (1920) published Ornamental details of the Italian renaissance, a manual of decorative details. It included 100 plates of line drawings of stucco decorations, capitals, balustrades and similar architectural elements that could enhance any building design. The plates did not show any context, as they simply provided raw data for architects. Some of William Hatcher's stucco ornaments in downtown Fort Pierce commercial buildings can be traced to this source.

Hatcher also owned an anonymous book published by the Boston architectural club in 1923, The domestic architecture of England during the Tudor period. As the other picture books, there was no text, but the black and white photographs and detailed line drawings provided useful professional content. Books of the period tended to focus on one architectural style, from a particular region. They would provide coherent visual data for professional use. Although a location may emphasize one style, some degree of 
diversity was commonplace. The creativity of the architect would start after mastering the fundamental features of a style. Neighborhoods from the 1920's valued diversity of form. A Tudor house, designed after an example from the book, would be compatible with a Spanish house along a tree-lined street.

The hardcover book had 45 pages full of advertisements of building products and local professionals. The commercial nature of the book did not detract from the quality of the content. On the contrary, it demonstrated that discussion of architecture along lines of style was part of the construction industry's mainstream business model. In fact, focus on content provided opportunities for business. One advertisement promoted polychrome terracotta religious sculptures in the manner of renaissance master Andrea della Robia. Another sold plumbing clay fixtures under the slogan of "the evidence of quality." To assist design professionals, Spauling-Moss company advertised drafting supplies for architects.

\section{Best Practices from the Journal Pencil Points}

In addition to the monographic picture books, Hatcher also owned two three-inch thick bound volumes from 1928 and 1929 of Pencil Points, a periodical of practical that information for the drafting room, as promised in the cover. Pencil Point Press had also published Van Pelt's scholarly book.

Pencil Points was a well-known national journal, published from the 1920's to 1943. The two volumes in Hatcher's library reflect the prevalence of traditional theory in architecture through the late 1920's. The typographical quality of the publication was exceptional, and consistent with the conservative aesthetic promoted by the content. Articles varied in subject matter from tips on lettering, almost always capitalis 
monumentalis very similar in design to the Trajan font in Adobe products, advice and education on construction materials, personal stories, business practices and even ethics. There were also employments advertisements and general publicity about construction businesses.

A cursory review of Pencil Points articles would provide a comprehensive view of the state of architectural practice in the 1920's. The standards and expectations were high. For instance, Magonigle (1929) published a lecture given to the architecture league of New York titled The values of tradition, where he critiqued "loose talk and incoherent thinking in the domain of the arts of design" and calls for more "craftsman like work" to be done. Towards the end of the presentation he showed a juxtaposition of images of contemporary and traditional works, where he compared Donatello to Brancusi and Matisse to Velazquez. The article concluded with selected minutes from a debate on the topic among top professionals, where modern architecture was dismissed as a "cult of self-expression." The "American Beaux Arts system” was recommended as a methodology to provide discipline to architectural education. Nevertheless, Ely Jacques Kahn, well-known designer of New York skyscrapers who did not follow historicist aesthetics, cautiously praised some modern European architecture.

On the same issue, Adams (1929) wrote Thoughts on modern, and other, ornament. By modern he meant specifically art deco, which was illustrated with 10 photographs and 10 detailed drawings of decorative bass relief panels for commercial or public buildings. In the center pages there were several illustrations, including a line drawing of a plateresque entryway from Burgos, reproduced from Prentice's classic book 
on Spanish renaissance architecture. The graphic composition was similar to the contemporaneous drawings of Walter da Garmo for Coral Gables buildings.

\section{Practices of the 1920's and Theory of Modern Architecture}

It is important to place 1920's publications reviewed in this study in historical context. For instance, as Merrick and his team developed Coral Gables with data and practices promoted in folio books about the history of architecture in various locations throughout Europe, LeCorbusier published Towards a new architecture, which was translated into English in 1927. His radical design and town planning ideas rejected historical references. In other words, he proposed different best practices.

Innovative architects of the early $20^{\text {th }}$ century believed Modern architecture would be inspired by function and would strive to reflect the spirit of its age. Soon afterwards, the folio books from the early $20^{\text {th }}$ century were forgotten. Architecture theory did not value style nor precedent for several decades in the mid- $20^{\text {th }}$ century. Although a postmodern revival of the 1980's reevaluated history, and influenced national zoning reform efforts and specific regulations in Coral Gables, best practices from the 1920's were

The evidence, in the form of the tools used by local practitioners such as Hatcher and De Garmo, would suggest that best practices of the 1920's were replaced slowly. For instance, Hatcher retained his professional library until the end of his career, as his work followed the trends of the times. Modern architecture theory rejection of history led unexpectedly to the obsolescence of content. Design and town planning drifted away from content towards bureaucratic efficiency. When Coral Gables was conceptualized zoning was not in place. Within a few years, however, the abstract language of zoning 
had replaced style as the initial tool of design. The administrative city of the $20^{\text {th }}$ century adopted only a few of the ideas of Modern architecture theory and minimized the role of aspirational content in local governance.

\section{Smart Reference Publications}

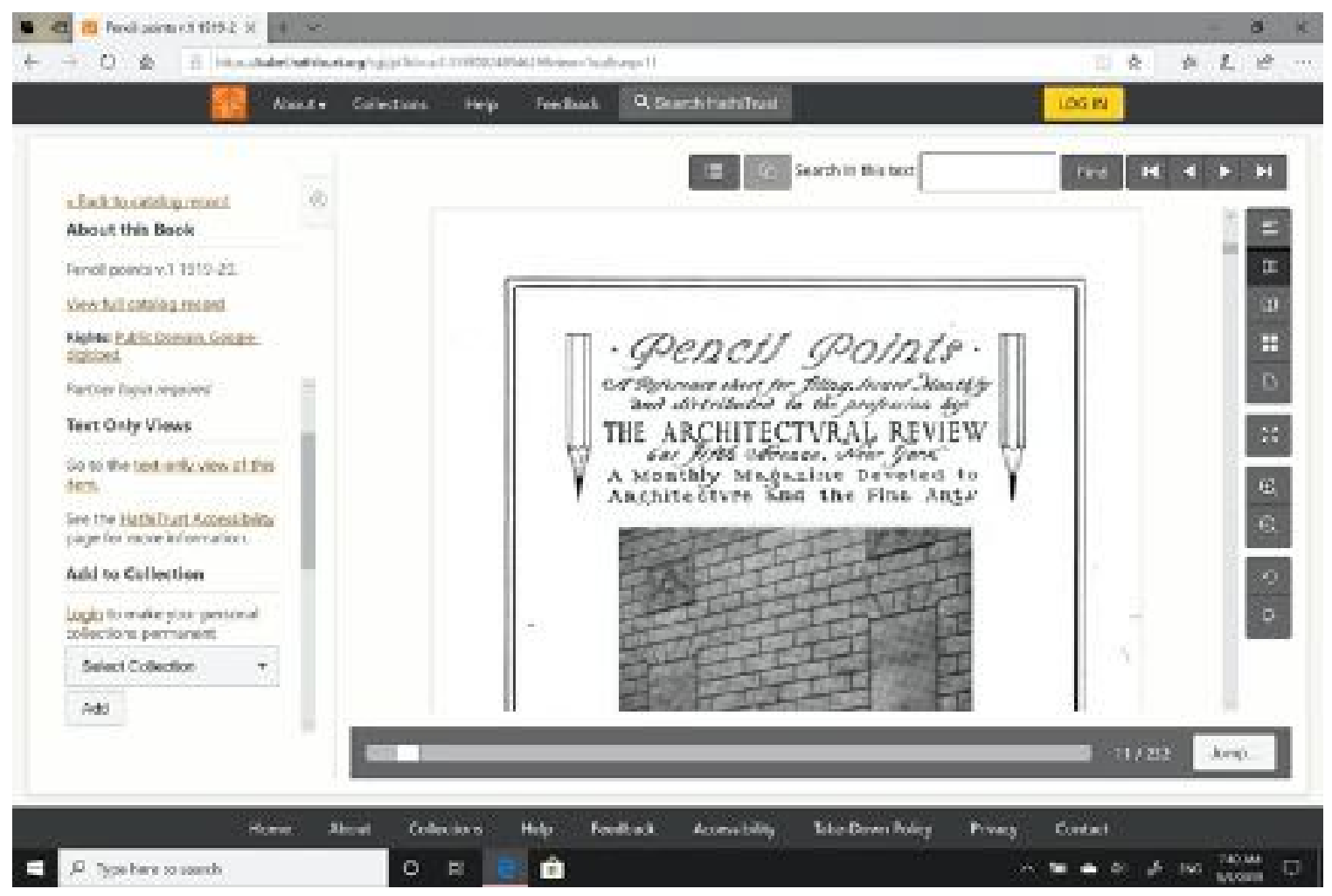

Plate 16. Pencil Point, PDF version. Source: HathiTrust website.

Smart technologies had led to a revival of content, and a reinvention of local democracy and bureaucracy. In the $21^{\text {st }}$ century, the folio books and periodicals of the 1920’s were universally available as digital files. Smart tools have rescued valuable educational materials. All data on place is available at any the time in multiple formats, including data from the 1920 's which led to excellence in design in many places, such as early Coral Gables. Best practices for design and design review can be updated and enhanced as theory reviews place from the point of view of content. 
In the past, only scholars or a few privileged professionals had access to original books or collections of historical drawings. New media and communication tools have expanded the distribution of content. For instance, images from the 1920's have been posted on the Coral Gables website and are used to inform professionals about the preferred characteristics of place. Only chronology bias would prevent present and future consultation of folio books as a best practice for architects, developers and administrators.

Aspirational content should define smart place, in ways that expand democracy and enhanced bureaucracy. Research on best practices of the 1920's revealed methods and debates that predated zoning and were thus overlooked by the bureaucracy of the administrative city. An objective review of the tools that were used to build Coral Gables and other cities and neighborhoods should enrich public administration theory.

\section{Findings}

1. Architects used extensive and detailed reference materials about the content of design for professional practice.

2. The format of folio books from the 1920's emphasized graphics, generally measured drawings in plan or elevation view and black and white photographs.

3. Folio books were practical tools for the implementation of quality design, through education about content and inspiration from exemplary buildings.

4. Early Coral Gables was inspired by the content of folio books, as early Fort Pierce, FL and other locations. The professional libraries of architects included similar books, but the selection of topics was extensive and promoted local calibration. 
5. There were multiple reference books, and the same books were used by many professionals in different communities.

6. Discourse centered on content and informed debate was encouraged. Articles or book introductions presented arguments for use in practice.

7. By the mid-twentieth century, architectural theory had discarded the folio books of the 1920's.

8. New Urbanism theory rediscovered the folio books of the 1920's in the late 1980's. However, architecture theory did not adopt them as a best practice in the late $20^{\text {th }}$ century. In the $21^{\text {st }}$ century, folio books from the 1920 's are not widely known nor used as reference, even though smart technologies have enhanced availability.

9. Contemporary practitioners may be skeptical about the value of best practices of the past because of chronology bias. Proposed theory would understand place as data and would validate the use of folio books for contemporary practice.

10. Reference publications from the 1920 's are more accessible in the $21^{\text {st }}$ century that at any prior point in history, thanks to smart technologies. In the past, professionals had to own rare publications, or visit collections of rare books in academic libraries. In the $21^{\text {st }}$ century, many rare books are universally available as digital files. 


\section{George Merrick's Narrative of Place}

\section{Narrative of Place, an Idea for Theory Development}

One of the contributions of this study is the concept of "narrative of place." Coral Gables inspired the idea, as the precise explanation of the design aspirations for neighborhoods and districts has created value for almost a century. Miller (2012) discussed the use of narratives for public administration. Study findings revealed opportunities to expand the topic within public administration theory, in terms of the effect of democracy and bureaucracy of place on quality of life.

"Narrative of place" can be applied to theory of governance, as it links local regulatory process, satisfaction about quality of life, and design review to aspirational content. A narrative for administration would be a concise and coherent expression of content, and thus, a record of democracy and a tool for bureaucracy. Research on George Merrick's work and data for resident surveys contributed to a preliminary understanding of the concept proposed in this study.

\section{George Merrick, Founder, Salesman and Symbol}

There is a bronze statue in front of the Coral Gables city hall of the founder of the city, George Merrick. He is dressed as a business man and holds a roll of plans in his right hand. He looks towards Miracle Mile, and in the distance, the Colonnade building, where he sold real estate (Parks, 2015). The statue is maintained meticulously, as there is no patina nor signs of aging. The pedestal was designed by professor Rocco Ceo out of stone carved in classical moldings in the manner of Michelangelo. The stone is informally known as coral rock, a limestone formed at the bottom of the sea, when the climate was warmer millions of the sea millions of years ago. The blocks were detailed 
with standards of the early $20^{\text {th }}$ century and appeared solid and timeless, as Merrick had intended.

The proper use of materials had a crucial role in the implementation of the narrative of place. Merrick's first local building code required a four-inch minimum depth for store veneers, to emphasize quality construction. On the other hand, $21^{\text {st }}$ century conventional practices, written into national codes, would allow veneers that range from $3 / 4$ of an inch to an inch and a half. That small change in regulations, as regulations became generalized in the $20^{\text {th }}$ century and calibration at the local level was outlawed, had major aesthetic consequences. Thinner stone appeared less solid and cast smaller shadows. From the point of view of casual observers, it would be less authentic. Large Mediterranean style buildings from the 1980's and 1990's would look flimsy and ill-proportioned when compared to the Biltmore hotel, as a consequence of this relatively minor specification. This is one example among many of the effect of content in administration, and the skillful contribution of Merrick and his team of professionals. In 2019, the zoning code required a depth of 4" from fenestration openings for buildings that followed the Mediterranean bonus program, a regulation consistent with Merrick's aspirations.

Although an outdoor statue in front of City Hall would be an appropriate memorial for a developer who prioritized architectural quality and public space, Merrick's work can be better understood inside the building. The second floor, the piano nobile where architect Phineas Paist located the Commission Chambers and the Mayor's office, is organized along a vaulted gallery intersected by a monumental staircase. Six full page advertisements from 1925 and 1926 Miami Herald and Miami Metropolis hung 
within frames on the gallery's wall for several decades, on the way to the Mayor's current office, which was relocated to the south East corner from its original place at the center of the floor plan, at the foot of the stair. The adds sold Coral Gables. For the potential buyer, the community was a place of aspiration, with refined ink renderings that suggested an aesthetic choice, but also an exceptional real estate investment. The pitch was that quality will make money.

The graphic design and text of George Merrick's newspaper advertisements should be understood as a best practice to conceptualize place. In the 1970's, young architects discovered them and learned from them in the early days of New Urbanism (Plater-Zyberk, 2018). In 2019 the Mayor placed the framed adds in storage and replaced them with photographs of the city's art in public places collection.

The memory of George Merrick and his work remained relevant in the $21^{\text {st }}$ century. Merrick's portrait hangs in the Commission Chambers, behind and above the Mayor's chair. His image overlooks all discussions by the Commission, Planning and Zoning Board and the Board of Architects. His legacy is routinely debated. A common question through the years, when confronted with challenging development requests has been "What would Merrick have done?" Competing answers would always lead to vigorous debate.

Research suggested that early design choices and aspirations created value for the long-term. For example, the city limits can be seen clearly in google maps: Coral Gables draws a green line along Miami and West Miami. The tree canopy would become emblematic of Coral Gables. Moreover, data on resident satisfaction with quality of life 
supported present day life in Coral Gables, with emphasis on vision and historic preservation. The "narrative of place" played a defining role in local governance.

George Merrick started Coral Gables as a private development, designed as a town and conceptualized as a suburb. Each choice was deliberate. A private project allowed aesthetic control, which was exercised through design review. A development in the form of a town could evolve and grow, enabling endless opportunities for future business. New neighborhoods and commercial districts were described collectively as a suburb of Miami, as they were located adjacent to the city limits. Suburb was a benign term, which could promote exclusivity and contribute to the sale of real estate. Merrick established aspirational goals for quality construction and aesthetics, in the form of a detailed master plan, deed restrictions and a building code, that would determine the character of place for decades into the future.

The Coral Gables plan was prepared by landscape architect Frank Button, under a one-page contract signed on April 18, 1921 that required "blocks and parkways or parks and such other detail as may seem necessary," to be completed in two months. Plate 5 reproduced a preliminary drawing from 1921, which has been preserved in the collection of HistoryMiami. The map depicted with extraordinary care the street layout, landscape and public space design.

A team of professionals under Merrick's direction crafted a narrative inspired by Mediterranean architecture and related design concepts, with evocative renderings and persuasive texts printed as full-page advertisements in the Miami Herald. As parcels were sold, a complete community was built one building at a time. 
On April 29, 1925 Coral Gables was incorporated as a local government by a Special Act of the Florida legislature, prior to the national implementation of conventional zoning. The original Special Act was amended six times in the late 1920's, to complete the transition from a private development to a local government. On May 8 , 1929 a seventh Special Act created a new city charter with home rule powers, in the form of a City Commission and Mayor. By then, Merrick's work on Coral Gables was over, as the Great Depression brought land speculation in South Florida to an abrupt end.

Conventional American zoning began in 1926, after the Supreme Court decision of Ambled Realty vs. the Village of Euclid. In 1930 the City Commission of Coral Gables adopted a zoning code. The sequence of events, and the historical timing, provide insight on the early scope of planning and zoning for local governments and illustrate the evolution of administrative ideas and practices through the past century.

The end of George Merrick's story was less memorable than his earlier experience in Coral Gables. By the time Coral Gables was incorporated and adopted a zoning code Merrick had lost his money, his development project, and had been dramatically expelled from the City Commission (Parks, 2015). He finished his career as postmaster in Miami and died in 1942. However, his vision for Coral Gables would prevail through the administrative tools of planning and zoning, in spite of periodic criticism and occasional skepticism as trends for architecture and development pressures evolved.

Coral Gables continued developing as a local government with strict regulations in the post-Merrick age. In 1957 Dade County, known as Miami-Dade County today, was granted home rule powers through an amendment of the Florida constitution, which 
enhanced County authority beyond what was typical for Counties in other areas of Florida. Nevertheless, one of the provisions in the county charter stated that "each municipality may provide higher standards of zoning (...) in order that its individual character and standards may be preserved for its citizens." Coral Gables residents and elected officials took full advantage of this provision thorough the decades. The zoning code became their preferred tool for bureaucracy of place.

Coral Gables had grown in ways consistent with the original concept initiated by Merrick's team, had developed complex zoning tools and robust design review, and it was known for high quality of life. Many residents believed this was the outcome of strict zoning regulations, a common explanation heard at public hearings and political discussions. Research showed this belief to be generally true and supported by data, for reasons that may improve conventional zoning practices. As Coral Gables adopted smart initiatives in the $21^{\text {st }}$ century and did not reject its history, a review of tools and procedures may lead to recommendations on best practices about the administration of place.

\section{The Merrick Narrative}

The story of Coral Gables was well-known in South Florida in the form of a consistent narrative (Patricios, 1994), (Parks, 2015). The foundation story, centered on George Merrick's dream of building "castles in Spain" on agricultural land inherited from his father, was commonly known (Parks, 2016). Patricios (1994) summarized the story favorably within the context of South Florida development. In his view, Merrick, rare among visionaries, was able to implement his dream. 
Parks (2006) had published an illustrated book entitled George Merrick's Coral Gables, Where your 'Castles in Spain' are Made Real, and had explained the Merrick foundation story multiple times since the 1970's. She also published the definitive biography on George Merrick after years of original research (Parks, 2015). Parks had collected original documents for decades and conducted interviews with key participants on the development of Coral Gables. Her views were considered authoritative and her lectures were assiduously attended by Coral Gables residents.

\section{Best Practices of City Beautiful Planning, Garden City and Mediterranean Architecture}

In the early $20^{\text {th }}$ century, best practices for architecture and city planning were developed by the professionals associated with the City Beautiful movement, which shaped Merrick's ideas of place (Parks, 2015). A theory model for place was proposed by Ebenezer Howard, as the Garden City. This theory model also developed best practices, summarized by Raymond Unwin's manual Town planning in practice, published in 1909. These ideas predated zoning and comprehensive planning for American local governments by almost two decades.

George Merrick deliberately applied many early $20^{\text {th }}$ century town planning practices to Coral Gables, which would be administered in the following decades through zoning regulations. Merrick even adopted the "The City Beautiful" as a marketing slogan, a phrase still used by City Hall to promote the community in the $21^{\text {st }}$ century. As a result, Coral Gables was intended to become a complete community and was masterplanned by a team of professionals. 
Merrick was influenced by contemporary town development projects, particularly Forest Hills, New York (Parks, 2015). Forest Hills was an innovative American development which adopted the principles of the Garden City Movement of Great Brittan. It had a town center along the railroad and residential neighborhoods within walking distance. The town center of Forest Hills shared design characteristics with the original rendering for Douglas Entrance in Coral Gables, in terms of public space, massing and architectural concept. However, there was one significant distinction. Forest Hills was designed in the in the Tudor style, which was derivative of contemporary English trends. Merrick and his collaborators chose at first the Spanish style, later known as Mediterranean.

Merrick's choice of Spanish architecture was significant, but not unique to his team of professionals nor particularly linked to South Florida. However, Spanish architecture was carefully calibrated by De Garmo, Paist and many others to local needs as it was transformed into Coral Gables Mediterranean architecture, a term preferred by George Fink (Parks, 2016).

The Spanish colonial style was fashionable in California in the early $20^{\text {th }}$ century, most notably in the work of architect Bertram Goodhue. It was also the theme of the buildings of the Panama-California Exposition of 1915, which was well-covered by the national press. But Merrick was also influenced by the aesthetic quality Spanish colonial town of St. Augustine, Florida, which he visited (Parks, 2016). Merrick and his wife Eunice posed for a photograph in front of the piers of the city gate, the precedent for the piers at the Prado Entrance, at the northern end of Coral Gables. 
In the late 1970's and early 1980's, the Coral Gables narrative of place was refined within an academic and professional context that emphasized design as a crucial process for enhancing the quality of life of American cities. In the mid and late $20^{\text {th }}$ century South Florida developed rapidly, in ways that did not result in sustainable urban form. By the 1980's suburban sprawl had become a major topic of concern in Florida. In that context, Frank Button's old Coral Gables town plan and De Garmo, Fink and Paist's urban design ideas provided a better model for growth. Faculty at the University of Miami School of Architecture researched Coral Gables, as an exemplary case study.

The Coral Gables public library and the University of Miami library were a repository of forgotten folio books and faded newspaper advertisements, which were carefully examined and shaped the intellectual core of a movement that was first called neo traditionalism and would be called New Urbanism years later (Plater-Zyberk, 2016) (Parks, 2016). Coral Gables Mediterranean memories, old public records, forgotten references and real estate aspirations were rediscovered as content for the New Urbanism, a town planning and zoning reform movement which transformed late $20^{\text {th }}$ century town planning. In turn, New Urbanism theory revived local interest in the Coral Gables narrative of place towards the end of the $20^{\text {th }}$ century.

Parks credited Merrick's uncle and collaborator, architect George Fink, for the term "Mediterranean" architecture (Parks, 2016). In the early 1980's Mediterranean architecture was erroneously understood as a revival, in a historicist sense (Parks, 2016). However, from Fink's point of view, Coral Gables Mediterranean architecture was a new 
style. It was a synthesis of influences from small town Renaissance Spain and Italy, appropriate for the Florida weather and evocative of the romantic history of the state.

Parks popularized the use of the term "Mediterranean" in the 1980's and enriched the contemporary content Coral Gables Mediterranean narrative with her publications. By the mid 1980's, development in Coral Gables was guided by cohesive aesthetic aspirations, supported by regulation and implemented with extensive public review. Nevertheless, buildings seldom achieved the quality of the examples from the early $20^{\text {th }}$ century. The use of the narrative of place to guide development towards quality already had a history, and outcomes could be compared.

\section{Content Sold Real Estate}

From 1925 through 1929 Merrick persuaded buyers of real estate that a Mediterranean town would be built from scratch. This was a surprisingly reasonable sales pitch at the time. Urban development was a common activity in the 1920's. A review of some business and design practices revealed lessons for best practices.

Full page newspaper advertisements, with thoughtful articles and elegant drawings were a preferred best practice. The promotional slogan always read:

“Coral Gables

Miami Riviera

40 Miles of Water Front

George E. Merrick"

Merrick's text proposed a persuasive narrative for South Florida, where a grapefruit grove could become a prominent place for business and living, within a great region of the future. The narrative might have been exaggerated at times. "Riviera" 
alluded to the Mediterranean, as an aspiration. The 40 miles of waterfront referred to drainage canals, often in the backyard of single-family houses. But Merrick's articles contained three basic strands of salesmanship: good weather, good investment and good aesthetics. But most importantly, Merrick promised a "unique city." Uniqueness would be achieved with detailed and unambiguous content, conveyed by pen and ink illustrations of buildings and public spaces.

All grand narratives should be viewed with skepticism (Lyotard, 1983) and Merrick's story had its supporters and detractors and only a few years of economic growth. All of his work began in 1921 and was finished by 1929, a period often known as the Florida land boom. In the end, most real estate value was lost in the Great Depression. Large tracks of his plan, such as the Biscayne section, were not developed until the 1960's, in a different way that the historic core of the city.

One advertisement asked a question: "How long can it last?" Coral Gables was only three years old at the time, and the future was already uncertain. Merrick predicted a few more years of fast growth and then years of stability. He would be correct in the long term, although the process would be eventful and controversial.

A review of data and events suggested that the most valuable contribution was the narrative of place, crafted at first as a branding strategy to increase sales. However, research demonstrated that skillful branding could become content for administration, and lead to enhanced place and superior quality of life measured in survey results.

In the 2010 census the average value of a single-family house was over $\$ 600,000$. The average value throughout Florida was $\$ 120,000$. Moreover, downtown Coral Gables had over 10 million square feet of office space. Merrick's investment promise was 
fulfilled in the long run, and best practices related to the implementation of place played a significant role.

Merrick's aesthetic choices were the source of public debates centered on modernity, history, styles and original intent. Nevertheless, form the point of view of theory, the aspirational content provided by Merrick and his team of professionals informed the process of public administration for the following century, and shaped enduring quality of place for neighborhoods and districts.

Coral Gables' zoning history offers multiple examples of the practical application of a narrative, for local government governance and administration. In the zoning code, the content from the narrative became a tool for development. During public hearings required by zoning law or initiated by elected officials or staff, the narrative became a tool for public participation. In time it informed complex zoning overlays designed to implement an aesthetic vision that had started decades into the past.

The narrative was repeated and reinterpreted for decades, with confliction opinions about details and application. The impact of the narrative on specific zoning regulations is discussed in the Results chapter. For the purpose of theory development, Merrick's narrative should be considered the initial aspirational content used for building the new community.

The documents produced under his direction provide significant insight into the use of real estate themes as a promotional strategy. These were the headlines of full-page advertisements:

"Winning Distinction In a New and Larger Field"

"Is there a Florida Bubble" 
"Great Value-Enhancing Features Insure Large Profits-Always"

"The Builders of Coral Gables"

"Why Coral Gables Sells \$1,000,000 Worth of Real Estate a Day"

"Why Coral Gables is First in the Minds of Wise Investors"

Many years later, the same advertisements, preserved at the Coral Gables library, inspired young architects from South Florida the late 1970's interested in postmodern ideas that led to new urbanism (Plater-Zyberk, 2018). In terms of use of printed media and enduring relevance to content, Merrick's promotional materials should be considered examples of best practices for implementation.

Merrick's narrative weaved complementary strands into a coherent vision for place. Merrick's vision was not a preliminary concept. Real estate value and precise aesthetics were at the forefront. The text stressed architecture and landscaping, and argued quality caused profits. There was concern about how long the market would last, which provided a realistic context.

Merrick's name and ideas are remembered every day in routine city activities in Coral Gables by the City Manager and staff (Iglesias, 2019). Merrick was often mentioned in Commission meetings in 2019. In contrast, Miami was founded by Henry Flagler, partner of Rockefeller in the oil business and builder of railroads. Flagler developed the East coast of Florida as he built the railroad to Key West. He built two major hotels in St. Augustine which were the early outstanding precedents of Spanish revival architecture. He created Palm Beach as a resort destination and transformed Fort Pierce into a railroad town. Flagler Street runs through the middle of downtown Miami. His bronze statute is at the top of the County courthouse staircase. He platted and sold 
most of the land where downtown would develop. Yet no one ever mentions Flagler's vision for Miami in contemporary city work (Iglesias, 2019). Flagler's narrative was about business development and travel destinations, but never about place. On the other hand, Merrick crafted the most effective narrative of place.

\section{Evolution of the Coral Gables Narrative of Place}

There were two distinct phases of the Coral Gables Mediterranean narrative during the first century of development. Each phase of the narrative was crafted and implemented with different tools, which responded to contemporary development needs and priorities. Evolving strategies reflected the practical needs of implementation. Although each narrative emphasized different aspects of the story, content, public discourse, and administrative tools and processes always played key roles.

\section{Phase 1: Merrick's Foundation Story, 1920's.}

Major Characteristics:

- Spanish architecture, inspired by contemporaneous folio books.

- Prominent public buildings and gateways, inspired by Spanish precedents.

- Spanish names for streets and public spaces.

- Articles and advertisements which described design concepts in terms of "castles in Spain."

- Supervising architect reviews all buildings for aesthetic compliance.

The first iteration of the narrative was crafted by George Merrick and a small group of talented collaborators, which included George Fink, Denman Fink, Frank Button and Walter de Garmo. Merrick decided to develop a town, inspired by the architecture of 
Spain. Thus, content was the primary focus during the first phase of the Coral Gables narrative.

The documented aesthetic sources for Architects of the time were thematic folio books published at the start of the $20^{\text {th }}$ century. The books followed the long tradition of architectural treatises that started in the Renaissance, with Palladio, Serio and others. Such treatises were designed to be copied. They contained useful illustrations of exemplary buildings, with little text. The early twentieth century folio books followed this format, and generally displayed a single line-drawing or photograph per page, which should serve a didactic purpose.

Folio reference books were organized around a single aesthetic theme. For South Florida architects of the 1920's, there was a preference for folio books on Spanish architecture. Content was precisely targeted, as the books did not reproduce major landmarks.

Of particular note was a book owned by De Garmo and many of his colleagues: "Lesser Known Architecture of Spain." From modest precedents of small-town Spanish vernacular, where proportions were classical and materials timeless, emerged the new Coral Gables Mediterranean style, which would be at the core of the narrative. The reference books used by Walter De Garmo were preserved at the Special Collections of the University of Miami.

As folio books had different aesthetic themes, not all buildings would be Mediterranean in style. Merrick also implemented thematic villages of unique aesthetic inspiration. A notable case was the Dutch South African Village, based on a monograph on the subject. This obscure style would become well-known among local architects, as 
New Urbanist leaders Andres Duany and Elizabeth Plater-Zyberk lived in a Dutch South African style house. Thus, the Mediterranean narrative allowed exceptions, which enriched the architecture of the community (Parks, 2016).

George Merrick's team of design professionals promoted the aesthetic narrative through their work and in publications, and their professional legacy enriched the early Coral Gables Mediterranean narrative. For example, Button (1921) explained his landscape concept in an article title "Suburb Beautiful." The text described the grand entrance on Tamiami Trail as the gateway to a wide parkway of the Spanish type, Granada Boulevard. As Button explained landscape concepts, the Spanish narrative was conveyed through names: Granada Boulevard, Alhambra Circle and Seville Avenue.

In addition to design, another aspect of the narrative of place was the use of language with specific meaning. Roy (1989) wrote a book about the names of the streets. The choice of Spanish and Mediterranean inspired designations for various locations throughout Coral Gables crafted an aspirational theme for the purpose of selling real estate at a premium value. Parks (2015) believed the names were arbitrary, selected at random from the text of Washington Irving's short stories set in the Alhambra and other unidentified publications. Roy carefully referenced the meaning of each word and did not find any general meaning. The street names were one of several cultural signs that contributed to the Spanish aesthetic of Merrick's narrative.

George Fink built a studio on Ponce de Leon Boulevard as a living illustration of the style he named "Mediterranean" (Parks, 2016). The façade recalled an illustration from page 12 of "Lesser Known Architecture of Spain.” Fink's studio was composed informally, as a vernacular structure from a small town in the plains of Castile would 
have been designed. Even though it had some classical details, it was not characterized by an academic interpretation of architecture. Rather, the building appeared to have been renovated through the centuries. The folio books and Fink's studio adopted the modest aesthetic of the Mediterranean vernacular as the source of content for the narrative of place. In 2016, with full understanding of the significance of Fink's design, the City of Coral Gables acquired the structure.

Even in the earliest days, each aspect of the narrative was implemented with public administration tools. In May of 1925 George Merrick appointed Phineas Paist Supervising Architect of Coral Gables. This appointed marked the start of professional aesthetic review of all buildings. Paist would review all buildings in Coral Gables in the 1920 's. His hand-written notes on early blue prints would be commonly studied decades later, during archival research of historic preservation projects.

Paist also contributed ideas to the narrative. In the October 1924 issue of National Builder magazine, he discussed the use of color "zoning," where rich colored areas would contrast with more muted districts would form a "tone symphony from cold to warm colors." This refined conception of artistic composition was discussed in the context of the "Spanish effect" achieved with a texture of rough stucco. It is significant that practitioners published their recommendations. The articles were administrative tools that provided support for aesthetic review.

Aesthetic review began at the start of the narrative, with the appointment of a professional by a private developer, prior to incorporation as a municipality. The process would be modified multiple times and adapt to changing times. However, the activity of design review of all exterior projects would continue without break to the present. 


\section{Phase 2: Postmodern Mediterranean Revival, 1980's}

Major characteristics:

- Eight exemplary buildings are listed in the City's zoning code.

- Bonus program provides additional height and area to buildings which follow Mediterranean design.

- Mediterranean architecture is understood as an aesthetic revival, but not defined in great detail.

- An appointed Board of Architects reviews all buildings for aesthetic quality.

Merrick's vision had been largely forgotten in the mid-20 ${ }^{\text {th }}$ century (Parks, 2016). The Coral Gables Mediterranean narrative was not applied to development in the 1960's and 1970 's. However, In the 1980's postmodern theory redirected academic research in the field of architecture towards history (Plater-Zyberk, 2016).

The new perspective rescued the content of the first phase of the narrative of place and contributed innovations to public administration strategies. Faculty and students at the University of Miami School of Architecture researched Coral Gables methodically. Observation and documentation of Mediterranean landmarks became the core pedagogy (Hernandez, 2016). In addition, academic work informed the on-going public discourse and contributed rigor to the narrative about the past and future of Coral Gables. These academic ideas influenced public policy (Gelabert-Navia, 2016).

In 1986, the restoration of the Biltmore Hotel, as a result of a request for proposals issued by the City, would prove to be very didactic, as architects, builders and administrators relearned the characteristics of original Mediterranean buildings (Parks, 
2016). The Biltmore Hotel was the most recognizable landmark of the style, and massing, detailing and use of materials would inspire zoning standards and aesthetic metrics. In fact, the Biltmore Hotel was mentioned by name in the zoning code, as a model of excellence. With the assistance of academics and practicing architects, Coral Gables established a zoning bonus program that provided additional height and mass if certain Mediterranean features were incorporated into a building (Gelabert-Navia, 2016). .However, even the Biltmore's preservation was surrounded by debate and conflict, as would be described later in the chapter. As prior theory and best practices did not anticipate a role for a "narrative of place," aspirational content would often be questioned when applied to conventional bureaucratic procedures and would appear inevitable only in retrospect. Although aspects of Merrick's narrative remained controversial, the effective use of administrative tools starting in the 1980's transformed ideas into actionable content.

\section{From Narrative of Place to Aspirational Content: Coral Gables, FL}

Research suggested that one competitive advantage of Coral Gables was a narrative of place translated into effective content for administration. The narrative had been conceptualized when the City was founded and had been refined for almost a century. Every aspect of public administration theory related to a narrative of place was present and could be researched through time. Thus, Coral Gables provided a model to investigate general ideas about theory and best practices.

Prior theory was silent on the role of aspirational content in the administration of place in local governance. Coral Gables data spanned almost a century and was rich enough for theory development. The community conceptualized in terms of content and 
place by founder George Merrick and his team of professionals. This fact alone would not be unique. Many real estate developments have robust starts based on narratives place, which are well implemented by developers in the context of the private sector. However, Coral Gables was incorporated as a municipality and private content was translated into zoning regulation. The content of the zoning code was implemented consistently throughout the decades with staff review or a volunteer board of architects.

The effective transition from a private narrative of place to administrative content was informative for public administration theory and best practices, as a local government must implement democracy and bureaucracy of place through regulation and discussion as times change. The success of Coral Gables in terms of real estate, in a difficult and competitive market of South Florida, was generally recognized. The role of aspirational content of place was researched, as it played a constant role in advertisement and sales, from the days of Merrick to the present.

An effective description of Merrick's work and influence is recorded in Coral Gables, Miami Riviera: An architectural guide (Millas, Uguccione, 2002). The book summarized the role of content in the $20^{\text {th }}$ century, as the $21^{\text {st }}$ century began. The text recreated the narrative that built the city and preserved its character in the form of historical essays and architecture tours. Aristides Millas was a professor of architecture at the University of Miami and Ellen Uguccione was at the time the historic preservation officer of Coral Gables. Thus, the book was written from an informed perspective on issues related to administration.

From the point of view of administration, the text and images record content for the place Coral Gables aspired to be. In fact, part one in titled "Coral Gables, the city 
inspired." The argument for place begins with the remembrance of Merrick's legacy, continues with a chronological review of steady progress and ends with a coherent explanation of the future. Data is provided with historic photographs, analytical maps, architectural critique and facts from different time periods. Administration and implementation were mentioned briefly.

\section{Timeless Coral Gables}

Behar and Culot (1997) organized the body of research collected by University of Miami faculty though the 1980's and 1990's, as then Dean Elizabeth Plater-Zyberk explained in the preface. Original maps, black and white photographs, old drawings, contemporary pictures of lush landscape and early newspaper advertisements from Merrick's day were used to support the argument that Coral Gables was an exceptional work of civic art. In addition, the text also explained that the city had been a real estate venture by a developer, who had profited from ideas that would create lasting value. The lesson from Merrick's narrative of place was that civic art and real estate profit would be compatible, under high quality development guided by the artistic and functional principles of the Mediterranean style.

Historic materials about Coral Gables had been preserved at public collections in the University of Miami and the Historical Museum of Southern Florida (currently known as HistoryMiami). Behar and Culot revealed the multiple layers of design and implementation with the reproduction of original graphic documents. The authors also highlighted the design of the landscape and of residential architecture, as innovative features of an ever-changing original project. Biographies of the many participants in 
early Coral Gables were included at the back of the book, which demonstrated that the narrative had been shaped by collaboration and discourse.

More recently, Stern (2013) described Coral Gables as a superior example of $20^{\text {th }}$ century planning, comparable to any contemporary garden suburb throughout the world. Stern cited the Merrick narrative as an example of design ideas that led to quality development. He also believed that significance of the city had been underestimated by historians, perhaps due to a bias against Florida urbanism, rooted on the perception of the state's towns and cities as resorts.

\section{Narratives Emerge from Conflict}

Narratives are not predetermined stories, and often result from conflict and disagreement. Any grand narrative should be read with skepticism (Lyotard, 1983) and Merrick's original narrative and its postmodern reinterpretation from the 1980's are not exceptions. This study did not explore conflict and tension in detail. The focus was on abstract content. Nevertheless, arguments did not dismiss historical methods which emphasize accounts of events or personal testimony.

The content of narratives about Coral Gables was always enriched by disagreement and evolved through time. Conclusions were never predetermined by utopian vision. In fact, the opposite interpretation was consistent with the facts.

Outcomes of the narrative of place were always restricted by business conditions and the trends of fashion. Coral Gables was the product of market forces, and quality place was one competitive advantage.

An illustrative example of the complex discourse associate with content was the public acquisition of the Biltmore Hotel by the City of Coral Gables, which led to its 
preservation (Doheny, 2017). The architecture and urban design of the Biltmore could summarize George Merrick’s original 1920’s narrative of place, and the restoration project of 1986 legitimized the reinvention of the narrative. In 2019, the Biltmore, owned by the City and leased to a private operator, had functioned as a historic landmark hotel and conference center for two decades and appeared inevitable and timeless. However, in 1968 its future had been uncertain.

A brief history of the building would remove any sense of inevitability for the narrative of place. The Biltmore Hotel and golf course opened in January 14, 1926. The New York architect, Shultze and Weaver, designed similar structures throughout the world, including the Waldorf Astoria and the Havana Biltmore. They also had designed the Roney Plaza Hotel in Miami Beach (Doheny, 2017).

In September of 1926 the "Great Miami" hurricane contributed to the end of the Florida boom and led to the collapse of Merrick's business activities in Coral Gables. The Biltmore hotel survived with other owners through the 1930's and was taken over by the Federal Government in 1942, during World War II (Doheny, 2017).

The building was used as a Veteran's Hospital until 1968. Through the 1980's it was abandoned, painted white and all distinctive architectural features were not maintained. Demolition by neglect seemed likely.

Preservation of the Biltmore Hotel appeared unrealistic for two decades. By the 1960's Merrick's narrative had been lost as a tool for administration (Parks, 2016). Aesthetic fashion in architecture had shifted to Modern design, and new buildings in South Florida followed a style that would be known as MiMo or Miami Modern. In 1968, the Roney-Plaza Hotel, designed in the Mediterranean style with a corner tower 
reminiscent of the Giralda in Seville similar in design to the central tower of the Biltmore hotel, was demolished. The narrative of place that led to the construction of the RoneyPlaza was no longer valued in Miami Beach. Alternative narratives would prevail as tools for preservation of Miami Beach architecture in the following decade.

Doheny (2017) concluded that in Coral Gables the Biltmore Hotel was saved by the people, and he described the individuals, their efforts and conflicts. The article "Saving the Biltmore" presented a detailed historical account of input from residents and officials, and diverse negotiations and lawsuits after the Federal government declared the building "surplus."

Attorney and philanthropist Parker Thomson, deceased in 2017, and wife Vann Thomson were credited with the legal strategy and public discussion which led to public ownership and restoration. But political debate and private development interests made the ultimate resolution less than certain. Mayors, Commissioners and interested neighbors participated in city meetings and legal proceedings. Doheny detailed the historical account of the complex "machinations" instigated to save the building, and acknowledged that the process of building restoration, which would address content related to place, had been described by other authors. Doheny wrote for a journal of history, and his perspective was that important decisions resulted from conflict among competing interests.

Another perspective on narratives would emphasize social issues. Although place is often described in terms of demographics, certain authors have critiqued George Merrick's from a contemporary perspective (Alkadry, Blessett, 2010). Alkadry and Blesssett cite Merrick's recommendation as a County Planning Board member in support 
of the redevelopment of prime real estate by removing residents. Similar policy considerations, and their effect on place have been discussed elsewhere.

This study researched the autonomy of place, as an existing set of physical conditions that can be enhanced with effective administrative tools. Early social motivations do not determine the long-term quality of place, as place is intended to last for several generations and transcend concerns of the moment. This does not dismiss the value of parallel research that would support equity and justice for place. Future research may enrich the conclusions of this study.

Finally, this study was not designed as a historian's account of Coral Gables, which had been published elsewhere in various forms discussed in the literature review chapter, most recently and definitively by Arva Parks in George Merrick, Son of the South Wind. In this study Coral Gables was an example for generalized discussion on theory and best practices. Alternative discussion of many topics of research could follow historical methods and emphasize certain arguments. It must be acknowledged that there should be no sense of inevitability to conclusions or recommendations. All narratives should be critiqued, and multiple interpretations may be legitimate. However, professionals interested in quality place may find conclusions that would enhance practice.

\section{Findings}

1. George Merrick's foundational narrative of place created and maintained real estate value with aesthetic concepts.

2. The foundational narrative guided development for less than a decade. 
3. The initial narrative of place lost relevance in the mid-20 $0^{\text {th }}$ century. I was not replaced by any alternative narrative.

4. In the 1980's a postmodern narrative emerged, which centered on the Mediterranean revival style. This narrative informed the tools of zoning to implement content of place.

5. In the $21^{\text {st }}$ century, the narrative of place enhanced by research and data informed aspirational content for administration, through the use of smart tools.

6. Place requires consistent choices about aesthetics. These choices are qualitative and require content and expertise.

7. Implementation of place may occur incrementally, with effective planning.

8. To maintain quality place, efficient democratic and bureaucratic processes should be calibrated by the narrative of place.

9. Narratives of place emerge from conflict, are fragile and may evolve through time. 


\section{Data for Smart Place}

\section{Data Should Explain Place}

Smart City strategies have evolved substantially in recent years and have transformed best practices for the implementation of place. In 2019 Coral Gables was a leading example for the application of smart strategies. This finding was unexpected, as Coral Gables was better known for historic preservation and conservative administrators. However, research showed that smart tools and history were compatible. Coral Gables had become a leader on the true Smart City innovation: technology in support of calibrated local content.

Research revealed synergies between time-tested content and smart strategies which would provide a foundation of best practices for contemporary place. Although many Smart City discussions centered on technology solutions for existing processes, the goal was better municipal operations. Typical early strategies enhanced routine municipal services. However, technology also provided opportunities as the field evolved for more substantive applications. Thus, smart strategies could support aspirational content developed though the past century, absent of any chronology bias. Information Technology Director Rodulfo (2019) led smart efforts in Coral Gables. City Manager Iglesias (2019) made Smart City strategies a priority. Faculty from the University of Miami (Lopez, 2019) and Florida International University collaborated on ideas for best practices. Research demonstrated that the robust ideas of Merrick's team in the 1920 's provided an effective platform for $21^{\text {st }}$ century innovation. Furthermore, smart strategies allowed access to all data, especially historic documents that could inform the administration of place. 


\section{From Smart City to Smart Place}

Smart City strategies can be calibrated for local needs with renewed focus on place. For instance, better monitoring of traffic light maintenance has been proposed as a smart strategy. This modest idea could be part of an overall mobility plan consistent with historic development and resident goals, should aspirational content be introduced in discussions. Data support policy. Thus, Smart City strategies, as understood in contemporary literature, should evolve towards the implementation of Smart Place. Smart Place would be the comprehensive goal, and each smart strategy would be guided with robust content.

Research suggested that technology has developed further than theory. At times data has been collected without practical application. More data would not necessarily lead to more effective administration. As smart strategies develop, emphasis should shift towards outcomes.

Theory about place does not depend on technology, but smart strategies may lead to efficiencies. More effective information about aspirational content would add value, without altering community aspirations. Moreover, research on smart strategies has the potential to enhance best practices for place, in terms of satisfaction with quality of life.

A smart approach for process was observed in Coral Gables, where the website portal graphics communicated long-standing aspirational content, in the form of a photograph of the loggia at City Hall reproduced in plate 17. The graphic design of the website was consisted with the Coral Gables narrative of place. This deliberate choice supported quality place. 


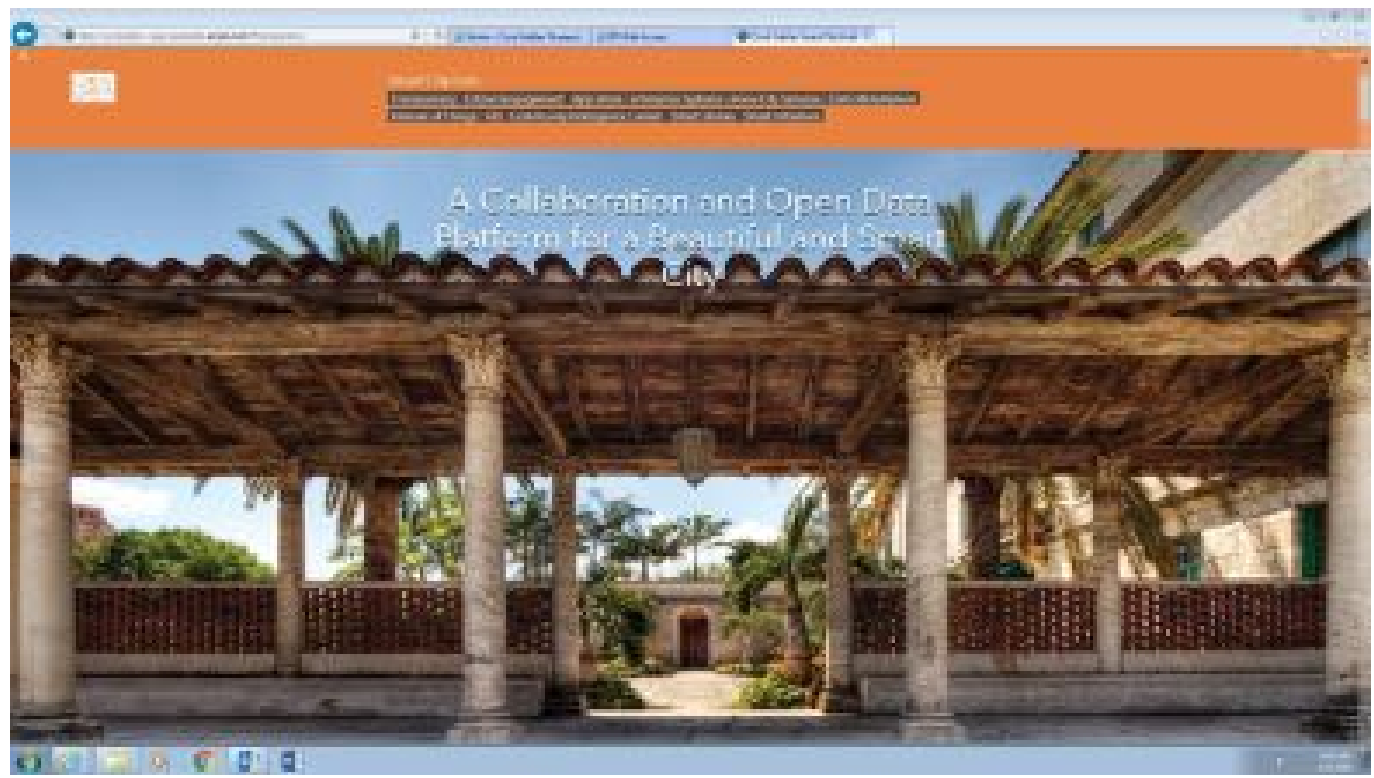

Plate 17. Smart City portal, 2019. Source: Coral Gables website.

The principal message of plate 17 was an update on Coral Gables' aspirational content. Data would measure and explain content. Smart city innovation would not imply a rejection of existing best practices. Smart place would express the continuation of quality place, or its enhancement as needed.

Coral rock carved under the established conventions of the Corinthian order conveyed a clear message about content in the field, or on a smart screen on a mobile device. Smart place can be beautiful, or not, depending on calibration. Smart strategies would add value to the process of administration, by finetuning processes with access to better data. The outcome would be quality place.

A smart strategies model can be expressed with a simple formula: Aspirational Content + Smart Data $\longrightarrow$ Enhanced Process $=$ Smart Place A community that has developed aspirational content can verify and expand implementation processes with smart data. The outcome would be quality place, which 
will be more dynamic and equitable than it might have been in the prior century, when place was not understood as data, an information was less accessible. Research on Coral Gables suggested that smart strategies enhance the quality of place, if guided by preexisting aspirational content and supported by dynamic data.

\section{In Search of Data for Administration of Place}

In the late $20^{\text {th }}$ century and early $21^{\text {st }}$ century, zoning reformers had searched for methodologies that would translate place into data and objective criteria. New Urbanism theory explored fundamental principles and codes and informed innovative professional practices. There was an interest in understanding the components of place, and the "lexicon" and "smart code" were early attempts. Such ideas would eventually be implemented in "form-based" codes (Duany et al, 2010).

Miami 21 was well known example of the early $21^{\text {st }}$ century city-wide form-based codes, but it predated smart strategies. At the time, zoning reform focused on the synergies of urban design and public administration. Initial attempts at developing theory and best practices for place led to new roles for public participation and regulation.

However, a full understanding of place as data proved elusive, but recent smart strategies open new paths for research.

A strand of late $20^{\text {th }}$ century research began the investigation of data for place, in terms of visual preference. In the 1990's Nelessen (1994) pioneered techniques for collection and evaluation of visual data for the purpose of town planning. His methods were designed for professional practice for design of small communities. Nelessen relied on surveys of pairs of carefully selected photographs, which were compared and contrasted. 
There were some limits to the visual preference methodology, as too many variables would present in any slide. Some variables, such as the color of the sky or the model of a car, were not relevant for research on place. Moreover, the sample of reference images was not random. Critics observed a potential for bias. Nevertheless, the goal that place could be analized with objective criteria provided insight for theory development.

Ewin and Clemente (2013) recognized that past efforts that focused on generalities, such as density and street connectivity, were inadequate to describe the quality of the public realm of cities. Findings from field research led them to develop a comprehensive methodology based on objective criteria about physical urban characteristics. Ewin and Clemente's research design, however, was influenced by bias from the transportation planning field. For instance, emphasis was placed on walkability as a proxy for quality place. Nevertheless, the proposed methods for measurement advanced the understanding of place as data.

Ewin and Clemente proposed measurement of five intangible qualities: "imageability, visual enclosure, human scale, transparency and complexity" (Ewin, Clemente, 2013). The fields of architecture, urban design and planning routinely apply the concepts. However, best practices for design at the start of the twenty-first century were not typically driven by data. On the other hand, transportation planning relied on data.

\section{Language for Place as Data}

Visual preference research advanced new language for theory, based on data. Ewin and Clemente proposed "fifty-one perceptual qualities of the built environment." 
These qualities were developed from literature review of classic planning works in urban design, (Sitte, 1889), (Jacobs, 1961), (Lynch, 1960), (Unwin, 1991), (Alexander et al, 1977). Some qualities in the list were: adaptability, imageability, diversity, singularity, enclosure, texture, formality, continuity, rhythm, openness, etc. (Ewin, Clemente, 2013). Individual qualities had emerged from theory and presented a partial idea of place shaped by perception as a pedestrian.

Visual preference was a valuable tool for conceptual discussion, but it was insufficient for implementation. As new types of data were able to be collected, tools for democracy and bureaucracy evolved. Smart data would quickly expand the conceptual framework of content and process for place, with new types of dynamic data that could supplement prior theory.

A list of perceptual qualities of the built environment demonstrated the value of language as an administrative tool (Ewin and Clemente, 2013). Others had attempted the task. But language about place had not resulted in best practices for administration. Findings suggested discussion should proceed with a more robust theory structure, where fundamental concepts are defined in abstract terms and features related to implementation are addressed with best practices, crafted in the most effective format.

If a concept was on a list of accepted terms of art it would be measured. Otherwise, it would not exist for the purpose of research. Moreover, without language, there would not be a narrative.

Without robust theory, urban design language would be ambiguous. For example, Ewin and Clemente quoted competing definitions for "human scale", as it related to the height of buildings, which ranged from three to six stories, according to several authors. 
But authors provided opinions based on limited data, without reference to methods, relying on their authority. Thus, there was room to enhance research methodologies to develop more precise variables.

Measuring urban design provided ideas for research design, related to content without consideration of process, although they did not used the terms. Researchers assembled an expert panel, which included professionals from urban design and public health fields. Victor Dover was on the panel and he recalled the experience as an experiment (Dover, 2019). A method was developed to mimic pedestrian experience with the use of video recording. Small screen captures from the video clips were included throughout the book to support data. Two hundred videos from twenty-two cities formed the dataset. Five Florida cities were researched, but Coral Gables was not among them.

Each video clip was assessed as high or low with respect to nine perceptual variables: imageability, enclosure, human scale, transparency, complexity, coherence, linkage, legibility and tidiness. Dover (2019) explained that the video method had some shortcomings. It was difficult to control all visual variables. For example, a cloudy day may affect perception, even though weather was not a research variable. Moreover, subjects would supplement their images with personal knowledge of certain places, and not others. Dover believed exclusively quantitative methods lacked the ability to consider qualitative data. Research design about place would require qualitative and quantitative data to have value for administration.

Ewin and Clemente performed regression analysis on the data, in an effort to follow public health methods (Dover, 2019). Their main conclusion was that "simple 
measurements of the physical features found in the physical environment can help explain urban design qualities," which explain walkability (Ewin, Clemente, 2013). The assumption was that walkability defined quality place. This opinion was common among urban design experts (Speck, 2012), derivative of New Urbanism theory about community (Duany et al, 2010), and related to health policy which encouraged physical activity (Burden, 2016).

\section{Smart Data Support for Qualitative Content}

Quantitative data on walkability was insufficient to evaluate quality of place, and New Urbanism theory never implied that it should be the only standard. In the early twenty-first century, transportation planning bias had weakened research design on community.

Speck (2012) explored the main topic of downtown design in Walkable city, in terms of qualitative experience. But qualitative arguments in support of urban life phrased in terms of the pedestrian experience were mainly a consequence of the extraordinary emphasis on automobiles on the second half of the $20^{\text {th }}$ century and transportation was the preferred topic of research. This was an incomplete perspective when compared to 1920 's best practices, where place was never conceptualized in terms of mobility, or expected trends for transportation in the 2020's.

Although prior walkable city theory discussions employed objective data, Smart City tools enhanced precision, as plate 18 summarizes. Pedestrian counts could be measured. The impact of special events, for example, could be precisely ascertained, with spikes on a graph, and lead to administrative actions For instance, parking management could be modified, as predicted by data. 


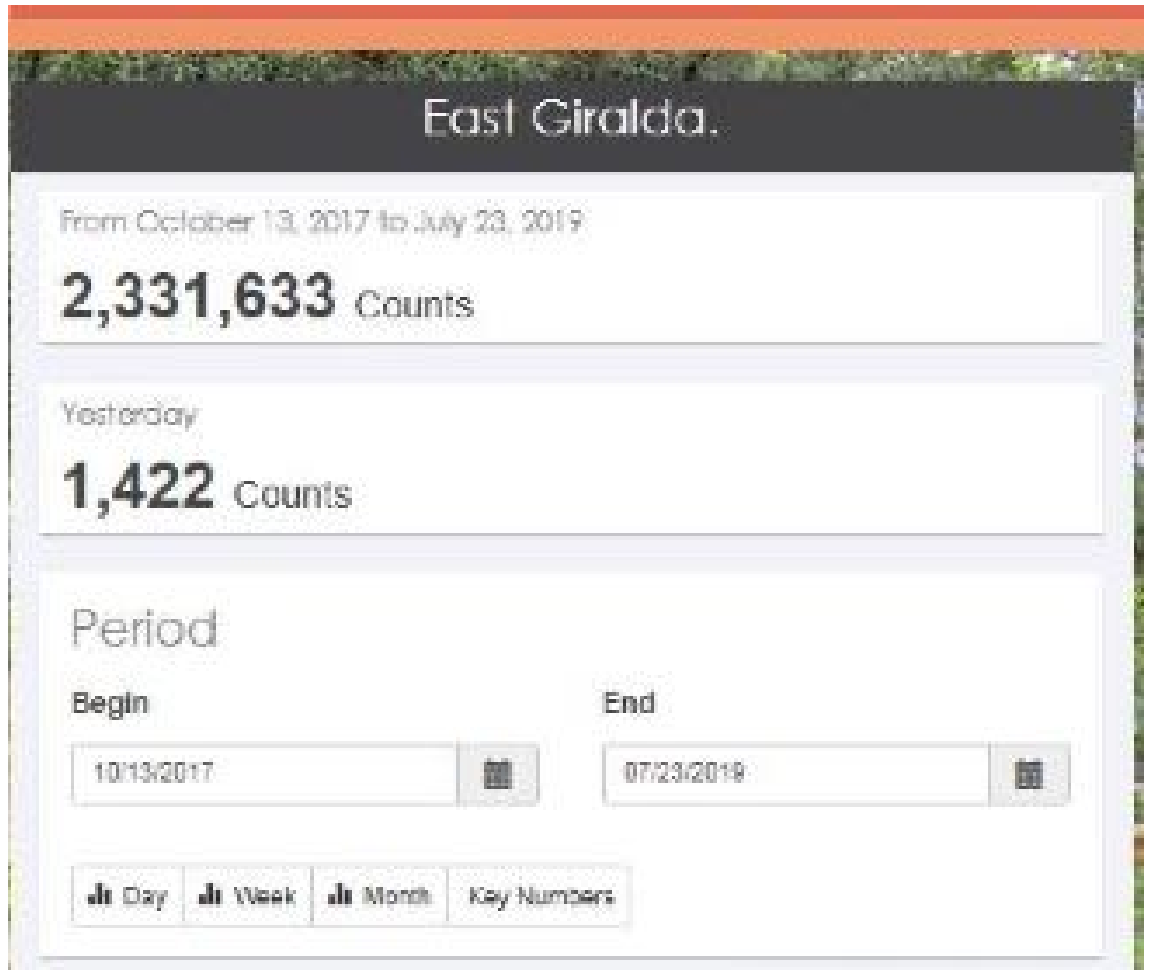

Plate 18. East Giralda, pedestrian counts. Source: Coral Gables website.

Smart strategies provided dynamic data that would support robust theory about place. Democracy and bureaucracy of place would be an evolutionary process, supported by historic data and analysis. For example, in the 1920's discussion was about design of buildings that would build communities. Data was provided in the form of measured drawing published as plates. Folio books for architects from the early $20^{\text {th }}$ century provided practical detailed about urban design qualities, effective at the time of publication and ready to be tested again with smart tools.

One topic not addressed in the 1920's was walkability, as there was no need to investigate mobility in a town designed for walking. At the time, buildings, neighborhoods and districts were designed for walking by default. Transportation planning would develop later in the century to promote automobile use. 
Evaluation of traffic data became a complex professional discipline, and a main topic for democracy of place. It was also an industry that employed consultants and bureaucrats. Public frustration led the transition to mobility planning in the $21^{\text {st }}$ century away from cars, and to reestablish walking as an important aspect of community. Related ideas, such as bicycle and transit planning became important aspects of community life. Smart tools would verify the effect of policy on place and encourage more democratic decisions.

Dover and Massengale (2014) published an illustrated textbook on street design which provided effective direction for urban design, for the perspective of building communities that were constructed with quality buildings and civic spaces. Street design: the secret to great cities and towns, was not about transportation, it was about place. The contribution to theory was significant, as the text and photograph provided examples that could become aspirational content for future development.

\section{Aspirational Content and Smart Data}

The administration of aspirational content for place in Coral Gables was regulated in the zoning code. In addition to zoning requirements, discussed in the Results chapter, the code also provided for historic preservation. In Coral Gables, history was part of the daily discourse about place. Discourse required content, and prior to smart strategies, content was difficult to curate and distribute. Endless debates about the meaning of Coral Gables Mediterranean architecture were inconclusive because of poor information.

One of the unexpected findings of the study was that smart technology made history relevant to best practices. For instance, historic preservation had drifted away from practice about place in the late $20^{\text {th }}$ century and become increasingly specialized. 
Coral Gables was different, as zoning regulation required inspiration from the past.

Lopez (2019) and his students from the University of Miami prepared measured drawings for several exemplary buildings listed in the zoning code, following the standards of the Historic American Building Survey (HABS), as supplemented by smart strategies.

The Fink studio was originally built as a model for Mediterranean architecture in 1925 (Parks, 2016). In 1986 it was listed as an example of the Coral Gables Mediterranean style in the first Coral Gables Mediterranean regulations ordinance. After 16 major revisions to the ordinance during the following 18 years, the list of exemplary buildings remained unchanged. However, quality reference materials were not available. If an architect wanted to follow the code, and find inspiration in the Fink building, he could only visit the structure, as historic preservation documentation was unavailable. Lopez and his team prepared new measured drawings, with classic tools such as pencils and measuring tape and also smart tools such as drones. Moreover, the documents were published in the Coral Gables website, and were available to all.

Drawings prepared in 2018 by the team of the University of Miami are an example of aspirational content, as understood by zoning regulations, of historic preservation, and of best practices for smart place. The students and faculty blended traditional methods based on paper, pencils and tape measures with innovative techniques from drone photography. The final deliverables were measured drawings of the highest quality.

Plate 19 is the front elevation of the building, as accessed from the City of Coral Gables website. The line drawing follows architectural technique and conventions. Although similar to drawings published in the folio books of the 1920's, it is 
unquestionably a smart tool which supports the standards of the zoning code, intended to contribute to the administration of smart place.

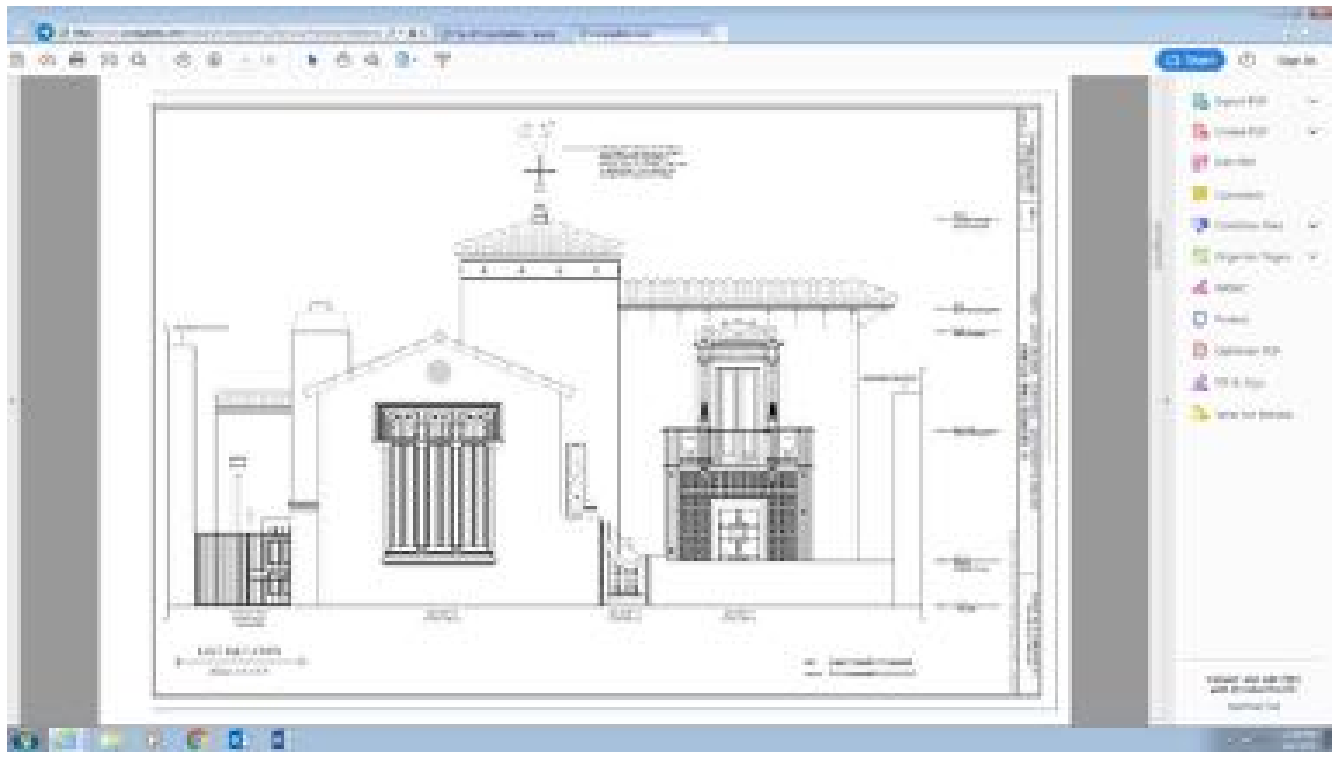

Plate 19. Fink Studio, Ponce de Leon boulevard façade. Source: Coral Gables website.

In addition, the standardized graphic technique of HABS drawings was very similar to best practices of the 1920's, as reproduced in the folio books. Smart tools made the documents accessible and dynamic. In terms of practice, specific requirements of zoning regulation, such as depth of windows and related construction details, can be readily consulted, from the original source.

Plate 20 depicts details from the front window and the interior lobby. The zoning code required a depth of four inches for exterior widows in some buildings, in an effort to enhance the architectural quality and appearance of exterior facades. The example in plates 19 and 20 comes from a building listed in the zoning code and demonstrates a 
successful implementation of the requirement. The drawing represents one smart strategy towards the implementation of smart place.

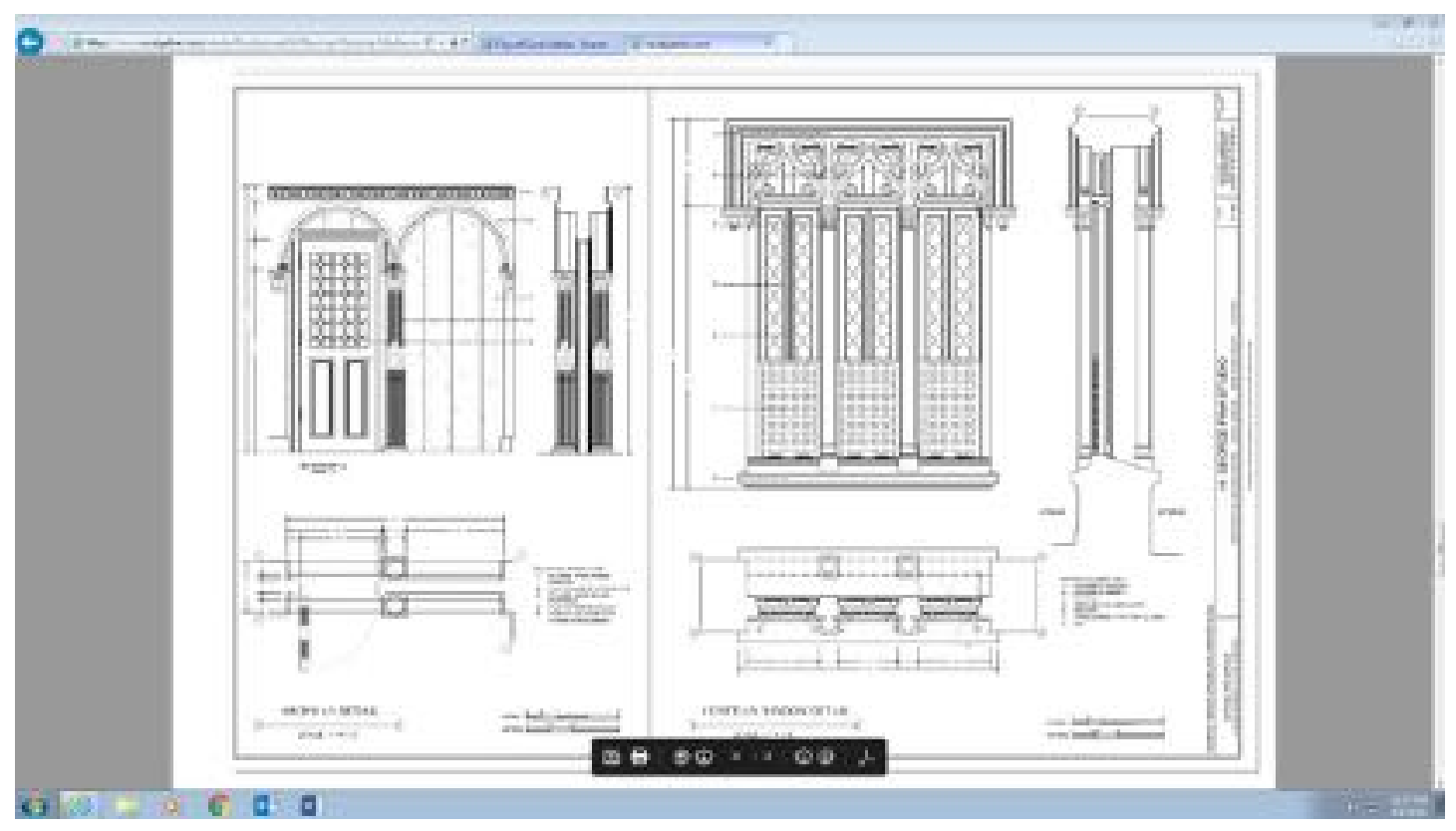

Plate 20. Fink Studio, details. Source: Coral Gables website.

Smart technology made content more accessible and reliable at the present time that a century ago. The resilient example of Coral Gables, where content has been relevant since the start, provides a laboratory for best practices for place.

\section{Coral Gables Becomes a Smart Place}

Nelessen, Ewin, Duany, Plater-Zyberk, Speck, Dover, and Massengale were familiar with Coral Gables and often mentioned it as a model for quality place. Much research of the turn of the $21^{\text {st }}$ century attempted to measure and replicate many features that were already present in 1920's Coral Gables, and develop processes to implement content for place, building on mid-century theory (Lynch, 1960), (Jacobs, 1961).

The utility of the design principles and foundation story of Coral Gables for contemporary best practices was known as the start of the $21^{\text {st }}$ century (Duany, Plater- 
Zyberk, Speck, 2000). Nevertheless, the influence of Coral Gables may have been significant for New Urbanism theory but had negligible impact in general practice, with the exception of town planning and historic preservation in South Florida.

In academia and professional practice of the early $21^{\text {st }}$ century, chronology bias often privileged a narrative of innovation based on date of publication over historical research of best practices tested by experience. This bias would be less relevant for smart place, as all data would be readily available and can be measured and analyzed. Thus, discussion about place would be objective.

Smart strategies were increasingly promoted by the University of Miami after 2010, and Coral Gables led local government initiatives related to Smart City, there was renewed interest in understanding Coral Gables as a city for the future (Faber, 2019). In fact, discussion about smart strategies was compared positively to Merrick's innovative blend of garden city ideas and the grandeur of the City Beautiful movement (Faber, 2019). Merrick's narrative proved resilient in the age of data, as Merrick was also an innovator in his time.

Research showed that the understanding of place as data had evolved quickly with Smart City strategies and was compatible with earlier best practices. Quality place would be administered best within a theory framework that adopted to innovation through the evolution and refinement of time-tested best practices. Theory would understand the "Digital City" as compatible with the "City Beautiful."

Plate 21 is a photograph of a 2019 publication about Coral Gables. Rodulfo (2019) and Iglesias (2019) have successfully promoted the implementation of smart 
strategies in Coral Gables. Their work has enhanced administrative practice and provided data and ideas for theory on smart place.

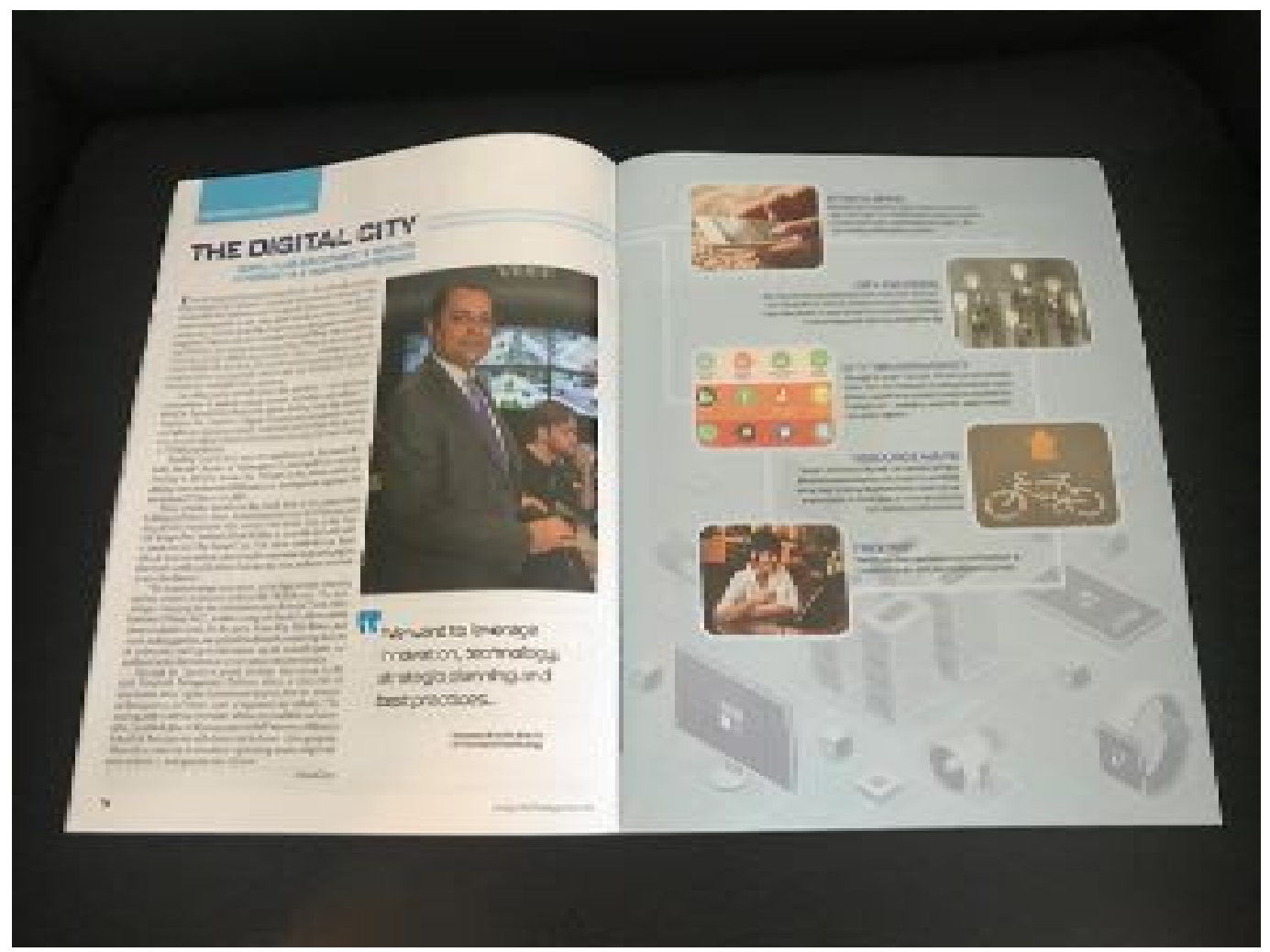

Plate 21. Coral Gables magazine article. Photograph: Ramon Trias.

Planning and zoning processes could be enhanced with best practices which address place dynamically and directly, in terms of democracy and bureaucracy. Many other public services also used enhanced data. For example, public safety tended to lead such efforts.

A comprehensive platform for city services would be the next step. A first version has already been implemented, reproduced on plate 22 . 


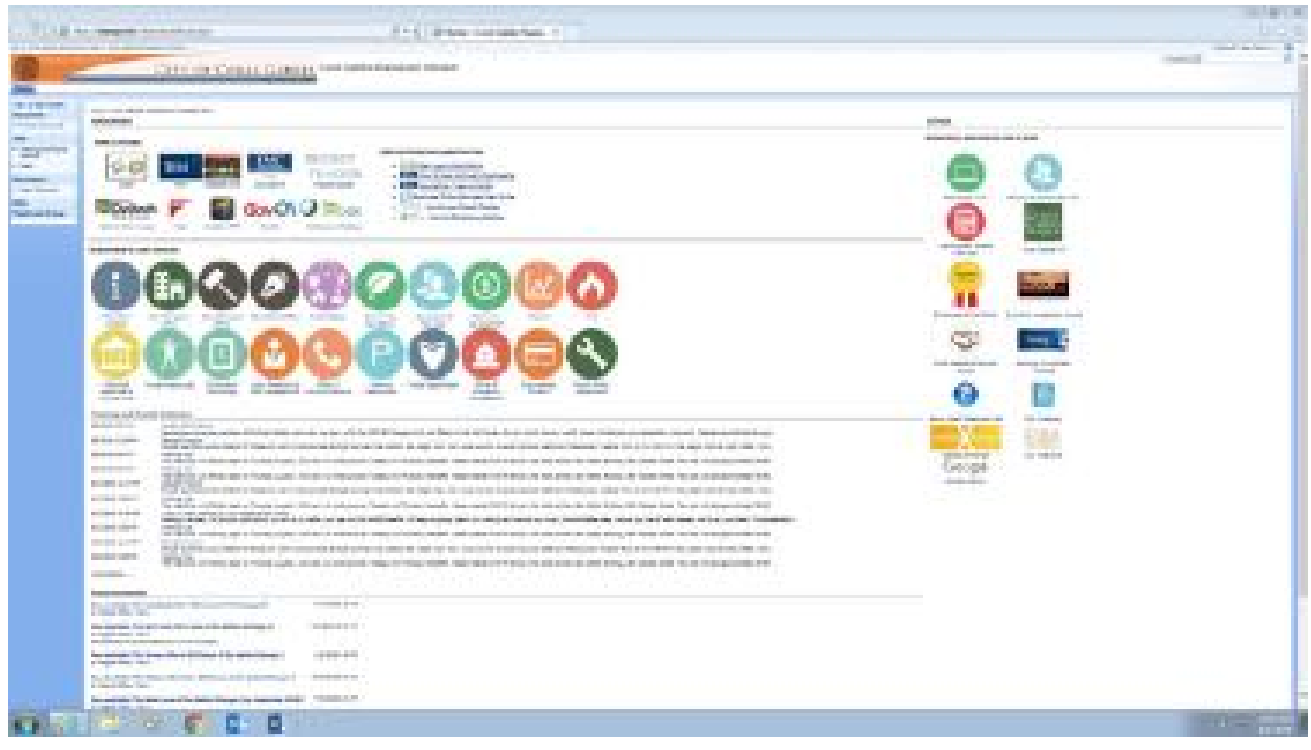

Plate 22. Coral Gables main menu. Source: Coral Gables website.

When all services and opportunities for input are supported with information about content, bureaucracy and democracy function seamlessly. The metaphor of "desktop" is used to speak of a digital page full of options. The graphic display would suggest multiple synergies.

Place as data is a developing idea, and research led to current practices that may evolve into best practices for administration. Below are a few examples of smart techniques for data collection, and discussion about recent trends:

A. Public safety

Smart city strategies are often first applied services that have relied on data in the past and have established methodologies for analysis. Criminal justice and emergency management were among the first priorities. As they play a role in the implementation of place, work on these subjects may lead to insights for best practices. In the case of Coral Gables data collection began in the public safety filed and immediately expanded its use for place. 
An important topic of public discussion was traffic, which was a major concern for local governance, and had been discussed in the past with limited data. Residents would have strong opinions on road conditions based on personal perceptions. Effective solutions were rare. However, automobile traffic was only one of many impacts of urban development. Accurate data would lead to a better understanding of the impact of traffic, in the context of the comprehensive management of the local government. Plate 23 displayed data on traffic conditions, with geographic information.

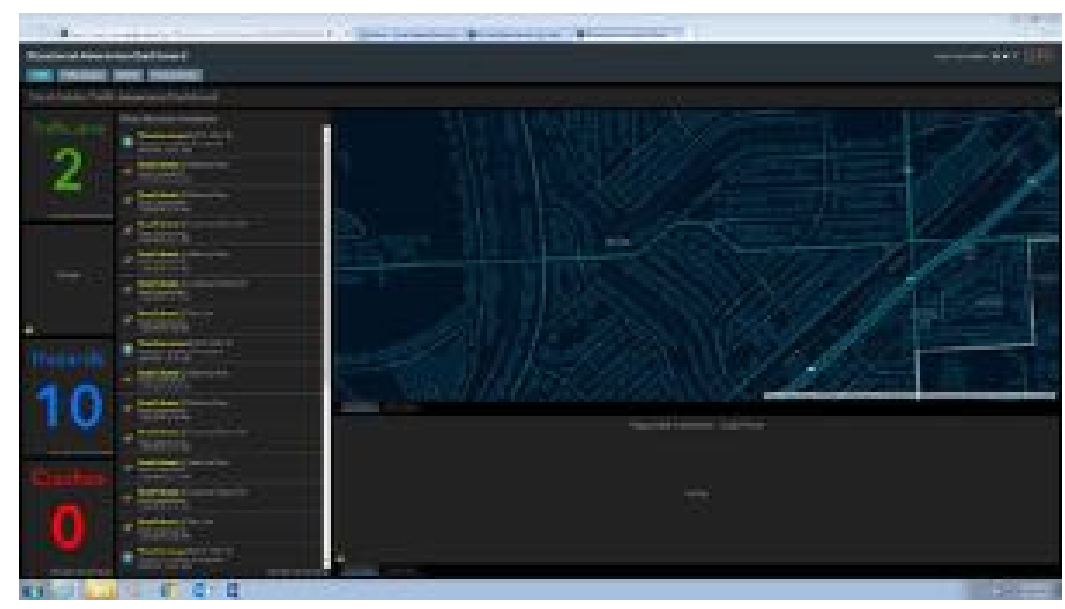

Plate 23. Traffic information. Source: Coral Gables website.

In this example, traffic events were monitored in real time throughout the local government. Although this activity may be initiated for enforcement, data became very valuable for planning purposes. Smart strategies placed traffic in its proper context.

B. Mobility

Although data may have been collected for automobiles at first, the opportunity to expand research to general mobility became immediately apparent. Mobility 
transformed policy discussions. Pedestrians and transit riders were valued for transportation planning. Moreover, parking was understood to generate automobile traffic. Capital projects for sidewalks and garages would lead to enhanced mobility and quality of life. Pedestrian counts verified the success of major capital improvement projects designed to enhance downtown activity. Smart tools provided very detailed information, which could be used to measure the impacts of policy, as recorded in plate 24 and 25.

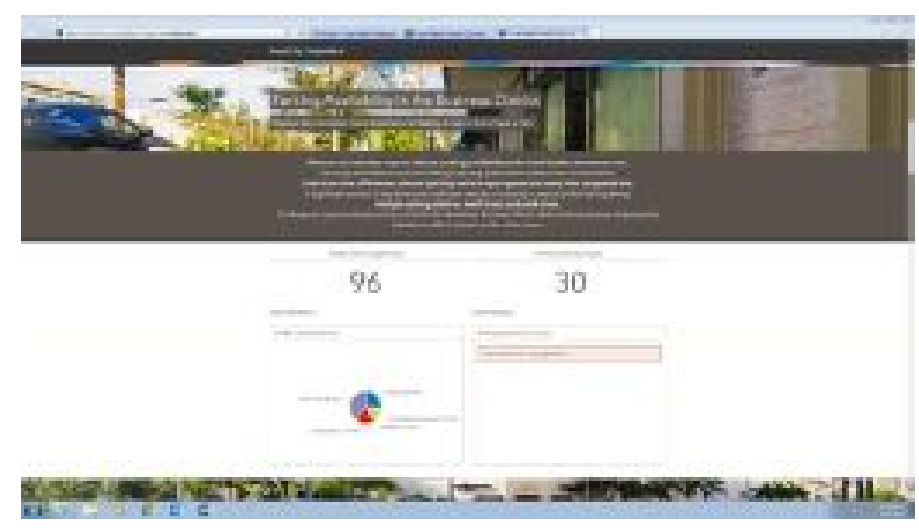

Plate 24. Parking information. Source: Coral Gables website.
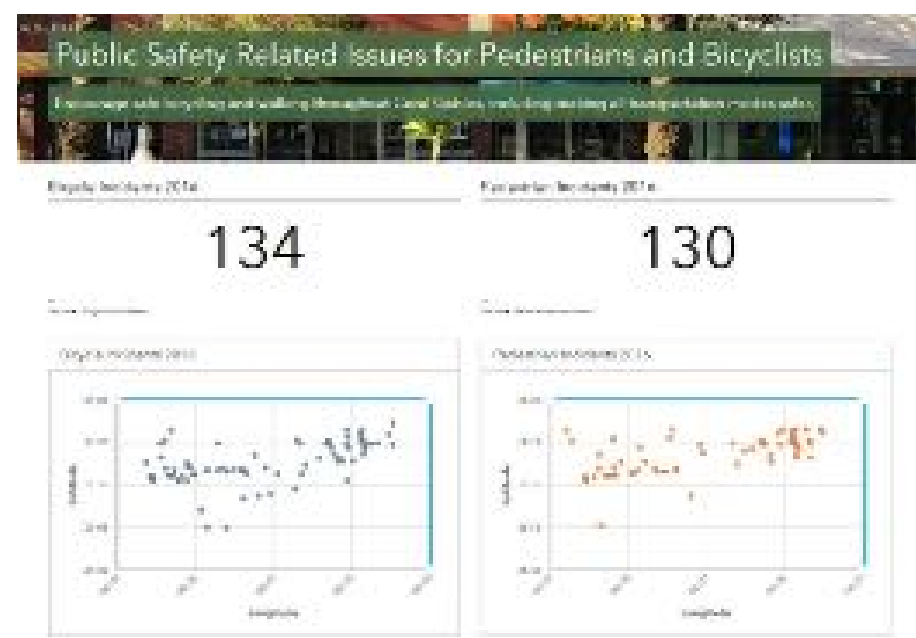

Plate 25. Bicycle and pedestrian incidents. Source: Coral Gables website. 
C. Municipal services

Provision of routine services was optimized with accurate data. Moreover, data collection led to enhanced planning, by providing a precise understanding of place at a given point in time. As conditions changed, data supported bureaucratic processes. For instance, plate 26 mapped debris collection.

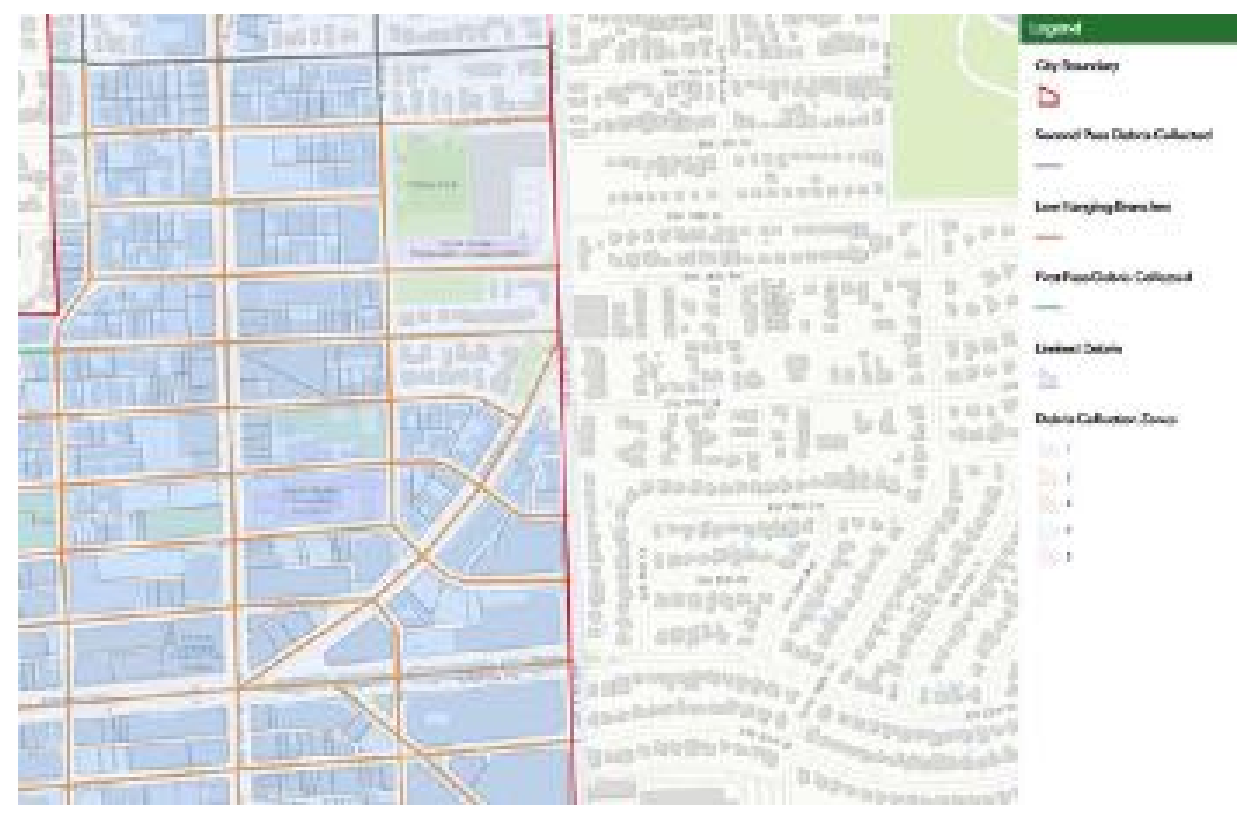

Plate 26. Sanitation information. Source: Coral Gables website.

As new services would be implemented, smart strategies would provide platforms for public information and tools for planning. For instance, plate 27 mapped electric vehicle charging stations.

This new technology supported mobility policies. In isolation, data on charging locations had limited use. As an element of a strategy for smart place, such data enhanced quality of life. Location and use data would provide information directly related to place. Thus, smart strategies provided actionable data on many topics, and created an ecosystem for future strategies. 


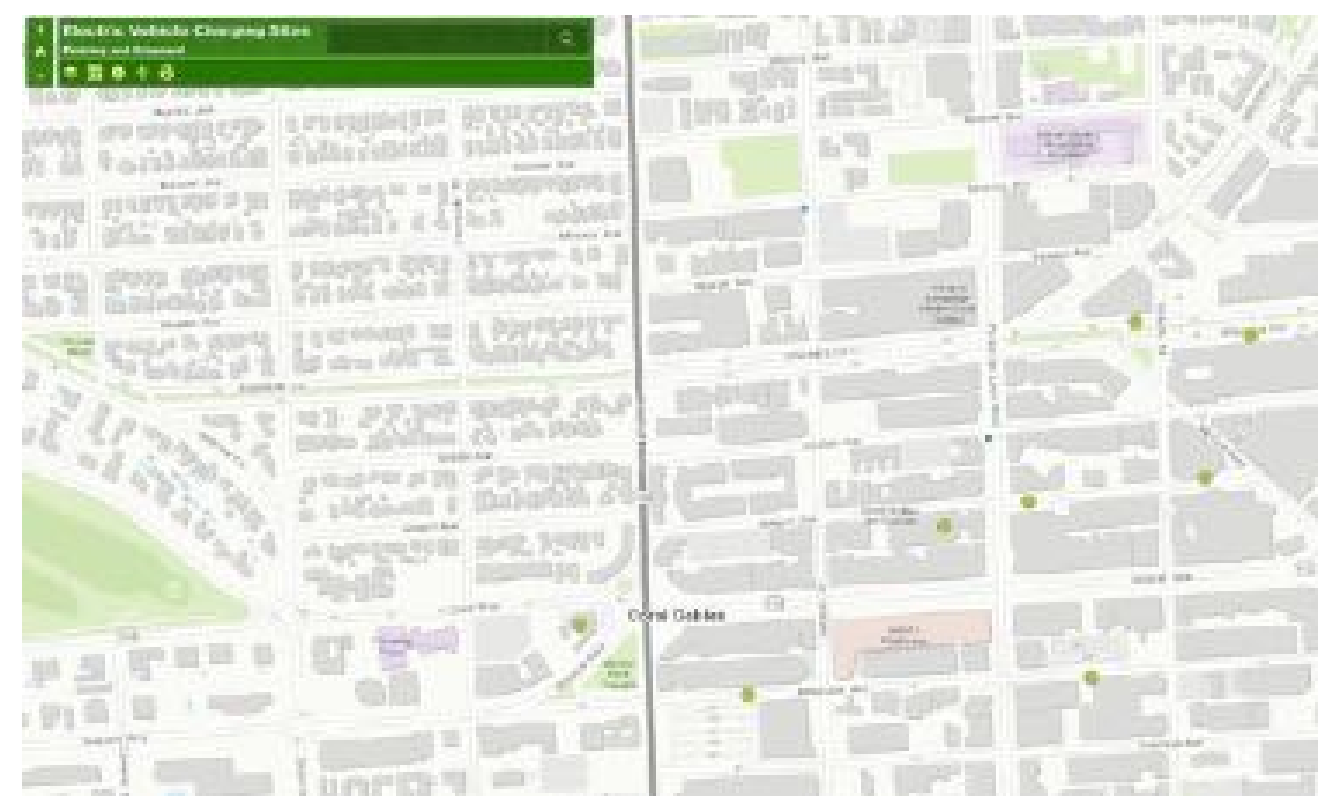

Plate 27. Electronic vehicle charging station locations. Source: Coral Gables website.

\section{Historic Preservation}

The history of Coral Gables was a fundamental subject of public policy discussions. Elected officials and staff routinely evaluate current issues within the context of past practice. Furthermore, residents and visitors are interest in learning about Coral Gables, its story and its heritage. Smart strategies provide information in various graphic and mapping formats.

Plate 28 provides a historic tour of the city. The tour would serve as an introduction to Coral Gables for interested visitors. It would also be an effective bureaucratic tool, as it displays historic buildings in the context of place. Thus, decisions about renovations or demolitions can be reviewed thoroughly. In addition, smart strategies promote democracy, as all information is public. 


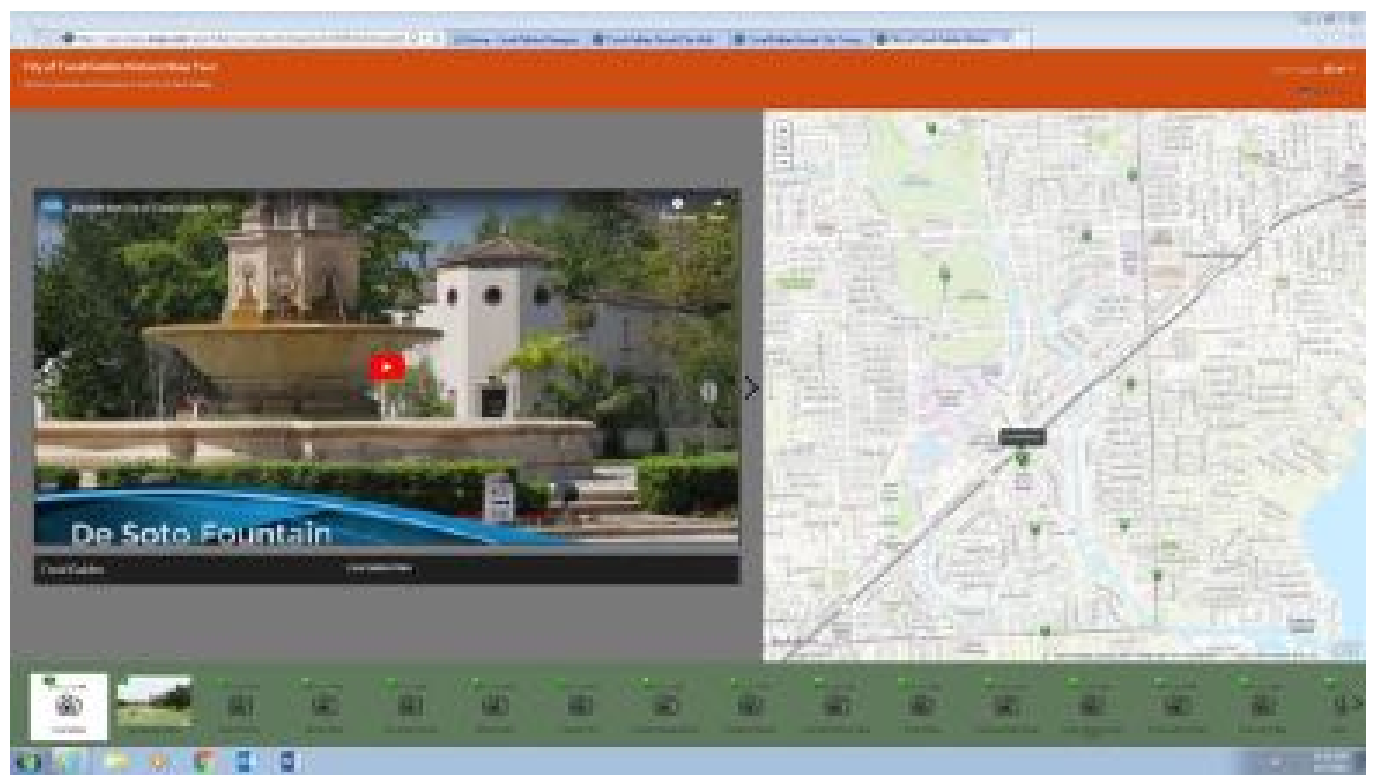

Plate 28. Historic preservation page. Source: Coral Gables website.

E. Development projects

Data on approved projects have the greatest impact on a community, invite public scrutiny and summarize the process of bureaucracy of place. Smart strategies promote accessibility for dynamic information, in the form of maps and updated project data.

Interested members of the public have a better understanding of changes in the community and can effectively influence outcomes. Research concluded that opposition to development projects is caused in part by incomplete information. Correct and complete information would enhance democracy of place.

Transparency about process and content should contribute to governance.

Plate 29 is an example of the display of development information, which can be updated dynamically, and could be linked to additional municipal data and media content. 


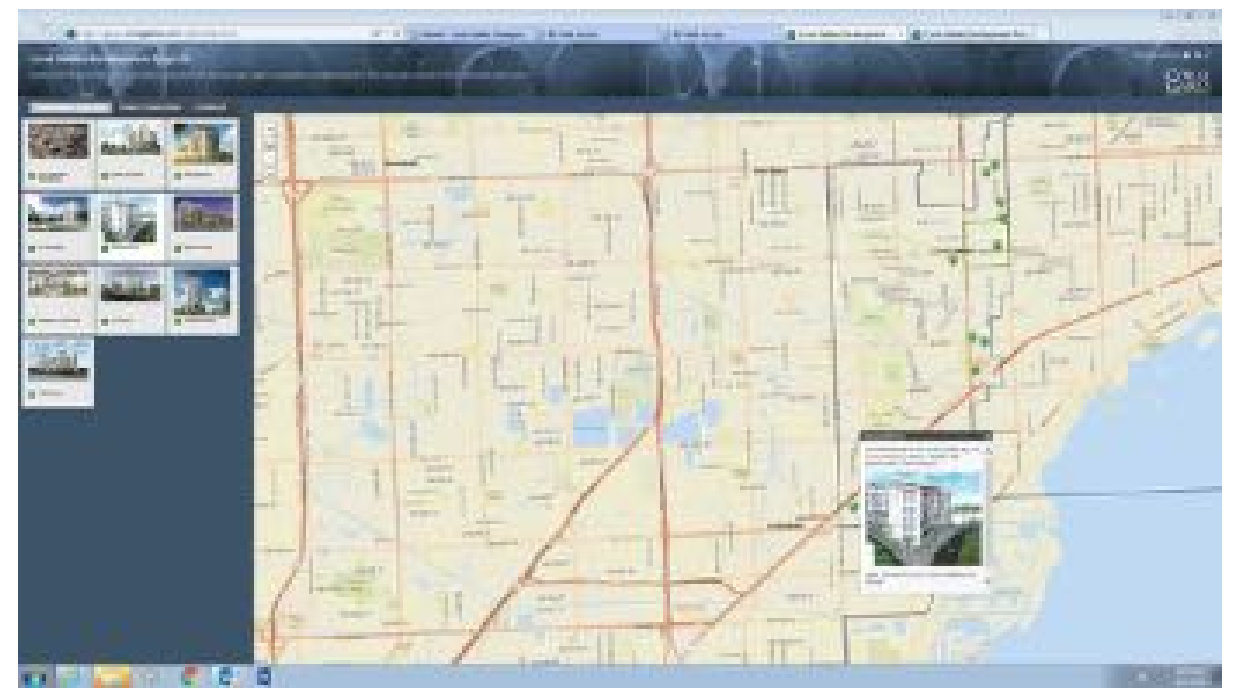

Plate 29. Current development projects. Source: Coral Gables website.

Current projects were represented by a rendering linked to a GPS map. Extensive information about project data and status was available and could be updated as conditions changed. For example, status reports could be generated about approval or construction process. Questions from the public could be answered directly, with a simple graphic interface.

F. Resident communication

Smart strategies were most effective for enhancing transparency and promoting democracy of place. Communications with residents had been a priority of city administrators. New media expanded the opportunities to discuss process and content and minimize concerns about lack of notice. In addition, new tools allowed better quality information, as video and dynamic formats enhanced the user experience. Plate 30 is a typical example of public information about renovations for a city park. 


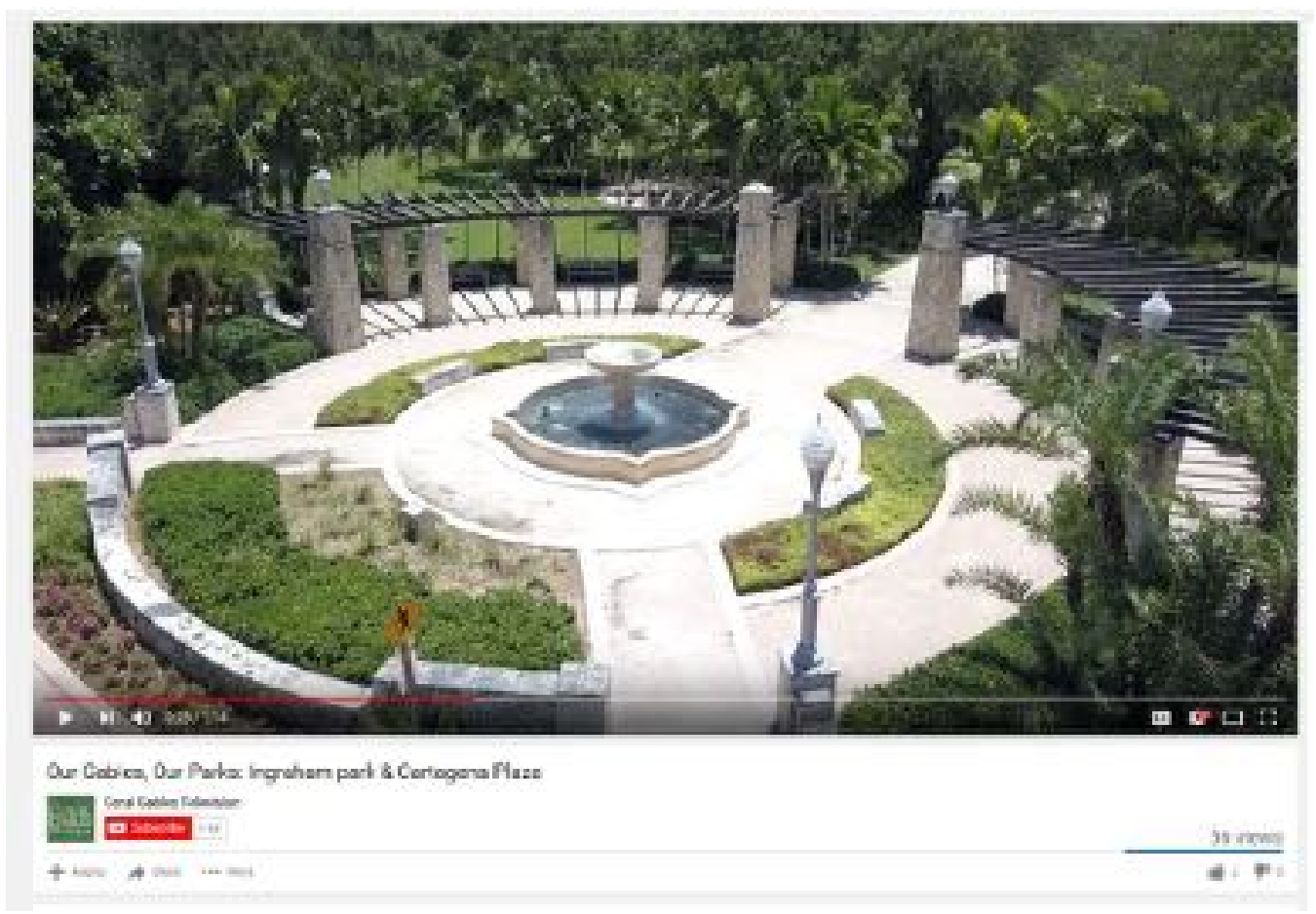

Plate 30. Parks page. Source: Coral Gables website.

\section{From Visual Preference to Smart Data about Place}

Literature on visual preference represents the earliest attempt at defining place in terms of data. Late $20^{\text {th }}$ century practitioners proposed best practices for democracy of place, in ways that emphasized content. At the time, information was displayed with twin carousels of comparable slides. The technique depended on professional expertise for interpretation and analysis. Thus, public perception could not be informed by objective data. As a result, politics often overwhelmed democratic processes, and governance would depend on the resolution of conflict. "NIMBY" (not in my backyard) was a term of that time for opposition to development, based on a political response to incomplete information. Many public planning efforts ended because of such opposition. 
Transparency and responsiveness would enhance democracy and bureaucracy. That is the precise contribution of smart data to place. Contemporary tools allow the following:

1. Continuous input

Organized public events for the purpose of collecting data are less necessary. A spectrum of public participation modes would be implemented, and lead to more informed residents and decision-makers.

2. Verification of policy choices

Data can be used to measure performance. Policy can be calibrated, based on analysis of data.

3. Transparency of development proposal

Data is publicly available on real time, and for the future and into the past.

Local democracy and bureaucracy have been often misunderstood because past

information about local governance tended to be incomplete and ambiguous. Once place is understood in terms of public and comprehensive data, quality of life would be clearly linked to policy and implementation. In the end, smart place should lead to an enhanced understanding of democracy and bureaucracy of place and resident satisfaction with public administration.

\section{Findings}

1. Coordinated Smart City initiatives should support processes for the implementation of place.

2. Dynamic and transparent data should inform policy and implementation, which enhance democracy and bureaucracy of place. 


\section{CHAPTER IV}

\section{RESULTS}

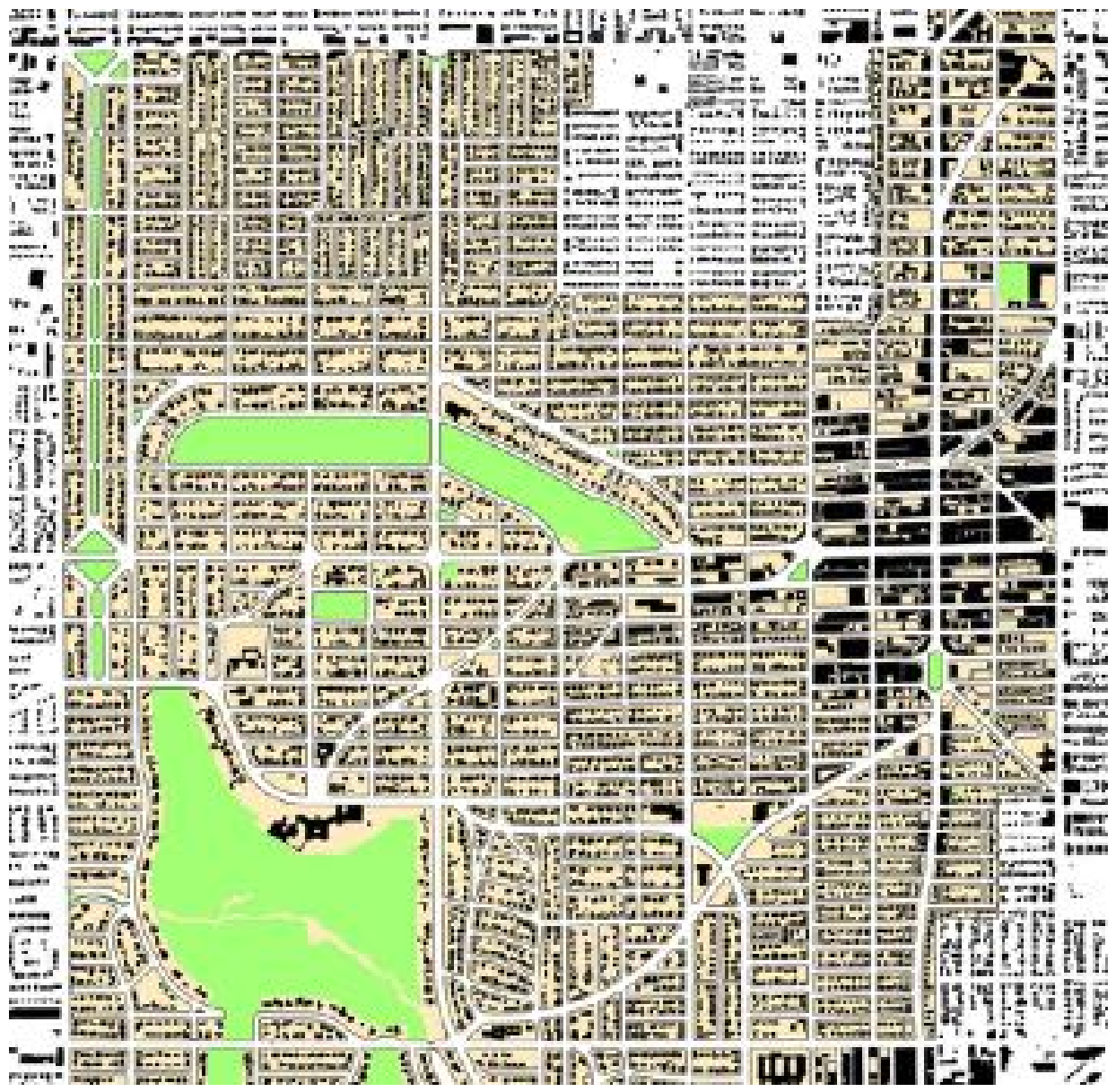

Plate 31. Coral Gables development, existing conditions, 2016. Source: City of Coral Gables 


\section{Qualitative Interviews on Place}

\section{Research Question}

What is the role of content and best practices for design in contemporary practice and local governance?

\section{Introduction}

Table 3 summarizes the people, subjects and topics of formal qualitative interviews performed during the data gather phase of research.

\begin{tabular}{|c|c|c|c|}
\hline Person & Date & Affiliation & Role \\
\hline Max Bernal & $10-16-18$ & $\begin{array}{l}\text { Coral Gables, } \\
\text { Staff }\end{array}$ & $\begin{array}{l}\text { Clerk, customer service for } \\
\text { Board of Architects }\end{array}$ \\
\hline Chuck Bohl & $4-9-19$ & $\begin{array}{l}\text { University of } \\
\text { Miami, } \\
\text { Professor }\end{array}$ & $\begin{array}{l}\text { National expert on real } \\
\text { estate education }\end{array}$ \\
\hline Dan Burden & $4-27-15$ & Consultant & $\begin{array}{l}\text { National expert on public } \\
\text { participation }\end{array}$ \\
\hline Judy Carty & $10-20-18$ & Architect & Chair, Board of Architects \\
\hline Devin Cejas & $3-25-19$ & $\begin{array}{l}\text { Miami, } \\
\text { Zoning official }\end{array}$ & Implemented Miami21 \\
\hline Victor Dover & $10-4-18$ & Planner & $\begin{array}{l}\text { National expert on New } \\
\text { Urbanism }\end{array}$ \\
\hline $\begin{array}{l}\text { Jose Gelabert- } \\
\text { Navia }\end{array}$ & $2-25-16$ & Architect & $\begin{array}{l}\text { Developed Mediterranean } \\
\text { bonus program }\end{array}$ \\
\hline
\end{tabular}




\begin{tabular}{|l|l|l|l|}
\hline Jorge Hernandez & $2-2-16$ & $\begin{array}{l}\text { University of } \\
\text { Miami, } \\
\text { Professor } \\
\text { Architect }\end{array}$ & Practitioner of \\
& & Mediterranean architecture \\
\hline Peter Iglesias & $2-20-19$ & $\begin{array}{l}\text { Coral Gables, } \\
\text { City Manager }\end{array}$ & Public administration \\
\hline Carlos Mindreau & $10-15-18$ & $\begin{array}{l}\text { Coral Gables, } \\
\text { City Architect }\end{array}$ & Board of Architects staff \\
\hline Arva Parks & $1-14-16$ & Historian & Author of Merrick's \\
& Zyberk & $10-11-18$ & University of \\
Rodolpho & Miami, & Edited book on Coral \\
\hline Leonard Roberts & $2-26-16$ & Former Dean of & Gables \\
\hline Sam Poole & $10-20-18$ & Retired Attorney & Author of article on design \\
& & $\begin{array}{l}\text { Economic } \\
\text { Architecture }\end{array}$ & Review \\
\hline
\end{tabular}

Table 3. Persons interviewed by Ramon Trias. 
Interviews were conducted during a period of three years with individuals who had knowledge or expertise on issues related to the administration of place, and were familiar with Coral Gables, FL. Each interview lasted approximately one hour. Questions dealt with public subjects only, as applied to the theory and practice of public administration. No personal questions were asked, nor personal data were collected. Interviews were transcribed and reviewed several times during the preparation of this study.

Each interview was designed for the expertise of each participant. They were unstructured and followed grounded theory methods. They were conducted after a majority of literature and archival research was completed. The objective was to gain insight into theory and best practices, from the framework established by the research questions. Additional informal conversations with a limited number of experts mentioned in the manuscript also provided data for research.

All subjects were informed about the goals and scope of the project and consented to participate. Florida International University waived the IRB (Institutional Review Board) process, as all data and information were public or addressed public topics related to local governance.

The following topics were discussed:

1. Literature review on Coral Gables

Literature review identified a discrete number of publications that addressed content of Coral Gables. Some of the original authors were interviewed and provided a new perspective on their work, at times several decades after publication. Plater-Zyberk (2018) commented on her experience as editor of Coral Gables: An American garden city 
(Behar, Culot, 1997) when she was Dean of the University of Miami's School of Architecture. Poole (2018) commented on his law journal article Architectural appearance review regulations and the first amendment: the good, the bad and the consensus ugly (1987) published shortly after graduation from law school.

Poole and Plater-Zyberk emphasized the education of the architect as the most significant factor in the success of place. This opinion was framed in the contrast of best practices from the 1920's and contemporary practice, and the focus on precedents and didactic content.

\section{Coral Gables Board of Architects process}

Several professionals involved in the operations of the Board of Architects provided comments on bureaucratic processes. Mindraeu (2018) and Bernal (2018) contributed contrasting perspectives on bureaucracy, from the perspective of staff. Carty (2018) reflected on her experience as Chair of the Board of Architects. The role of staff and the role of the Board were contrasted. Discussion highlighted the democratic aspects of the process, such as open meetings, notice and public comments. The use of content was discussed, in terms of Mediterranean architecture and other styles listed in the zoning code. The key finding was that the Board of Architects implemented democracy and bureaucracy of place.

3. Miami21, a zoning code based on new urbanism theory

As an adopted example of zoning reform based on New Urbanism theory, the experience of Miami21 provided insights on best practices. Cejas (2018) provided input as a former zoning director in the City of Miami. In his view, zoning reform was less important than proper implementation of adopted regulations. The role of content was 
emphasized in the Coral Gables zoning code, and less relevant in Miami21. However, Miami21 had improved predictability of massing and intensity, and elevated aesthetic expectations.

4. Mediterranean architecture in Coral Gables

Parks (2016), Gelabert-Navia (2016) and Hernandez (2016) provided complementary perspectives as a historian, a participant in zoning reform and an architect in private practice. These interviews focused directly on the role of content for place in Coral Gables.

Parks also discussed her recent book on Merrick, George Merrick: son of the southern wind (Parks, 2015). Moreover, she reflected on her early involvement of the discussions about Mediterranean architecture for new buildings in Coral Gables, and the role of Merrick's vision through time. Parks observed that Merrick's Mediterranean aesthetic was lost for several decades in the mid-twentieth century. Gelabert-Navia commented on his experience as a proponent of the Mediterranean bonus program in the 1980's and confirmed that the list of exemplary buildings had been included at the request of the City Commission upon recommendation from staff, to clarify the content of the ordinance. Hernandez compared design for houses and large mixed-use buildings, in the context of Mediterranean architecture, from the point of view of a practicing architect. He also described professional practice challenges of the application of content. In addition, Hernandez was a professor of the University of Miami's School of Architecture, and he offered insight into the education of the architect and offered commentary on best practices from the 1920's

5. Public participation 
Bohl (2018) and Plater-Zyberk (2018) discussed public participation, and the experience of the Coral Gables charrette of 2002, which was led by them and resulted in significant discussion about content and bureaucracy. They also discussed shortcoming of current democratic discussion about place. Burden (2016) explained his use of Coral Gables as an example in his national practice as a facilitator of civic participation processes and his experience with generalizing local ideas for use throughout America.

6. New Urbanism

Plater-Zyberk (2018), Dover (2018) and Bohl (2019) provided insight on New Urbanism theory and practice. Plater-Zyberk confirmed the inspirational role of Coral Gables in early New Urbanism. Dover explained the emphasis on participation in town planning practice. Bohl, as a professor of real estate, also explained the focus of New Urbanism on private sector projects, and the role of the public sector as a facilitator and regulator of development.

7. Public administration and city management

Iglesias (2019) discussed public administration challenges from his experience as former assistant city manager in Miami and Coral Gables City Manager. He observed a significant difference in the use of place in Miami and Coral Gables. He supported the use of smart strategies to implement quality design and planning. Roberts (2016) provided insight into the economic development aspects of place and the synergy between real estate and bureaucracy.

8. Smart city initiatives

Rodulfo (2019) explained Coral Gables smart city initiatives and provided context for best practices. For instance, dynamic data was available to measure pedestrian traffic 
in real time and he encouraged additional use of smart tools for planning and zoning. Work on innovative applications continues under Rodulfo's leadership.

Lopez (2019) explained the use of innovative tools for historic documentation.

He led a team of University of Miami students in the documentation of City Hall for the Historic American Building Survey. The experience developed innovative smart tools for historic preservation. Iglesias (2019) explained his administrative vision for the use of technology in local government.

Education for professionals was a consistent concern among many interview subjects (Plater-Zyberk, 2018), (Poole, 2018), (Dover, 2018). Effective application of content required education, as experts believed that current practice lacked information about preferred design concepts and effective town planning principles. These ideas had formed the core of New Urbanism theory, as stated in the New Urbanism Charter. However, education reform would be an ambitious topic beyond the scope of the study. Nevertheless, analysis of qualitative input led to the conclusion that education should be understood as training on best practices.

Several recent publications were profoundly didactic (Tachieva, 2010), (Dover, Massengale, 2014), (Duany, Plater-Zyberk, Speck, 2000) and were formatted to inform best practices. For example, Suburban nation included a "Traditional Development Checklist" and the Charter of the New Urbanism appendices. Both documents promoted the language of New Urbanism, neighborhood, district, block, street, all terms of art that transcended vernacular use. The Charter mentions "placeless sprawl" as a problem. It fails to speak of place as a solution. Updated theory should propose smart place as the preferred alternative to placeless sprawl. 


\section{Qualitative Findings for Enhanced Best Practices}

Methodical research on best practices for design of place has been rare, as anticipated by literature review. Nevertheless, interviews with academics (Plater-Zyberk, 2019), (Bohl, 2019), (Hernandez, 2016) and practitioners (Poole, 2018), (Dover, 2018) revealed an interest in new approaches to theory and a need to explore evidence-based methods in design disciplines, with comparable rigor to standard methods from social sciences. Moreover, this research should emphasize administration and implementation as aspects of design. However, as the experts interviewed where mainly practitioners even when they also held academic appointments, contributions to academic literature would require collaborations with additional scholars.

Education for professionals was a consistent concern among many interview subjects (Plater-Zyberk, 2018), Poole (2018), Dover (2018). This was the most critical role for content, as experts believed that current practice lacked information about preferred design concepts and effective town planning principles. These ideas had formed the core of New Urbanism theory, as stated in the New Urbanism Charter. However, an evaluation of the effectiveness of education would merit further research. Although it was reasonable to assume that better trained professionals would implement better places, this view overlooked the role of aspirational content on democracy and bureaucracy. In other words, qualitative findings revealed that the role of public administration required additional consideration.

Smart City initiatives were researched (Rodulfo, 2019). However, many ideas are at an early stage of development and address routine issues, where data enhances 
efficiencies. Although data was abundant, and much data could be used of understand place, planning and zoning issues were not at the forefront.

\section{Findings}

1. Mediterranean architecture could be understood as a proxy for content in Coral Gables. However, generalized content also included other variables related to the implementation of place.

2. Smart strategies have expanded tools for democracy and bureaucracy of place but have not reached their full potential in the early $21^{\text {st }}$ century.

3. Education about content of place would enhance professional practice. Best practices for continuing professional education should include instruction on smart place.

4. Effective professional practice would require best practices for democracy and bureaucracy, topics that could be discussed more effectively in professional education with the support of robust theory.

5. New urbanism and Miami 21, a form-based code, have contributed reform ideas for democracy and bureaucracy of place, with new tools for public participation and zoning regulation.

6. The Coral Gables board of Architects process implements content of place though democratic and bureaucratic steps.

7. Smart city initiatives should center on place. 


\section{Zoning the City Beautiful}

\section{Research Question}

What was the evolution of zoning language related to aspirational content for place in Coral Gables?

\section{Conventional Zoning Practice}

The zoning code has been a standard tool for local administration of place since the late 1920's. Research was performed on Coral Gables zoning, by deconstructing regulatory language. Codes evolve through time, often with incremental amendments which have cumulative effects, at times unpredictable. The meaning of zoning code content should be reviewed comprehensively, as it changes through time.

Typical zoning amendments implement policy priorities of elected officials or the private interest of an applicant. Although drafting and considering amendments triggers democratic and bureaucratic procedures, the process seldom reviews the effects on the civic aspirations of the community, beyond cursory compliance with the Comprehensive Plan. However, conventional planning and zoning could also be implemented with outstanding emphasis on aspirational content of place. Unfortunately, typical bureaucratic practice does not emphasize content or democratic discussion, beyond the requirements of the law.

Nevertheless, methodical review of the evolution of zoning language has been overlooked as a tool for analysis of place. Zoning is expressed as language, and language can be deconstructed. Each clause is designed to regulate one issue and could be interpreted as data. A close reading of the meaning and intent behind language related to content should lead to a coherent vision. All zoning regulations should collectively 
implement the future goals of the community, as stated on the adopted Comprehensive Plan.

The process of conventional planning and zoning would be complex and was designed with multiple opportunities for failure. As Coral Gables implemented an early zoning code in 1930 and staff, the Planning and Zoning Board and the Commission reviewed and adopted countless revisions since that time, research could inform best practices.

\section{An Early Zoning Code, Coral Gables in 1930}

The master plan and aspirational ideas that would guide the implementation of Coral Gables' early vision were firmly established prior to the adoption of the first zoning code. Nevertheless, the language of zoning would become the principal tool for the implementation of place. Findings revealed that Coral Gables successfully transformed aspirations into actionable content, with the administrative tool of a conventional zoning code.

The first zoning code, adopted in 1930, stated as one of its purposes "architectural beauty and harmony" (Coral Gables Zoning Code adoption ordinance, 1930). However, aspirational language about beauty and harmony required specific content and an administrative process to be effective. Both content and process were addressed with language, which was sufficient at the time, given best practices of the 1920's discussed in the Literature Review chapter.

The code established a "supervising architect" who would review and approve all buildings. The architect would provide a process of review, but also content from 
professional expertise. This framework would evolve through time, but the general concept would not change.

Professional oversight was an administrative practice that dated to the earliest implementation of Coral Gables, as Merrick had set up a design studio prior to incorporation. Implementation of aspiration content required expertise. Zoning language had a bounded role, to be supplemented by professional review. This important concept would be lost in conventional zoning practice of the $20^{\text {th }}$ century, as codes evolved towards ever increasing description of legal considerations and away from civic vision and aspirational content.

Section 17 of the 1930 zoning code established the office of the supervising architect. There were three qualifications, which reflected that content should be interpreted professionally when a building permit is under review:

1. 10 years of experience

2. Professional registration in Florida

3. Membership in the American Institute of Architects

Every permit would be submitted to the supervising architect, who would review the project for compliance with zoning requirements and for "harmonious architectural construction of buildings in the subdivision or section in which such land in located" (Zoning Code, 1930). The architect would "suggest or recommend such changes in said plans and specifications as in his judgment may also be requisite or appropriate to the maintenance of a high standard of construction, architectural beauty and harmony" (Zoning Code, 1930). 
Sufficient guidance for aesthetic content was provided with a few words, as best practices from the early $20^{\text {th }}$ century would guide all professionals involved in each project. Section 18 established unique architectural style districts. These areas were 8 villages of unique design. The brief language included in the zoning code would be read in conjunction with appropriate design manuals. Each style had accepted aesthetic conventions. The specific meaning of "Dutch South African" or "Chinese" would be determined by the professionals involved in design and review. Early zoning was intended to be iterative and aspirational.

Best practices of the time included the consultation of reference folio books that provided relevant examples of each style (Plater-Zyberk, 2018). The books reproduced measured drawings, analytic diagrams and photographs of exemplary buildings, catalogued by style. This practice was also common in professional journals.

During the 1920`s Pencil Points was a practical publication for use in the drafting room, and a majority of the content was educational. Thus, terms such as Mediterranean, Spanish or Northern Italian would be understood with precision by professionals. Such terms of art were signs, with unambiguous meaning.

A professional library supplemented sparse zoning language. Common reference folio books could be highly specialized or absurdly modest, such as Lesser known architecture of Spain (Yerbury, 1925). The publications were practical and didactic. From the point of view of $21^{\text {st }}$ century practice, the content was intended to be copied. However, in the trained hands of a 1920's architect, the content was reinterpreted and calibrated to match local aspirations for place. 
Such practices would be lost by the mid-century, as modern theory influenced by positivism decried style in favor of abstract criteria which could be measured. Late $20^{\text {th }}$ attempts at codifying style would result in verbose statements or simplified guidelines, with poor outcomes.

Zoning theory and practice for most of the $20^{\text {th }}$ century did not emphasize place. Review of relevant precedents and professional interpretation of design intent of exemplary models by architects were practices anticipated by the zoning code in the 1930’s. Zoning language was not expected to predict the nuances of aesthetic choice. Moreover, the zoning code required and promoted a robust and independent process of review, to verify an adequate level of execution.

The approach of the Coral Gables code, which provided direct language about style and required professional review, would contrast with codes from the late $20^{\text {th }}$ century which would establish prescriptive guidelines. Contemporary Coral Gables practitioners considered design guidelines to be an inferior process, as prescriptive zoning language would not be sufficient, in isolation, for the implementation of quality architecture (Plater-Zyberk, 2018). Place was the outcome of aspirational content implemented with design thinking, and findings from Coral Gables research provided practices for the practical implementation of place.

\section{Chronological Data on Coral Gables Zoning Code, 1930-2007}

After initial adoption in 1930, the Coral Gables zoning code had eight major versions and countless minor revisions. All revisions followed conventional planning and zoning practice. Although some early emphasis on content was lost through the years, most of the superior features of the code proved resilient. 
Major versions were implemented as summarized in table 4.

\begin{tabular}{|c|c|c|}
\hline Date & $\begin{array}{l}\text { Ordinance } \\
\text { Number }\end{array}$ & Major topics, as listed on ordinance title \\
\hline 12.15 .1930 & No. 153 & $\begin{array}{l}\text { Location of trades and industries } \\
\text { Location of buildings for dwellings, apartment } \\
\text { houses, trades, industries and other specified uses } \\
\text { Height and size of buildings } \\
\text { Intensity of use of lot areas } \\
\text { Building lines } \\
\text { Creation of Board of Appeals } \\
\text { Creation of office of Supervising Architect } \\
\text { Purpose: Preserve property values and general } \\
\text { prosperity through the maintenance of a high } \\
\text { standard of construction and architectural beauty } \\
\text { and harmony. }\end{array}$ \\
\hline 2.16 .1937 & $\begin{array}{l}\text { No. } 271 \\
\text { (Revised in 1947) }\end{array}$ & $\begin{array}{l}\text { Erection, reconstruction, alteration of buildings, } \\
\text { structures and water or land for trade } \\
\text { Size of buildings, erected or altered } \\
\text { Size of yards, courts and open spaces } \\
\text { Percentage of lot that may be occupied } \\
\text { Density of population } \\
\text { Districts to impose regulations and restrictions }\end{array}$ \\
\hline
\end{tabular}




\begin{tabular}{|c|c|c|}
\hline & & $\begin{array}{l}\text { Office of supervising architect, associate } \\
\text { supervising architect and structural engineer } \\
\text { Permit fees } \\
\text { Purpose: General prosperity through appropriate } \\
\text { land use and buildings and maintenance of a high } \\
\text { standard of symmetrical architectural design and } \\
\text { construction }\end{array}$ \\
\hline 8.7 .1956 & No. 988 & $\begin{array}{l}\text { Rearranging and renumbering and amending } \\
\text { adopted regulations } \\
\text { Incorporate district and use maps } \\
\text { Creation of a Zoning Board of Appeals }\end{array}$ \\
\hline 2.5.1957 & No. 1005 & Creating Zoning Board and Board of Architects \\
\hline 6.30 .1965 & No. 1525 & $\begin{array}{l}\text { Incorporate amendments though } 1965 \\
\text { Creating Planning and Zoning Board and Board of } \\
\text { Architects }\end{array}$ \\
\hline 1.9 .2007 & No. $2007-1$ & $\begin{array}{l}\text { Regulations for city commission and boards, } \\
\text { including Planning and Zoning, Board of } \\
\text { Adjustment, Historic Preservation, Code } \\
\text { Enforcement, Development Review Committee. } \\
\text { Development review procedures, including } \\
\text { conditional uses, planned area developments, } \\
\text { moratoriums, variances, subdivisions, transfer of }\end{array}$ \\
\hline
\end{tabular}




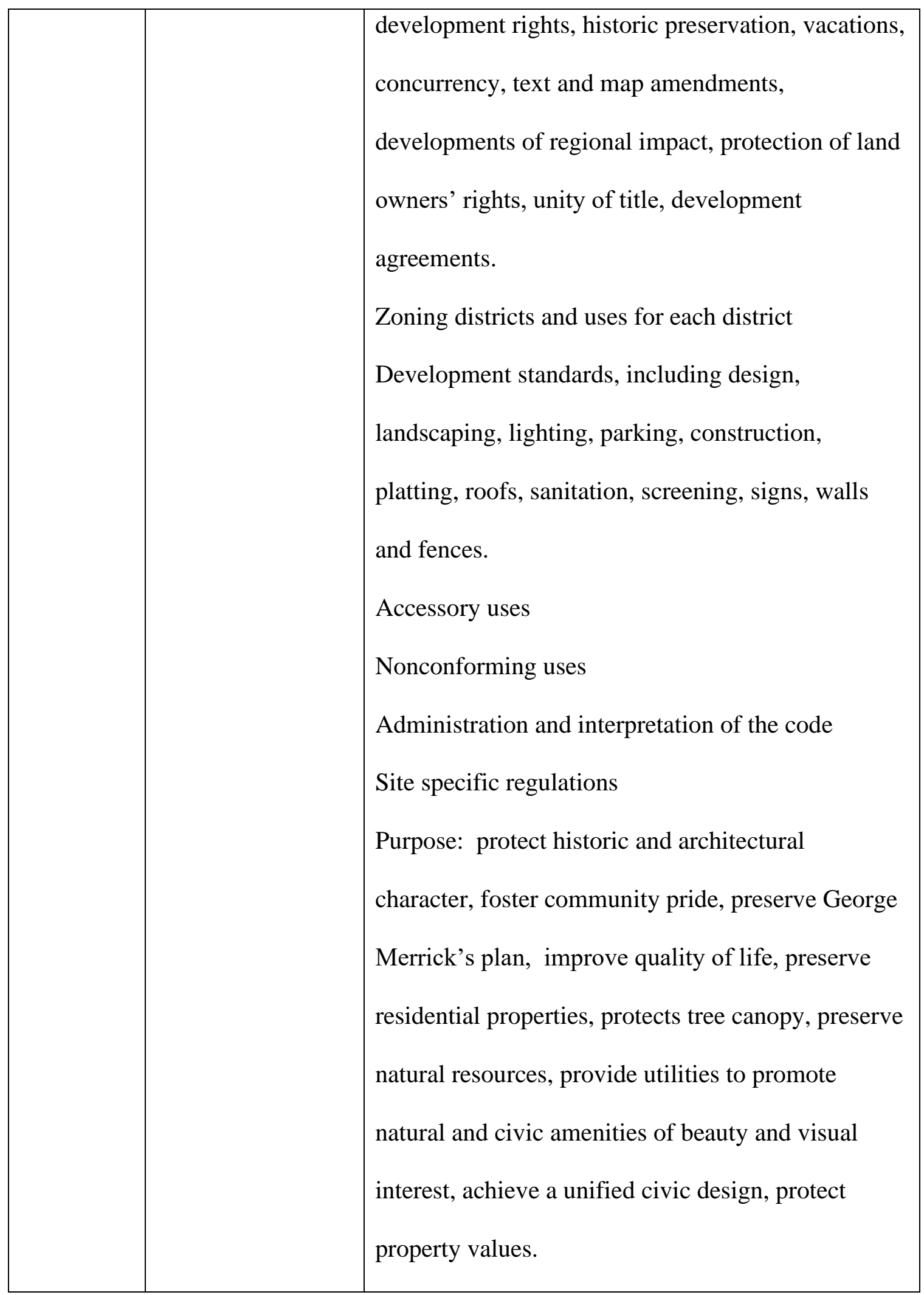

Table 4. List of Coral Gables zoning ordinances. Source: City of Coral Gables. 
In addition, from 2007 to 2018 the code was amended 123 times (Coral Gables zoning code, 2018). The range of topics was vast, from corrections to new programs, such as "Art in Public Places (2008)," "Metal roofs (2009)," "Mixed-use district (2011)." "Shared parking (2016)," and "Electric vehicle charging stations (2018)." This level of activity illustrated the fact that a zoning code is always a work in progress. It also demonstrated the limits of a code as a tool for the implementation of policy. The list of recent amendments revealed the fragmentary nature of regulation of place under conventional planning and zoning methods. Coherent direction about content would be an administrative challenge, as narrowly focused incremental change may result in unforeseen consequences.

The chronology demonstrated that Coral Gables zoning quickly evolved beyond simple Euclidian notions of separation of use and limited design standards. Such evolution would be common to zoning codes through the $20^{\text {th }}$ century, as increasingly complex techniques, such as parking requirements by use and performance-based zoning for area calculations and lot coverage would be introduced progressively to local government administration. However, in the Coral Gables zoning code aspiration content was always a core concern. Moreover, multiple rewritings related to content demonstrate a significant investment of time and effort in the administration of aesthetics.

Two characteristic ideas, unusual in conventional zoning practice, evolved through time:

1. Aesthetic architectural requirements

2. Professional review of architecture 
Aesthetic standards were always aspirational and adopted through a democratic process. An initial goal of the principal administrative tool, the zoning code, was "architectural beauty and harmony." The method established to achieve this goal relied on bureaucracy, in the form of staff review.

\section{Deconstructing Aesthetic Content}

In terms of content related to design, language about architecture introduced by the Coral Gables zoning code of 1930 and modified through the 1980's was precise, in the context of early $20^{\text {th }}$ century best practices of architecture. A detailed review of the internal evolution of zoning language, deconstructed through addition and subtraction and the evolution of meaning, outlines the practical application of content to bureaucratic tools.

At first, the preferred style was named "Spanish," and was to be used in all areas except the industrial district and the villages. The villages had unique aesthetic requirements, which had been previously regulated through deed restrictions. The zoning code did not attempt to describe the features that would comply with the style. Compliance would be determined by the Supervising Architect, upon review.

Contemporaneous professional publications on particular architectural styles were in common use by architects for reference, a professional practice that clarified the design intent of adopted code language. Several books used in the design of buildings in Coral Gables during that decade are listed in the reference section. Architects of the 1920's used the publications routinely for reference. The folio books enhanced the quality of architecture, regardless of the individual abilities of local practitioners. In the 1970's this best practice was rediscovered (Plater-Zyberk, 2018). 
In 1951, the term "Spanish" was expanded to "Mediterranean." Mediterranean did not imply architecture from the shores of the Mediterranean sea, or an imprecise suggestion at the discretion of each architect. On the contrary, it was a term of art to be understood as a vernacular style of Coral Gables, developed from a foundation of Spanish aesthetics, with added influences. In the 1980's the Coral Gables Mediterranean style would be codified with eight exemplary local buildings, listed individually in the zoning code.

In the 1950's and 1960's other styles were listed by name. This level of precision was unusual in an American zoning code, and had its origin in deed restrictions imposed by George Merrick, as he sold buildable lots in the 1920's.

The specific amendments listed in table 5 track the codification of aspirational content into administrative language, with strikethrough and underlined text, which record removed language and new language.

\begin{tabular}{|c|c|}
\hline 1930 & $\begin{array}{l}\text { All buildings must be of "Spanish Type," except: } \\
\text { - Where an M Use (Industrial) is permitted } \\
\text { - Villages or other deed-restricted areas }\end{array}$ \\
\hline 1951 & $\begin{array}{l}\text { All buildings must be of "Spanish, Venetian, Italian, or other } \\
\text { Mediterranean or similar harmonious type architecture," except: } \\
\text { - In the Industrial, McFarlane, Golden Gate sections } \\
\text { - In the Biltmore section and Addition (Modernistic type houses } \\
\text { permitted) } \\
\text { - Riviera section (One block permitted Dutch Colonial) }\end{array}$ \\
\hline
\end{tabular}




\begin{tabular}{|c|c|}
\hline & $\begin{array}{l}\text { - Villages or other deed-restricted areas } \\
\text { - In Commercial districts }\end{array}$ \\
\hline 1965 & $\begin{array}{l}\text { All buildings must be of "Colonial, Spanish, Venetian, Italian, or other } \\
\text { Mediterranean or similar harmonious type of architecture," except: } \\
\text { - In the Industrial, McFarlane, Golden Gate sections } \\
\text { - In the Biltmore section and Addition (Modernistic type houses } \\
\text { - permitted) } \\
\text { - Riviera section (One block permitted Dutch Colonial) } \\
\text { - Villages or other deed-restricted areas }\end{array}$ \\
\hline 1983 & $\begin{array}{l}\text { All buildings must be of "classical style of Colonial, Spanish, Venetian, } \\
\text { Italian, or other Mediterranean or similar harmonious type of architecture," } \\
\text { except: } \\
\text { - In the Industrial, McFarlane, Golden Gate sections } \\
\text { - Riviera section (One block permitted Dutch Colonial) } \\
\text { - Villages or other deed-restricted areas } \\
\text { - In Commercial districts }\end{array}$ \\
\hline 1989 & $\begin{array}{l}\text { All buildings must be of "classical style of Colonial, Spanish, Venetian, } \\
\text { Italian, or other Mediterranean or similar harmonious type of architecture," } \\
\text { except: } \\
\text { - In the Industrial, McFarlane, Golden Gate sections } \\
\text { - Riviera section (One block permitted Dutch Colonial) }\end{array}$ \\
\hline
\end{tabular}




\begin{tabular}{|l|l|}
\hline & $\begin{array}{c}\bullet \quad \text { Villages or other deed-restricted areas } \\
\text { Mediterranean bonus program }\end{array}$ \\
\hline 2007 & $\begin{array}{l}\text { All buildings must be of "elassical style of a specific architectural style } \\
\text { such as but not limited to Colonial, Spanish, Venetian, Italian, or other } \\
\bullet \quad \text { In the Industrial, McFarlane, Golden Gate sections } \\
\bullet \quad \text { Riviera section (One block permitted Dutch Colonial) } \\
\bullet \quad \text { In Commercillages or other deed-restricted areas } \\
\text { Mediterranean bonus program }\end{array}$ \\
\hline
\end{tabular}

Table 5. Evolution of zoning language. Source: Coral Gables Zoning Codes 1930 - 2007.

Moreover, after 1989 the Mediterranean bonus program expanded aesthetic regulation.

\section{An Aspirational Zoning Code}

Research on Coral Gables zoning demonstrated the full potential of conventional planning and zoning, when aspirational content guides discussion. The code included some best practices for democracy and bureaucracy of place since 1930. It could be argued that the best code was adopted in 1930, at the start of American zoning practice, and that it was much more complex in revisions of the $21^{\text {st }}$ century, but not necessarily more effective. It should also be understood that administrative tools required constant 
refinement, as the long-term vision of the community evolved, and opinions changed through tine. Aspirations did not imply that quality outcomes were inevitable.

Analysis revealed that the regulation of aspirational content required two difficult features:

1. Actionable description of content

Content was expressed with zoning language, a conventional administrative tool. To be effective, aspirational ideas must be translated into administrative tools

2. Professional design and review

Regulations require interpretation. Quality outcomes would result from competent implementation, from initial design to permit review.

Both topics reflect a significant investment of time and resources, and political conviction through decades of change. Moreover, even when adequate tools and processes are available, quality outcomes are not guaranteed. Debate and disagreement should be expected. However, the Coral Gables experience and data demonstrate that the effort result in enhanced quality of life and general satisfaction with the development process.

\section{Findings}

1. Zoning language evolves incrementally, and the process is best when guided by aspirational content.

2. Language alone can never describe place comprehensively.

3. The impact of language on place may exceed original intent.

4. Design review supplements zoning regulations for the implementation of place. 


\section{The Coral Gables Mediterranean Bonus Program}

\section{Research Question}

How did the Mediterranean Bonus Program implement content of place?

\section{The Mediterranean Bonus Program, 1986-2007}

The Mediterranean Bonus Program was a postmodern example of the use of content in conventional planning and zoning. Architectural theory and practice of the 1920's often discussed buildings in terms of style, as evidenced in folio books from the period. In the later decades of the $20^{\text {th }}$ century precise language about style was less favored by architects. In its place there was an attempt to define quality in terms quantifiable abstractions. Moreover, elected officials and residents often expressed faith in the ability to regulate quality with prescriptive zoning language with negligible discretion.

This trend towards the implementation of aesthetic abstraction was applied in Coral Gables through discussions about "Mediterranean" architecture, as a way to enhance aesthetic quality. But the Coral Gables zoning code would never become a simplistic document. The code retained legacy language about multiple styles. In addition, the code also retained design review by the Board of Architects or the City Architect. Thus, superior provisions of the 1930 code would remain, slightly modified through time.

The new administrative tool was performance zoning. Thus, during the 1980's discussions would be focus on the meaning of "Mediterranean" and the public benefit of the incentives which encouraged specific design. Parks (2016) used the term “Mediterranean revival" during the 1980's and 1990's until she received new information 
during her research on Merrick's biography, published in 2015. A scrapbook on H George Fink, provided by his granddaughter, led Parks to understand the Coral Gables Mediterranean style as invented by Fink.

Parks proposed that the style was not a strictly a revival, but a local vernacular aesthetic inspired by professional literature, in the form of folio books from the early $20^{\text {th }}$ century. Finks' architecture studio was designed as a model home for a new aesthetic. His successful practice designed much of early Coral Gables. In 2016, the City of Coral Gables acquired the building for preservation. In 2018 Lopez (2018) and his University of Miami students prepared measured drawings of the Fink Studio, which were available for reference in the Coral Gables website, a smart strategy version of Fink's original intent.

Parks' conclusion did not dismiss other similar efforts from the same time at other locations. Mizner's work in Palm Beach or even Hatcher's work in Fort Pierce were also consistent with a building program led by aesthetic content. Parks (2016) believed they copied Coral Gables, as Fink's work predated comparable work by others. Regardless of authorship, Coral Gables represented the most effective and long-lasting implementation of the idea that content could shape place. Part of the reason is that in Coral Gables content was implemented through an effective administrative process.

The general concept of the Mediterranean bonus program was straightforward: buildings that followed Mediterranean architecture could be taller and larger than allowed by basic zoning regulations. The real estate value of the incentives, additional FAR and height, made the program a success. Most commercial buildings took full advantage. However, the quality of the architecture would be a source of debate, which demonstrated 
the challenges of translating aspirational content into conventional zoning language. Late $20^{\text {th }}$ century and early $21^{\text {st }}$ century architects were generally unfamiliar with best practices of the 1920's. Some believed they were sufficiently knowledgeable about style to design without references. Others disagreed with the concept of style and proposed a loose interpretation of the bonus program requirements. There were attempts at manuals of best practices, but the questions about correct style remained open.

The Mediterranean Bonus program was strictly a zoning tool. In other words, in spite of the name, the program was not structured in the form of design guidelines. Implementation of aesthetics would remain the responsibility of staff and the Board of Architects. Aesthetic choice would be based on precedent, analogous in concept to the use of picture books of the 1920's but regulated by zoning language and the Board of Architects process.

The bonus program was an expression of democracy as it was development and adopted though countless public meetings, which resulted in an extensive public record of citizen input and aspirations. Records of official meetings also memorialized significant debate and disagreements. Moreover, implementation during the Board of Architects process had remained contentious (Mindreau, 2018).

A review of building records proved it was a practical tool for bureaucracy, as most commercial buildings in the city built since the late 1980's followed the standards of the program. Coral Gables' innovative administrative tools implemented the aesthetic aspirations of elected officials, appointed boards and the community with the assistance of a staff of professional administrators. 
A review of the ordinances adopted by the Commission revealed the considerable effort required to adapt the language of design to the standards of administration. The bonus program was adopted in 1986 and revised significantly 13 times. Each revision reflected new information about content, debated publicly and adopted upon recommendations from experts. The Mediterranean bonus ordinance was not an isolated amendment to the zoning code. In Coral Gables, the Mediterranean bonus program would become a persistent democratic process for several decades, with the goal of bureaucratic implementation of aspirational content. It was always a work in progress, and the outcome was a business district designed to fulfil the aesthetic and functional aspirations of the community, as adopted in the zoning code.

Table 6 outlines the process of adoption.

\begin{tabular}{|c|c|c|}
\hline $\begin{array}{l}\text { Ordinance number } \\
\text { (year) }\end{array}$ & Subject & Major Topics \\
\hline 2632 (1986) & $\begin{array}{l}\text { Coral Gables } \\
\text { Mediterranean } \\
\text { Regulations }\end{array}$ & $\begin{array}{l}\text { Applicability to downtown } \\
\text { Elements of style, eight exemplary } \\
\text { buildings } \\
\text { Eligibility for bonus } \\
\text { Bonus table }\end{array}$ \\
\hline 2665 (1987) & $\begin{array}{l}\text { Height and off-street } \\
\text { parking allowances }\end{array}$ & $\begin{array}{l}\text { Bonus height of two stories (where three } \\
\text { are allowed) } \\
\text { Bonus height of three stories (where } 13 \\
\text { are allowed) }\end{array}$ \\
\hline
\end{tabular}




\begin{tabular}{|c|c|c|}
\hline & & $\begin{array}{l}\text { No parking required for buildings that } \\
\text { don't exceed } 1.45 \text { FAR }\end{array}$ \\
\hline 2714 (1987) & $\begin{array}{l}\text { Amendment of } \\
\text { Eligibility }\end{array}$ & $\begin{array}{l}\text { Eligible geographic area designated } \\
\text { Maximum bonus height defined in terms } \\
\text { of stories } \\
\text { Special provisions for projects abutting } \\
\text { single family properties }\end{array}$ \\
\hline $2740(1987)$ & $\begin{array}{l}\text { Amendment of } \\
\text { Eligibility }\end{array}$ & Additional eligible area designated \\
\hline 2766 (1988) & $\begin{array}{l}\text { Additional bonus for } \\
\text { mixed-use buildings }\end{array}$ & $\begin{array}{l}5 \% \text { reduction of required parking for } \\
\text { commercial and industrial uses }\end{array}$ \\
\hline 2990 (1992) & $\begin{array}{l}\text { Revised } \\
\text { architectural } \\
\text { standards and } \\
\text { bonuses }\end{array}$ & $\begin{array}{l}\text { Mediterranean style defined as element } \\
\text { of eight exemplary buildings, illustrated } \\
\text { by a guide. } \\
\text { Board of Architects review, and } \\
\text { approval required. } \\
\text { Bonus area defined more accurately } \\
\text { Notions of a chart with optional } \\
\text { requirements. }\end{array}$ \\
\hline
\end{tabular}




\begin{tabular}{|c|c|c|}
\hline 2992 (1992) & Clarifications & $\begin{array}{l}\text { Gross floor area defined } \\
\text { Design standards stated in more detail, } \\
\text { as to the elements of a building that } \\
\text { should be reviewed. }\end{array}$ \\
\hline 3006 (1992) & $\begin{array}{l}\text { Relationship to } \\
\text { single family houses } \\
\text { revised }\end{array}$ & $\begin{array}{l}\text { Buffers and walls required adjacent to } \\
\text { single family houses } \\
\text { Maximum height of } 2 \frac{1}{2} \text { stories next to } \\
\text { single family } \\
\text { Regulations for driveways and parking } \\
\text { areas }\end{array}$ \\
\hline 3243 (1997) & $\begin{array}{l}\text { Comprehensive Plan } \\
\text { amendments }\end{array}$ & $\begin{array}{l}\text { Future land use element, with emphasis } \\
\text { on pedestrian design for downtown, } \\
\text { aesthetic standards, neighborhood } \\
\text { character, preservation of Mediterranean } \\
\text { architecture and design. } \\
\text { Traffic circulation element, with } \\
\text { coordination of land use and traffic. }\end{array}$ \\
\hline 3350 (1998) & $\begin{array}{l}\text { Revisions on } \\
\text { eligibility, parking } \\
\text { requirements and } \\
\text { process of review }\end{array}$ & $\begin{array}{l}\text { New and existing buildings } \\
\text { (renovations) eligible. } \\
\text { Final approval by City Commission, } \\
\text { after Board of Architects and Planning } \\
\text { and Zoning Board review. }\end{array}$ \\
\hline
\end{tabular}




\begin{tabular}{|c|c|c|}
\hline 3374 (1999) & $\begin{array}{l}\text { Revisions to bonus } \\
\text { and special } \\
\text { allowances }\end{array}$ & $\begin{array}{l}\text { Allows off-site mitigation of landscape } \\
\text { requirements. } \\
\text { Allows setback reductions. }\end{array}$ \\
\hline 3375 (1999) & Revisions to height & $\begin{array}{l}\text { Maximum bonus height of } 2,3,4 \text {, or six } \\
\text { stories, depending on zone. }\end{array}$ \\
\hline $3559(2002)$ & $\begin{array}{l}\text { Corrections to } \\
\text { mixed-use } \\
\text { provisions }\end{array}$ & $\begin{array}{l}\text { Table with new requirements for style, } \\
\text { underground parking, retail on ground } \\
\text { floor, terracing, landscaping courtyards } \\
\text { and arcades. }\end{array}$ \\
\hline 2007-01 (2007) & New Zoning Code & Corrections and format changes \\
\hline
\end{tabular}

Table 6. List of regulations related to the Mediterranean bonus program. Source: City of Coral Gables.

\section{Aspirational Content beyond Aesthetics}

Although the intent of the ordinance was clear in terms of aspirational content, some of the language in the multiple amendments addressed topics of more general application. At times, issues unrelated to architecture or aesthetics, such as bicycle parking requirements, were added to the text. As the ordinance was considered and amended, more precise direction on aesthetics was needed.

Design preferences for larger buildings were summarized in the Mediterranean Bonus program, which started with general discussions in the mid 1980's. It was adopted in the zoning code in 1986 and refined with multiple amendments through the 1990's. At its essence, the program awarded additional height and FAR (floor area ratio) to buildings 
that satisfied specific design criteria. For instance, in the 2007 zoning code, all projects considered for the Mediterranean bonus program had to provide the elements in table 7.

Provide architectural elements on all building facades (no blank walls, parking garage treatments) Include architectural relief elements at street level (windows, landscaping, ornamentation, etc.) Provide bicycle storage facilities Incorporate vertical breaks, step backs or variations in bulk/massing of building facades Exclude vehicular access for drive through facilities on Alhambra Cir, Miracle Mile, and Ponce de Leon Blvd

Provide minimum landscape open areas as a percentage of total lot area (based on proposed use) Street lighting shall be provided and located on all streets/rights-of-way Ground floor parking shall not front on a primary street and is required to be surrounded by retail uses or residential units on secondary/side streets

Exclude porte-cochere access to/from Alhambra Cir, Miracle Mile, and Ponce de Leon Blvd Sidewalks/pedestrian access (requires pedestrian entrances be oriented towards adjoining streets) All buildings shall have their main pedestrian entrances oriented towards adjoining streets Structural soil shall be utilized within all rights-of-way for all street level planting areas Mediterranean buildings shall provide a minimum window casing depth of four (4) inches

Table 7. Mediterranean bonus program, standards of review. Source: Coral Gables Zoning Code.

Many of the bonus program criteria were abstract and technical, and deliberately crafted to avoid direct references to aesthetics. However, there were two levels in the bonus program and to achieve all the benefits, the building had to include elements from a select list of eight exemplary buildings, which dated to the 1920's. Table 8 lists the exemplary buildings, required by the zoning code to be used as models for Coral Gables Mediterranean style. 
H. George Fink Offices, 2506 Ponce de Leon Boulevard

The Colonnade Building, 169 Miracle Mile

Douglas Entrance, 800 Douglas Road

Coral Gables Elementary School, 105 Minorca Avenue

Granada Shops/Charade Restaurant, 2900 Ponce de Leon Boulevard (demolished)

San Sebastian Apartments, 333 University Drive

Coral Gables City Hall, 405 Biltmore Way

Biltmore Hotel, 1200 Anastasia Avenue

Table 8. List of exemplary buildings for Coral Gables Mediterranean style. Source: Coral Gables Zoning Code.

This practice echoed the design techniques promoted by the folio books of the 1920's. Architects were requested to study precedents and apply lessons learned to their projects. Although this was a common practice in the early twentieth century, architects from the early twenty first century often questioned the method. In fact, the panel of experts that recommended the process to the city commission did not include the list of buildings. The list was included at the request of the elected officials during a commission meeting, in an effort to clarify the rules (Gelabert-Navia, 2016). Nevertheless, discussions about the proper interpretation of the zoning code language were common and were decided during the process of design review (Mindreau, 2018).

\section{Implementation of the Mediterranean Bonus Program}

Architects had the primary responsibility for the correct implementation of Coral Gables Mediterranean architecture. Implementation faced the following challenges: 
1. Many architects did not believe zoning should restrict aesthetics, objected to the process and refused to follow clear zoning language. Some architects believed this position was ethical.

2. Parking requirements did not exist in the 1920's and presented a new challenge for large buildings. Parking podiums were designed at the scale of the automobile. Mediterranean design was conceptualized for human scale. For instance, the Biltmore Hotel did not include parking, and its slender proportions could not be replicated with parking.

3. Mediterranean architecture was more expensive than other aesthetic options. Thus, value engineering would lead to inferior results.

4. Mediterranean architecture design required superior skill. Moreover, lack of skill would be evident, as standards were defined in the zoning code and exemplary buildings from the past were common throughout the city. Compliance with the Mediterranean bonus was reviewed by the City Architect and approved by the Board of Architects. Most larger projects and all mixed-use projects required Commission approval afterwards, for zoning and land-use.

The code required that aesthetic review be performed first, and that it always remain outside the purview of politics. This was a deliberate policy choice at the time of adoption of the program (Gelabert-Navia, 2016). This was also an impossible goal, and a misunderstanding of democracy of place.

The Board of Architects made decisions during noticed meetings. Thus, the bonus program was an example of the implementation of democracy of place. However, public debate and disagreements, although common, were not well integrated into the 
format of the meetings. Moreover, politics would often be infused at the end of the process, as Commissioners at times expressed opinions on architecture. The distinction between politics and democracy not anticipated in the adopted process. Democracy of place should have been designed as a spectrum of opportunities for input beyond political discussion with elected officials. The Board of Architects process, although very effective as support for bureaucracy, could have been enhanced with more robust theory about democracy of place.

Poor execution of the Mediterranean bonus requirements during the 1990's led to criticism, which was often the subject of public discussions in the early $21^{\text {st }}$ century. During the 2002 charrette the topic was revisited, with the publication of educational illustrations. In spite of practical recommendations included in the charrette report, implementation of content remained a topic of permanent debate.

\section{Implementation}

Implementation of aspirational content required effective process, for democracy and bureaucracy. To follow up on the 2002 charrette, a committee was organized to discuss strategies, with participation of members from the Planning and Zoning Board, the Historic Preservation Board and the Board of Adjustment. Discussion never stopped, a fact that strengthened the role of democracy in shaping place. However, insufficient theory direction and lack of best practices left many issues unresolved.

In the 1920's Merrick's team had different best practices. Developers and architects had access to effective data about aesthetics, without chronology bias. The folio books of the 1920's provided precedents for contemporary design challenges. 
Qualitative findings emphasized the educational role of the books, in terms that would be applicable to the $21^{\text {st }}$ century.

By the 2010's, architects and administrators enhanced the process through precise discussion about content, as required by the eight exemplary buildings listed in the zoning code. Although quality of design improved, debates about proper implementation of the bonus program did not end. Plate 32 is an example of a mixed-use building from 2015, which followed the requirements of the zoning code.

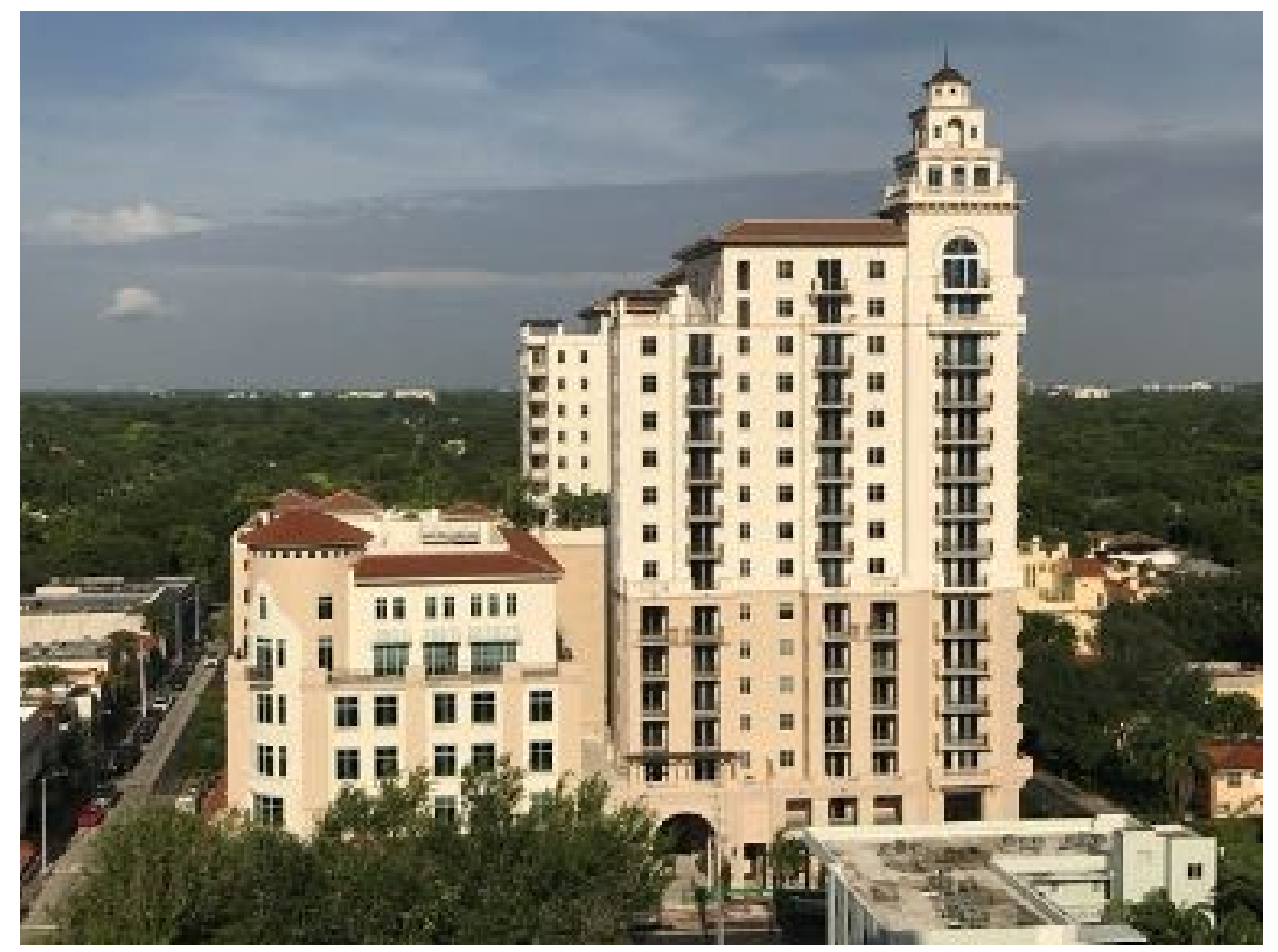

Plate 32. 2020 Salzedo. Photograph: Ramon Trias.

Although the review and approval processes were complex, with three levels of compliance and multiple charts and checklists, the outcomes could be summarized concisely. This review resulted in development bonuses that would typically require conditional use review and Commission approval in other local governments. 
The Mediterranean bonus provided:

1. Additional height

\section{Additional FAR}

3. Flexibility of setbacks and step backs

All of those features added real estate value. To qualify for the bonus, a project would provide public benefits. The equation "bonus $=$ good design + public benefit" would appear unambiguous. The complex experience of Coral Gables would suggest otherwise. Zoning tools from the $20^{\text {th }}$ century did not address qualitative issues effectively. Smart tools could provide contemporary assistance for best practices.

As the potential enhancement of real estate value was significant, a majority of large buildings located in the central business district followed the Mediterranean bonus program. Buildings that required Commission review and approval are depicted in darker red, in plate 33.

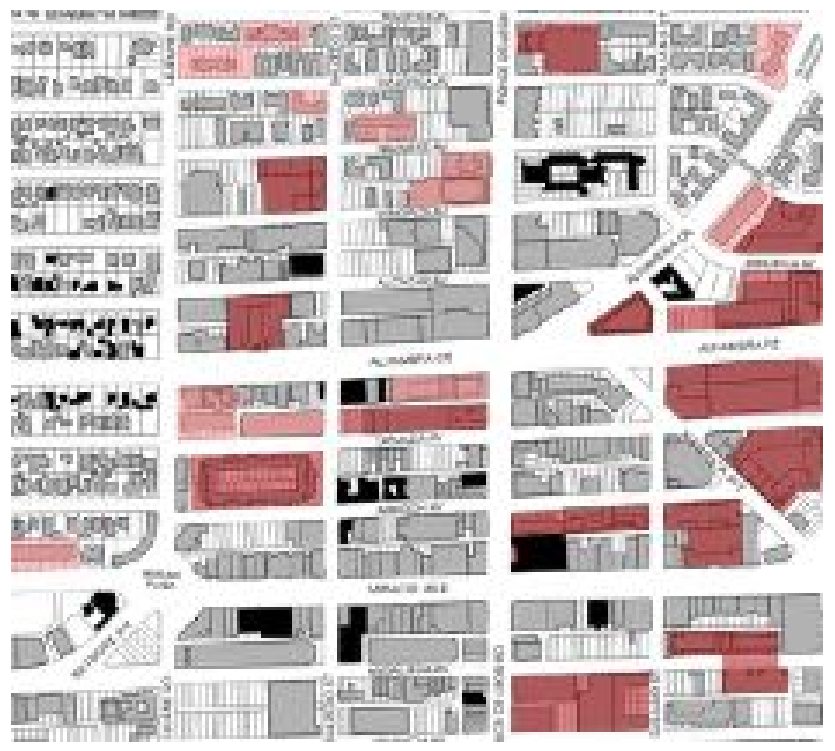

Plate 33. Diagram of buildings which received Mediterranean bonus, highlighted in red. Source: City of Coral Gables. 


\section{A History of Making Content by Committee}

Discussion about aspirational content in Coral Gables may had been exceptionally thorough from 1986 to the end of the century, but it was also fluid and open to multiple interpretations. On September 25, 2001 the City Commission authorized by resolution a "Mediterranean Review Committee." This was not the first time that questions about Mediterranean architecture had been asked. In fact, such a fundamental question had provided context to politics since incorporation and could never be resolved. Moreover, the fact that a committee was needed demonstrated that the original and reinterpreted vision of Coral Gables had been vigorously debated. Merrick's narrative of place had been a starting point for a town for the future, but it was never understood as the blueprint for an inevitable outcome. Conflict had been more common than consensus.

The committee received a large binder with background materials that dated back to 1983 , when the first ideas about a zoning bonus program were discussed by the Commission. Most of the binder was filled with verbatim minutes from Planning and Zoning and Commission meetings. Draft design manuals prepared by staff were also included.

In addition of providing a substantial historical record, the binder also demonstrated respect for precedent. Coral Gables policy discussions were always framed in terms of prior decisions. Thus, policy evolved incrementally. The original master plan was also intended to develop in ways consistent through time. The goal of coherent policy and design implementation was expressed regularly in public meetings. Confluence of policy and design through time was a best practice for democracy of place. 
The story of conflict about content was long. In the 1940's Walter de Garmo warned in a newspaper article of the lack of stringent design standards. After the midcentury, discussion shifted from aesthetics to the real estate potential of zoning incentives, and the Mediterranean style was reinterpreted as a proxy for quality. Moreover, at the start of the $21^{\text {st }}$ century there was a methodical attempt to enhance the process of aesthetic review and zoning flexibility, guided by elected official and professional staff. For instance, a manual of best practices for the Board of Architects was published, to reinforce the role of content in discussions about place.

The 2001 committee had seven members, one appointed by the Planning Board, another one appointed by the Historic Preservation Board and by each of the five elected officials. Thus, the committee performed a role for democracy of place.

Committee members reviewed the following information, organized as follows, by year of publication:

1. 1983

Coral Gables' attempt to use zoning to express aspirational content dated back to 1983, when the City Commission requested a study of Mediterranean architectural design standards. The members provided input to the Planning and Zoning Board and the City Commission during the next few years. They were often present at public meetings. Two members were interviewed in 2016 for this study: Jose Gelabert-Navia and Arva Moore Parks. They provided qualitative context to the review of archival records.

2. 1985

In 1985 William Mayville, Chairman of the Committee, stated that the goal was to transform "the downtown area of our community into a quaint Mediterranean 
village"(City of Coral Gables, 2001). A video was shown during the meeting that provided background on prior discussions. Arva Parks provided content with examples of the standards in the proposed ordinance. Sandy Youkilis, assistant planning director at the time, explained the process of implementation. Damodar Airan described a plan for transfer of development rights. After the video ended, discussion continued on human scale, villages in Spain or weather every building would be painted pink. Jose GelabertNavia mentioned Addison Mizner's Worth Avenue in Palm Beach as a model, a project contemporaneous to Merrick's work which shared aesthetic goals.

The members agreed that incentives would be needed. John Vinsant, planning director, reviewed bureaucratic issues related to implementation and suggested amendments to the zoning code. Neither George Merrick nor his narrative of place were mentioned. However, there was also no detailed discussion about community vision. Many ideas were assumed to be understood, which left much room for administrative discretion. Don Slesnick, a future mayor, expressed concern through a letter about the uneven role of the Board of Architects. The quality of 1980's architecture, after the rise of the Modern movement and at the start of the post-modern period, was understood by critics as inferior to the architecture of the 1920's. Part of the reason might have been that in the 1980's best practices no longer included reference folio books.

A memorandum from then Planning Director Youkilis dated October 28, 1985 memorialized discussion by planning board members and listed technical issues. There were concerns about process: the type and composition of the Board, parking requirements, review of materials, underground parking, bonuses for courtyards and arcades and maximum FAR. There was no discussion on aspirational content, quality 
architecture, community vision or George Merrick's narrative of place. Nevertheless, staff recommended adoption of the Mediterranean architectural ordinance.

2. 1986

Minutes from the process of adoption of zoning regulations in 1986 revealed extensive discussion about the bureaucratic aspects of the proposed regulations. Discussion about the content of "Mediterranean style" was sparse, as if content was selfevident. Jose Gelabert-Navia made a rare comment on Merrick, who in his view would be shocked that fifty years after his death Coral Gables would have to beg developers to build in accordance to the city's character. However, he admitted the difficulty of delivering Mediterranean architecture at the time. Unfortunately, best practices from the 1920's, which may have assisted in discussions about content delivery, were overlooked by the literature of the time.

The focus on process was an expected consequence of the bias of conventional zoning for procedure. Staff provided data and commentary on density, FAR and compatibility. Planning and Zoning Board members debated the composition of boards and asked about the implementation particular projects in terms of zoning incentives. Recommendations were crafted on topics considered important, such as open space, parking or the makeup of the Board of Architects. Mediterranean content was mentioned rarely and tangentially. Some members of the public considered design review problematic, as it would limit the creativity of architects or the options of homeowners.

New Urbanism theory was at its inception at the time at the University of Miami in Coral Gables. Some early practitioners rediscovered the folio books and Merrick's narrative of place. There were some attempts to enrich policy discussions with 
aspirational content, at first from the perspective of academia (Plater-Zyberk, 2018).

However, Coral Gables minutes from public minutes on zoning reform do not reflect this type of input.

Public debate about additional FAR and density, on the other hand, was extensive and nuanced. According to the minutes from public meetings, democracy of place was perceived as a question of real estate incentives. For example, underground parking was often discussed and was included in the zoning table of features which would result in incentives.

At no point there was discussion of community vision, or even the ultimate physical outcome of the regulations. Nevertheless, Planning and Zoning board members recommended adoption and requested a workshop to clarify the regulations of the ordinance.

To explain the content that would be regulated by the ordinance, staff prepared a list of six exemplary buildings, which would be expanded to eight buildings after discussion. Staff intended to prepare a manual, with detailed information and photographs. On March 24, 1986, the Planning and Zoning Board recommended approval unanimously for the Coral Gables Mediterranean Architectural regulations, which included a list of eight exemplary buildings. The Biltmore Hotel, which was under restoration at the time, was added to the list. On June 10, 1986, the City Commission adopted the ordinance on second reading with a 3-2 vote and requested additional information on its effects from the Planning and Zoning Board. Within the following two months, three new projects and a renovation project were submitted under the new regulations. 
Soon after adoption, discussion continued. Amendments were proposed less than a year later and would continue to be reviewed through the years.

3. 1987

In 1987 staff published the Mediterranean Architectural Style Guide. A draft had been presented to the Planning and Zoning Board on November 10, 1986, where members recommended review by the Historic Preservation Board. The final document included photographs of the eight exemplary buildings and brief descriptions of their major characteristics. Some details, such as windows and entrances, where highlighted with descriptive commentary. However, contemporary measured drawings, original drawings or historic photographs were not included. The graphic quality of the style guide was significantly inferior to the typical standards of folio books from the 1920's.

Although the document explained the general content of Mediterranean architecture, it required interpretation, as contemporary examples were not included. For instance, none of the buildings of the 1920's provided parking. Contemporary development was characterized high parking requirements that were often implemented with garages. There were no stylistic models for garages among the exemplary buildings.

4. 1991

In 1991 the Commission had requested a review of the ordinance. A committee was established and a report was produced, with the assistance of staff. Jose GelabertNavia and Arva Moore Parks were among the members of the Committee. The Committee met eight times, documented Mediterranean projects to date, reviewed the effects of bonuses and outlined critical issues. Recommendations proposed routine process improvements: 
1. Establish a separate Mediterranean committee.

2. Hold monthly meetings of the Mediterranean committee.

3. Require a written application, for bonus requests.

4. Enhance the style guide with information on new projects.

5. Simplify zoning code requirements.

6. Preserve historic commercial buildings.

7. Preserve historic houses.

Analysis of recent projects provided significant insight. For instance, only $42 \%$ of projects used all available bonuses. Moreover, $75 \%$ requested variances, generally for ground area coverage and setbacks. Although the report reviewed 19 projects, an aesthetic assessment of the impact of the regulations was not attempted. The impact of content was reduced to abstract zoning measures, such as height, FAR, density or basic questions about designed features, such as the area of an arcade or of a pedestrian courtyard. Implied in the review was concern about the outcomes, when compared with early $20^{\text {th }}$ century buildings. The fundamental gap in the research was the lack of awareness of 1920's best practices included in the folio books. Style manuals in the 1980's and 1990's were objectively inferior. Moreover, current projects were also inferior in aesthetic quality. There appear to be a causal relationship, but data about the content of place was not collected, as conventional planning and zoning did not account for it.

Although zoning regulations were amended incrementally until the 2007 code reorganization, many recommendations were not implemented. Part of the reason was consequence of the limits of zoning, as a tool for content. Although Coral Gables ranked 
among the most innovative and effective local governments for the regulation of aesthetics, good design still required good designers, and content emerged from vision. As a result of the review performed in 2001, Coral Gables scheduled a charrette for 2002, with assistance from faculty from the University of Miami's School of Architecture.

The following actions were taken as a result of the discussions of the committee:

1. 2002

The 2002 charrette produced a report, which was discussed in the Literature Review chapter. Concern about the visual character of downtown led to specific discussion about the Mediterranean bonus program. Page 88 of the report reproduced a rendering which transformed an existing office building into a Mediterranean design, which illustrated a picturesque method of architectural composition. The caption read "responding to popular demand for an illustration showing the recladding of an existing building" (Charrette Report, 2002).

A charrette was an expression of democracy of place, as interested participants provided input. But aesthetic regulation required careful thought about bureaucracy, a topic that was discussed superficially. Therefore, charrette recommendations, in spite of the best effort of staff, had limited effect in practice. Suggestions for administrative reform proved insufficient.

\section{Resilient Content for Bureaucracy of Place}

With the $21^{\text {st }}$ century, architectural theory and fashion would trend away from traditional aesthetics represented by the Mediterranean bonus program. The implication was that "modern" design would be more appropriate for the age. However, discussion about style had become less prevalent among design professionals as a proactive tool for 
content. "Modern" was often interpreted as the absence of regulatory content for aesthetics. Thus, the implementation of aspirational content in public administration became more difficult, once again. But the Coral Gables zoning code did not change, with the 2001 committee or later on. Bureaucracy of place proved resilient.

In spite of controversy and disagreement, Coral Gables Mediterranean architecture was a rare example of implementation of aspirational content through the bureaucracy and democracy of place. Results from the past four decades can be evaluated. As the bonus program is not mandatory, the buildings can be compared to structures that do not follow the standards of the bonus program.

Quantitative data demonstrated support, as depicted in figure 4 in the Results Chapter. Mediterranean architecture ranked 12 out of 31, when residents were asked to rank characteristics that contributed to quality of life, in an anonymous random survey. The fact that a topic as narrowly focused and specialized ranked ahead of public schools, historic landmarks and recreational activities supports the crucial role of content, when applied consistently through time.

Research on Coral Gables development in the $21^{\text {st }}$ century suggested the Mediterrenean bonus provisions had enhanced quality of place. However, democratic debate continued on what constituted a quality outcome. Better outcomes would require enhanced best practices for bureaucracy.

Review of adopted zoning regulations revealed the limitations of conventional practices for the administration of place. Deconstruction of zoning language illustrated an incremental process guided by content, but devoid of robust theory. Thus, 
conventional zoning, even when enhanced with certain aspects of form-based techniques, lacked effective best practices for democracy and bureaucracy of place.

Design of buildings and public spaces cannot be summarized with a handful of guidelines if the goal is quality place. On the other hand, public administration requires clear rules. A solution may be found in a theory framework that emphasized governance and fully adopts smart strategies for the creative generation of place. The basic tools exist in multiple formats, from the content in zoning language to the enhanced public discussions enabled by social media. Best practices should guide content and process towards the ultimate outcome: smart place.

\section{Findings}

1. Quality place depends on the implementation of content. Content should result from public discussion and must be implemented with administrative tools.

2. Zoning is one tool for the implementation of place, with limited effectiveness.

3. A design review board should implement aspirational content, with democratic processes and with bureaucratic support.

4. Content is never static. It is developed through debate.

5. Bureaucratic implementation of content requires democratic support from residents and elected officials.

6. Coral Gables used Mediterranean aesthetic qualities to develop content. Other places must calibrate content based on their aspirations and needs.

7. Smart place should be the outcome of effective local governance. 


\section{Coral Gables Board of Architects}

\section{Research Question}

What was the process of implementation of content through the Coral Gables Board of Architects?

\section{Every Thursday Morning}

Every Thursday morning throughout the year the Coral Gables Commission Chambers is the center of well-organized frenetic activity. The members of the Board of Architects review dozens of projects under a life-size portrait of city founder George Merrick. Thick pads protect the wood dais during the meeting, as roof barrel tiles, granite pavers and marble samples are often presented for close inspection. The task last from eight until noon or later in the day, every week of the year, except Thanksgiving day and a day at year's end scheduled for the holidays. If the pace slows down, the change is universally perceived as a sign of an incoming national recession.

The format of the meeting was reminiscent of an architectural jury, the timetested evaluation of a class assignment at a School of Architecture at the end of the year. This process is often misunderstood by administrators, as it differs from conventional public meetings that follow Robert's Rules of Order strictly. But Robert's Rules work best when questions are direct and clear. Review of aesthetics is complex, if the aspiration is quality. With such a goal, democracy and bureaucracy of place require innovation and patience.

The Board of Architects process may be perceived by some administrators as too informal, as discussions overlap and recommendations change rapidly. At times, tempers 
flare and opinions are contradictory. But in-depth observation reveals that the process is subtle, complex and highly structured for quality outcomes.

Moreover, each Board meeting is an expression of raw democracy and it is practically incompatible with the bureaucracy of conventional planning and zoning. Administrators have attempted to change it through the years (Mindreau, 2018), but in the end, the Board of Architects continues to function as intended. It is an open and fair forum of debate for the implementation of aspirational content for place.

\section{The Process of Democracy of Place}

Review of the aesthetics was performed by three to seven volunteer registered architects with no less than ten years for experience practicing in the city, over a period of years. The project would be presented by the architect, with adequate graphics. The jurors, in this case members of the Board of Architects, would react to the aesthetic quality if the design, and provide comments. Most of the time they would defer the project with comments on the first review. By the second or third revision at a future meeting, most projects would be approved. The success of the process depended on the quality of the architect and the effectiveness of the comments.

The Coral Gables zoning code required two tiers of review for all exterior building permits. This included a wide range for requests, from replacing windows on a single-family house to a new mixed-use building located downtown, sixteen stories in height. The same board, composed of a panel of three architects or a full board of seven or more, would review projects based on criteria from the zoning code.

Some smaller projects could be approved administratively by the City Architect, as the supervising architect of the 1930 code was known in the 2007 code. The process 
was lengthy. Nevertheless, in a customer satisfaction survey completed in 2018 customers expressed satisfaction. In fact, specific questions about the value of the process received high marks.

The design review process was modified several times during the past century. First, a professional architect reviewed projects. Later, a volunteer board of professional architects performed the review, without the assistance of an architect on staff. Finally, a professional architect provided support staff for the volunteer board, and review was performed administratively and at the board, depending of the project.

In 2019, Board of Architects' design review was continuous, professional, criticized extensive and strict. In the fiscal year of 2017- 2018, the Board met 50 times and reviewed 5,367 applications, which were fairly evenly spaced thought the year. When the total population of Coral Gables is considered, about 51,000 people in 2018, the impact is substantial. Although downtown and commercial areas were large, the number of applications was very high. The scope of the Board of Architects work is important for discussion about best practices. If design review is implemented, it should be comprehensive and have adequate staff support.

A typical agenda had over 100 items, to be decided every Thursday morning. In contrast, most city boards had agendas with less than 10 items. The Board of Architects' work load was exceptionally large and the process of review was very efficient.

Many applications were simple request for new roofs or new windows, but they were carefully considered. Of all items reviewed at the meetings, 926 were deferred and 78 were rejected. Generally, new buildings or major renovations would be deferred with comments, and revised drawings would be submitted soon afterwards. 
After the Board of Architects approved a project, it would be reviewed by all building trades and zoning. At times, zoning would deny a request that did not comply with code requirements, and the process would start again.

Staff's focus was customer service (Bernal, 2018). There are two general categories of customers: home owners and professionals. Home owners may require extensive assistance, and the projects undertaken under "owner builder permits" tend to be small, such as a driveway or minor repairs. Thus, small projects required the personal attention of staff. On the other hand, larger projects are handled by professionals, such as contractors or architects. Moreover, permit runners had emerged as a profession, as the process of getting permits has become more time consuming in recent years.

Professionals may require less assistance but are more likely to complain should issues arise.

The Board meetings may be frustrating, unless the applicant knew what to expect. The lengthy agenda resulted in long meetings. Applicants waited. Board members tend to work in a slow and deliberate manner. At times, comments from the members may appear excessively critical. But there was a general understanding that the process made Coral Gables a better place (Mindraeu, 2018).

\section{One Large Project}

On September 1, 2016, a concept for large mixed-used project was reviewed by the Board of Architects. It was called "Mediterranean Village." As the project included approximately 1.1 million square feet of retail, offices, residences and a hotel it was reviewed in five packages, to allow construction phasing. 
The illustrations prepared by the architects were extracted from a rivet model, the state of the art of software for architecture at the time. But the style would be recognizable to De Garmo, Paist or Fink. Current technology depicted the timeless design language preferred by Merrick and reinterpreted for almost a century.

One request had been controversial. The tallest cupola needed a maximum height that exceeded current rules. Nevertheless, at its highest point, it was shorter than the Biltmore by a few feet, and was thus approved. During the next three years the project name changed to "The Plaza," details would be revised, and the highest point would be lowered to comply with standard zoning requirements. The overall design of the project, however, remained consistent, guided by staff and the Board members.

The review process of aesthetics spanned three years. This step was performed prior to permit review by each building trade and regulatory department. Package one was approved on December 7, 2017 and revised on June 28, 2018. Package two received preliminary approval on November 29, 2019. Package three would be approved on the summer of 2019. Package four had not been submitted in early 2019. Package five's last revision had been approved on September 20, 2018. The process worked efficiently. Zoning requirements and design review facilitated the effective implementation of aspirational content.

Throughout the aesthetic review process, construction of the foundation had already begun, under a phase permit. All revisions were carefully evaluated by city staff for compliance with the original intent. During construction, a full-scale sample of the stone details was installed on site for review by staff and the Board members of the quality of the materials and the accuracy of Mediterranean details. 


\section{Phineas Paist, First Supervising Architect}

Phineas Paist was appointed Supervising Architect of Coral Gables by developer George Merrick in May of 1925, prior to incorporation (Miami Herald, 1926). The position would be formalized in the zoning code of 1930.

At the time of appointment, he modestly declined an interview. The Miami Herald described him as a national figure in architecture, with an extensive professional background in Philadelphia. He had recently completed work with Paul Chalfin in the two Deering Estates, known as Vizcaya and the Deering Estate at Cutler Bay, academic examples of Renaissance architecture that would be among the precedents for the Mediterranean style of South Florida.

Paist reviewed and approved all buildings constructed from 1926 to the Great Depression of 1929. He also practiced architecture. Among the buildings he built was City Hall, designed in 1927 and completed in 1928 (Alper, 1981). The buildings remain in use, without changes to the exterior appearance and only minor interior remodeling through the years. Reproductions of the original drawings hung on the walls of the administrative offices. The current zoning code lists city hall as one of eight exemplary buildings that define Coral Gables Mediterranean design.

Paist (1924) had published an illustrated article in National Builder on color for stucco buildings. It became a classic text for bureaucratic administration in Coral Gables. And yet, it was originally sponsored by the Bermico Sheathing Paper construction company, to promote quality construction. Paist's discussion would set a high standard for the future of architectural review. 
Paist recommended a weathered effect for stucco, to be achieved with texture and color (Paist, 1924). He described the application of the material in Coral Gables as the "Spanish effect." The second coat of stucco would be deliberately made to look aged, with a subtle superimposition of deeper colors and highlights. Among artistic urban design recommendation, he suggests zone coloring for Coral Gables. Along certain streets, buildings could have consistent coloring, which could range from rich hues to grays to almost pure white. He proposed that each house should be studied in terms of color, in the context of the neighborhood. The article recorded the high state of aesthetic aspiration at the inception of Coral Gables. It included three photographs of Mediterranean houses and three pictures of stucco details.

\section{Evolution of the Administration of Architectural Review}

Founder George Merrick established a strict process of design review of aspirational content when he developed Coral Gables as a private sector project, prior to incorporation. Review was initially performed as part of the sale of real estate, which often included conditions related to design. Local architects collaborated with the development team, and deed restrictions narrowed design options for the future. This approach would be applied often throughout $20^{\text {th }}$ century development, but it would seldom transition into an adopted process for local government bureaucracy. Coral Gables was the most successful and long-lasting example of the evolution of a process of review of aspirational content from the private sector to local government bureaucracy. The experience should inform best practices.

Review of aesthetics was first performed by a staff professional and ninety years later by a volunteer board of architects. But the process had many iterations. Eventually, 
the Board was appointed by the City Manager, when many boards were appointed by elected officials. In Coral Gables design would not be political, but the process would still implement democracy in the form of public meetings in front of a Board of professionals. This was an important policy decision, consistently applied to all relevant provisions of the zoning code.

The Board of Architects would be a best practice for democracy of place. It is anticipated that smart tools may enhance the work of the Board in the future. Table 9 summarizes the history of architectural review after the City was incorporated in 1926.

\begin{tabular}{|c|c|c|}
\hline Feb. 16, 1937 & $\begin{array}{l}\text { Ord. } 271 \text { (Early Zoning } \\
\text { Code) }\end{array}$ & $\begin{array}{l}\text { City Manager appoints: } \\
\text { - Supervising Architect } \\
\text { - Associate Supervising } \\
\text { Architect } \\
\text { - Structural Engineer }\end{array}$ \\
\hline July 31, 1946 & Zoning Code & $\begin{array}{l}\text { City Manager appoints: } \\
\text { - Five Supervising Architects } \\
\text { - Structural Engineer }\end{array}$ \\
\hline June 1963 & Ord. 1005 & $\begin{array}{l}\text { City Manager appoints: } \\
\text { - Board of Architects (paid) }\end{array}$ \\
\hline Dec. 1994 & Ord. 1525 & $\begin{array}{l}\text { City Manager appoints: } \\
\qquad \quad \text { Board of Architects } \\
\text { (volunteers) }\end{array}$ \\
\hline
\end{tabular}

Table 9. Evolution of Coral Gables Board of Architects.

Source: City of Coral Gables. 
At first, the supervising architect was an employee of the city. In the early $21^{\text {st }}$ century, the members of the board of architects were professionals who volunteered their time, appointed by the City Manager. In addition, the zoning code provided for a City Architect, who provided staff support, and had administrative authority to approve minor requests. The City Architect supervised a small staff of clerks who provided personal attention to applicants.

Throughout the history of design review there were many critiques of the process and attempts to modify procedures. For example, discussion during in the late 1980's related to the Mediterranean bonus program centered on the role and the limits of expertise, as applied to the process of approval. In minutes from planning board minutes of 1986 about the process of awarding additional height and FAR for certain architectural features some members supported professional membership and other members believed that a board comprised only of architects would not be in the best interest of the city. This discussion illustrated the tension between democracy and bureaucracy. In the end expertise prevailed, but within a democratic setting of volunteer board memebrs. Nevertheless, periodic criticism would be provoked by specific Board actions. Part of the strength of the process was that it was constantly questioned, and thus constantly improved.

In 2019 the board had at least seven members, with the option of appointing more members, at the discretion of the City Manager. Qualifications for membership were strict:

1. Architect or landscape architect registered in Florida. 
2. Responsible for design and construction of buildings in Coral Gables during the past five years.

3. Ten years of experience in the profession.

4. Live or work in the city.

The requirements for membership in the Board of Architects were practically the same as the qualifications listed for the supervising architect in the 1930 zoning code.

Two members were sufficient quorum for a three-member panel. Most items were reviewed by panels, although large or controversial projects would be reviewed by the full board. Discussion was informal and direct. It gave the appearance of a conversation about art. Nevertheless, the board was quasi-judicial and made final decisions.

There was a process for appeals that had several steps, including staff mediation, special master and a hearing before the Commission. However, appeals were rare, as the process tended to work exactly as intended. Two or three appeals a year would be typically resolved with staff mediation, without a need for a Commission meeting.

\section{Democracy and Bureaucracy of Design Review}

Many American local governments have some type of design review. However, other communities do not have a zoning code that regulates aesthetic content, a sufficient number of qualified professionals to hold weekly meetings to review all permits that affect the exterior of any building and a century of experience and political support.

Coral Gables' design review process must be considered the best practice for the following reasons:

1. Design review has always been in place, since incorporation. 
2. There is a coherent narrative about Coral Gables architecture.

3. Well qualified local professionals serve on the board.

4. Residents and professionals support the process.

Furthermore, Coral Gables did not have design guidelines, and this is a deliberate choice. The zoning code addressed architecture directly in terms of aesthetics. However, prescriptive regulations are not provided. Professional review by the board is believed to be a superior process. Qualitative interviews supported this view.

\section{Customer Satisfaction Survey}

The Board of Architects process was strict and, at times, controversial (Mindreau, 2018). In an effort to evaluate the process, the city conducted an anonymous survey. Customers who submitted projects at the desk were asked to fill out a questionnaire during a period of three months in 2018. The questionnaires were collected and analyzed by a consultant. Raw data was analyzed with STATA, at a section of the Results chapter.

The composite variable for customer satisfaction with the Board of Architects process was positive, a result discussed and placed in proper context later in the study:

- sum BOAsatisfaction

\begin{tabular}{r|rrrrr} 
Variable & Obs & Mean & Std. Dev. & Min & Max \\
\hline BOAsatisfa n & 62 & 1.048387 & .3810004 & 1 & 4
\end{tabular}

The value of 1 was "very satisfied" and 4 was "very dissatisfied." The measured result was 1.04. This result surpassed expectations from extensive qualitative interview data (Bernal, 2018), (Mindreau, 2018), (Caty, 2018), (Iglesias, 2019). Moreover, quantitative survey data (Coral Gables, 2018) demonstrated the effectiveness of the process and measured high customer satisfaction. The positive finding was surprising, as 
the process was believed to be rigorous and demanding. Detailed discussion on regression analysis of multiple variables follows in another chapter.

\section{Findings}

1. Design review has been implemented continuously in Coral Gables for almost a century.

2. The process of design review has changed multiple times. The objective has remained.

3. The Board of Architects implements democracy of place based on aesthetic content. Robust debate is encouraged.

4. The City Architect implements bureaucracy of place, through professional expertise about aesthetics.

5. The Coral Gables Board of Architects process is a best practice for local governance, because it implements democracy and bureaucracy towards the outcome of quality place.

6. Effective design review required a significant investment of resources and a high level of professional expertise.

7. Smart tools should enhance the process in the future. 


\section{Quantitative Data on Content and Process for Coral Gables}

\section{Research Questions}

1. What was the role of content in quality of life in Coral Gables?

2. What was the level of customer satisfaction with the implementation of content through the Coral Gables Board of Architects process?

\section{Measuring Conceptual Theory}

Research explored whether general theory concepts could be tested with quantitative data. Existing research data from two surveys performed 2018 was timely and relevant. The surveys had been prepared on behalf of the city of Coral Gables to measure satisfaction with city services. Questions about quality of life were also included. Thus, quantitative data was available to measure ideas developed during the qualitative phase of research.

Raw data from two surveys, prepared by the Baldrige Group for the City of Coral Gables, were public record, available at the City Manager's web page. Analysis was performed with STATA.

\section{Two Anonymous Random Surveys}

In 2017 Coral Gables city management prepared a strategic plan with the assistance of a consultant and the participation of senior staff. The strategic plan generated policies that would lead to "world class" performance, defined as the top decile among comparable local governments (Levi-Garcia, 2019). This objective required measurable strategies and quantitative data on performance. Coral Gables had not collected this type of data in the past, but city staff intended to perform similar surveys in the future. 
During strategic planning discussions among city staff it became clear that city services could be enhanced with adequate data to evaluate performance and customer satisfaction. Moreover, data could lead to more informed decisions about resident priorities for service and budgets.

The city manager decided to conduct anonymous surveys to collect data which could be used to set future priorities on actionable items (Levi-Garcia, 2019). The goal was to conduct future resident engagement surveys on a regular schedule, and to incorporate survey data into the budget process as a standard best practice. Surveys reviewed for this study were completed by November of 2018.

Data from city surveys proved useful for research because it included multiple measurements relevant to place, content and process and quality of life which could be used to test conceptual theory ideas. In addition, there were questions that compared Coral Gables with Miami-Dade County which could help identify data related to local content.

Although survey design was intended to provide raw data for general public information and use by staff, there was sufficient information for regression analysis for the purpose of theory development. As the goal of research was a theory sketch, multiple models with different variables were run.

Results were used to review general trends or positive-negative relationships, as the degree of accuracy generated by STATA would only by reliable after robust theory was developed. A false sense of accuracy was avoided during discussion and analysis, as quantitative findings should be understood as preliminary suggestions for future research. 
Nevertheless, survey results supported many theory assumptions and provided ideas for future research methods.

\section{Description of Surveys}

A “Community Engagement" survey measured topics related to quality of life in Coral Gables and Miami-Dade County (South Florida). Many questions were related to place or public administration.

Survey questions measured satisfaction with routine city services and features and qualities of Coral Gables. Results reflected personal perceptions and priorities. Data could be used to test for theory concepts.

A second survey was the "Board of Architects customer satisfaction." This survey measured satisfaction with the implementation of place, which is achieved through a formal process of design review.

\section{Data Sets}

Existing data from surveys conducted in 2018 was reviewed. All variables were renamed for clarity. In the Community Engagement survey, two variables which addressed content were transformed into dummy variables, "medCG" which recorded whether Mediterranean was a priority or not, and "neighborhoodCG," which recorded whether sense of place was a priority or not. Variables with two types of measurements were included. Some were measured with a Likert scale. Others were ranked on a list, which were not useful for regression analysis. A question on Mediterranean architecture was included at my suggestion, to measure content specific to Coral Gables.

In the Board of Architects Customer Satisfaction survey, variables were renamed, and on new variable was created, "BOAsatisfaction," which merged three related 
variables. Variables for content "Mediterranean" and "long term vision" were included, at my suggestion, during discussions with the city consultant as the survey was developed.

\section{Review of Community Engagement Survey}

The Community Engagement survey was mailed to 2000 residents of Coral Gables who were selected randomly. The goal was to gather data on ways to improve quality of life. The purposes stated in the survey instrument were:

- Increase resident engagement

- Identify key areas that impact quality of life

- Collect input on fiscal planning and capital improvements

- Measure satisfaction with city services

Results were presented by the City consultant to the City Commission during the regular meeting of August 27, 2019. There was general satisfaction with the result, and a commitment to continue surveys in future years.

\section{Fundamental Data Point}

When quality of life in Coral Gables was compared to quality of life in MiamiDade county results were positive and showed greater satisfaction with Coral Gables, where 1 was excellent and 4 was poor:

- sum qualityoflifecoralg qualityoflifemD

\begin{tabular}{c|ccccr} 
Variable & Obs & Mean & Std. Dev. & Min & Max \\
\hline qualityofl G & 894 & 1.558166 & .5953115 & 1 & 4 \\
qualityofl D & 883 & 2.520951 & .7302676 & 1 & 4
\end{tabular}


Quality of life Coral Gables was a full point superior to quality of life in MiamiDade county. This result would be expected and was significant. The following formula summarized the interpretation of the data:

Quality of life in Coral Gables = Quality of life in County + aspirational content of place.

Data led to an equation for quality of life which could test the role of content of place. As both results were positive, quality of life in Coral Gables would be a function of quality of life in Miami-Dade county plus other variables. The additional variables would measure the effect of issues related to place. As data was not collected specifically for this type of analysis, some interpretation would be needed. Prior qualitative research on bureaucracy and democracy of place provided theory guidance. The role of content would be one possible explanation for the survey results.

\section{Raw Data on Content of Place}

As the survey was designed to compare raw results directly, the ranking of factors for Coral Gables and Miami-Dade were reviewed. Respondents were asked to rank the top five factors which contributed to quality of life from a list of thirty-one. The question was asked separately for Coral Gables and Miami-Dade county. Several factors were realted directly to content or place, although theory terms were not used. The factor topics were typical of similar surveys in American communities. The topic unique to Coral Gables was one question on Mediterranean architecture.

The thirty-one topics were ranked in figure 4. Most topics would be typical of this type of survey. Data was analyzed from the theory perspective proposed in this study. 


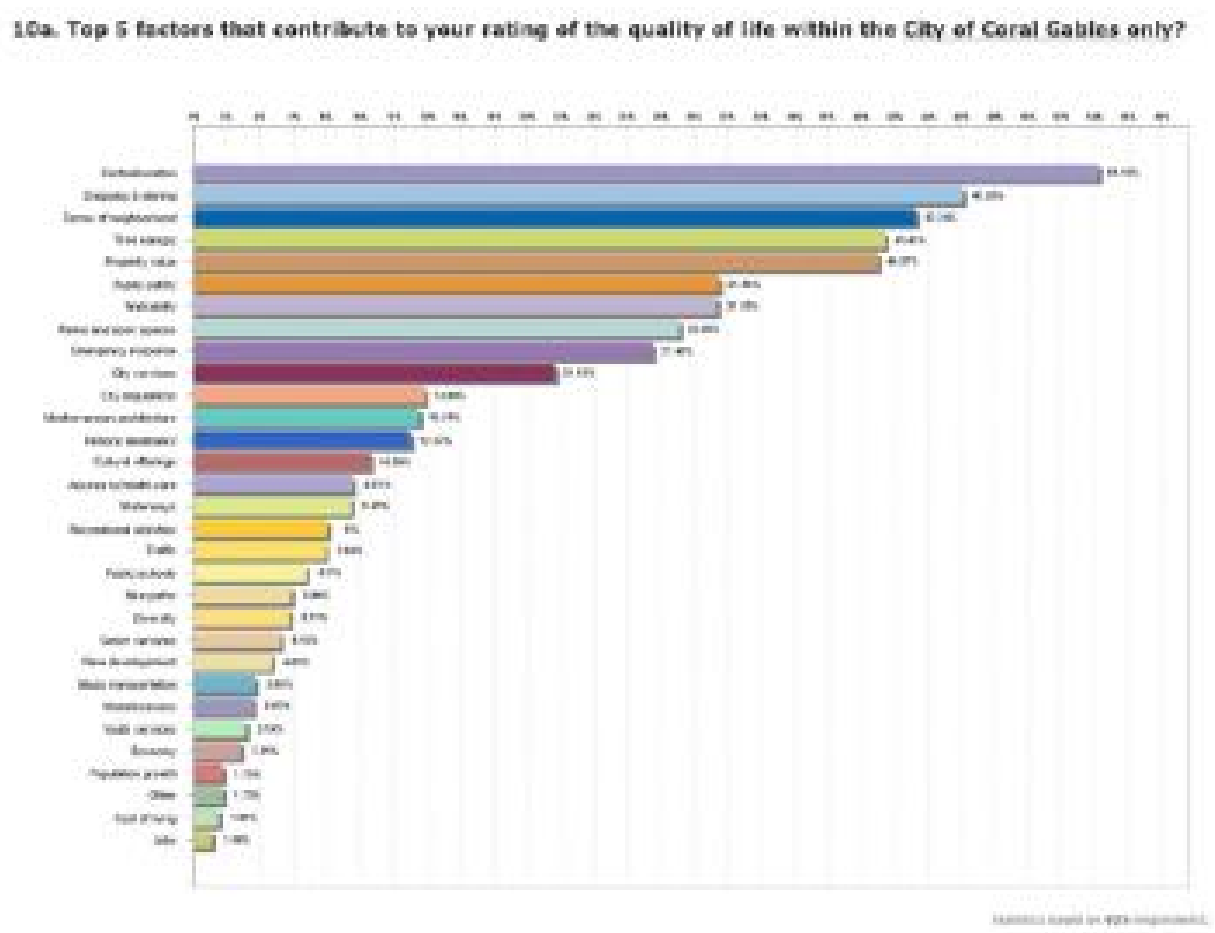

Figure 4. Quality of life in Coral Gables statistics.

Source: City of Coral Gables website.

The top results from the Coral Gables question reflected content of place or content specific to Coral Gables, such as "Mediterranean architecture." For example, content related to place such as sense of neighborhood and tree canopy were among the top five. "Central location," "shopping and dining," and "property value," all related to implementation of place, completed the top five. The key Coral Gables content variable "Mediterranean architecture" was number 12, on the top half. This result was unexpectedly high, as the survey was focused on city services. The delta between quality of life in Coral Gables and Miami-Dade county could be partially explained by the general awareness of unique Coral Gables qualities.

Inferred from this data is that content and process of place are the topics that influence quality of life. On the other hand, general economic measures such as cost of 
living, population growth and the economy were close to the bottom. "Jobs" was in last place, a result that demonstrated that Coral Gables' quality of life was not associated with personal opportunity.

Other findings revealed priorities about the type of content. For instance, "new development" was ranked in $23^{\text {rd }}$ place, while "historic landmarks" was ranked $13^{\text {th }}$, a result that supported priorities for content of place as regulated by the zoning code.

Miami-Dade results provided contrasts that highlighted the role of content and its relationship to quality of life. Variables related to content, in terms of Coral Gables and of place in general were less prominent in the list. General topics related to life in South Florida ranked higher. This would be expected, as residents ranked quality of life in the county fairly high, although quality of life in Coral Gables was higher.

For instance, "Mediterranean architecture" was the second result from the bottom of the list, which indicated a clear understanding of distinctions among places by respondents. On the other hand, regional qualities unrelated to content of a specific place such as beaches, traffic and diversity, ranked among the top five factors. Perhaps traffic could be related to the implementation of place, although current planning practice accepted background traffic at the scale of the county to be beyond the scope of variables that could be controlled through project review.

Only "shopping and dining" was ranked on the top five on both charts. Figure 5 summarizes results for Miami-Dade county, which ranked "Beaches" on second place. Coral Gables had no public beach. 


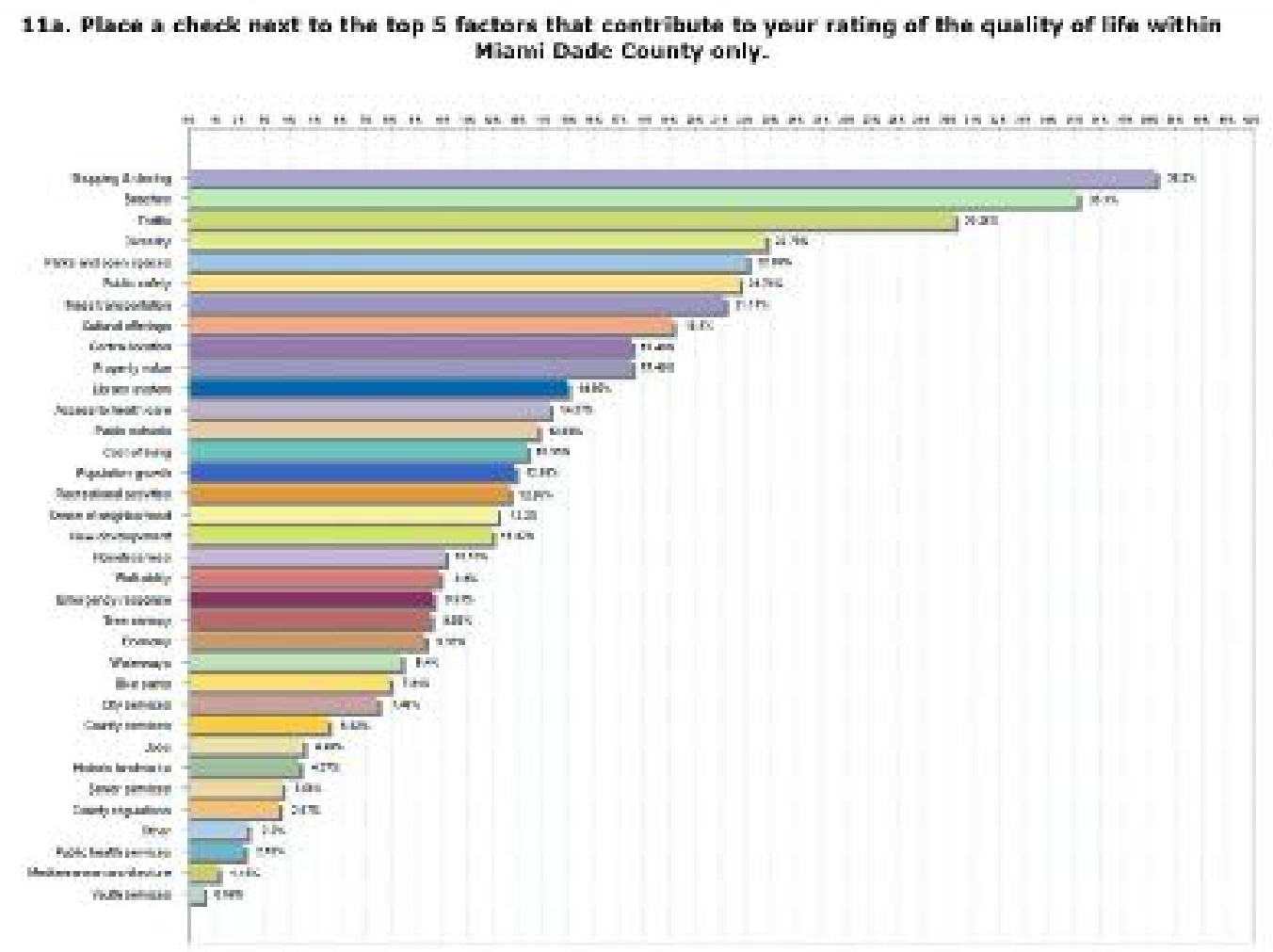

Fig. 5. Quality of life in Miami-Dade County statistics.

Source: City of Coral Gables website.

\section{Write-in Comments}

The survey also collected brief written comments about quality of life. One question asked to list three favorite places. Another question inquired on any reason that would cause one to move out of Coral Gables. Finally, general comments and suggestions could be written in the form.

Figure 6's word cloud from NVIVO depicts the frequency of certain terms. "Excellent" was the most common. 


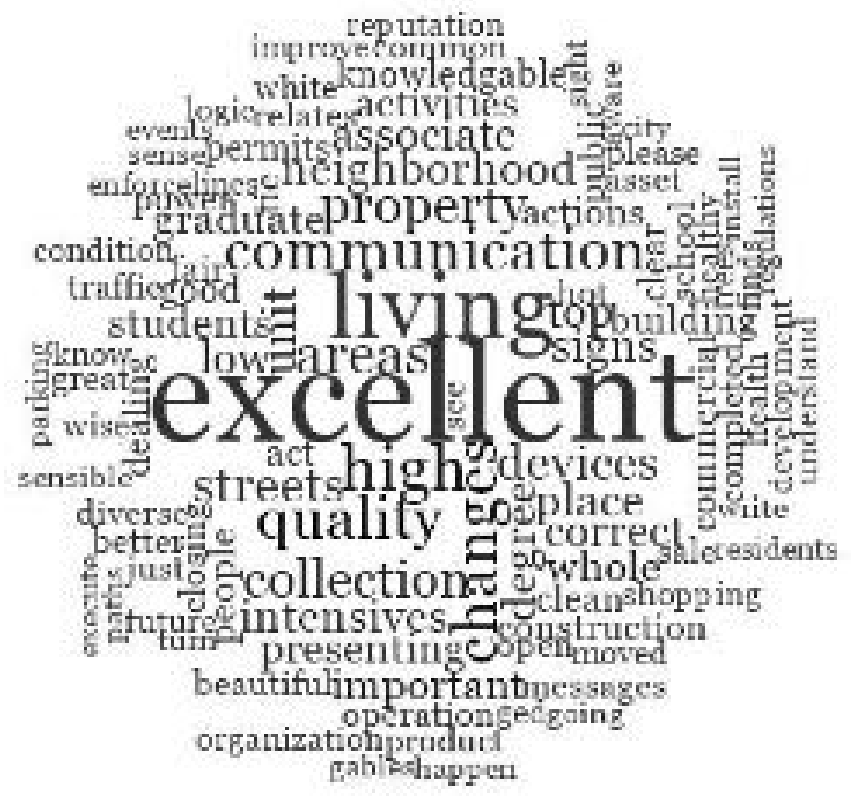

Figure 6. Word cloud from Community Engagement survey write-in comments. Source: Ramon Trias.

The overwhelming tone of comments was positive. This was not a surprise, as quantitative data for Coral Gables quality of life showed satisfaction. Moreover, word cloud analysis highlighted terms related to place, such as "neighborhood," "streets," even the word "place." The most common word was "excellent," as results of questions on a Likert scale included this option.

Respondents were asked what question should have been asked in the survey. Commissioner's performance was among the missing questions, according to written responses from the Community Engagement survey. Moreover, questions about the budget were not included. A person suggested that Mayor and Commissioners should be ranked. These comments revealed that the survey did not ask about topics related to democracy of place. 
The Community Engagement survey was designed by senior city management to evaluate bureaucracy only. Democracy was not measured. This was a common weakness of survey design related to city services, as questions about public input were rare. This fact demonstrated the need of robust theory that linked democracy and bureaucracy. With that limitation in mind, data was reviewed and interpreted for the purpose of research on place as the outcome of democracy and bureaucracy.

\section{Regression Analysis}

Although raw data provided support for the role of content in quality of life, more precise analysis was possible with regression tools. However, regression would provide results that may appear very accurate. Interpretation of data would be necessary to prevent a false sense of precision. Given the conceptual nature of research and the limits of data, results would best be suited for identifying trends and suggesting limits to scope.

Variables were renamed for clarity. Two indicator variables on content were generated from responses to the question on factors that contribute to quality of life in Coral Gables. Answers about Mediterranean architecture in Coral Gables were reinterpreted as "medCG," a dummy variable with values 1 and 0 , where one was assigned to answers that selected this factor among the top five. Another variable for generic place characteristics "neighborhoodCG" was generated. Data was analyzed with statistical tools from STATA.

Regression analysis reported in the following pages attempted to measure the role of content in quality of life, in terms of positive or negative impacts, with some analysis of scope. The concepts reviewed with survey data, based on personal perceptions of general topics, did not support greater accuracy. Content was measured with multiple 
independent variables, with a common Likert scale. However, the term "content" was not used, as the survey was developed before the conclusions of the current study were published. Instead, questions about specific characteristics of Coral Gables, such as sense of neighborhood, parks, historic preservation were interpreted as content. This interpretation focused on generalizations about place, which would be applicable to theory of administration. In addition, Mediterranean architecture was a topic related to content calibrated for Coral Gables.

Questions about the process were also included, such satisfaction with city services. Questions about democracy were less direct, but some responses would contribute data for analysis first model attempted to measure the impact of several content variables on quality of life. Nevertheless, better data on democracy should be collected on future surveys.

Available data allowed some quantitative analysis of the coefficients for several variables related to quality of life in Miami-Dade county. Some contributed to the superior value of quality of life in Coral Gables. Regression analysis attempted measurements.

Dependent variable "qualityoflifeCoralG" was regressed with "qualityoflifeMD" and independent variables for the importance of Mediterranean architecture, one variable for the importance of several city departments that had a role in content or process of place: historic preservation, public works, parks, zoning and Board of Architects. As data was not collected for regression analysis, results were interpreted in the context of multiple models, with low r-squared values and high $\mathrm{p}$ values considered. 
The following table summarized results on quality of life variables:

- reg qualityoflifeCoralg qualityoflifeMD medCG impoeducationhis improadPW impqualityparks impzoning $>$ DS impboaDS

\begin{tabular}{|c|c|c|c|c|c|c|}
\hline Source & SS & $d f$ & MS & Number of obs & $=$ & 235 \\
\hline Model & 12.8912296 & 7 & 1.84160423 & Prob > F & $=$ & 0.0000 \\
\hline Residual & 65.8321747 & 227 & .29000958 & R-squared & $=$ & 0.1638 \\
\hline Total & 78.7234043 & 234 & .336424805 & $\begin{array}{l}\text { Ad] R-squared } \\
\text { Root MSE }\end{array}$ & $\begin{array}{l}= \\
=\end{array}$ & $\begin{array}{l}.1380 \\
.53853\end{array}$ \\
\hline
\end{tabular}

\begin{tabular}{r|rrrrrr}
\hline qualityoflifeC G & Coef. & Std. Err. & $t$ & P >|t| & [95\% Conf. Interval] \\
\hline qualityoflifeMD & .2851657 & .0494478 & 5.77 & 0.000 & .1877303 & .3826012 \\
medCG & .1045435 & .112004 & 0.93 & 0.352 & -.116157 & .325244 \\
impoeducationhis & .0191017 & .0533365 & 0.36 & 0.721 & -.0859963 & .1241996 \\
improadPW & .0264223 & .0764837 & 0.35 & 0.730 & -.1242866 & .1771311 \\
impqualityparks & .0682635 & .0541705 & 1.26 & 0.209 & -.0384778 & .1750047 \\
impzoningDS & .0441539 & .0763432 & 0.58 & 0.564 & -.106278 & .1945858 \\
impboaDS & -.0777077 & .0786497 & -0.99 & 0.324 & -.2326845 & .077269 \\
_Cons & .4775367 & .3678148 & 1.30 & 0.195 & -.2472311 & 1.202305 \\
\hline
\end{tabular}

The most relevant independent variable was "qualityoflifeMD." In other words, quality of life in Coral Gables was perceived as high because of its location in South Florida. Moreover, Quality of life is Coral Gables was superior because of unique characteristics of place or additional municipal services.

Results for "medCG" were second. This variable was generated to represent an aspect of content of place specific to Coral Gables. It was considerable higher than other variables. Thus, this result confirmed that Mediterranean architecture improved residents' opinions about quality of life in Coral Gables. In a more general sense, the result supported a crucial role of content for the implementation of place. But content would not be sufficient to implement place, and data showed that it was one of several factors that enhanced quality of life.

However, content specific to Coral Gables was not the only variable that contributed to superior quality of life. Parks and roads were also important. Variables about process, such as zoning and historic education also had positive values. Thus, both 
content and process could be measured in terms of quality of life. Superior quality of life in Coral Gables could be expressed with the following formula:

Coral Gables quality of life $=$ Miami-Dade quality of life + Coral Gables content of place + Coral Gables process of place

An unexpected result was that the only negative value was "impboaDS," for importance of the Board of Architects. Perhaps this result reflected the common anecdotes about frustrations with the process, as respondents were random residents who were not likely to be regular customers of the Board of Architects. Nevertheless, when data from the customers of the Board of Architects was reviewed, findings showed general satisfaction, discussed later in this section.

\section{Additional Models}

Multiple models were measured to explore findings from related qualitative research, which highlighted priorities and relevant topics for place and the role of content from a select group of experts. Findings were organized in the following strands:

\section{Education}

Qualitative findings emphasized the need for enhanced education about place and design. The Community Engagement survey had several questions about specific aspects of education, related to city processes and services. When the topic was measured, with dependent variable "quality of life" and independent variables for education development process, code enforcement and history results did not support a strong relationship, with R squared value of .01. 
- reg qualityoflifecoralg imporcodeeducation impeducationDs impoeducationhis

\begin{tabular}{|c|c|c|c|c|c|c|}
\hline Source & SS & $d f$ & MS & Number of obs & $=$ & 279 \\
\hline Model & 1.09801484 & 3 & .366004947 & Prob > F & $=$ & 0.4107 \\
\hline Residual & 104.543562 & 275 & .380158408 & R-squared & $=$ & 0.0104 \\
\hline Total & 105.641577 & 278 & .380005673 & Root MSE & $=$ & \\
\hline
\end{tabular}

\begin{tabular}{|c|c|c|c|c|c|c|}
\hline qualityoflifeCor G & Coef. & Std. Err. & $t$ & $P>|t|$ & [95\% Conf. & Interval] \\
\hline imporcodeeducation & -.0337757 & .0673622 & -0.50 & 0.616 & -.1663868 & .0988353 \\
\hline impeducationDS & .0054056 & .0641603 & 0.08 & 0.933 & -.1209022 & .1317135 \\
\hline impoeducationhis & .0752081 & .0471776 & 1.59 & 0.112 & -.0176671 & .1680833 \\
\hline _cons & 1.377205 & .2495462 & 5.52 & 0.000 & .8859417 & 1.868469 \\
\hline
\end{tabular}

The model could be interpreted in general terms. The low coefficients suggested that education did not influence quality of life. In other words, the general public assumed that professionals involved in the implementation of place would be experts and would perform their responsibilities with acceptable standards of care. However, the low r-squared value suggests that the model is not reliable.

As the experts repeatedly express the need of education (Poole, 2018), (PlaterZyberk, 2018), it should be concluded that survey data did not adequately measure this topic. Further quantitative data would be needed.

\section{Design Review}

A probit model run with "medCG" as dependent variable and several process independent variables, to measure the effect of this specific type content, unique to Coral Gables and highly valued for quality of life, on the importance of the process of implementation of place. 


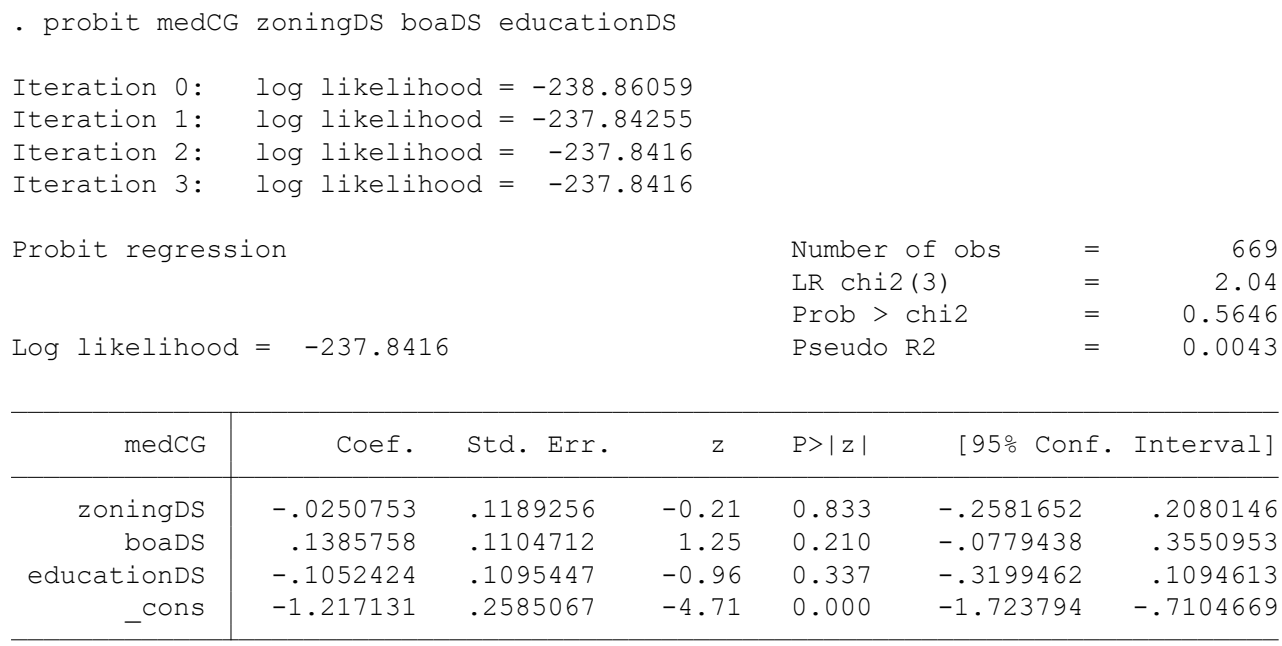

The model was considered sufficient for conceptual theory research. Results showed support for the importance of Board of Architects process, as a method to implement Coral Gables content. This variable represented democracy of place, as the Board of Architects is organized as a public meeting were all input is accepted. Variables related the importance of the bureaucratic process show negative results.

When the model was run with the variable for merged aspects of place, neighborhoodCG only zoning and the importance of zoning show negative results:

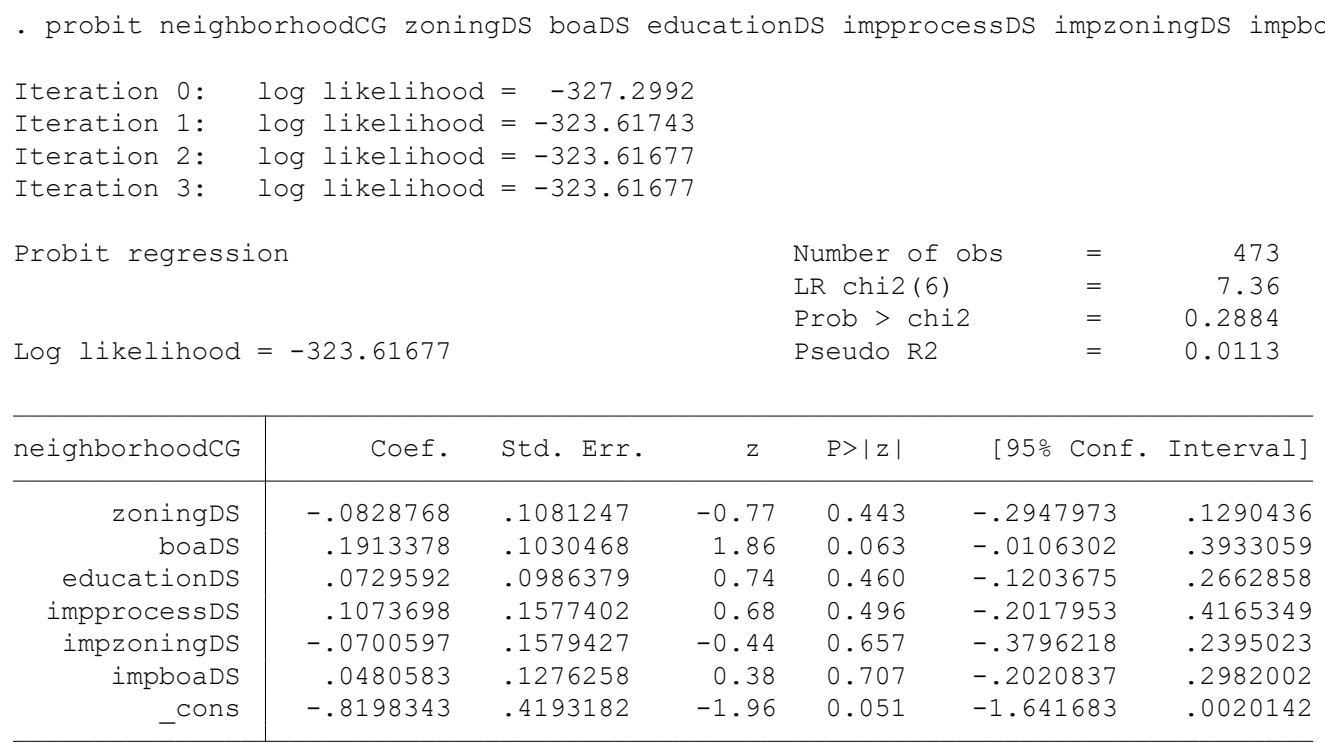


This result may be surprising at first, as zoning has always been important. However, it reflected a keen understanding of place, which transcended simple zoning regulation. The Board of Architects process has the highest positive results. This demonstrated a nuanced understanding of the unique process of design review throughout the community. As many residents have gone through the process, for a new house or even for the replacement of a front door, this result was consistent with theory that values the role of design review.

\section{Content and Process for the Implementation of Place}

Quality of life was considered a proxy for the effective implementation of place in Coral Gables. When “qualityoflifeCoralG” was measured against conventional city services, such as fire, police and medical response, very few variables were positive. This result was unexpected, as survey managers assumed that city services not associated with place would be among the most significant factor of quality of life. Perhaps that would be true in local governments that lacked strong characteristics of place. The role of place was the topic of research, and such results supported the idea that features unique to place were significant.

Consistent with prior results from other models, quality of life in Miami-Dade county had the highest positive result. Only art in public places, parks and garbage also were positive. Several critical city services, such as police response, had negative coefficients. 
- reg qualityoflifeCoralg policeresponse fireresponse garbage art qualityparks parking zoningDS boaD $>$ S qualityoflifemD

\begin{tabular}{|c|c|c|c|c|c|c|}
\hline Source & SS & $d f$ & MS & Number of obs & $=$ & 315 \\
\hline Model & 16.3344027 & 9 & 1.81493363 & Prob $>\mathrm{F}$ & $=$ & 0.00 \\
\hline Residual & 86.3513116 & 305 & .283119054 & $\mathrm{R}-$ squared & $=$ & 0.15 \\
\hline Total & 102.685714 & 314 & .327024568 & Root MSE & $=$ & .532 \\
\hline
\end{tabular}

\begin{tabular}{r|rrrrrr}
\hline qualityoflife G & Coef. & Std. Err. & $t$ & $\mathrm{P}>|\mathrm{t}|$ & [95\% Conf. Interval] \\
\hline policeresponse & -.1030627 & .0583688 & -1.77 & 0.078 & -.2179192 & .0117939 \\
fireresponse & -.0044966 & .0666066 & -0.07 & 0.946 & -.1355633 & .12657 \\
garbage & .0771639 & .0466566 & 1.65 & 0.099 & -.0146458 & .1689735 \\
art & .026834 & .0413107 & 0.65 & 0.516 & -.054456 & .108124 \\
qualityparks & .0093866 & .05903 & 0.16 & 0.874 & -.1067709 & .1255442 \\
parking & -.0446253 & .041069 & -1.09 & 0.278 & -.1254397 & .0361891 \\
zoningDS & -.0617621 & .0504574 & -1.22 & 0.222 & -.1610509 & .0375267 \\
boaDS & -.0304632 & .0484001 & -0.63 & 0.530 & -.1257036 & .0647773 \\
qualityoflifeMD & .2578087 & .0422893 & 6.10 & 0.000 & .1745929 & .3410244 \\
Cons & 1.216173 & .2965744 & 4.10 & 0.000 & .6325817 & 1.799764 \\
\hline
\end{tabular}

Coral Gables residents had high expectations for city services. The positive result of garbage collection was expected, as the high level of service of sanitation workers is a valued city amenity. Positive results for parks and the art in public places program measure appreciation for some of the most visible aspects of the content of place.

On the other hand, process of place (zoning and board of architects) received negative coefficients. The may be the result of general frustration with bureaucracy. Surprisignly, police and fire response were also negative. However, $\mathrm{p}$-values for all results were high. Data should develop and test proposed theory.

Quality of life in Miami-Dade was again the highest coefficient. This was the most consistent result in all models, and supported the fundamental theory assumption. Locally calibrated variables for content of place enhanced the good quality of life which resulted from general location. Moreover, variables for process of place tended to be negative. Therefore, public administration's emphasis on optimizing process and bureaucratic efficiencies were not consistent with the priorities of residents. Content of 
place, on the other hand, contributed to quality of life. Data was consitent general theory assumptions, and future research could refine conclusions.

\section{Review of Customer Satisfaction Survey, Board of Architects}

The customer satisfaction survey of the Board of Architects was provided to users of the BOA desk, after an application was submitted. The survey was anonymous, was completed on paper, and was collected on a box at the counter. Sixty-seven responses were tabulated, which was determined sufficient for theory research. Questions beyond demographic topics were structured with Likert scales. Thus, results fit regression techniques better that results from the Community Engagement data.

The survey collected data on the following topics:

- Zoning application process

- Plans review staff

- Board of Architects process

- Zoning code knowledge

- Zoning requirements

Questions about zoning requirements and the plans review process measured the general topic of bureaucracy. The Board of Architects process, as it centered on public meetings, was determined to explore the aspects of democracy related to the implementation of place. In addition, two questions measured awareness and support for specific topics related content of place. Thus, data from this survey would be measured with several models, to test several theory ideas developed through qualitative research.

The population sample included contractors, permit runners, homeowners and other professionals involved with construction and design. Thus, results could be 
compared with data from the Community engagement survey, which measured responses from a random sample of Coral Gables residents. Raw data was a public record, provided by the City of Coral Gables, as prepared by the Baldrige Group, LLC.

During the preparation of the survey instrument, the author of this study provided suggestions on questions related to content. Two questions which addressed content directly related to the Coral Gables zoning code were included:

"The Mediterranean architectural requirements contribute to the city's overall beauty"

"The city zoning code requirements add to the long-term vision of the city."

All variables were renamed for STATA analysis in this study, to make them more descriptive. One new variable was generated, BOAsatisfaction, to merge all values related specifically to the Board of Architects. No other changes were made to data provided by the City consultant.

\section{Survey Results}

A surprising result was overall satisfaction, which was $98.78 \%$. Prior anecdotes about the Board of Architects process tended to be negative. However, customer satisfaction was very high.

This finding suggested that stories about bureaucratic interaction could be used to influence outcomes, if decision-makers lacked objective data and were willing to listen to complaints based on anecdotes. Qualitative interviews revealed many instances in which aggrieved individuals had attempted to discredit or alter the process, for their own purposes. Survey results provided objective data for the first time on the process that 
merged democracy and bureaucracy of place, the Board of Architects. The data were positive.

In contrast, results from the "Community Engagement" survey did not provide positive results for the importance of the Board of Architects process. Although customers were satisfied, the general public was more influenced by second hand information. Thus, past criticism about the experience of presenting a project to the Board, code requirements, and aesthetic direction of the city could be addressed objectively with updated data. On the other hand, positive results should not be taken at face value, as it is likely that there may be some bias towards responding positively, as the sample was small, and comprised of people who work with the Board regularly.

The goal of the survey was a review of city processes where there was substantial interaction with customers. However, in the public sector customers are citizens, and their views should be considered from the point of view of civic life. The distinction between customer and citizen is significant for theory. Private sector surveys measure customer satisfaction. That would be an insufficient standard for the public sector. In the public sector, questions about democracy should be included.

The Board of Architects was a democratic activity for the implementation of place. Board members were volunteers. Meetings were public and advertised. Participants discussed and debated the merits of each application, in ways that content always prevailed over procedure. Multiple meetings on the same request were common, as recommendations of the members of the board were incorporated. In terms of bureaucracy, the survey asked questions about steps in the process and interactions with staff. 


\section{Satisfaction with the Board of Architects Process}

A composite variable for satisfaction, BOAsatisfaction, where 1 was "very satisfied" offered surprising results:

- sum BOAsatisfaction

\begin{tabular}{r|rrrrr} 
Variable & Obs & Mean & Std. Dev. & Min & Max \\
\hline BOAsatisfa n & 62 & 1.048387 & .3810004 & 1 & 4
\end{tabular}

The level of customer satisfaction of the composite variable was very high. When each variable used to create "BOAsatisfaction" was measured individually, results were similar:

- sum boardrepect boardinfo boardrules

\begin{tabular}{r|rrrrr} 
Variable & Obs & Mean & Std. Dev. & Min & Max \\
\hline boardrepect & 62 & 1.048387 & .3810004 & 1 & 4 \\
boardinfo & 62 & 1.032258 & .2540003 & 1 & 3 \\
boardrules & 60 & 1.033333 & .2581989 & 1 & 3
\end{tabular}

Satisfaction with the Board of Architects was unexpected, as complaints appeared common to some managers. Data demonstrated that anecdotes were unreliable. This finding was of immediate use for practice. Experienced administrators would have concluded that complaints about the Board of Architects process would come for a selfselected group of customers who were unable to get the results they wanted. Random anonymous data confirmed this bias and provided accurate information to staff and elected officials.

The finding of high levels of satisfaction with the Board of Architects also contributed to theory development on the effect of design review on governance, as the separate effect of democracy and bureaucracy could be measured with several 
coefficients. One simple model measured dependent variable "longtermvision," a proxy for content of place, with one variable for democracy, "boardrespect," and one variable for bureaucracy, "staffknowledge."

- reg longtermvision boardrepect staffknowledge

\begin{tabular}{|c|c|c|c|c|c|}
\hline Source & SS & $d f$ & MS & Number of obs & 46 \\
\hline Model & 4.66329626 & 2 & 2.33164813 & Prob > F & 0.0000 \\
\hline Residual & 7.1627907 & 43 & .166576528 & R-squared & 0.3943 \\
\hline Total & 11.826087 & 45 & .262801932 & $\begin{array}{l}\text { Aa] R-Squared } \\
\text { Root MSE }\end{array}$ & .40814 \\
\hline
\end{tabular}

\begin{tabular}{r|rrrrrr}
\hline longtermvision & Coef. & Std. Err. & $t$ & P > t | & [95\% Conf. Interval] \\
\hline boardrepect & .0465116 & .2365501 & 0.20 & 0.845 & -.4305371 & .5235603 \\
staffknowledge & .8604651 & .2952323 & 2.91 & 0.006 & .2650724 & 1.455858 \\
_cons & .2325581 & .1962741 & 1.18 & 0.243 & -.1632663 & .6283825 \\
\hline
\end{tabular}

Results for bureaucracy were positive and reliable. Nevertheless, democracy also had a positive coefficient. However, if the model included an independent variable for content, "mediterranean," results were very different, with a better fit for data:

- reg longtermvision boardrepect staffknowledge mediterranean

\begin{tabular}{|c|c|c|c|c|c|c|c|}
\hline Source & SS & $d f$ & MS & \multicolumn{2}{|c|}{$\begin{array}{l}\text { Number of obs } \\
F(3,41)\end{array}$} & $=$ & 45 \\
\hline Model & 8.75097087 & 3 & 2.91699029 & Prob & & $=$ & 0.0000 \\
\hline Residual & 2.44902913 & 41 & .059732418 & $\mathrm{R}-\mathrm{squ}$ & ed & $=$ & 0.7813 \\
\hline Total & 11.2 & 44 & .254545455 & Root & & $=$ & .2444 \\
\hline longtermvision & Coef. & Std. Err. & t & $P>|t|$ & {$[95 \%$} & Conf. & Interval] \\
\hline boardrepect & .3033981 & .1453237 & 2.09 & 0.043 & .009 & 9108 & .5968853 \\
\hline staffknowledge & -.3592233 & .2334804 & -1.54 & 0.132 & $-.830^{\circ}$ & 7465 & .1122999 \\
\hline mediterranean & .8980583 & .110356 & 8.14 & 0.000 & .675 & 897 & 1.120927 \\
\hline _cons & .1699029 & .1179756 & 1.44 & 0.157 & -.068 & 3536 & .4081594 \\
\hline
\end{tabular}

Data proved content had the most significant positive role in democracy and bureaucracy of place. These results confirmed two theory assumptions, which explained the role of aspirational content on the scope of bureaucracy of place:

1. Bureaucracy could function without local content.

2. Robust aspirational content transformed communities, when properly applied. 
The finding suggested that bureaucracy could be autonomous, but that outcomes from processes that did not value content would be inferior to the outcomes of bureaucratic processes informed by content.

\section{Design Review Data}

Data supported the two research questions explored in this chapter. Moreover, results suggested additional in-depth investigation on design review.

Data from Community engagement data measured the effect of Board of

Architects and zoning process and generic characteristics of place for quality of life in Coral Gables:

- reg qualityoflifeCoralG boaDS zoningDS neighborhoodCG qualityoflifeMD

\begin{tabular}{|c|c|c|c|c|c|c|c|}
\hline Source & SS & $d f$ & MS & \multirow{2}{*}{\multicolumn{2}{|c|}{$\begin{array}{l}\text { Number of obs } \\
\text { F }(4,607) \\
\text { Prob > F }\end{array}$}} & \multirow{2}{*}{$\begin{array}{l}= \\
= \\
=\end{array}$} & \multirow{2}{*}{$\begin{array}{r}612 \\
26.41 \\
0.0000\end{array}$} \\
\hline Model & 30.3191236 & 4 & 7.5797809 & & & & \\
\hline Residual & 174.208654 & 607 & .28699943 & $R-s q u$ & & $=$ & 0.1482 \\
\hline Total & 204.527778 & 611 & .33474268 & Root & & $=$ & .53572 \\
\hline qualityoflife G & Coef. & Std. Err. & t & $P>|t|$ & {$[95 \%$} & Conf. & Interval] \\
\hline boaDS & .0082058 & .0376858 & 0.22 & 0.828 & $-.065 \xi$ & 8045 & .0822162 \\
\hline zoningDS & -.1102811 & .0384695 & -2.87 & 0.004 & -.1858 & 8305 & -.0347317 \\
\hline neighborhoodCG & -.1150643 & .0437279 & -2.63 & 0.009 & -.200 & 9407 & -.0291879 \\
\hline qualityoflifemD & .2456454 & .0304618 & 8.06 & 0.000 & .185 & 8221 & .3054687 \\
\hline Cons & 1.222583 & .1238792 & 9.87 & 0.000 & .9792 & 2987 & 1.465867 \\
\hline
\end{tabular}

The Board of Architects process had a positive result, although it was very close to zero. Nevertheless, the effects of process and generic characteristics of place were negative. 
- reg impboaDS impzoningDS impprocessDS impeducationDS impoeducationhis

\begin{tabular}{|c|c|c|c|c|c|c|}
\hline Source & SS & $d f$ & MS & Number of obs & $=$ & 323 \\
\hline Model & 105.70511 & 4 & 26.4262776 & Prob $>F$ & $=$ & 0.0000 \\
\hline Residual & 46.8707411 & 318 & .147392268 & R-squared & $=$ & 0.692 \\
\hline Total & 152.575851 & 322 & .473838048 & Root MSE & $=$ & .383 \\
\hline
\end{tabular}

\begin{tabular}{|c|c|c|c|c|c|c|}
\hline impboaDS & Coef. & Std. Err. & $t$ & $P>|t|$ & [95\% Conf. & Interval] \\
\hline impzoningDS & .4716585 & .0506442 & 9.31 & 0.000 & .3720184 & .5712986 \\
\hline impprocessDS & .3683428 & .0545154 & 6.76 & 0.000 & .2610864 & .4755992 \\
\hline impeducationDS & .0865932 & .0422995 & 2.05 & 0.041 & .0033709 & .1698155 \\
\hline impoeducationhis & -.0104869 & .0274545 & -0.38 & 0.703 & -.0645022 & .0435285 \\
\hline Cons & .2858737 & .146424 & 1.95 & 0.052 & -.0022085 & .5739559 \\
\hline
\end{tabular}

A variable was generated from all Board of Architect variables related to customer satisfaction (BOAsatisfaction). It was regressed as dependent variable with all process variables, which would measure the impact of bureaucracy.

- reg BOAsatisfaction zoningreq staffprofessionalism resources zoningstaffadvice

\begin{tabular}{|c|c|c|c|c|c|c|}
\hline Source & SS & $d f$ & MS & Number of obs & $=$ & 49 \\
\hline Model & 7.02447133 & 4 & 1.75611783 & Prob $>F$ & $=$ & 0.0000 \\
\hline Residual & 1.7918552 & 44 & .040723982 & R-squared & $=$ & 0.7968 \\
\hline Total & 8.81632653 & 48 & .183673469 & Root MSE & $=$ & .2018 \\
\hline
\end{tabular}

\begin{tabular}{|c|c|c|c|c|c|c|}
\hline BOAsatisfaction & Coef. & Std. Err. & t & $P>|t|$ & [95\% Conf. & Interval] \\
\hline zoningreq & .0135747 & .2040719 & 0.07 & 0.947 & -.3977052 & .4248545 \\
\hline staffprofessionalism & 1.208145 & .0920678 & 13.12 & 0.000 & 1.022594 & 1.393695 \\
\hline resources & -1.208145 & .2998741 & -4.03 & 0.000 & -1.812501 & -.6037883 \\
\hline zoningstaffadvice & .0135747 & .2040719 & 0.07 & 0.947 & -.3977052 & .4248545 \\
\hline -cons & .959276 & .2995666 & 3.20 & 0.003 & .3555391 & 1.563013 \\
\hline
\end{tabular}

The highest result was staff professionalism. This was expected, as Coral Gables administrators provided an unusual level of service. It also demonstrated that effective bureaucracy of place had a significant role in customer satisfaction.

\section{Content for Design Review}

The blended variable BOAsatisfaction was regressed against two variables for content ("mediterranean") and one variable for process ("zoningrequirementsend"): 
- reg BOAsatisfaction mediterranean zoningrequirementsend

\begin{tabular}{|c|c|c|c|c|c|c|}
\hline Source & SS & $d f$ & MS & Number of obs & $=$ & \\
\hline Model & 3.40962567 & 2 & 1.70481283 & $\begin{array}{l}F(\angle, 4 \angle) \\
\text { Prob }>F\end{array}$ & $\begin{array}{l}= \\
=\end{array}$ & $\begin{array}{l}13.28 \\
0.0000\end{array}$ \\
\hline Residual & 5.39037433 & 42 & .128342246 & R-squared & $=$ & 0.3875 \\
\hline Total & 8.8 & 44 & .2 & Root MSE & $=$ & .35825 \\
\hline
\end{tabular}

\begin{tabular}{|c|c|c|c|c|c|c|}
\hline BOAsatisfaction & Coef. & Std. Err. & $t$ & $P>|t|$ & [95\% Conf. & Interval] \\
\hline mediterranean & .6096257 & .1186154 & 5.14 & 0.000 & .3702502 & .8490012 \\
\hline zoningrequirementsend & -.5935829 & .2132342 & -2.78 & 0.008 & -1.023907 & -.1632588 \\
\hline cons & .9679144 & .2140374 & 4.52 & 0.000 & .5359695 & 1.399859 \\
\hline
\end{tabular}

Results are statistically acceptable for the study, with low p values and r-squared value of 38 and show that satisfaction results from content. When a comparable regression is run with data from the Community Engagement survey, content (medCG) and the importance implementation of content (impboaDS) also have positive values when values for process are negative. However, results for this model were statistically unreliable.

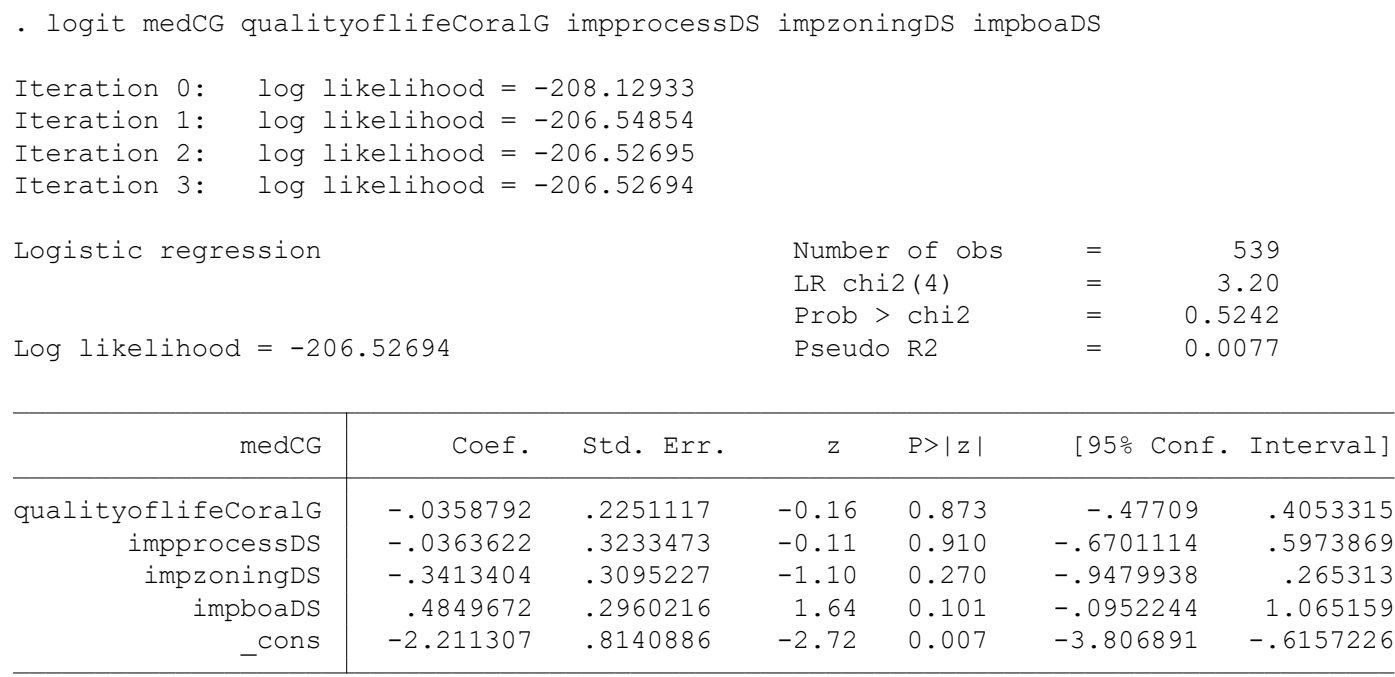




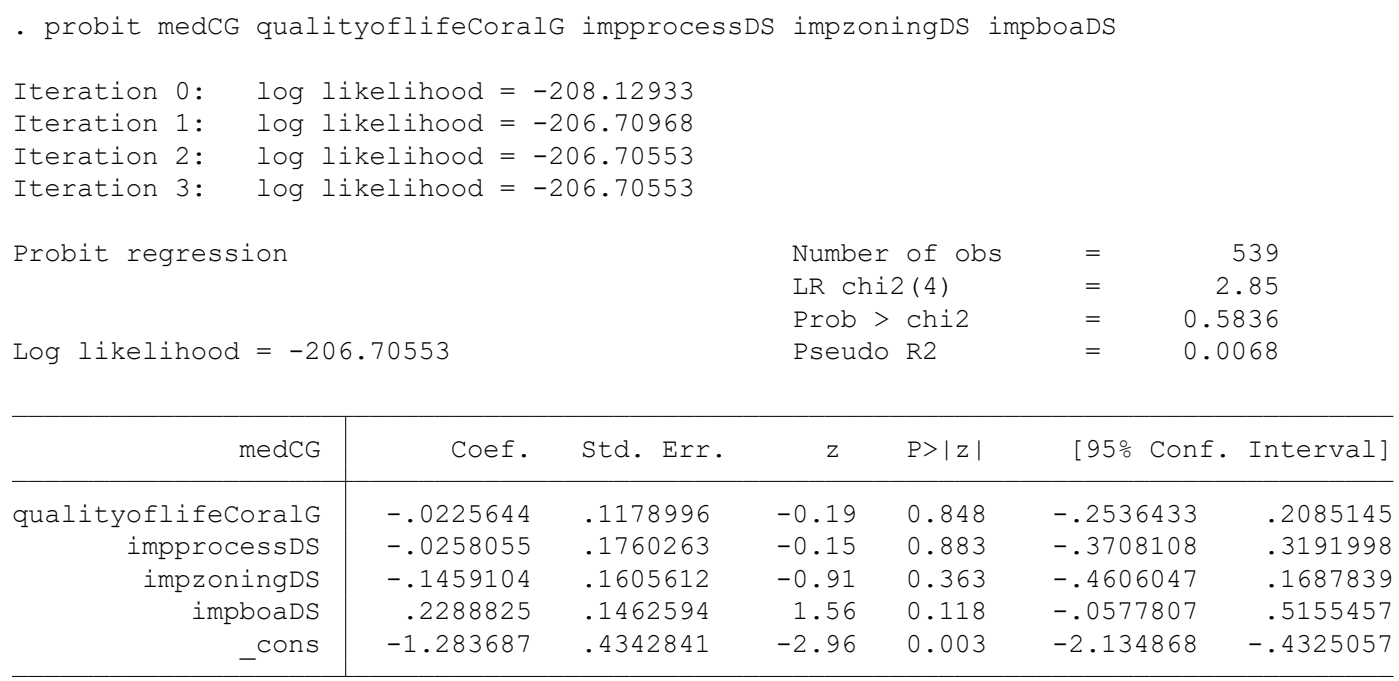

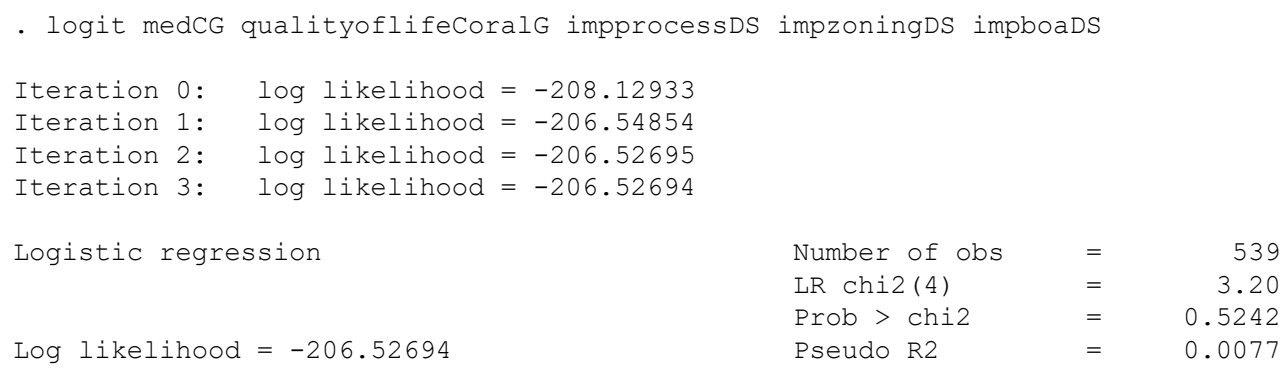

\begin{tabular}{|c|c|c|c|c|c|c|}
\hline medCG & Coef. & Std. Err. & $\mathrm{z}$ & $P>|z|$ & {$[95 \%$ Conf. } & Interval] \\
\hline qualityoflifeCoralG & -.0358792 & .2251117 & -0.16 & 0.873 & -.47709 & .4053315 \\
\hline impprocessDS & -.0363622 & .3233473 & -0.11 & 0.910 & -.6701114 & .5973869 \\
\hline impzoningDS & -.3413404 & .3095227 & -1.10 & 0.270 & -.9479938 & .265313 \\
\hline impboaDS & .4849672 & .2960216 & 1.64 & 0.101 & -.0952244 & 1.065159 \\
\hline _cons & -2.211307 & .8140886 & -2.72 & 0.007 & -3.806891 & -.6157226 \\
\hline
\end{tabular}

A model for the implementation of content in the Board of Architects showed the crucial role of staff, results which provided additional support for bureaucracy of place. It also measured a negative value for "boardrespect," the quality of the behavior of the members towards the applicants, which had been mentioned occasionally as a concern by some unsatisfied customers. Thus, data highlighted an area of the democratic process that could be improved. The Board members had a responsibility to treat customers as citizens who participate in a democratic activity, with adequate respect and deference for 
their views. Moreover, democracy of place was not politics. It was a collaboration, with support from bureaucratic staff. Such distinctions removed misunderstandings about democracy and bureaucracy which could interfere with effective governance.

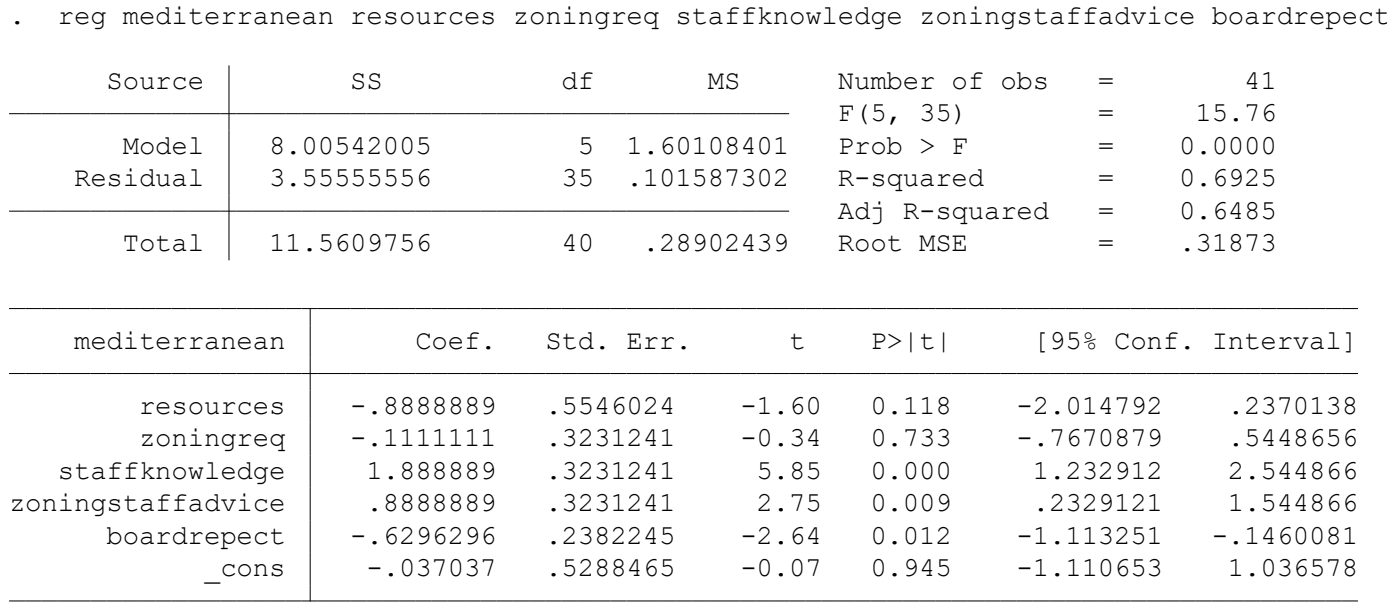

The survey included a line for written comments. The word cloud produced with NVIVO showed "satisfied" as the most common word, and many other topics mentioned in positive terms, as seen in figure 7.

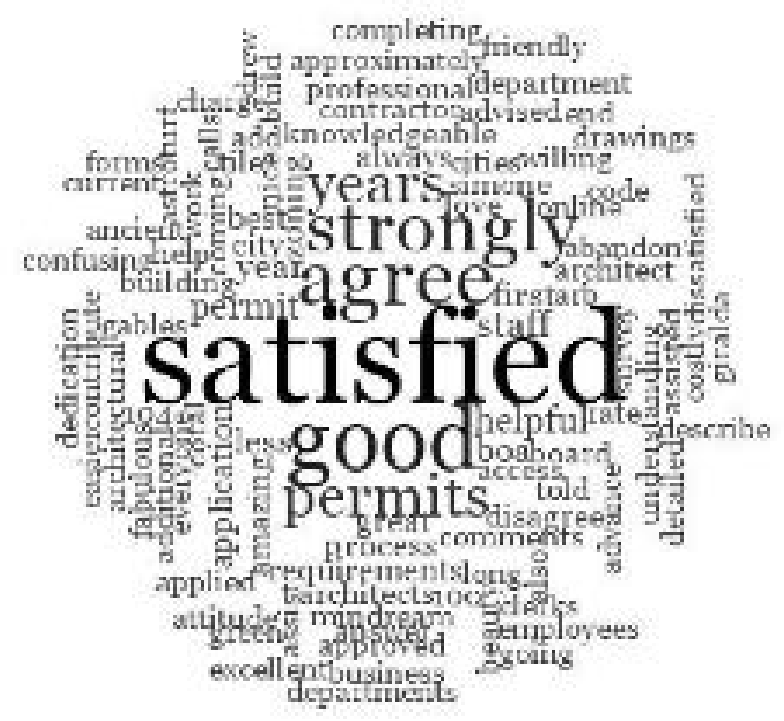

Figure 7. Word cloud from Board of Architects survey write-in comments.

Source: Ramon Trias. 
The surveys measured customer satisfaction, although such survey design may be excessively narrow for the public sector. In terms of raw data, which was the intended report method of survey results, overall satisfaction was at $98 \%$. Zoning application process satisfaction was $100 \%$. City zoning requirement satisfaction was $95.88 \%$. Such results indicate customers valued a strict design review process, as predicted by qualitative input.

Two questions measured support for content of place. The Mediterranean architectural requirements contribution to the beauty of the city were valued by 95.83 of customers. "The zoning requirements add to the long-term vision of the city" was supported by 95.92 of responses. Therefore, there was general awareness, understanding and satisfaction about the two most crucial aspects of content: aspirational ideas and regulatory details.

The population of the Board of Architects survey was smaller than the Community Engagement survey, as there were only 67 responses. Moreover, although the survey was random, the population was self-selected to some extent, only people who did business personally at the counter completed surveys. It may be expected that some subjects may have responded positively because of their business before the Board. Nevertheless, this was the first anonymous survey performed on Board of Architects activities, and results should inform future research.

\section{Democracy for Smart Place}

The surveys did not include direct questions about public input or participation in policy. This was a decision of survey design. Thus, data provided a narrow perspective 
on local governance. Not measuring democracy presented a significant gap in data for the purpose of testing proposed theory.

Oher Coral Gables initiatives have been exploring public input and discussion in terms of smart data. Future research should explore public input and interaction, which may be meaningful measurements of engagement. Smart technologies are starting to provide dynamic tools for input and discussion. This finding suggests that democratic interaction is undergoing a significant transformation. One recent tool adopted by the city of Coral Gables is ZenCity, a product that aggregates public discussions about topics related to governance of place. The program searches internet media and organizes and displays raw information, as shown in plate 34 and 35, with limited analysis.

\section{Trending Topics}

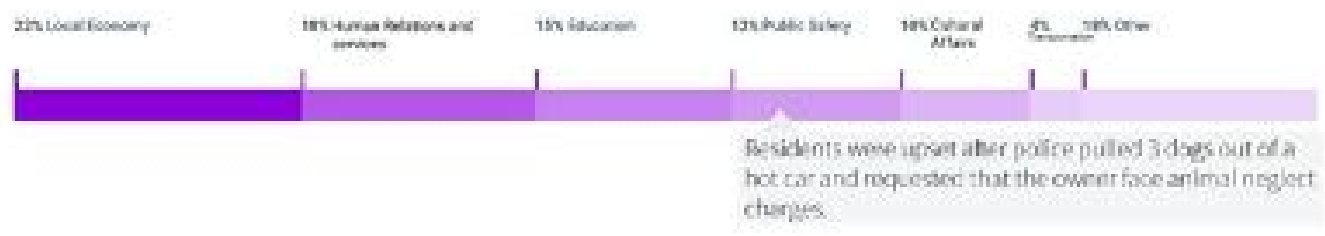

\section{Highlighted Topics}

\section{Planning and Development - Discourse Trend}

D.ring the manth of July [unti 19.2) there was an increase in the velune ef discourse (Q7) interactices) on plsaniag and development compoed to June (AT) i-taractions and Mar 129 interastisns]

The incosase was msing due so Mismi-0nde County's rejectisn of the ciry's

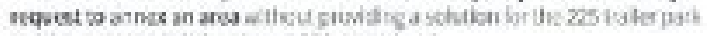

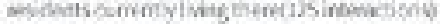

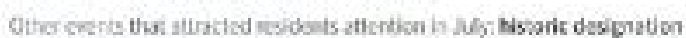

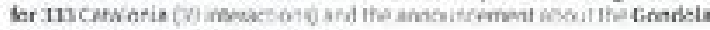

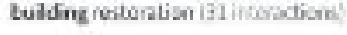

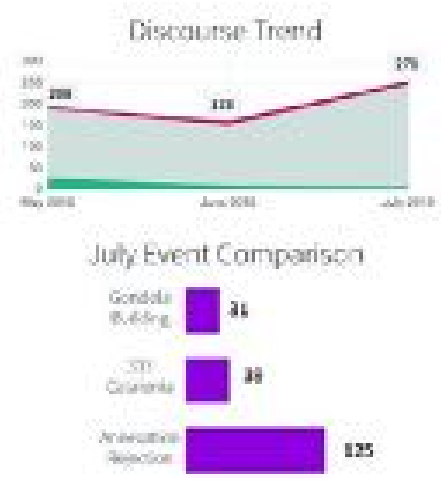

Plate 34. Summary of topics, ZenCity. Source: City of Coral Gables. 


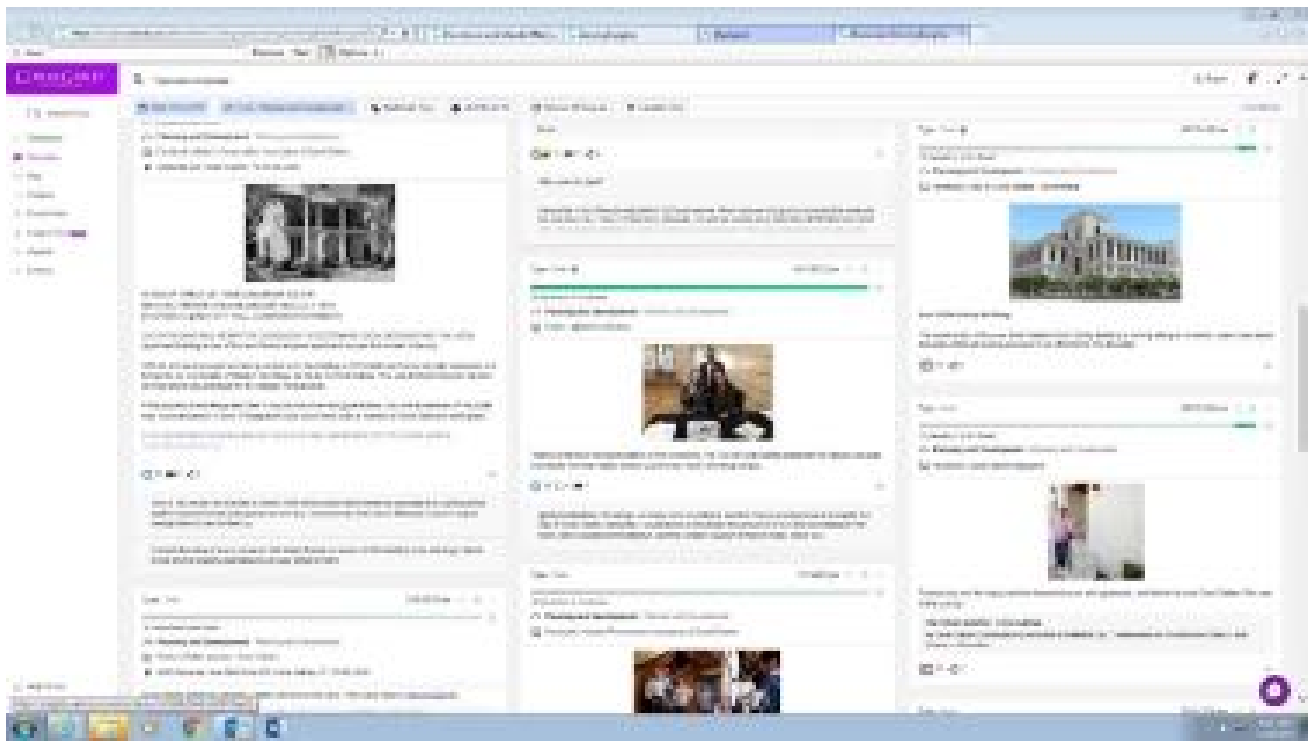

Plate 35. Social media comments, ZenCity. Source: City of Coral Gables.

Public commentary provided valuable information and expanded the role of content in quality of life. Nevertheless, it is unclear how data from multiple media sources could be used methodically to enhance democracy of place.

Random input is not content, but it should not be dismissed without review. Content has to be actionable. Moreover, local politics is not democracy, as the spectrum of democratic activities far exceeds elections or Commission meetings. Best practices need to be developed, in ways that inform democracy and bureaucracy and lead to smart place.

The concept of governance would guide best practices along a spectrum of participation and decision. Data from public comments would find a place in the earliest stops in the process. Conventional planning and zoning privileged the grand decision crafted at an adversarial public hearing. Democracy of place would be better understood as dynamic input for a sequence of iterative decisions, at multiple times and scales, with opportunities for revisions. 


\section{Discussion}

Analysis used existing survey data which measured some of the topics of research directly, and other topics indirectly. Survey data measured bureaucracy, with positive results. Democracy was not measured directly, but some data provided insight into specific aspects of public participation and input. Findings provided strong support for the proposed theory framework and sketched robust theory ideas that should be verified with future research.

An objective review of data from the surveys depicted an effective local government in Coral Gables, with practices that could be generalizable, as they addressed common topics of governance and typical community aspirations. The most common word used in the "Community Engagement" survey used term was "excellent." The most common term used in the Board of Architects satisfaction survey was "satisfied." Qualitative findings and historical research on bureaucratic processes were validated by survey results. Moreover, the role of content was also consistent with assumptions. It could be concluded, pending future in-depth research for further details, that local content of place was the critical factor for superior quality of life in Coral Gables. From this point of view, data proved the hypotheses.

However, this study explored bureaucracy and democracy of place. Aspirational content was intended to result from a democratic process. The surveys were silent on the topic of public participation. They did not include questions about the performance of elected officials. This limited perspective was significant finding of the study. In recent decades, theory of public administration had increasingly incorporated the values of business. According to some public managers, a transaction with a happy customer 
should be the contemporary standard for excellence. But such a standard had little to do with values that preserve democracy and sustain bureaucracy. Existing quantitative data proved the public awareness of content and process but provided insufficient support to enhance governance of place because relevant questions were not included.

There were several questions about staff courtesy. This was important to administrators because Coral Gables was known for superior customer service (LeviGarcia, 2019). There were several questions about routine process, which measured general satisfaction but did not allow detailed feedback. However, there were no questions about policy, budgets, public input or commission meetings. Residents were asked for preferences on receiving information, but they were not asked about their interest in public participation where they would give information.

The surveys interpreted local government bureaucracy as a proxy for business efficiency and explored satisfaction with transactions in terms of superficial interactions between employees and customers. This approach was a typical practice of local government consultants which required reform. This bias on the survey instrument was a significant finding, because it reflected a lack of focus on democracy, and a misunderstanding of public sector bureaucracy.

Staff were not customer service employees and citizens were not customers. Public administration was fundamentally different from business. Aspects of bureaucratic activities may be applicable to public and private bureaucratic organizations, but democracy was a distinct feature of the public sector. The interactions between bureaucracy and democracy resulted in civic outcomes, and this fundamental relationship of governance was not explored. 
The Community Engagement survey did not ask questions about democracy, as a deliberate choice of research design. The authors were interested in satisfaction with the performance of staff and priorities for actionable items (Levi-Garcia, 2019). In addition, the survey was lengthy and conducted on paper. There was a practical limit to the number of questions, and bureaucracy was the priority. Coral Gables surveys followed standard practice of government surveys conducted by the consultant throughout the United States (Levi-Garcia, 2019).

Current practice does not consider democracy a topic for a "Community Engagement" survey sponsored by a local government, partially because democracy is misunderstood as politics. Nevertheless, in 2019 a separate "citizen engagement" website, within a smart city hub, allowed payments and collected input from citizens. This was done informally, and it gave the appearance of participation in local government. It also provided interesting statistics, such as daily pedestrian counts on Giralda Plaza. Thus, staff had access to comprehensive data on public comments. However, it was unclear how data would guide administration or whether unfiltered information led to enhanced democracy and governance.

The barrier to a more comprehensive survey on effective community engagement may be due to a gap in theory. Democracy was understood only as politics by public administrators, which coincidentally was also Wilson's understanding and phrasing at the founding of the discipline (Wilson, 1887). Politics was not the business of administrators. However, democracy as a spectrum of opportunities for input and feedback should be the concern of bureaucracy, in the form of effective governance. 
Data collection design suggested that public input was seen as transactional. For instance, input would be a payment for service, a complaint to code enforcement, or a report that trash had not been picked up. However, politics and transactions were narrow aspects of democracy. "Democratic governance" may guide the topic of public input more effectively than "politics."

Survey results provided data for an initial discussion of bureaucracy and democracy of place. Best practices for governance would expand bureaucracy and democracy. Conventional surveys about customer satisfaction did not measure public governance because they were initially conceptualized for business and were never adapted to public administration. Governance would view customers as citizens, and staff as facilitators of smart place. This updated theory framework would transform current best practices for measuring performance of local bureaucracy and would enhance assessments for civic service.

\section{Findings}

1. Content of place was a factor in superior quality of life.

2. Customer satisfaction with bureaucratic processes contributed to quality of life.

3. The content of Mediterranean architecture enhanced quality of life for Coral Gables residents, but aesthetic choice was not the only component of content of place.

4. Customers were satisfied with the Board of Architects and the implementation of content. 
5. Survey design did not consider democracy a factor in quality of life. Updated theory would remedy this shortcoming.

6. Smart tools collect general public input, which best practices should transform into content for democracy of place. 


\section{CHAPTER V \\ DISCUSSION}

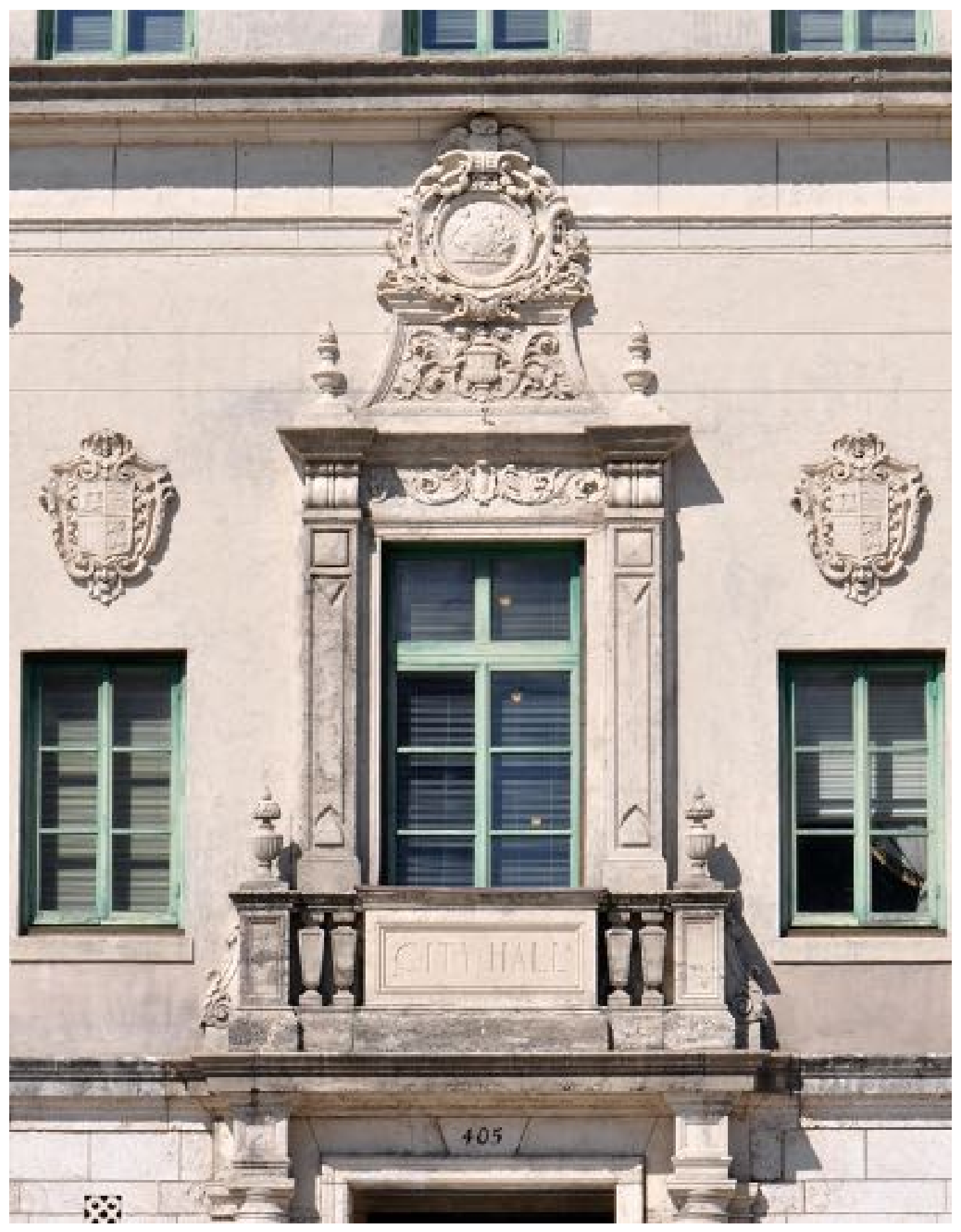

Plate 36. Coral Gables City Hall, South Facade, 2016. Photograph: Ramon Trias. 


\section{Aspirational Content}

\section{Hypothesis}

Board of Architects satisfaction was enhanced by aspirational content of place.

\section{On Content and Governance of Place}

Quantitative data from the Community Satisfaction survey proved that residents were more satisfied with quality of life in Coral Gables than in Miami-Dade County. Unique characteristics of Coral Gables accounted for the difference. When data was measured, variables related to content appeared to have a greater effect. However, available data for the survey had limitations.

On the other hand, data from the Board of Architects survey provided a more targeted tests for the role of aspirational content. As the subjects had business before the Board, there was also the possibility of bias. Future research could review findings, with a different sample. However, the sample was considered sufficient for initial investigation, consistent with research design.

One model tested the hypothesis directly, with satisfaction as a dependent variable as follows:

$Y_{i}=\beta_{0}+\beta_{1} X_{1}+\beta_{2} X_{2}+\beta_{3} X_{3}+\beta_{4} X_{4}+\mu i$

$Y_{i}=$ Board of Architects satisfaction, a variable that merged three measurements related to customer interaction with the process.

$\mathrm{X}_{1}=$ Mediterranean, a variable for aspirational content

$\mathrm{X}_{2}=$ lengtermvision, a variable for democracy in local governance, for

content-driven process

$\mathrm{X}_{3}=$ zoningrequirementsend, a variable for bureaucracy in local governance that measured understanding of requirements at the end of the process

$\mathrm{X}_{4}=$ ease, a variable for governance that measured the customer experience with process 
- reg BOAsatisfaction mediterranean longtremvision zoningrequirementsend ease

\begin{tabular}{|c|c|c|c|c|c|c|}
\hline Source & SS & $d f$ & MS & Number of obs & $=$ & 45 \\
\hline Model & 3.55496689 & 4 & .888741722 & Prob $>F$ & $=$ & 0.0003 \\
\hline Residual & 5.24503311 & 40 & .131125828 & R-squared & $=$ & 0.4040 \\
\hline Total & 8.8 & 44 & .2 & Root MSE & $=$ & .36211 \\
\hline
\end{tabular}

\begin{tabular}{|c|c|c|c|c|c|c|}
\hline BOAsatisfaction & Coef. & Std. Err. & $t$ & $P>|t|$ & [95\% Conf. & Interval] \\
\hline mediterranean & .397351 & .2345806 & 1.69 & 0.098 & -.0767541 & .8714561 \\
\hline longtremvision & .2384106 & .2264515 & 1.05 & 0.299 & -.219265 & .6960862 \\
\hline zoningrequirementsend & -.5364238 & .2456212 & -2.18 & 0.035 & -1.032843 & -.0400049 \\
\hline ease & -.0794702 & .4248909 & -0.19 & 0.853 & -.9382067 & .7792663 \\
\hline _cons & .9602649 & .3810548 & 2.52 & 0.016 & .1901244 & 1.730405 \\
\hline
\end{tabular}

OLS regression results were positive for aspirational content, and for content driven process. Conventional process variables, on the other hand, had negative results. The R-squared value was sufficiently high at 40 to have confidence in the model.

Nevertheless, the conceptual nature of the hypothesis would suggest that results suggest trends.

Long term vision and Mediterranean, variables for content of place specific to Coral Gables, had positive values. The variables for process, "zoningrequirementsend" and "ease" had negative coefficients. However, the variable "ease" which related to governance, was close to zero. Thus, bureaucracy in the form of regulations had the least impact on customer satisfaction in the Board of Architects. This model supported the hypothesis that aspirational content enhanced satisfaction.

Data was measured with another model, to explore the effects of different variables on content. In this case, Mediterranean was the dependent variable. The model was as follows:

$$
\begin{aligned}
& Y_{i}=\beta_{0}+\beta_{1} X_{1}+\beta_{2} X_{2}+\mu i \\
& Y_{i}=\text { mediterranean, a variable for aspirational content } \\
& X_{1}=\text { zoningreq, a variable for conventional bureaucratic process }
\end{aligned}
$$


$\mathrm{X}_{2}=$ boardrespect, a variable for democratic governance

$\mathrm{X}_{3}=$ staffknowledge, a variable for bureaucratic governance

- reg mediterranean zoningreq boardrepect staffknowledge

\begin{tabular}{|c|c|c|c|c|c|c|}
\hline Source & SS & $d f$ & MS & Number of obs & $=$ & \\
\hline Model & 7.02774327 & 3 & 2.34258109 & Prob > F & $=$ & 0.0000 \\
\hline Residual & 4.59130435 & 38 & .120823799 & R-squared & $=$ & 0.6048 \\
\hline Total & 11.6190476 & 41 & .283391405 & Root MSE & $=$ & \\
\hline
\end{tabular}

\begin{tabular}{|c|c|c|c|c|c|c|}
\hline mediterranean & Coef. & Std. Err. & $t$ & $P>|t|$ & [95\% Conf. & Interval] \\
\hline zoningreq & -.426087 & .2862692 & -1.49 & 0.145 & -1.005609 & .1534347 \\
\hline boardrepect & -.4289855 & .2219537 & -1.93 & 0.061 & -.8783072 & .0203362 \\
\hline staffknowledge & 1.573913 & .2862692 & 5.50 & 0.000 & .9943913 & 2.153435 \\
\hline _cons & .4202899 & .3027198 & 1.39 & 0.173 & -.1925344 & 1.033114 \\
\hline
\end{tabular}

Results were positive for staff knowledge, which measured the process of governance where the applicant works closely with bureaucracy of the city, to understand and apply effectively aspirational content.

The variable "staffknowledge" measured the work of the City Architect, who routinely assisted applicants with design recommendations, and approved limited requests. The role of staff knowledge was characteristic of the Coral Gables Board of Architects process, and unusual in typical processes of design review. Independent professional input about aesthetics was not anticipated by conventional planning and zoning. Thus, the variable could be interpreted as a proxy for the proposed alternative governance of place, where conventional planning and zoning processes are modified to promote creative solutions and collaboration.

Process based on creative input had the highest impact on aspirational content. The model supported an alternative approach to conventional planning and zoning procedures, to implement content. For instance, conventional local government measurements, such zoning requirements and public meetings had negative results. This 
finding may suggest a need for enhanced best practices and use of smart strategies. Rsquared value was .6, which should be considered sufficient for this type of research. These results supported the need for best practices

Data from the Community Engagement survey was also tested. The following probit model measured "medCG" or Mediterranean content of Coral Gables as the dependent variable, with multiple bureaucratic and democratic independent variables:

\begin{tabular}{|c|c|c|c|c|c|c|c|}
\hline Iteration 0 : & \multicolumn{3}{|c|}{ log likelihood $=-208.60254$} & & & & \\
\hline Iteration 1: & \multicolumn{3}{|c|}{ log likelihood $=-206.58202$} & & & & \\
\hline Iteration 2: & \multicolumn{3}{|c|}{$\log$ likelihood $=-206.57755$} & & & & \\
\hline Iteration 3: & \multicolumn{3}{|c|}{$\log$ likelihood $=-206.57755$} & & & & \\
\hline \multirow{3}{*}{\multicolumn{4}{|c|}{ Probit regression }} & \multirow{2}{*}{\multicolumn{2}{|c|}{$\begin{array}{l}\text { Number of obs } \\
\text { LR chi2( } 5)\end{array}$}} & $=$ & 572 \\
\hline & & & & & & $=$ & 4.05 \\
\hline & & & & \multicolumn{2}{|c|}{ Prob > chi2 } & $=$ & 0.5422 \\
\hline \multicolumn{4}{|c|}{ Log likelihood $=-206.57755$} & \multicolumn{2}{|c|}{ Pseudo R2 } & $=$ & 0.0097 \\
\hline medCG & Coef. & Std. Err. & $\mathrm{z}$ & $P>|z|$ & {$[95 \%$} & Conf. & Interval] \\
\hline educationDS & -.1310785 & .1199655 & -1.09 & 0.275 & -.3662 & 2064 & .1040495 \\
\hline zoningDS & -.0848013 & .1271134 & -0.67 & 0.505 & -.333 & 389 & .1643363 \\
\hline boaDS & .1619739 & .1215447 & 1.33 & 0.183 & -.076 & 2494 & .4001971 \\
\hline courtesyDS & .0709742 & .1264866 & 0.56 & 0.575 & -.17 & 5935 & .3188834 \\
\hline codecourtesy & .0819057 & .1207838 & 0.68 & 0.498 & -.154 & 3262 & .3186376 \\
\hline _cons & -1.504218 & .3750065 & -4.01 & 0.000 & -2.23 & 9218 & -.769219 \\
\hline
\end{tabular}

The model concluded that the Board of Architects process and that courtesy from staff have more impact on aspirational content than zoning requirements and education about the requirements. Thus, results supported collaborative governance of place over conventional planning and zoning based on bureaucracy.

\section{Discussion}

Findings from quantitative data demonstrated that Board of Architects customer satisfaction was directly related to aspirational content. As the Board of Architects was 
responsible for design review, based on aesthetic criteria, this result was expected. Data from the survey proved the hypothesis.

When a model measured both content and process, content had a positive value and process a negative value. This result should be interpreted within the theory context framed by additional qualitative data. Process is not dismissed. However, findings suggest that process is less important than content. Moreover, data measured conventional zoning requirements, which were adopted at the time in Coral Gables, and followed established practices. An alternative process guided by governance goals may be more effective but could not be measured.

Qualitative discussions and zoning analysis would suggest that results would be generalizable. Findings and analysis supported this assumption, with the caveat that Coral Gables procedures required public commitment and investment of time and resources beyond conventional planning and zoning practice.

Many cities claimed to perform, or aspire to implement, design review. Qualitative discussion from experts praised the Board of Architects process as exceptional, in terms of scope and content. A cursory review of comparable design review processes confirmed this view.

However, an objective review of the administrative tools used to regulate the Board of Architects demonstrated that the process was regulated by conventional planning and zoning tools, and it combined routine aspects of democracy and bureaucracy of place. Implementation may be outstanding, with unusually high standards for members, staff and applicants, but the process would still be generalizable. 
Other local governments could establish comparable processes and develop appropriate content, calibrated to their opportunities and needs. Future research should explore administrative barriers which may prevent effective processes for democracy and bureaucracy of place. Moreover, findings from other local governments may explain if these ideas can be applied to communities that are less wealthy and more diverse than Coral Gables, FL.

Aspirational content had the potential of transforming place, if defined and implemented effectively, in ways that would be equitable and inclusive. Definition and implementation of community aspirations for place should result from democratic activities.

Effective theory should guide effective methodology for data collection and analysis. In terms of local government administration, the most direct application of aspirational content is design review. Current research supported the beneficial role of aspirational content. Future research should expand discussion on the types of content that may be effective, and the best processes for governance of place. 


\section{Governance of Smart Place}

\section{Hypothesis}

Quality of life in Coral Gables is enhanced by democracy and bureaucracy informed by aspirational content of place.

\section{Democracy and Bureaucracy for Community Engagement}

Research explored governance of place as an alternative to conventional planning and zoning. This theory framework was intended to provide direction to best practices of local government administration. Governance of place proposed a rough sketch for theory development. Data from the two surveys conducted by Coral Gables could be used to measure certain aspects of governance, as many questions investigated bureaucracy and the interactions between the public and government officials.

Quality of life was interpreted as a proxy for satisfaction with the general governance of Coral Gables. Community Engagement survey design and data supported this interpretation, as the survey measured city services and procedures, which proposed theory would describe as governance of place. High scores on quality of life would express satisfaction with current governance and related data would identify areas that could be enhanced. However, future research should survey governance directly, and include questions about democratic processes.

Survey questions included topics beyond planning and zoning or development issues, which was consistent with proposed theory about governance. Survey data measured bureaucracy in great detail, provided some information on democracy, and included key questions about the specific content of place for Coral Gables and South 
Florida. Furthermore, customer satisfaction data from the survey on the Board of Architects process could also test the hypothesis.

\section{Quantitative Tests of Hypothesis}

The first test of the hypothesis analyzed data from the Community Engagement survey. The dependent variable was "qualityoflifeCoralG" which measured the concept of satisfaction with place directly. The question measured satisfaction with quality of life specifically in Coral Gables. The context of the question encouraged consideration of unique distinctions related to place. Thus, data on quality of life would be reliable.

Three independent variables were included for content (medCG), bureaucracy (ZoningDS) and democracy (Tellfriend). The first two were direct measurements of each topic. The last variable was interpreted to represent democratic input, as it measured how likely the respondent was to recommend Coral Gables to a friend. It was interpreted to measure democratic activities, given the limitations of existing data.

This was the formula:

$$
Y_{i}=\beta_{0}+\beta_{1} X_{1}+\beta_{2} X_{2}+\beta_{3} X_{3}+\mu i
$$

$Y_{i}=$ qualityoflifeCoralG, a variable that measured satisfaction with Coral Gables, which was assumed to include characteristics of place and smart city initiatives.

$\mathrm{X}_{1}=$ medCG, a variable for aspirational content, yes $=1$ for Mediterranean architecture is a factor relating to quality of life.

$\mathrm{X}_{2}=$ zoningDS, a variable for bureaucracy in local governance, for existing process of zoning.

$\mathrm{X}_{3}=$ tellfriend, a variable for democracy in local governance that measured in a Likert scale the interest in telling others that Coral Gables is a great place to live, work and play 
- sum qualityoflifeCoralg medCG zoningDS tellfriend

\begin{tabular}{|c|c|c|c|c|c|}
\hline Variable & Obs & Mean & Std. Dev. & Min & $\operatorname{Max}$ \\
\hline qualityofl $\sim G$ & 894 & 1.558166 & .5953115 & 1 & 4 \\
\hline medCG & 957 & .1306165 & .3371567 & 0 & 1 \\
\hline zoningDS & 733 & 2.536153 & .7946989 & 1 & 4 \\
\hline tellfriend & 888 & 2.11036 & 1.50129 & 1 & 10 \\
\hline
\end{tabular}

- reg qualityoflifeCoralg medCG zoningDS tellfriend

\begin{tabular}{|c|c|c|c|c|c|c|}
\hline Source & SS & $d f$ & MS & Number of obs & $=$ & 654 \\
\hline Model & 7.1481226 & 3 & 2.38270753 & Prob > F & $=$ & 0.0001 \\
\hline Residual & 219.39622 & 650 & .337532646 & $\mathrm{R}$-squared & $=$ & 0.0316 \\
\hline Total & 226.544343 & 653 & .346928549 & Root MSE & $=$ & .58098 \\
\hline
\end{tabular}

\begin{tabular}{|c|c|c|c|c|c|c|}
\hline qualityofl G & Coef. & Std. Err. & t & $P>|t|$ & [95\% Conf. & Interval] \\
\hline medCG & -.0193246 & .0682563 & -0.28 & 0.777 & -.153354 & .1147047 \\
\hline zoningDS & -.1312452 & .0286032 & -4.59 & 0.000 & -.187411 & -.0750793 \\
\hline tellfriend & .0005347 & .015558 & 0.03 & 0.973 & -.0300154 & .0310847 \\
\hline _cons & 1.871479 & .0821165 & 22.79 & 0.000 & 1.710233 & 2.032725 \\
\hline
\end{tabular}

Results had limited reliability, as r-squared value was very low and two $p$ values were high. Nevertheless, the lowest value was assigned to process. The variable for aspirational content, "medCG," had a negative value close to zero and a low p value. The variable for democracy, "tellfriend," was positive, but the p-value was very high.

Analysis showed that data from the Community Engagement survey was more valuable in raw form that when analized with regression tools. Moreover, democratic processes were not explored directly, as the survey questions focused on city services and bureaucracy. Research relied on existing data and models were limited by the original survey design. Future research would be designed to measure the proposed theory assumptions directly.

An alternative model was measured, with data from the Board of Architects satisfaction survey. Survey design led to fewer observations than the Community Engagement survey, but data was more directly linked to proposed theory, and more 
consistent Likert scale measurements were effective for regression analysis. The model

was as follows:

$$
Y_{i}=\beta_{0}+\beta_{1} X i+\beta_{2} X_{2}+\beta_{3} X_{3}+\mu i
$$

$\mathrm{Y}_{\mathrm{i}}=$ longtermvision, a variable that measured satisfaction with the general direction of Coral Gables, including characteristics of place and smart city initiatives.

$\mathrm{X}_{1}=$ mediterranean, a variable for aspirational content, measured on a Likert scale for Mediterranean architecture contributed to city's overall beauty.

$\mathrm{X}_{2}=$ zoningreg, a variable for bureaucracy in local governance, for existing process of zoning.

$\mathrm{X}_{3}=$ boardrespect, a variable for democracy in local governance that measured in a Likert scale satisfaction with the Board of Architects public meeting and interactions with members in a public setting.

- sum longtermvision mediterranean zoningreq boardrepect

\begin{tabular}{r|rrrrr} 
Variable & Obs & Mean & Std. Dev. & Min & Max \\
\hline longtermvi n & 49 & 1.22449 & .5109349 & 1 & 3 \\
mediterran n & 48 & 1.208333 & .5035336 & 1 & 3 \\
zoningreq & 58 & 1.051724 & .2234038 & 1 & 2 \\
boardrepect & 62 & 1.048387 & .3810004 & 1 & 4
\end{tabular}

- reg longtermvision mediterranean zoningreq boardrepect

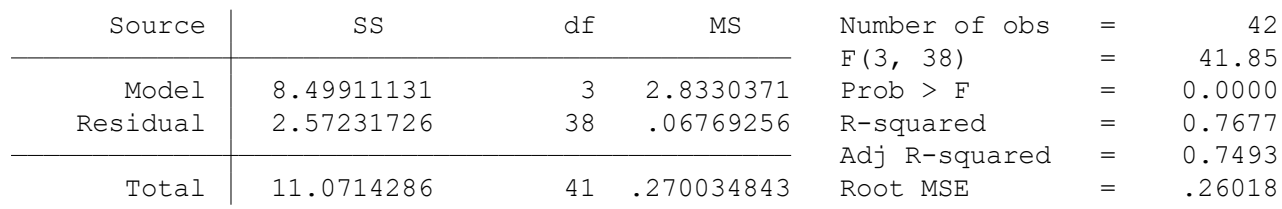

\begin{tabular}{|c|c|c|c|c|c|c|}
\hline longtermvis n & Coef. & Std. Err. & $t$ & $P>|t|$ & [95\% Conf. & Interval] \\
\hline mediterranean & .7791602 & .0906175 & 8.60 & 0.000 & .5957146 & .9626058 \\
\hline zoningreq & .096423 & .1908548 & 0.51 & 0.616 & -.2899423 & .4827883 \\
\hline boardrepect & .1425609 & .1036251 & 1.38 & 0.177 & -.0672172 & .352339 \\
\hline _cons & -.0041472 & .2265826 & -0.02 & 0.985 & -.4628397 & .4545452 \\
\hline
\end{tabular}

This model provided reliable results, as the r-squared value was .76. The dependent variable "longtermvision" measured agreement with the statement that code requirements add to the long-term vision. The variable for content, "mediterranean," had the highest positive value. There were no negative values, which suggests that both 
democracy and bureaucracy were important for a long-term vision, and the role of content was robust.

If satisfaction with the long-term vision of Coral Gables is interpreted as a proxy for quality of life, data showed that satisfaction was enhanced by activities related to democracy and bureaucracy, and the role of aspirational content had the highest coefficient. Given the limits of available data, the model provided support for the hypothesis.

\section{Quantitative and Qualitative Discussion}

Governance of smart place was proposed as the goal of local government bureaucracy and democracy of place. However, the hypothesis required interpretation of existing survey data to fit new language and theory. Research on the qualitative aspects of the hypothesis, from in-depth interviews, provided support for this interpretation.

Satisfaction with quality of life in Coral Gables was interpreted as satisfaction with local governance. As the hypothesis measured satisfaction with city services the interpretation was appropriate. City services are the output of local government bureaucracy and affect some aspects of democracy. Bureaucracy and democracy at the local level equal governance of place.

Although quantitative data provided robust support for the hypothesis, some aspects of the topic were researched more effectively with qualitative data and literature review. Research design blended qualitative and quantitative strands, and both should be considered in a coordinated way for the evaluation of proposed ideas. 
Quality of life proved simpler to measure than expected. Qualitative findings suggested that the concept would be elusive and subjective. Survey data proved otherwise, as respondents answered the question clearly:

"How would you rate the overall quality of life in the city of Coral Gables ONLY?"

The question was narrowly focused and underlined and capital letters emphasized place. Thus, results were reliable.

Bureaucracy was also measured well. Both surveys were principally about city services, which were described collectively as local government bureaucracy for the purposes of public administration theory. However, governance would also include democratic activities.

The surveys were less direct in measurements related to democracy. The perception on the part of survey designers and senior staff that democracy in unrelated to bureaucracy in local government may be a barrier for enhance governance of place. A focus on governance would integrate bureaucracy and democracy and expand theory on both.

\section{Discussion}

Data supported the hypothesis. Raw data proved awareness of the positive role of aspirational content. Regressed data, within statistical limitations, measured processes of bureaucracy and democracy relative to content. Data allowed measurements of general content related to place and calibrated content specific to Coral Gables. Findings showed trends, but future research based on precisely targeted data could lead to more reliable results. 
Moreover, conclusions were generalizable because Coral Gables was regulated with the democratic and bureaucratic tools of conventional planning and zoning, which were applied similarly to local governments throughout Florida and in similar ways throughout the United States.

In terms of public administration process, Coral Gables was typical of American local governments. Although it is true that some processes were implemented well, as the zoning language analysis showed or especially design review through the Board of Architects, no activity was beyond the scope of conventional planning and zoning practice.

Coral Gables had not adopted late $20^{\text {th }}$ century zoning reforms, such as a formbased code. Regulations addressed form and aesthetics exceptionally well because they were guided by aspirational content. Aspirational content guided conventional administrative tools and was translated effectively into specific zoning language. Although Coral Gables bureaucracy may not be typical among American local governments of similar size and demographics, processes and regulation did not exceed the scope allowed by conventional practice.

The study proposed concepts for theory which were not measured typically with quantitative tools. Existing data from anonymous surveys performed in 2018 provided some opportunities to measure the role of content, in the context of current Coral Gables governance. Data supported general ideas sufficiently to continue theory development. Future research should explore democracy more extensively, as existing data was focused on bureaucracy. 
Surveys on "Community Engagement" and satisfaction with the Board of Architects were commissioned to evaluate city services from the point of view of a customer. Write-in comments recorded an interest in input about elected officials and public meetings, which suggests observations from the point of view of a citizen.

A review of write-in comments revealed some limitations on the survey. Concerns about decisions, input, budgets, priorities and goals were expressed. In terms of theory, the survey was designed to measure bureaucracy and the subjects also had questions about democracy. Data supported the theory framework proposed by this study, even though the surveys were not specifically designed to measure the hypotheses. Results validated the general approach and suggested future path for research, with other places and more targeted data. The unit of analysis, the local government, could remain, but the scope may be expanded to compare and contrast diverse experiences.

In the end, existing data was sufficient for the current study, as the goal was new theory and best practices, with the understanding that future research would be required to refine and generalize conclusions. Findings and analysis expanded the original scope of the survey towards bureaucracy and democracy of place, but future research should attempt to measure proposed theory directly. 


\section{From the Administrative City to Smart Place}

\section{General Conclusions}

This study collected and organized qualitative and quantitative data on place from several perspectives, with the goal of drafting a conceptual theory sketch which would lead to enhanced implementation of local democracy and bureaucracy and implement smart place.

Literature review, qualitative interviews, quantitative data from Coral Gables and research on smart strategies for administration provided sufficient findings to articulate theory and outline opportunities from best practices. Although the study was narrowly targeted, recommendations would be generalizable, as only public processes and activities within accepted local government practice were investigated. Future research should expand the geography of research and further develop best practices prompted by local calibration.

\section{Scope and Limits of Research Design}

This study proposed a general discussion of democracy and bureaucracy of place, although data was limited in geographic scope. This was a deliberate choice of research design, as a solid foundation for new theory could be best outlined with in-depth review of one local government.

A limitation of research design was that prior literature or perceptions of Coral Gables could interfere with an objective reading of the arguments. For some South Florida readers, Coral Gables may have multiple social or aesthetic layers of meaning, as the community was well-known in public discussions about real estate or quality of life. For instance, prior literature reviewed some topics not covered in this study and some 
authors have been critical of George Merrick or Coral Gables. Public Administration literature often prevents this concern through more expansive research design, where observations have various sources. Each approach has benefits, but current research was believed to lead to solid conclusions.

A concern was that some readers may believe Coral Gables was an imperfect example which does not represent the diversity of the region, a view that could be supported with census data. Nevertheless, readers less familiar with South Florida history of development may appreciate data and analysis as presented. Moreover, conclusions should not lead to a false sense of accuracy or inevitability. Place is complex and evolves and it is reinterpreted according to each interaction of professional practice.

Social science methods and theory on town planning and design provided imperfect guidance for understanding outcomes, but opinions supported by data should not be construed as proven cause-effect relationships. In particular, there may be alternative explanations for certain outcomes. Some topics designed to be beyond the scope of research, such as the effect of conflict on policy, debates on interpretation of administrative language, the effects of economic development on demographic diversity.

\section{Democracy and Bureaucracy Lead to Smart Place}

The main conclusion is that Democracy and Bureaucracy of place follow a spectrum of participatory and administrative activities. Democracy is more than electoral

politics and bureaucracy transcends paperwork. Enhanced local governance should result from a complete and nuanced understanding of both topics. Alternatively, a misunderstanding of democracy and bureaucracy would lead to resident frustration and administrative ineffectiveness. In addition, the main task of the public sector in the 
United States is the implementation of democracy. Thus, democracy should shape the core of public administration theory and best practices, as bureaucracy is an organizational structure common to the public and private sectors. Critics who believe the public sector is excessively bureaucratic when compared to private enterprise should consider the role of aspirational content, or the content of democracy, in governance. Democracy is not principally concerned with business efficiency, as values related to quality of life and resident satisfaction prevail over expediency.

\section{Governance as the Fundamental Goal}

Zoning reform discussions from the late $20^{\text {th }}$ century, often guided by New Urbanism theory, exposed gaps in the practice of conventional planning and zoning. In particular, important aspects of design review and regulation of place were overlooked by conventional theory and practice. Aspirational content was undefined and, thus. understudied. Bureaucratic process had overwhelmed professional practice, to the detriment of democratic participation. Significant examples of successful implementation of place, such as Coral Gables, were not discussed sufficiently by the literature, as place was not a main priority of public administration theory. Conclusions form this study support a transition from the administrative city of conventional planning and zoning to governance of place guided by aspirational content.

Research was designed to explore the formative ideas which led to standardized zoning regulation in local governments throughout the United States, to verify if some concepts should be revisited based on a century of experience and to update current theory and best practices, based on qualitative input from experts and quantitative data 
from Coral Gables, Florida. Analysis of data led to new concepts related to place and public administration.

Findings confirmed a long-standing concern of academic literature: local government bureaucracy is misunderstood. As bureaucracy was increasingly evaluated as a series of transactions, crucial civic dimensions of place may be dismissed. Moreover, findings revealed that local government democracy was also misconstrued, as citizens were considered customers instead of active participants in civic life and local politics was believed to be the full extent of public discourse. Conventional administrative practices were constrained by the general misunderstanding of local bureaucracy and democracy.

Effective governance at the local level must propose an alternative theory construct which should support smart best practices, within a constructive framework for democracy and bureaucracy. Current research on literature, Coral Gables and hypothesis testing of proposed theory confirmed the following generalized recommendations, which are compared to general theory ideas summarized in the Literature Review Chapter and suggest concepts for a comprehensive explanation of place:

1. Adopt a plan that directly addresses place, in the manner of the Law of the Indies, which will be resilient and may improve with time.

2. Develop content of place, as introduced by Ildefons Cerda in the $19^{\text {th }}$ century and expanded in the early $20^{\text {th }}$ century, which can be defined and measured.

3. Prepare design manuals, which are a best practice for the implementation of place, as J. N. Durand proposed in the early $19^{\text {th }}$ century, and multiple authors expanded in the 1910's and 1920's. 
4. Nurture a narrative of place, as crafted by George Merrick and strengthened by subsequent retellings, which creates enduring value for real estate and promotes quality of life.

5. Promote zoning reform, such as concepts proposed by New Urbanism theory, which can be expedited with smart tools.

6. Implement Smart Place, as a goal to enhance governance for local administration, with the tools of democracy and bureaucracy guided by aspirational content.

Research conclusions based on the evaluation of quantitative data may be summarized under two generalized recommendations:

1. Conventional planning and zoning activities should transition to governance of Smart Place.

2. Aspirational content should guide local government democracy and bureaucracy on issues related to place and quality of life.

\section{From the Administrative City of the $20^{\text {th }}$ Century to Governance of Place}

Local governance should result from democracy plus bureaucracy for place.

Place should be guided by aspirational content. Findings suggest that conventional administration of the urban built environment could be improved in terms of democracy and bureaucracy, should content support process. This idea would enhance conventional planning and zoning as follows:

1. Participation for democracy, with a spectrum of multiple and varied opportunities for input and dynamic feedback. 
2. Place as data, for transparent bureaucracy, collaborative planning, elimination of chronology bias and accurate design review process.

3. Fluid processes, as the outcomes would be better understood and would encourage creativity by all participants.

Governance of smart place would replace the administrative city. The administrative city, for the purpose of the implementation of place, was an invention of the first third of the $20^{\text {th }}$ century. The origin can be traced to 1926 , with the publication of the Zoning primer and A standard state zoning enabling act. Zoning empowered the "legislative body of all cities and incorporated villages" to "regulate and restrict" (Department of Commerce, 1926). Those words summarized a democratic mandate for policy and required a bureaucracy for implementation. They also implied a theory framework consistent with classic bureaucracy, where compliance and enforcement would be the priority.

In a general sense, the administrative city was organized to provide services, with bureaucratic efficiency. The range of activities was extensive, from police to sanitation, from building permits to recreation. Services provided by each city varied widely. Some cities provided all. Some provided few. Moreover, cities also had enterprise funds which managed unique facilities, such as a marina or an airport. Thus, the administrative city could expand or contract, guided by policy decisions. Policy would be defined in a democratic forum and bureaucracy would provide services.

On the other hand, governance would be designed to envision and guide. This proposed approach would promote discussion, and decisions informed by data and consensus, with appropriate processes to ensure equity. However, consensus should not 
be understood as the primary goal of democracy. It is only one tool in the spectrum of activities. In some instances, consensus my be ineffective or inappropriate. Governance should include meaningful opportunities for participation and decision-making.

\section{Towards Smart Place}

Smart place would implement an update of local governance, as participation and transparent data will take the place of regulation and restriction. In the $20^{\text {th }}$ century, the primary process of administration was conventional planning and zoning, as practiced by practically every local government in the United States for the past century.

Conventional planning and zoning provided inflexible processes for democracy, limited to citizen boards and public hearings. Bureaucracy was also inflexible, as it followed abstractions in the form of standardized zoning codes which discouraged local calibration. Nevertheless, conventional administrative tools could be used effectively, but theory offered limited guidance, and best practices were rare. The example of Coral Gables illustrated the opportunities for calibration of administrative tools based on aspirational content and a superior best practice for aesthetic review, and also the severe constraints of conventional planning and zoning.

In the administrative city democracy and bureaucracy for urban development were expressed in terms of regulations and restrictions. Conventional planning and zoning created an arbitrary language to facilitate local politics. Democracy and bureaucracy were restricted and were not intended to shape a clear outcome. The goal was adversarial debate, within Robert's rules of order. This is a different goal from effective governance of place. 
By the end of the $20^{\text {th }}$ century, reform movements such as New Urbanism proposed alternative methods for democratic and bureaucratic processes, which emphasized content. In recent years, enhanced ability to measure and analyze data at has opened new opportunities for administration. The new process will be understood as "governance of Smart Place."

Best practices for Smart Place emphasize aspirational content informed by interactive dynamic data. Data is always local but is never linked to a time period in history. Moreover, data reflects existing conditions, regardless of original intent. The main characteristics of smart strategies would be:

1. Timeless and autonomous data

Discussions about cities in history tend to follow a chronology which implies progress. For instance, old ideas were dismissed by Modern theory because of chronology bias. The benefits of innovation were promoted by mid-20 $0^{\text {th }}$ century theory of design and architecture. On the other hand, best practices from the 1920's valued diverse ideas about place, whether they resulted from innovation or scholarly research into the past. Smart Place would eliminate concerns about obsolescence, as ideas about place would be understood as autonomous data. Data does not expire because it informs theory and practice. As place would be intended to last, all data would have relevance.

2. Calibration to local needs

Place should always be local, in contrast to the universal abstraction of regulation and restriction promoted by zoning in the administrative city. Data should be calibrated constantly, to local and present needs. 
3. Governance through participation, with varied opportunities and formats Public participation and an actionable narrative of place are fundamental components of governance. The narrative should be implemented as aspirational content for administration. Consensus should be one type of deliberative process, along a spectrum of formats for participation.

4. Dynamic adaptation of practice

Smart strategies promote collection and use of dynamic data, to be used by administrators to enhance practice.

5. Lasting value

The fundamental benefit of the governance of place framework is that is shifts emphasis towards long-term goals. Conventional planning and zoning were often criticized as reactive and focused on present issues, where outcomes were the result of local politics and discrete transactions with customers. Place requires a longer perspective of time. Smart Place should be the outcome democracy and bureaucracy crafted and implemented by citizens.

\section{Aspirational Content for Quality of Life}

Survey data from Coral Gables measured a direct relationship between highly valued characteristics of place and satisfaction with quality of life. Moreover, when specific questions about local content were measured, the results were positive. Thus, quantitative analysis proves that satisfaction about quality of life is related to place and the aspirational content of place.

Findings also demonstrated that the adaptation of concepts and vision into actionable content for administration would be a complex and detailed process. The 
deconstruction of zoning language illustrated the precision of the task. It also revealed that conventional planning and zoning followed an uncertain process of input and revisions, where consequences cannot be predicted accurately.

Moreover, implementation of content would depend on effective design review, which must be consistently pursued through decades of development. The example of Coral Gables showed the potential, and the challenges, of long-term aesthetic review. While many local governments may desire to review aesthetics, the investment of time and resources, particularly professional staff and expert board members, may not be possible everywhere.

Nevertheless, perceptions about Coral Gables should not overwhelm findings. Data from Coral Gables was informative and generalizable, but it should not be understood as a proxy for all data from all local governments. Future research may explore a range of processes and their limits, in varied locations.

Aspirational content will determine quality of life, and should be conceptualized and implemented as follows:

1. "Aspirational" means democratic.

Not all content is equal. Content may have multiple sources, but for effective administration, aspirational content must result from public input and debate. The transition towards governance of place is predicated on enhanced opportunities for democratic discussion. Democracy should provide multiple formats and opportunities for input and decision. Place would be the cumulative outcome of democratic debate.

2. Content should be informed by dynamic data. 
Content should be based on data, collected with smart techniques. Dynamic data may be old or new, and it is subject to change with additional information. Better data should promote targeted and effective discussion and decisions. Content should adapt to new conditions, within the framework of a long-term vision. Communities that discard historic content periodically in favor of new content would struggle with the implementation of place.

3. Place should be the bureaucratic outcome of the implementation of content. The process of bureaucracy should be redirected towards the implementation of aspirational content. Place should be the predictable long-term outcome of local bureaucracy. Effective implementation of place requires the persistence of bureaucracy.

4. Content plus process should enhance quality of life.

Quality of life can be defined and measured quantitatively. Findings from quantitative survey data highlighted the role of aspirational content in resident satisfaction with quality of life.

\section{Next Steps}

The current study was designed to generalize theory and best practices on democracy and bureaucracy of place from the close study of the example of one local government. Research design provided a practical first step to towards that goal, but also could be critiqued for relying excessively on Coral Gables. The limitations of the study were anticipated, and conclusions should be understood as a sketch for theory development, which encourages extensive follow up. 
Furthermore, Coral Gables was not a neutral or abstract subject for theory. It was a real place with a century of debate about itself, its role in South Florida, its founder and countless opinions based on perception. Thus, the manuscript should not be misconstrued as an incomplete story on Coral Gables.

Alternatively, preexisting perceptions about Coral Gables could interfere with study objectives. Although multiple readings were possible, and even anticipated, in the end it was decided that available robust data and qualitative input would begin to close a major gap in public administration literature, democracy and bureaucracy of place.

Future research should focus more directly on theory issues related to Democracy and Bureaucracy of place.

\section{Governance of Place will Predict Quality of Life}

Research conclusions showed that quality of life would be less elusive if the role of content in administration were understood and fully implemented through effective governance. Implementation of governance of place would imply an ambitious agenda of change for conventional democratic and bureaucratic activities designed to "regulate and restrict." However, smart strategies are quickly transforming local administration in ways that may or may not enhance quality of life. Smart Place based on aspirational content provides a framework to envision and guide dynamic change.

In the end, local public administration strives to enhance quality of life. Future research should verify findings and determine with certainty that they are generalizable. Governance of smart place will implement locally calibrated democracy and bureaucracy for the post-administrative age. Quality will replace efficiency as the measurement of success. 


\section{Best Practices for Democracy of Smart Place: \\ Education, Participation, Decision}

\section{Towards Democratic Place}

The principal goal of local governance should be the administration of democracy along a spectrum of activities and a variety of formats carefully designed for effective participation. Processes established in local governance for the implementation of democracy are often confused with bureaucracy. Democracy may require public notice, structured input and paperwork, but it should not be misunderstood as bureaucracy. Democracy of place must be clearly understood from the point of view of the public interest, and processes associated with implementing effective input and discussion must be always be characterized as "democratic."

Qualitative input from expert interviews often stressed a need for education about place. The true meaning of this concern was the need to understand ways to operationalize local democracy. Better understanding of various democratic activities would promote measurement of data and enhancement, as needed. As an example, research revealed that questions about democracy were not included in the survey of community engagement in Coral Gables. This oversight demonstrates the need for better theory on the role of local governance.

Local government should encourage direct input for residents on deliberations and decisions that influence place and quality of life. However, expectations from the public and the actions of administrators are seldom consistent. It is tempting for staff and elected officials to limit democratic interaction to the minimum standards required by state law, and for residents to claim they received insufficient notice. Compliance with 
the law is a low standard for the implementation of place, as qualitative concerns may be overlooked. Similarly, more opportunities for input would not necessarily result in enhanced democracy. Best practices must be developed and followed.

Democracy should craft actionable content for local governance. However, a more democratic place presents multiple challenges for practice. Local democracy is the most direct type of democracy, or at it least it may appear to be. Often, decisions about development which affect place are contentious. In recent times, neighborhood opposition and resident frustration have been common in conventional planning and zoning. Adversarial formats for public hearings, notice in the form of impersonal letters, concerns with inflexible development impacts, procedures that privilege the opinions of nearby residents, are all antiquated early $20^{\text {th }}$ century processes that has evolved minimally as conditions have changed. Few fundamental modifications have taken place in the past century of planning and zoning practice since it was conceptualized in 1926.

The expectations of residents towards local governance had changed in recent years, as information became more accessible, mobility transformed priorities for public space and the scale of new development had transformed neighborhoods and districts. Residents are citizens, not customers. Many people have demanded an active role in decisions related to place.

Conventional public input has followed a predictable pattern for almost a century. A resident may receive a letter in the mail which advises the public of a new project to be discussed at a public hearing. The resident may attend the hearing and voice an objection. Nevertheless, the project may be approved. The resident may express 
frustration and disbelief about the process. All of these actions would appear antiquated in an age of smart tools.

Nevertheless, some beneficial aspects of democracy and bureaucracy of place shape the conventional process of review of development projects. For instance, the process has multiple steps before and after a public hearing, and input may be collected at various times, formally and informally. Participants may be confused, and their expectations may result from a misunderstanding of procedures. Governance of smart place would organize and explain all those steps and encourage meaningful participation and professional review.

\section{A Measure of Democracy}

Democratic participation and input may have increased in recent decades, but in informal ways, which should be measured and researched further. An unexpected finding of the study was that democracy was not typically measured by local government survey data. The finding can be explained through the bureaucratic bias against politics that guided ethical administration in the $20^{\text {th }}$ century. However, democracy should not be defined only as politics, because politics can exist without democracy.

Qualitative research suggested that meaningful public input was not a priority of conventional planning and zoning in current administrative practice. However, public participation was an important subject of zoning reform promoted by New Urbanism theory. Nevertheless, the appearance of democracy that may result from smart tools is insufficient. A better understanding of democracy, as a process for civic governance, is necessary for a transition beyond conventional planning and zoning. 
Effective governance of place would require input formats and coordination beyond perfunctory notice and adversarial public hearings. This is a significant change from conventional practice. Current practice values oversimplified processes, which undervalue thoughtful discussion of aspirational content.

Legacy processes from the first half of the $20^{\text {th }}$ century did not have access to $21^{\text {st }}$ century information technology and did not account for evolving public expectations. Future process design is anticipated towards the goal of Smart Place. Smart tools are well-suited to facilitate a transition towards enhanced governance, where democratic activity is centered on discussion of aspirational content.

\section{Local Governments Implement Democracy of Place}

An important finding of the study was that the role of public administrators on issues related to place is the implementation of democracy. This statement may appear self-evident in the context of the United States, but it may require clarification.

Local administration is often critiqued as excessively bureaucratic. The implied distinction is that the private sector is not bureaucratic. This fundamental misunderstanding interferes with the implementation of place.

The correct distinctions between public and private sector organizations emerge from democracy. On issues related to place, which often attract scrutiny from neighbors and reveal differing priorities among participants, effective democracy is essential for governance. Typically, business interests attempt to minimize democratic processes and neighborhood groups insist on expanding opportunities for input.

Public and private organization may be designed as bureaucracies, but only public organizations are tasked with the implementation of democracy, a critical distinction on 
issues that relate to place. Public processes provide input or hearings. They may appear to be bureaucratic, as they are often implemented with permits and reviews, but they are fundamentally democratic.

Democracy of place facilitates conflict resolution through informed debate. Processes must account for multiple priorities and opinions, and content should provide standards and define the scope of arguments and viewpoints. Findings suggest that the principal barrier to governance is argument without content, implemented through process without content.

\section{Discussion of Aspirational Content for Administrative Practice}

Aspirational meant democratic. Content meant practical ideas about place to be implemented by bureaucracy. Thus, best practices for aspirational content could be organized in terms of democracy, or the discussion of content, and bureaucracy, or the implementation of content.

In the early $20^{\text {th }}$ century, local bureaucracy and democracy were intended to lead to quality place, and best practices of design and administration emphasized content. At the same time, zoning was established to formalize bureaucracy and democracy for the local administration of land development.

Democracy was required in the form of a planning board, board of adjustment and public hearings. Bureaucracy structured authority over some aspects of development. Zoning provided minimum standards, but it did not preclude enhanced processes. Some local governments, such as Coral Gables, exceeded minimum requirements, with results measured in terms of satisfaction with quality of life. 
In the $21^{\text {st }}$ century, "smart" tools allowed increasingly direct input and dynamic feedback. The transition from place towards smart place provided opportunities to review conventional administrative practice. The role of aspirational content in governance could be defined and implemented with updated tools.

\section{Best Practices for the Generation of Content}

The main activity of local government in the United States should be the implementation of democracy. This task often confused with delivery of services through a bureaucracy. Public participation takes place along a spectrum of formats and should be informed by aspirational content.

New types of public participation emerged at the turn of the $20^{\text {th }}$ century, although implementation tended to be informal. The range of activities varied greatly, from public hearings to charrettes. Conventional planning and zoning practice had not encouraged development of content, and new tools for participation were not anticipated by adopted administrative procedures.

As an alternative to conventional administration, local governance would emphasize discussion, critique and consensus, with the goal of generating content. Content should it result from democratic activities, which required effective methodologies supported by theory. Three main categories of best practices were needed for structured governance of place:

1. Education, to develop standards for content for use by all participants in governance.

2. Participation, to offer a taxonomy of opportunity for input.

3. Decision, to lead to equity of place. 
Examples of best practices from Coral Gables were included for illustration purposes, as research revealed significant innovation. They represent the current state of the art in local government administration but continue to be a work in progress. Qualitative findings confirmed that smart city ideas are evolving quickly. An approach based on outcomes for place would provide effective theory direction.

\section{Education}

Interviews from professionals often led to a concern about education. Most experts identified a lack of education about the specific characteristics of content, with a focus on practitioners. Most people would not be planners, but professionals had the opportunity to guide public discussions with enhanced content.

Several experts believed that the concept of place was not understood by some professionals, and better information about content would lead to enhanced outcomes. Furthermore, findings also supported a better understanding of bureaucracy and democracy of place, as public expectations and administrative practice often resulted in conflict. In conventional settings. However, education itself would also have limits, as it would attempt to establish a common set of expectations for practice.

Archival research on best practices for architecture from the 1920's provided a model for education about place that was tested in the implementation of Coral Gables and other places. Information about the content of place led to implementation of communities that created and retained value, as demonstrated by census data and literature review of Coral Gables. Moreover, a coherent understanding of content would allow efficient administration. These are some opportunities to enhance education about content for key participant in the governance of place: 
1. Equity of place should be the goal of civic education.

This concept has to be expressed in terms of content of place.

Recommended best practices:

a. Dynamic communication with residents

Smart tools allow extensive input and immediate feedback. Recent developments on communication have transformed established democratic processes. Although information has become available, conventional procedures have not adapted. The shift towards a framework of governance would promote more discussion in less formal formats. Plate 37 depicts an I-phone view of statistics about comments on Coral Gables, aggregated from social media.

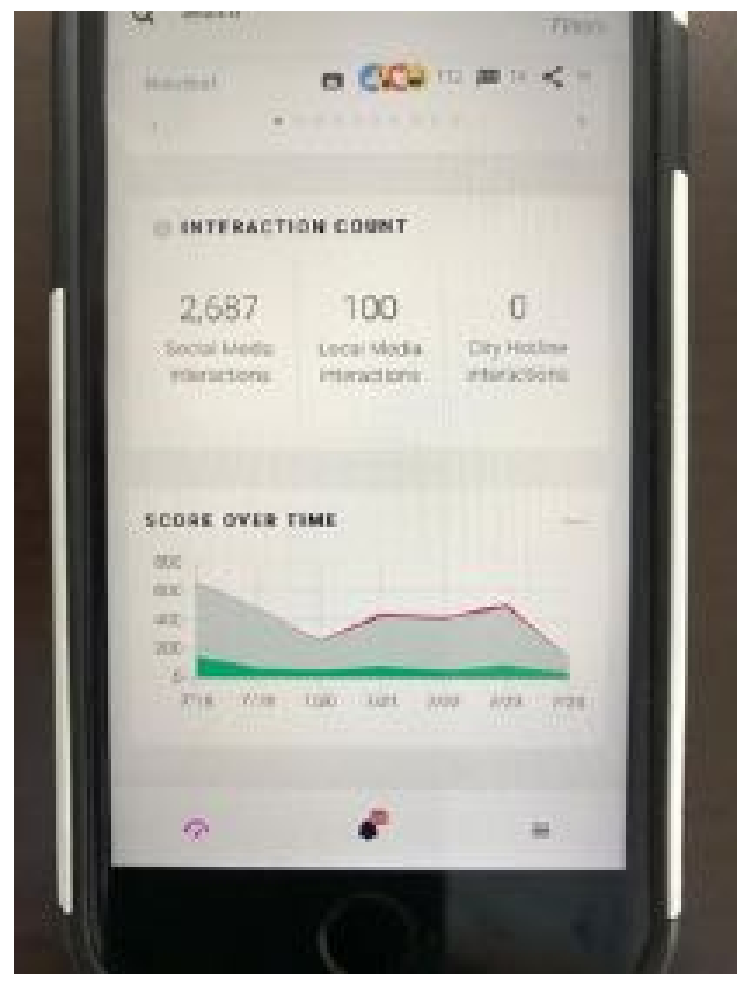

Plate 37. ZenCity information on I-Phone display. Source: City of Coral Gables. 
Mobile access to aggregated data on media comments provides opportunities for real time communication. The challenge is to develop techniques that enhance democracy. The concern is that administrators may be satisfied with the appearance of democracy.

b. Public discussion

Democracy for place should include opportunities for input beyond public hearings. Planning events can be supplemented with video and graphic information posted online. Plate 38 is a screenshot from a web page of a workshop conducted in 2019.

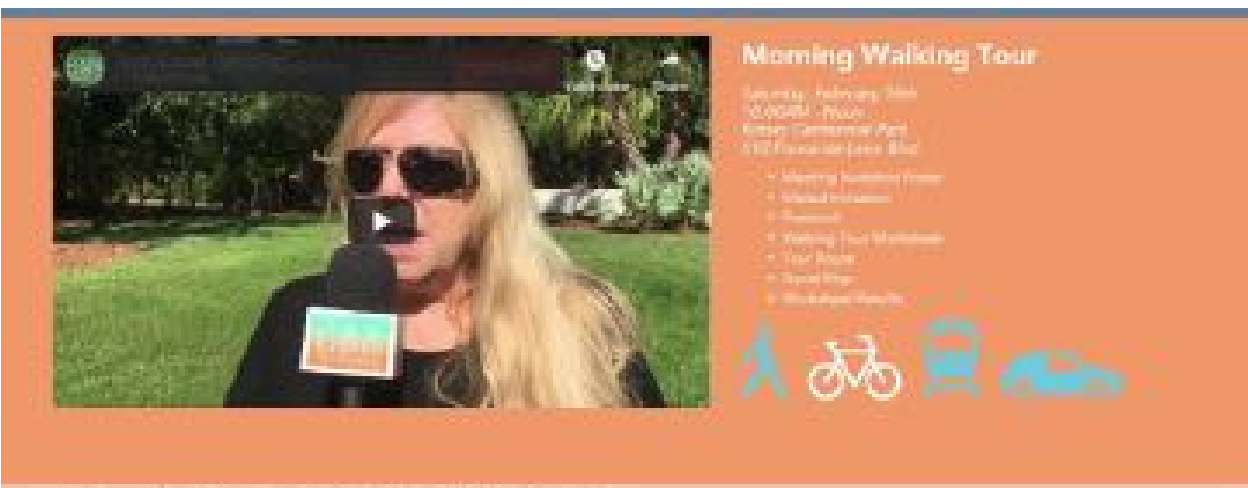

\section{FLAGLER SECTION} COMMUINTIY VISTON WORKSHIOF ROIARY PARK \& CORAL CAMAS MIISHIM HBRUARY 16 \& 71,2019

Be imsolved in steering your Community. Provide input

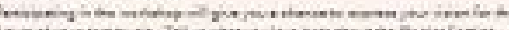
thow was xivatiogectom

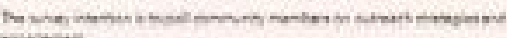
nuser

Neighborhocd Events

Merk your calendars for some of the activities happening in your neighborhood July: 2019 .

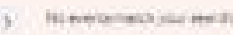

Plate 38. Flagler Section page. Source: Coral Gables website. 
Discussion would be enhanced with smart tools. The challenge is to integrate recommendations in the process of project review.

c. Smart reference materials

Reference materials about place should be dynamic and accurate.

Geographic information systems and smart data strategies provide opportunities that require guidance to be effective. Data provides content for place. Contemporary zoning maps may include extensive data, and can be consulted directly by residents, without filters from staff or elected officials. Once place is understood as data, transparency can be promoted with smart tools. Plate 39 is a screenshot of the interactive Coral Gables zoning map, with related GIS information. Additional links to aerial photographs, current and historic, would add actionable information for decisions.

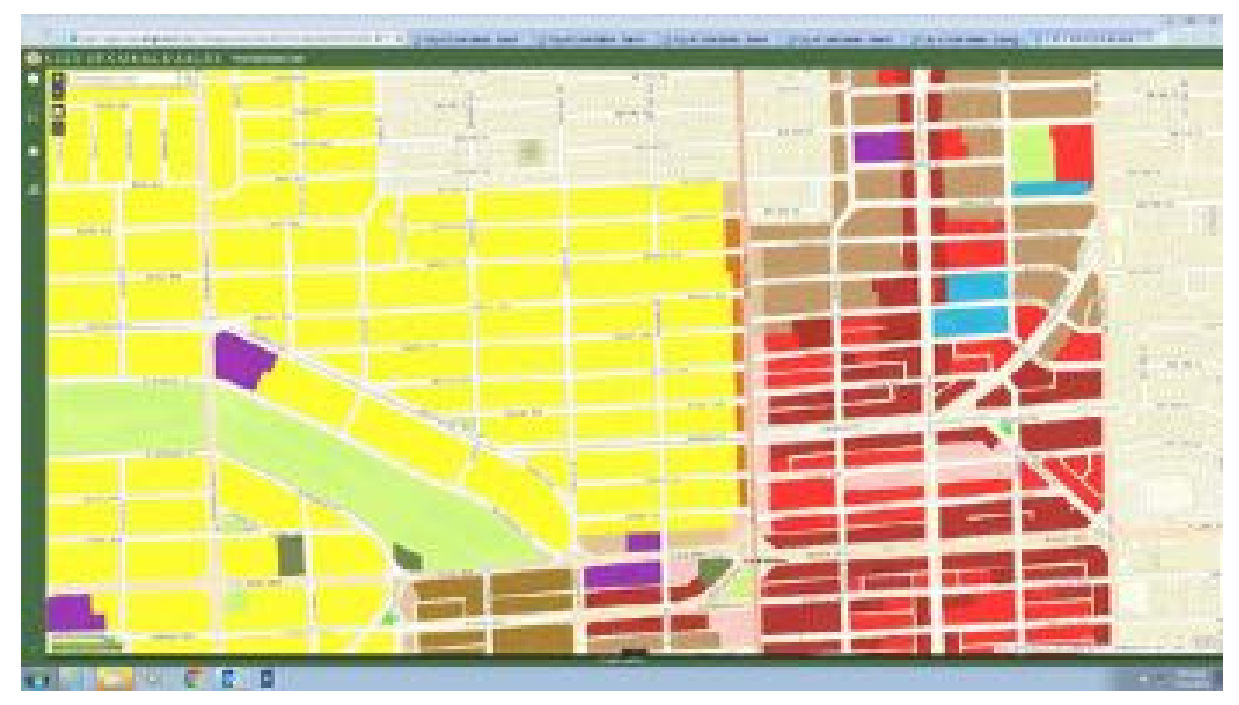

Plate 39. Coral Gables interactive zoning map. Source: Coral Gables website. 
2. Education about place should start with continuing education for design professionals.

a. Collaboration with local universities

Governance of place should include close collaboration with local institutions of higher learning. In Coral Gables collaboration with the University of Miami dates to the founding of both, City and School, by George Merrick. Plate 40 reproduces a drawing prepared by University of Miami architecture students of the Coral Gables City Hall, for the Historic American Building Survey, from the city of Coral Gables website.

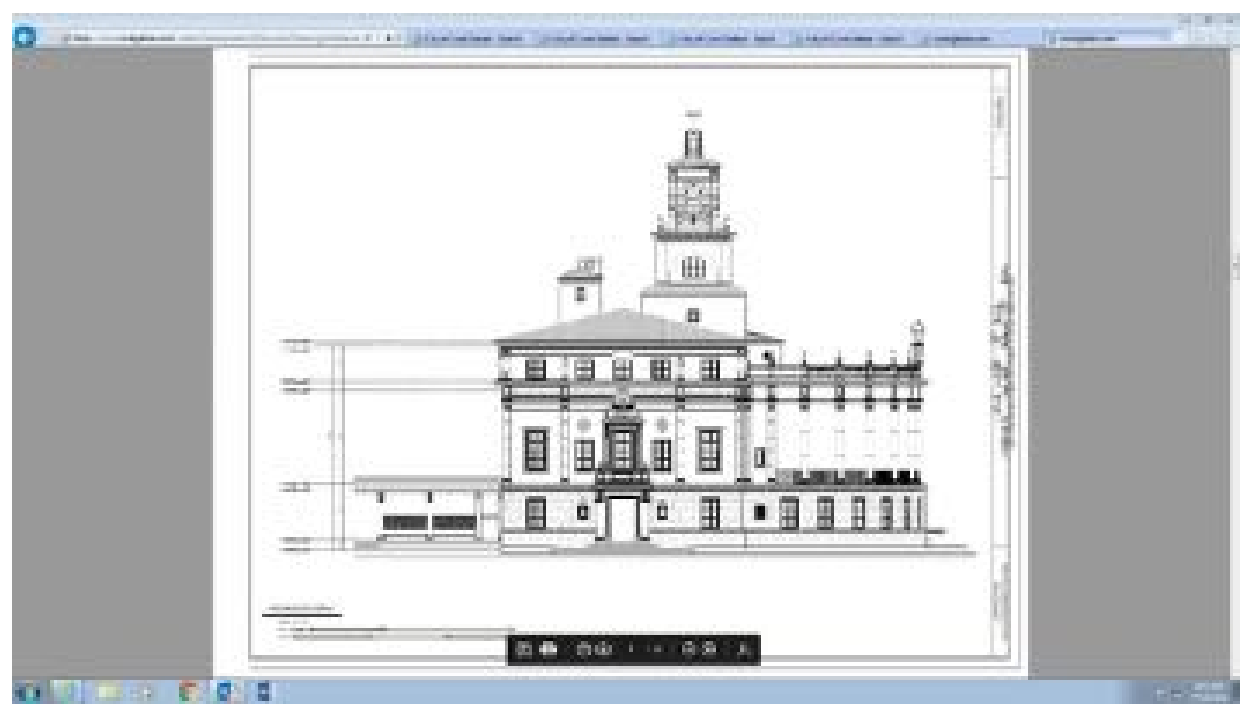

Plate 40. Coral Gables City Hall, South Elevation. Source: Coral Gables website.

\section{b. Continuing training for professionals}

Smart tools provide unparallel access to data. In the past, research about content was cumbersome. Smart tools have made old and new data equally current, as all data are universally available in multiple formats. 
In a Smart Place, content is always available and informs democracy and bureaucracy. A community that has developed effective content would prioritize education, which should influence place and enhance quality of life. Plate 41 is the Coral Gables webpage on Mediterranean architecture, which supplements and clarifies the language in the zoning code. In particular, it reproduces original drawings of exemplary buildings listed in the zoning code, which would be the definitive refence materials for aesthetic review.

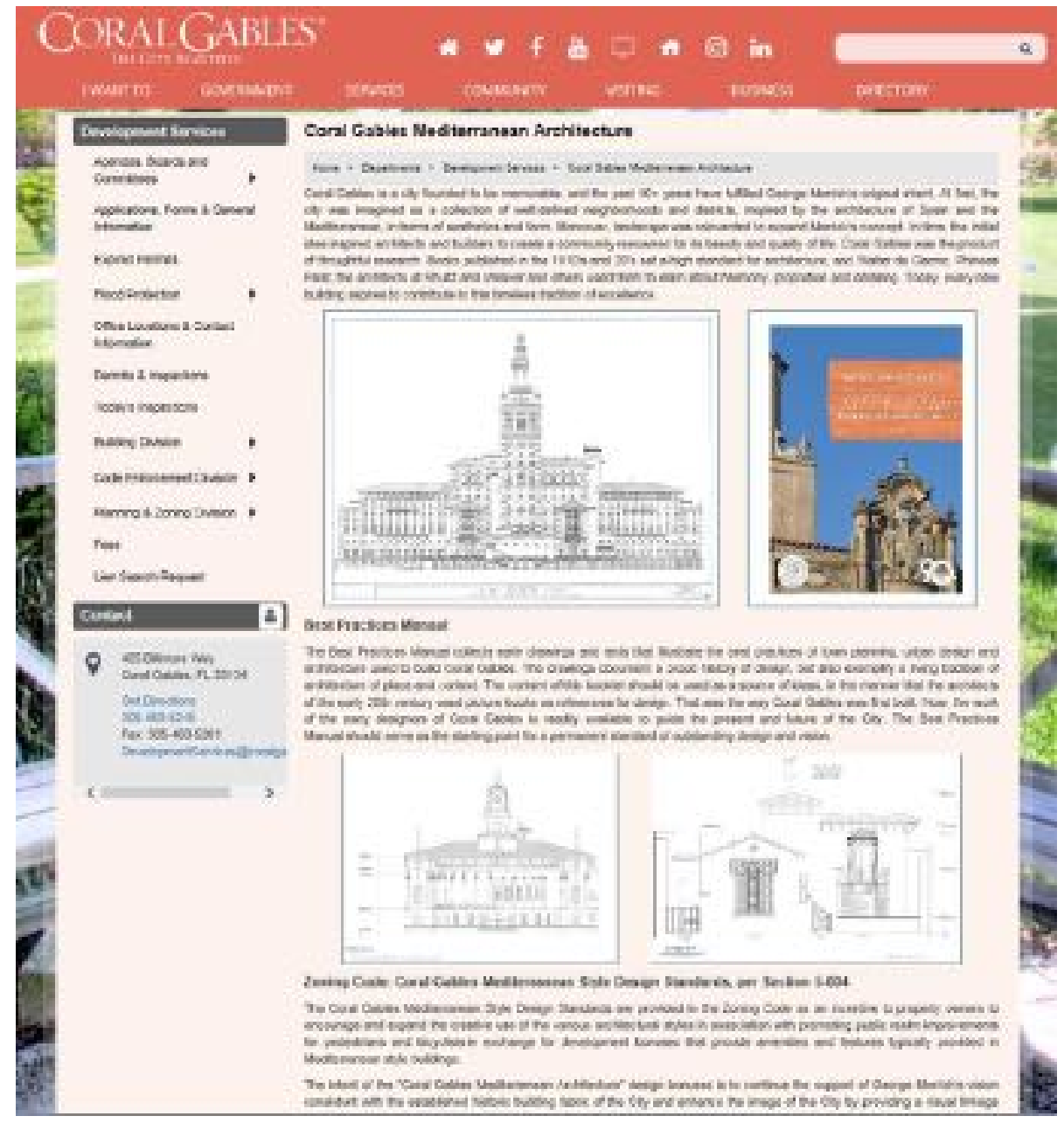

Plate 41. Coral Gables Mediterranean Architecture page. Source: Coral Gables website. 


\section{Participation}

The Zoning Primer (1926) established a rigid structure for limited public participation, which has been followed during a century of conventional practice practically unchanged. Emphasis was placed on impacts on the immediate vicinity. In time this led to a cumbersome process of development that focused on proper notice and bureaucratic procedure, but which neglected content.

More recently, New Urbanism theory proposed the charrette as the preferred process (Duany, Plater-Zyberk, Speck, 2000). Charrettes expanded and refocused discussions, in terms of content and participants. However, conventional zoning codes, including the Coral Gables code, rarely expanded mandatory participation beyond minimum requirements. Any additional meetings or workshops were optional or discretionary, and not part of adopted processes.

Qualitative findings led to a recommended spectrum of democratic activities. Not every activity would be appropriate to every situation. Not all activities would be required for every project. Activities may or may not involve all interested people. Professional judgement would guide public participation design. Research revealed that public participation activities were common but lacked robust theory. Further research may lead to more precise recommendations, upon review of data and outcomes.

Plate 42 illustrates recent planning initiatives for a district of Coral Gables. Public participation events were designed in the format of workshops that would lead to actionable ideas, with the assistance of a professional team. Participants debated ideas and presented their conclusions. Comments were received online and during public 
hearings. Capital projects were selected and implemented through the budget and construction process. All information was available to the public, all the time.

Transparency enhanced the democratic aspects of the process and encouraged synergies with bureaucratic procedures. It also required innovation by staff, as planning and implementation required enhanced coordination.

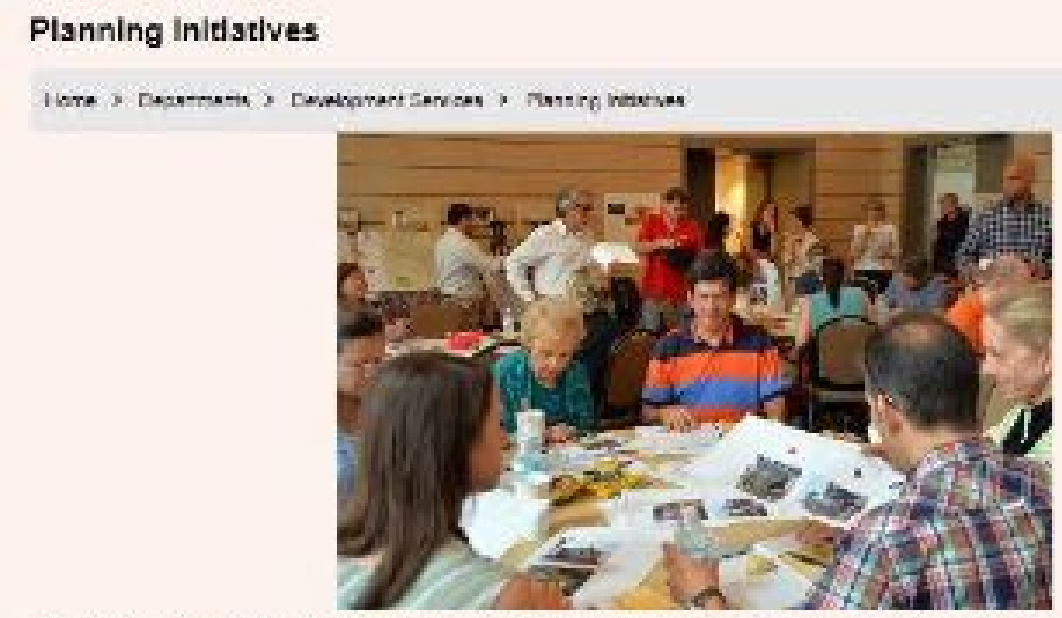

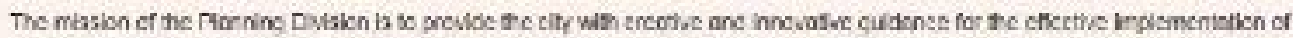

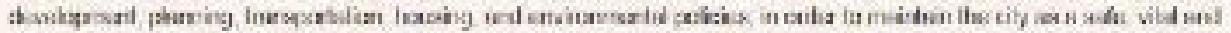

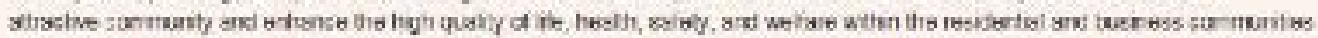
n sessciston whin tre presenzacon of tha lesioncsi haitago.

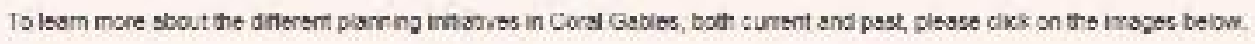
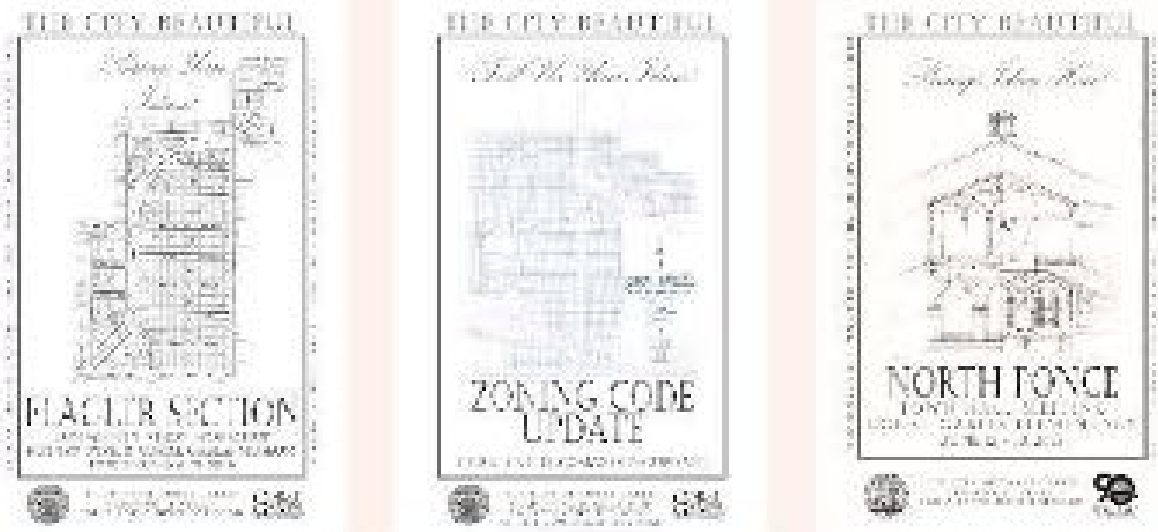

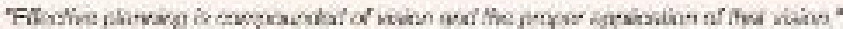

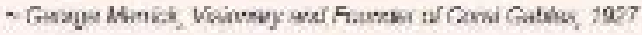

Plate 42. Coral Gables planning initiatives page. Source: Coral Gables website. 
The following list of public participation tools should serve as a starting point for best practices:

1. Taxonomy of opportunity for input for the generation of content:

a. Direct public discussion

Social media promote public discussion and Smart strategies should translate opinions into democratic input. Plate 43 reports comments on a Coral Gables project proposed in 2019 , prior to discussion at the Commission meeting. Public opinions, therefore, became input for decisions.

\section{Arquitectonica's Design for the New Hotel}

horal desige pienty develaperert

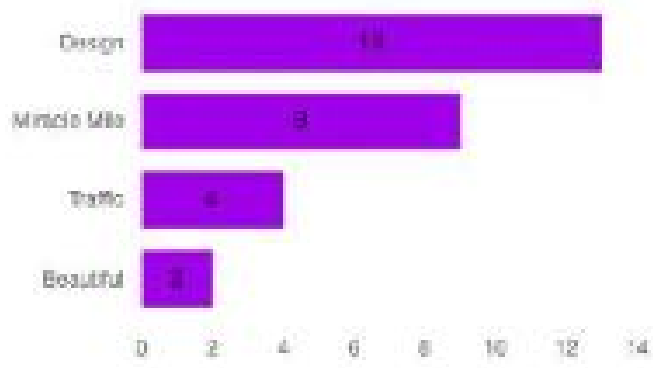

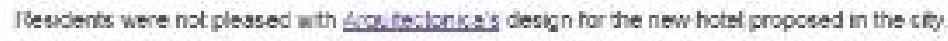

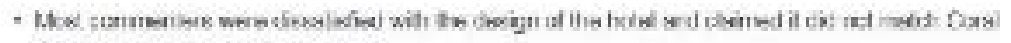
Gables sesthatres (13) interastons)

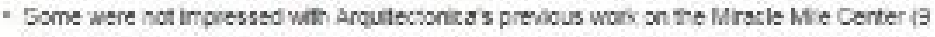
interactonsit

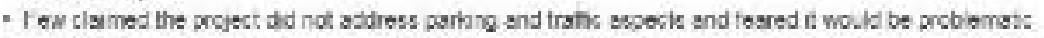
(4 njera:tions).

- Merely 2 nxerastiona cepressed poedisty towam the desan ond thought i wes beoutifli.

Plate 43. Social media comments. Source: ZenCity. 


\section{b. Charrette}

Charrettes were informal, intense and creative and fundamentally democratic. Moreover, charrettes were an explicit critique of public hearings required by zoning enabling legislation from the 1920's. In a charrette, content would be provided by study of the context and history and by the opinions and aspirations of the participants.

The goal of charrettes was conceptual visioning, and recommendations would give general diction for policy. Although charrettes are organized often to gather input about neighborhood plans or major capital projects, the process is seldom required or defined in the zoning code. Local administrators may view public input from the point of view of bureaucracy. Public input may be a requirement to be fulfilled, but it may have a limited role in the process of making decisions or implementing policy. A democratic perspective would enhance local governance. Effective best practices for democratic input require structure and staff support. Moreover, initial ideas must be implemented through a transparent and collaborative bureaucratic process. Input from participants should be recorded and explained, and future modifications should be reviewed by all affected.

Plate 44 summarized alternative designs for review by interested neighbors. Illustrations of alternatives and video of public debates provided adequate context to prioritize projects. 


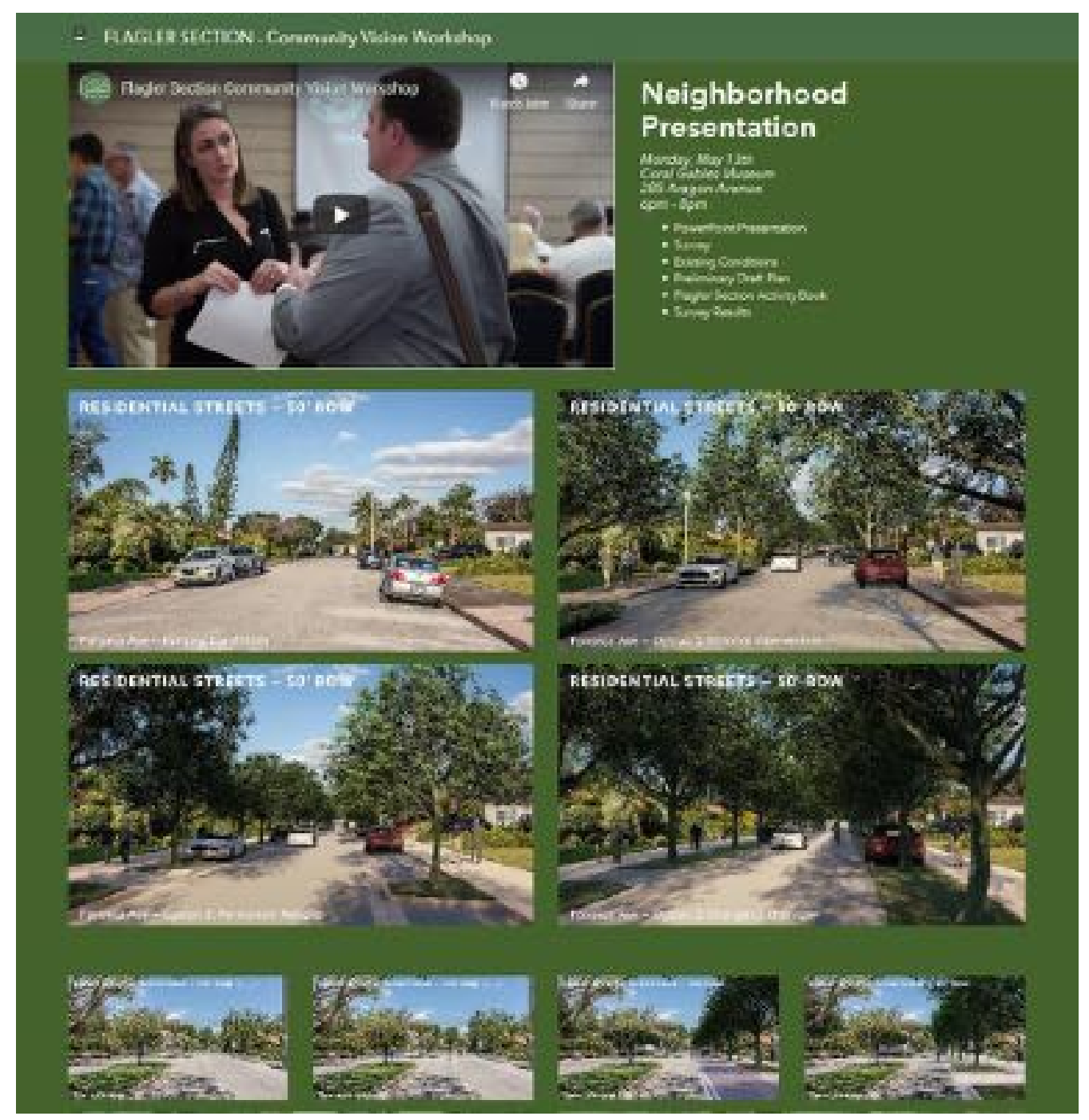

Plate 44. Neighborhood presentation page. Source: Coral Gables website.
c. Workshop

Workshops may be more structured and specialized than charrettes.

Typically, the topic would be defined and discrete, and

recommendations would be actionable. Plate 45 is a photograph of a

typical design workshop, where residents conceptualize ideas and

express support or opposition for capital or development projects. 


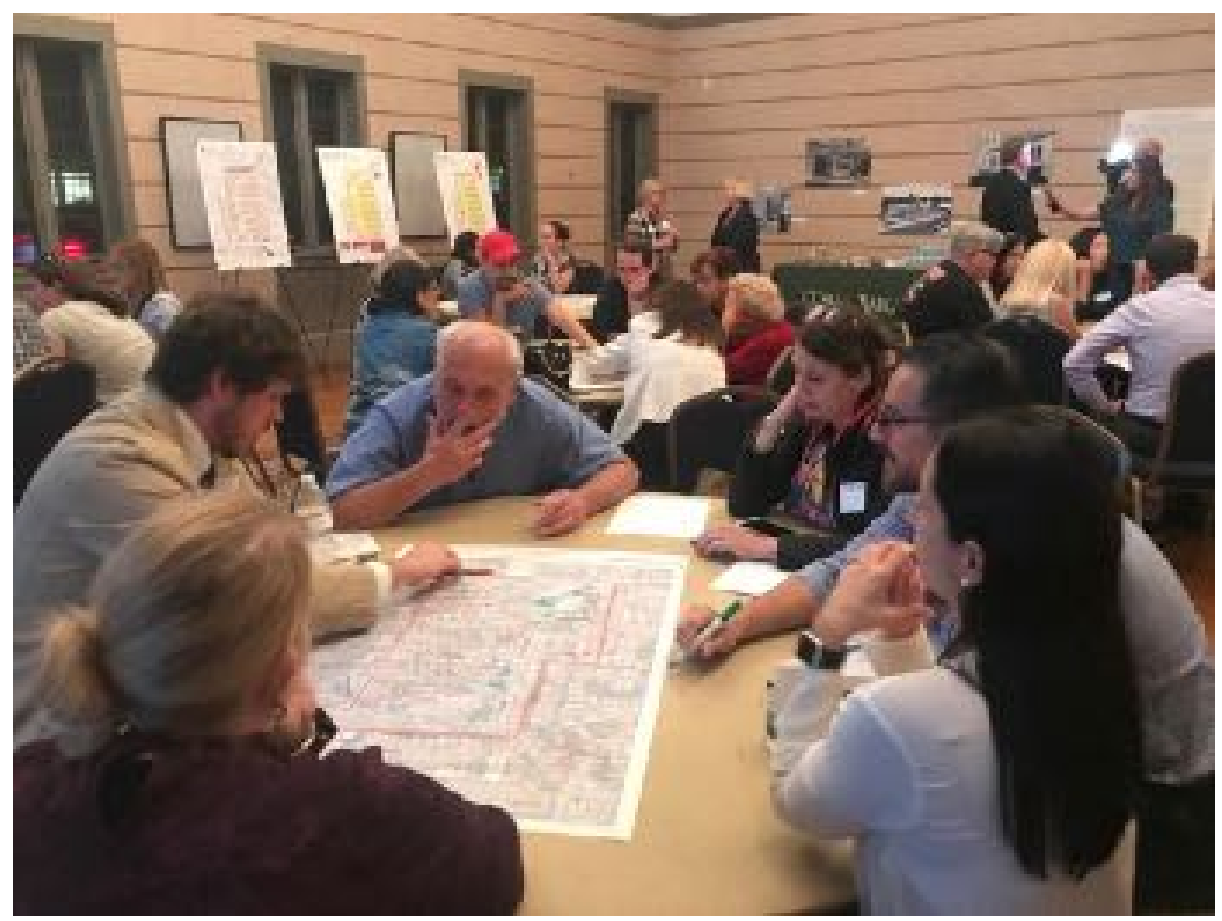

Plate 45. Neighborhood workshop. Photograph: Ramon Trias.

d. Informal Meeting

Community meetings should be scheduled to verify progress towards goals expressed in terms of content and to build resident trust and support. However, there should be a clear link between meetings and bureaucratic implementation. Community meetings should be required steps for the implementation of place. Plate 46 is a photograph of a walking tour led by a consultant. Neighborhood residents were able to express their concerns and received immediate feedback. Moreover, neighbors were able to discuss and contrast their views in a structured setting with a professional facilitator. 


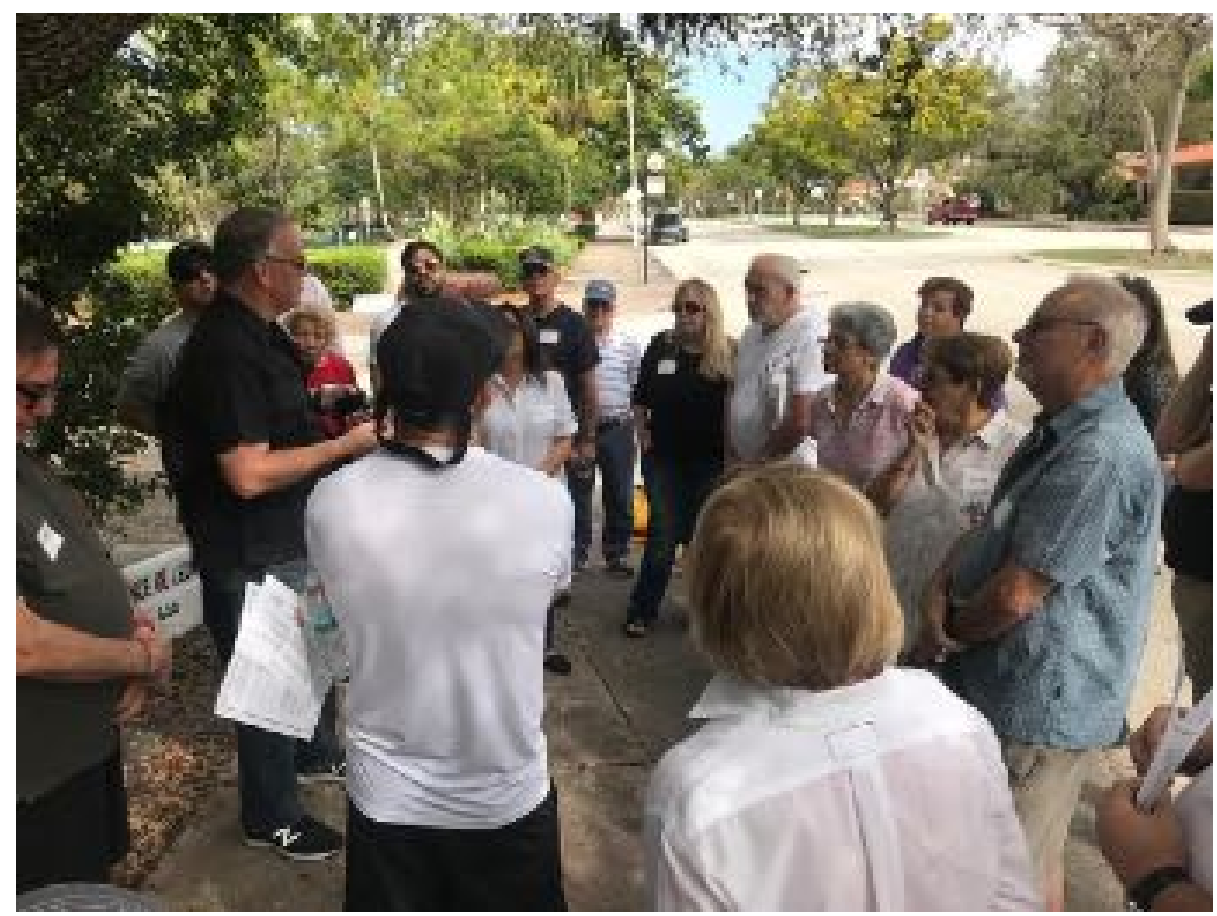

Plate 46. Neighborhood walk. Photograph: Ramon Trias

\section{e. Public Meeting}

Projects should be discussed in official public meetings, in processes established by the zoning code. Input and interaction should be encouraged, and aspirational content should guide decisions.

Governance of place should privilege collaborative discussion over an adversarial process. However, differences of opinion should be resolved through clearly defined processes adopted in the zoning code. A clear process, with notice to the public and options for appeals is necessary for long-term effectiveness of design review. Plate 46 displays a typical meeting of the Coral Gables Board of Architects, where board members discuss in great detail the aesthetic merits of development projects. Projects are presented with conventional tools, 
as drawings on paper provide an efficient medium for critiques and red pens can record comments in sufficient detail. Applicants explain their design ideas and volunteer board members offer suggestions. Professional staff is available to assist, as questions of technical of zoning compliance or long-term vision often arise. Most projects are deferred at least once. Multiple revisions are common, as a result of debate and different interpretations of aesthetic goals. Once the Board approved the preliminary design, it continued through the permit process. Communities have attempted design review in a variety of formats, but the Board of Architects is a best practice for democracy of place.

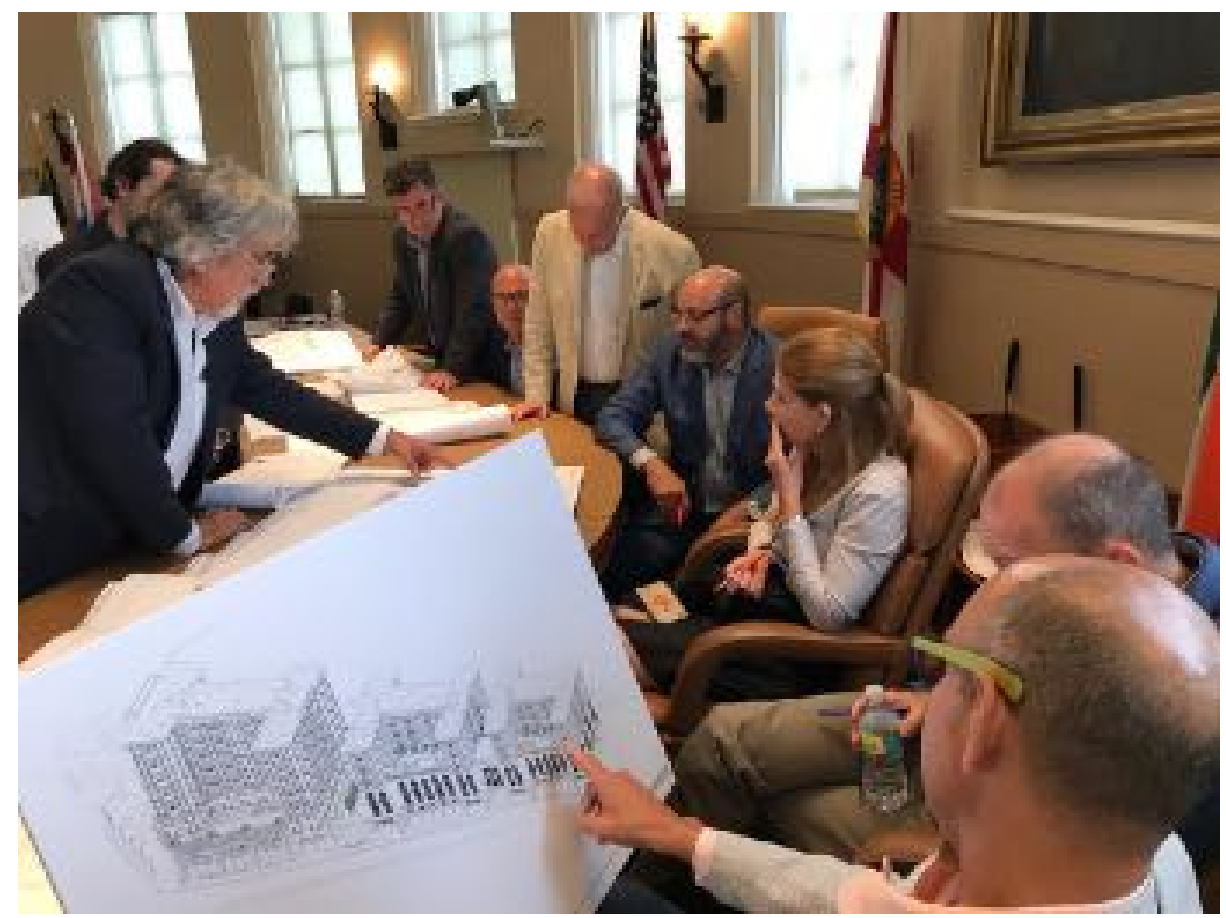

Plate 47. Coral Gables Board of Architects meeting. Photograph: Ramon Trias. 


\section{f. Workshop}

Controversial topics may require extensive public discussion, and workshops are often an effective step in the process of debate. Plate 48 is a photograph of a Commission workshop and plate 49 is a screenshot of the description of the workshop provided by the city website. Elected officials were able to hear public concerns and discuss priorities and policy on a proposed annexation. No decision would be taken at the workshop. This type of format provides transparency and should lead to enhanced democracy of place, as controversial topics can be discussed in a constructive format.

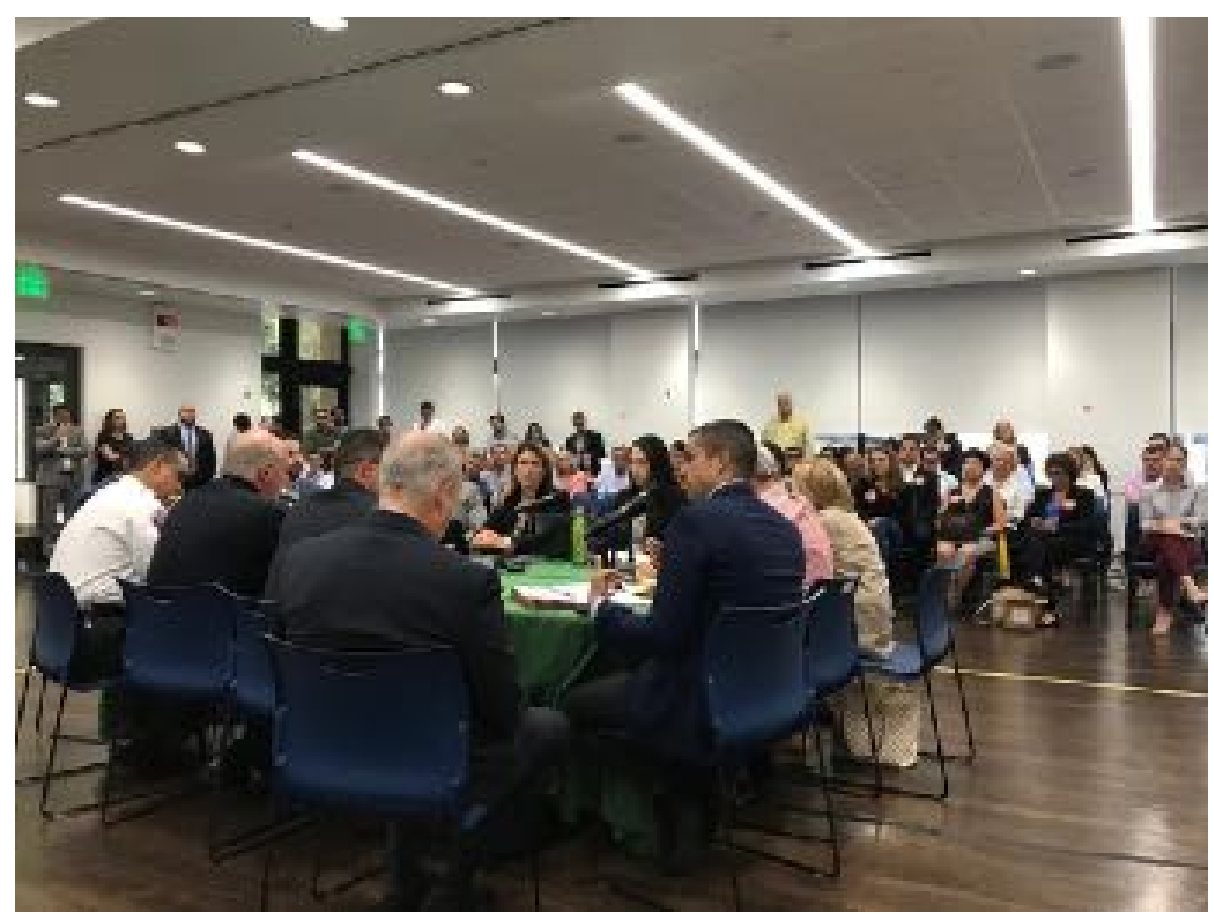

Plate 48. Coral Gables Commission Workshop. Photograph: Ramon Trias. 


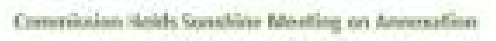

The Coral Gablus City Conmisobe held a Susshine Meeting on Mondas.

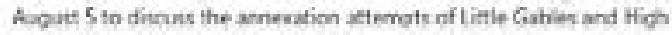

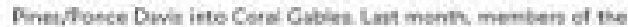

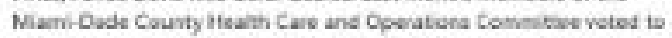
defy the amesation pibcess ter both zeas trom movisg forward. The freeting which lated abeut thee heur. war well ateoded and featared s good diecuntion on the topic where membest of the poble

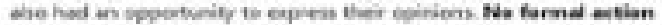
was taken ty the Oty Commbsian as if wat a Jurienise Meetng the how will be further discutsed at tuture Cry Comrission mentisgs.

\section{Paine roorz}

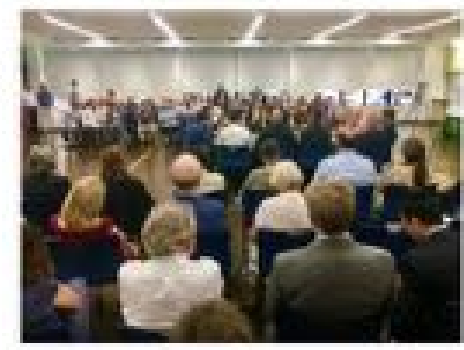

Plate 49. Report on workshop. Source: Coral Gables website.

g. Public hearing

Public hearings are the most visible format of local governance and are typically associated with politics and adversarial presentations. It may appear that public hearings at a Commission meeting make up the totality of the democratic process, but that would be a misunderstanding of democracy of place.

Official public hearings should be part of a dynamic framework for governance of place, at the end of a spectrum of opportunities for participation. These types of meetings must be clearly identified in zoning codes and should be coordinated with less formal opportunities for public input. As final decisions take place at public hearings, conceptual discussions must have taken place during prior workshops or charrettes. A final public hearing would never be an effective format to reach consensus among all interested parties on content for quality place. In plate 50 , a resident speaks to elected officials during a Commission meeting. 


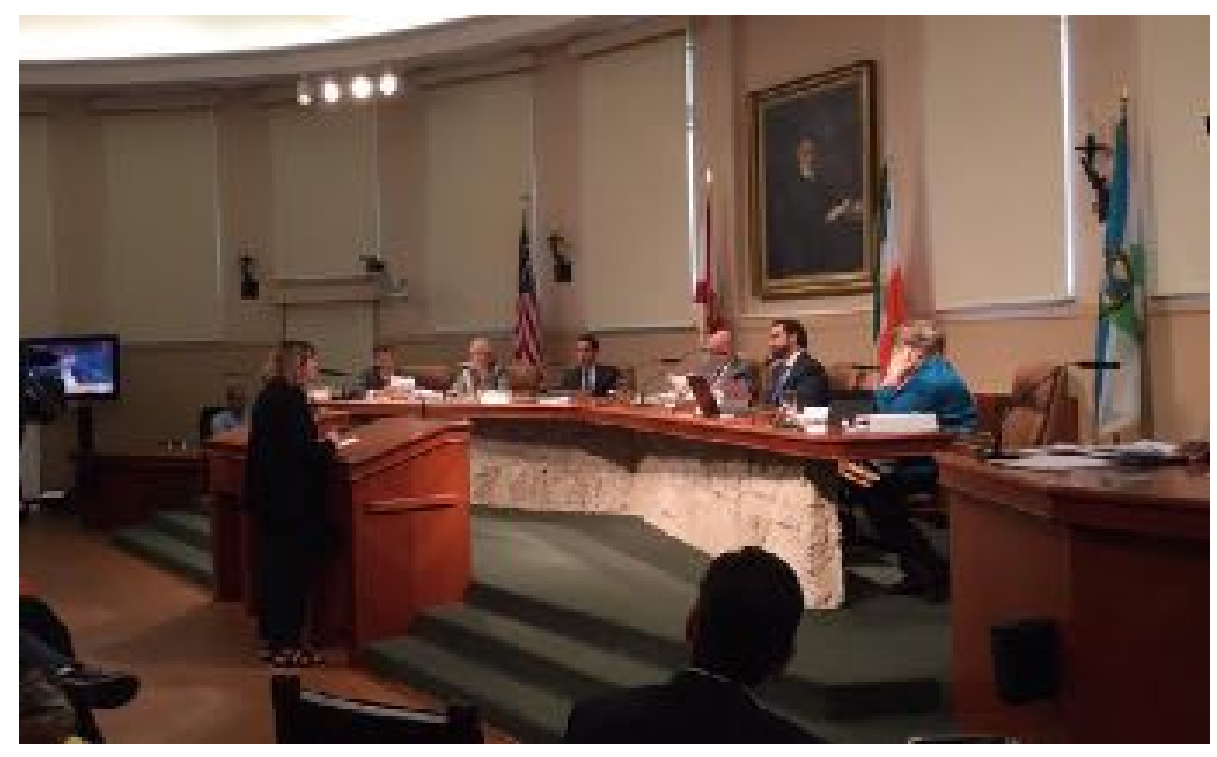

Plate 50. Coral Gables Commission Meeting. Source: City of Coral Gables.

\section{Decision}

Democracy should lead to equitable decisions. In conventional planning and zoning, discussions about development follow predictable and inflexible formats. Often, residents believe they did not have an opportunity to be heard effectively. Public hearings are designed to reach decisions. They are not intended to encourage dialogue. Additional opportunities for decision would enrich implementation of place.

The following are proposed as best practices:

1. Dynamic content should inform decisions about place.

a. Smart information for staff review

Real time information about content should be available to staff and the public. Smart tools encourage transparency of data, which should lead to enhanced decisions about place. Plate 51 is a GIS map that 
identifies trees. The map is constantly updated and allows accurate decisions about tree removal permits.

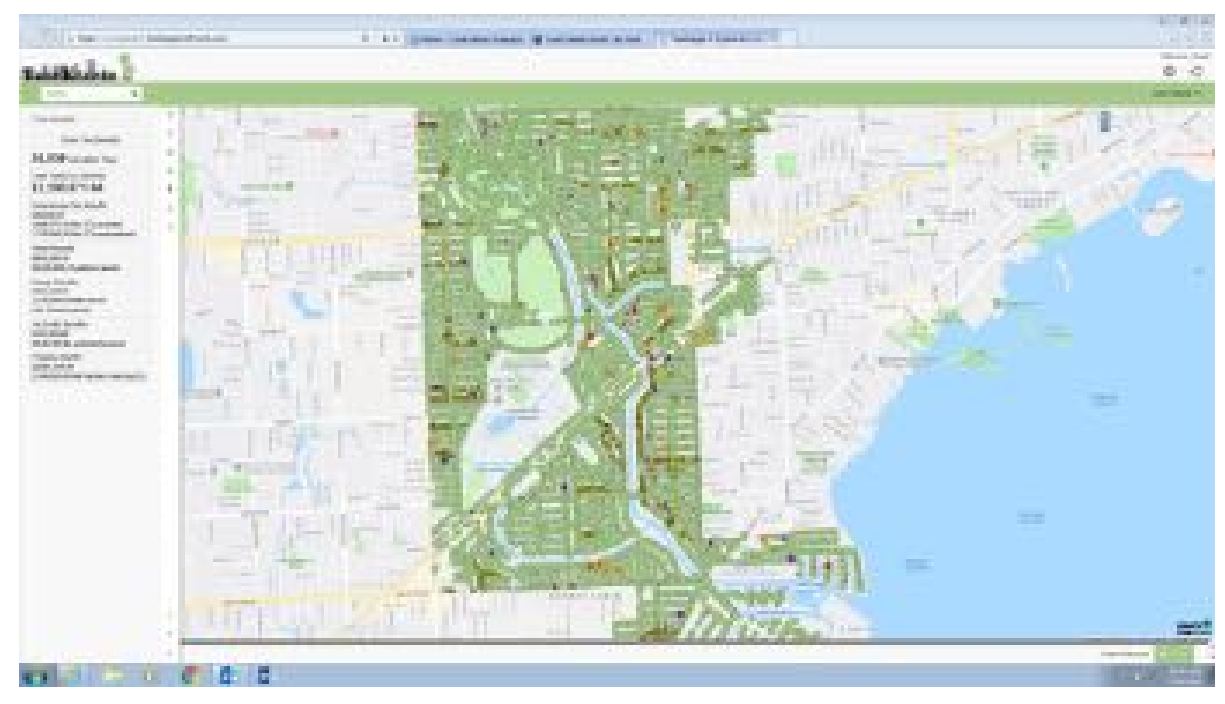

Plate 51. Tree Keeper page. Source: Coral Gables website.

b. Open and public information.

Once place is understood as data, data can be shared with the public for the purpose of enhancing quality of life. Smart tools encourage direct review of information and guide collaboration among residents and administrators.

2. Volunteer and appointed board autonomy.

Citizen engagement should include participation in boards and direct input multiple times throughout the process of review. Board members should provide their best recommendations, with the assistance of smart tools. Governance of place would be most effective with autonomy of individuals and transparency of data. Plate 52 is the tool that coordinates public input for Coral Gables. 


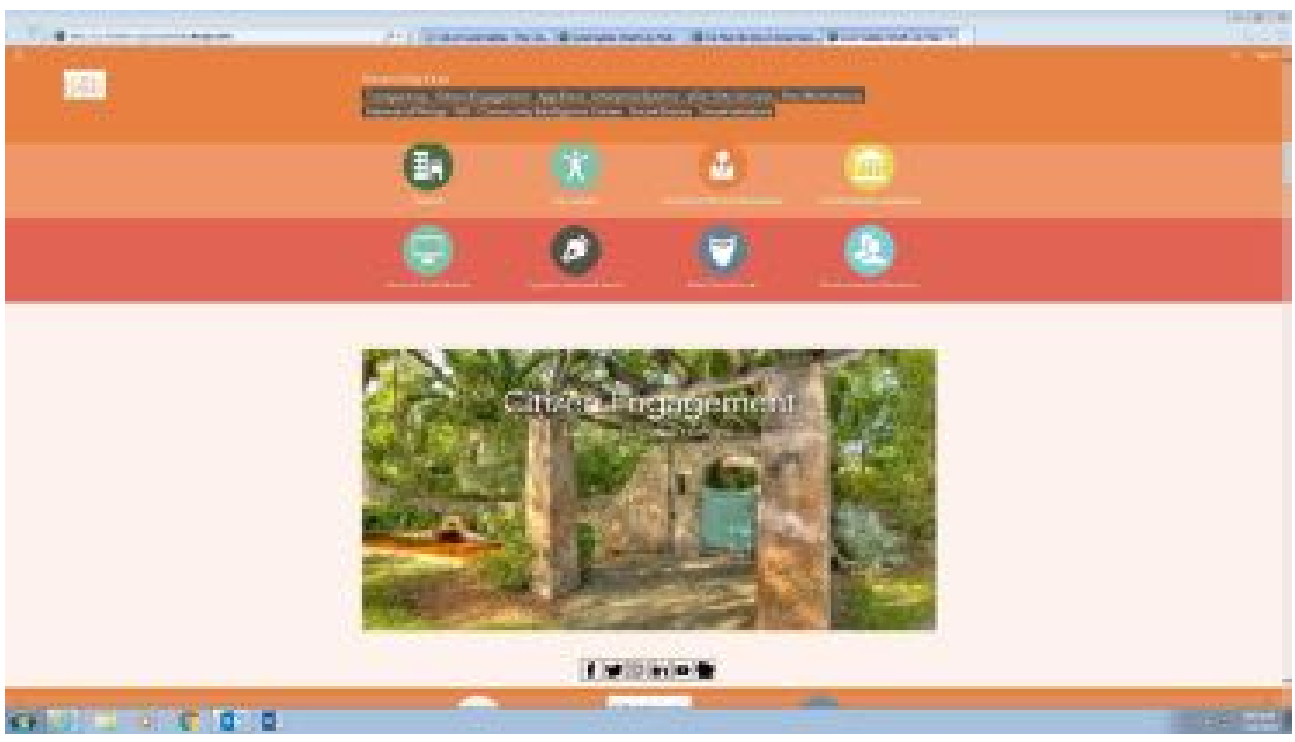

Plate 52. Community engagement page. Source: Coral Gables website.

\section{Commission transparency}

Commission meetings should be transparent and broadcast across multiple media, with emphasis on smart tools. Background information provide to commissioners should be available to the public at all times. At a minimum, all documents should be available on-line, and such record should be permanent. Future questions about decisions should be answered with data available to the public. Plate 53 is a television broadcast of a Commission meeting. The same broadcast is available on-line, and it is linked to commission agendas, for future reference about the public record of governance. But place supported by technology should be tools for democratic governance. For example, the monitor photographed in plate 53 was located in the hallway of City Hall and carried a love broadcast of a Commission meeting. Staff, applicants and residents would be able to follow the meeting outside the chambers, and thus be able to discuss items and 
finalize outstanding negotiations. The physical design of City Hall should provide adequate locations for these interactions, as smart place strategies should include interior design of public buildings, where architecture and technology would facilitate democracy, along a spectrum of informal to formal activities.

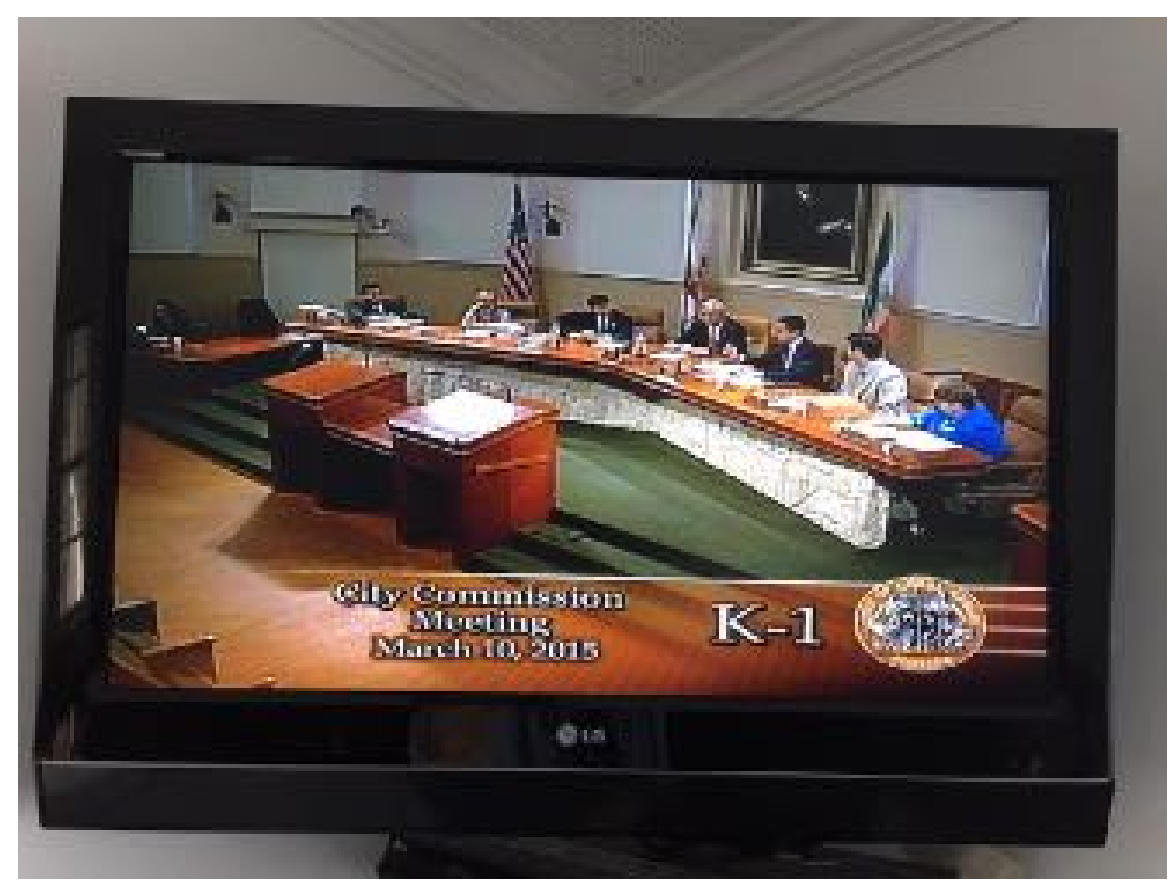

Plate 53. Coral Gables City Commission meeting on television. Photograph: Ramon Trias. 


\section{Best Practices for Bureaucracy of Smart Place:}

\section{Data, Language, Manuals, Procedures}

\section{Smart Bureaucracy for Local Governance}

Effective democracy and bureaucracy lead to Smart Place. Survey findings revealed bureaucracy was considered crucial for the regulation of place and democracy was undervalued. Theory should attempt to provide a more balanced framework for local practice. Recommended best practices should strive to promote governance, which should blend democracy and bureaucracy for best practices.

Throughout the $20^{\text {th }}$ century, bureaucracy was well-established in countless predictable interactions of residents with administrators at the local level. Survey data from Coral Gables provided detailed insight on the way place was understood by residents. The fact that "community engagement" and "customer satisfaction" surveys were conducted demonstrated an interest by administrators on enhancing local government practice.

Although interest in bureaucracy supported theory assumptions, there was not a similar concern about democracy. In fact, survey data was exclusively about bureaucracy. Democracy did not appear relevant to administrators. Proposed theory suggests that place should be the outcome of local government democracy and bureaucracy, and that aspirational content has a dual role. Thus, recommended best practices for bureaucracy assume additional research on democratic activities, and anticipate further calibration based on findings.

Quantitative data demonstrated general satisfaction with administrative procedures informed by content. Qualitative interviews with experts on smart strategies 
showed practical uses of technology which would enhance procedures. If local governments were businesses, one could conclude that they were doing a great job, based on customer satisfaction with bureaucratic activities. But governance requires a higher standard than business transactions, and public sector bureaucracy must account for this.

Smart Place strategies would make bureaucracy accessible and collaborative. Qualitative data suggested that past misunderstandings of goals and procedures led to frustration about bureaucracy. Best practices would enhance awareness and participation and provide realistic expectations.

Customer satisfaction data for surveys reviewed for this study emerged from incomplete information because questions tend to be phrased to evaluate isolated transactions. Local governments are not businesses. Place is not real estate. The civic dimension of place can be enhanced with Smart Place tools, that can be more dynamic and comprehensive than past strategies.

Local governments in the United States apply democracy directly to decisions that affect quality of life. Bureaucracy may as efficient for private and public organizations. There may be an appearance of democracy in some public or private activities, amplified by the implied recent accessibility of smart tools. However, democracy only exists in the public sector. Addressing the crucial distinction of participation between private business and public activity would determine success or failure of best practices for bureaucracy of place.

Public administration theory and best practices must account for the transformative effect of democracy on public bureaucracy. Democracy does not stop with politics because it leads to governance. Thus, effective best practices for public 
administration must be calibrated for the requirements of bureaucracy and democracy. Public aspirations should be content for governance of place.

The bureaucracy for governance of place would be enhanced with best practices for the following topics:

1. Data

2. Language

3. Manuals

4. Procedures

The examples of best practices from Coral Gables are included for illustration purposes. The are not proposed as normative or ideal. They are a work in progress,

\section{Data}

A fundamental recommendation of this study is that place should be understood in terms of data. This perspective should be effective for bureaucracy.

Data are discrete and independent from historical time. In terms of best practices for Smart Place, data require a smart ecosystem for dynamic records and decisions. Generally, as place is a physical environment, the interface should be graphic, which can be best achieved with mapping and GIS capabilities.

New technology can enhance historic practices. As an example, a classic model for mapping place is the Nolli map of Rome of 1748. The map was crafted as an engraving, which did not allow easy updates. However, the information and graphic technique represented the state of the art of communication of content for place until digital media provided smart tools. 
Smart tools would allow a dynamic depiction of data, with frequent updates and enhanced accuracy. GIS would allow additional layers of data. However, more data would not be necessarily better data. Data from the Nolli map, for example, would be sufficient to understand the content of Roman urbanism. Today's version of such a map would learn from the original display of data and would support it with updated smart tools. Plate 54 compares a section of Coral Gables depicted as a Nolli map, with the original.
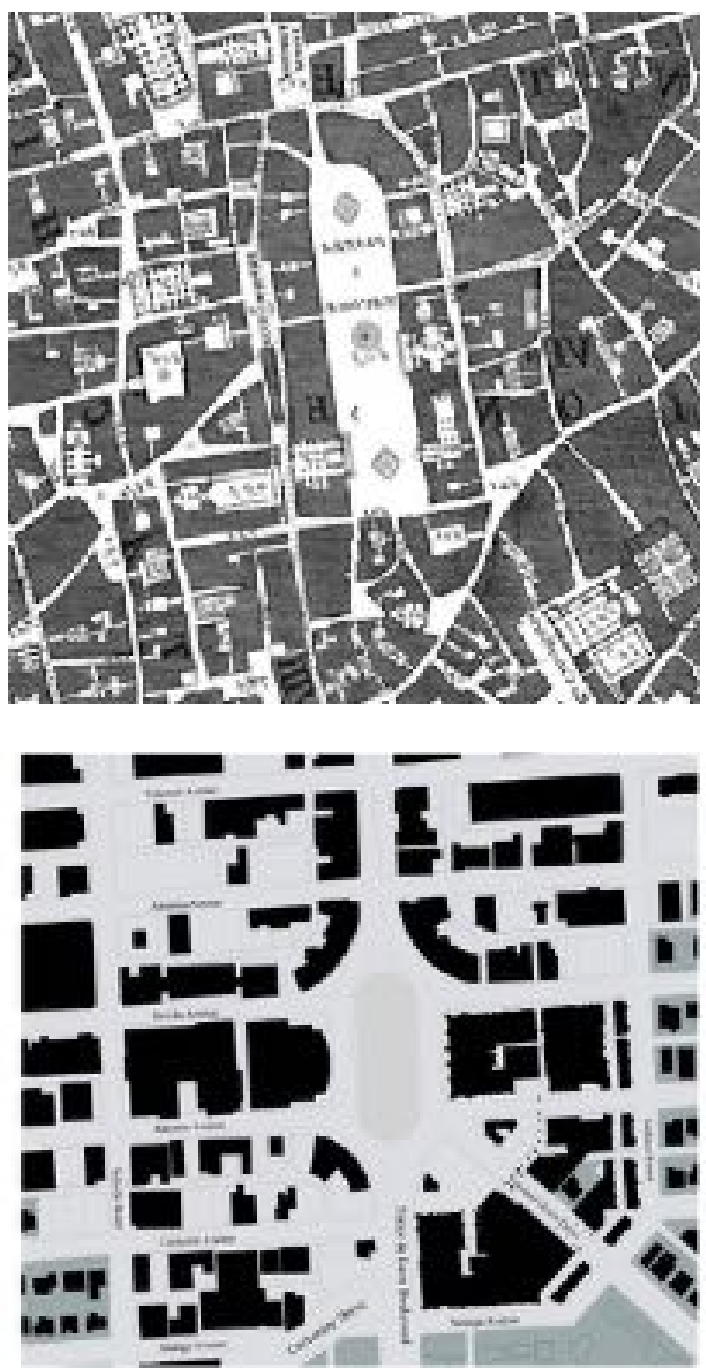

Plate 54. Above, Nolli map of Rome, 1748. Below, map of Coral Gables, after Nolli map technique, 2019. Source: City of Coral Gables. 
In terms of process, research demonstrated that Coral Gables had a clear original vision, and that innovative administrative tools were calibrated to implement and enhance original ideas, as needs changed through time. The fundamental finding is that vision was translated into effective administrative tools based on content, at multiple times. This transformation of ideas into actionable data took place early, with the first zoning code of 1930, and continued to the present.

Findings from the deconstruction of zoning language illustrates the evolution of ideas towards content. In addition, language was supported by a master plan which provided direction and structure to the zoning code.

After almost a century of administration of design with the tools of zoning, the experience of Coral Gables leads to the following theory conclusions, which should inform public administration best practices:

1. Maps

Conventional planning and zoning were centered on two abstract maps: zoning and future land use. Neither graphic documented reality, which was referred to as existing conditions.

Contemporary best practices should use GIS graphics, GPS technology, threedimensional photographic representation, video cameras, and other smart techniques have significantly enhanced mapping. Technology should depict place accurately and dynamically.

Plate 55 is an example of a smart zoning map. Conventional zoning maps were two-dimensional abstractions of urban form, which provided limited information 
and predetermined bureaucratic discussions along a few topics, such as use or setbacks. Smart maps display additional information, such as dynamic existing conditions or contextual renderings in three-dimensions, which should lead to more effective implementation of policy.

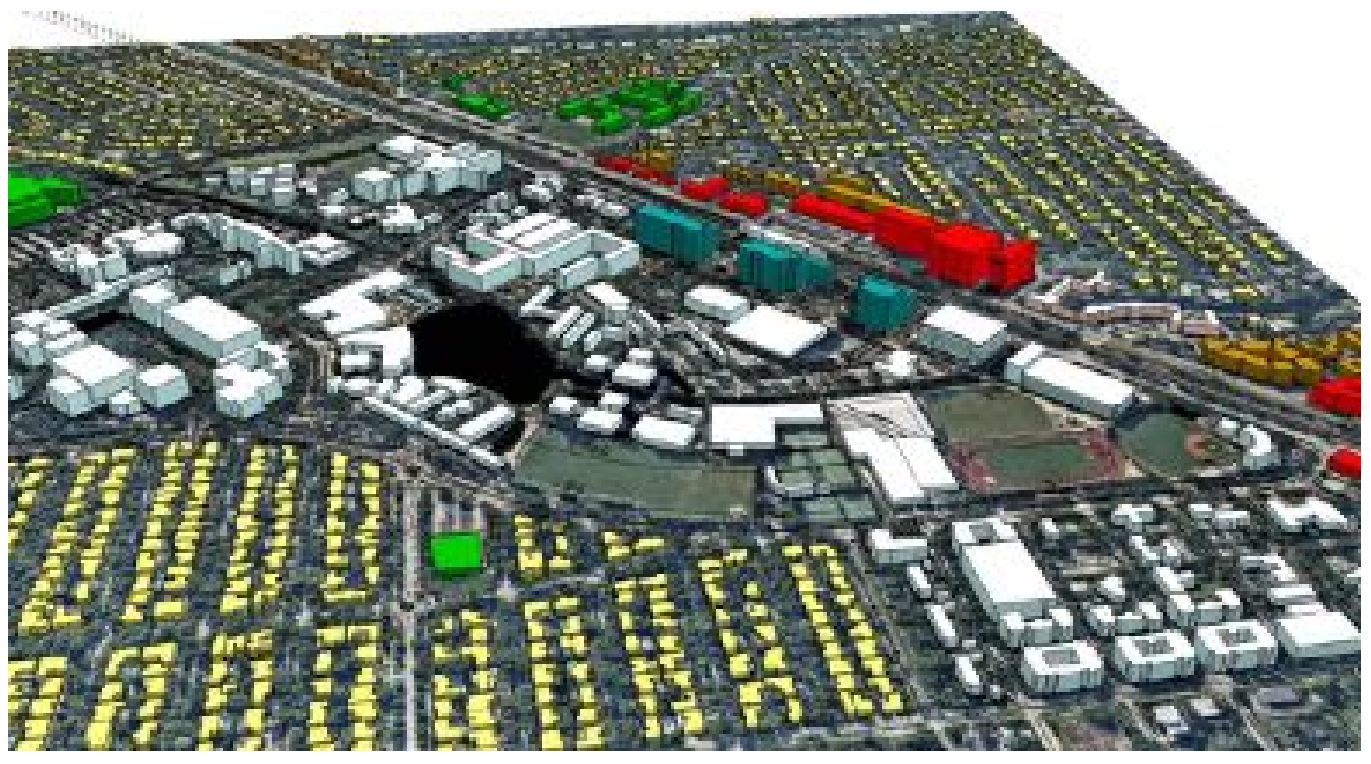

Plate 55. Zoning map, with volumetric data and existing conditions photograph. Source: City of Coral Gables.

Information on zoning may be depicted with color. Additional information may be:

- Aerial photograph of existing conditions

- Volumetric representation of existing buildings

- Volumetric representation of zoning potential

- Numerical data linked to graphics (Square footage, number of parking spaces, etc.)

- Site specific regulations linked to parcels 
In addition, artificial intelligence programs are beginning to review projects for routine zoning compliance. Should this practice develop efficiently, professional staff will have more time to enhance the implementation of aspirational content and qualitative design ideas.

\section{Design}

Zoning regulations should address design directly and should provide exemplary illustrations as precise as the community's aspirational content would require. An example from Coral Gables is plate 56, in the format of a web document. Zoning should evolve away from complete reliance on abstract text and should be supplemented with concrete illustrations of aspirational content.

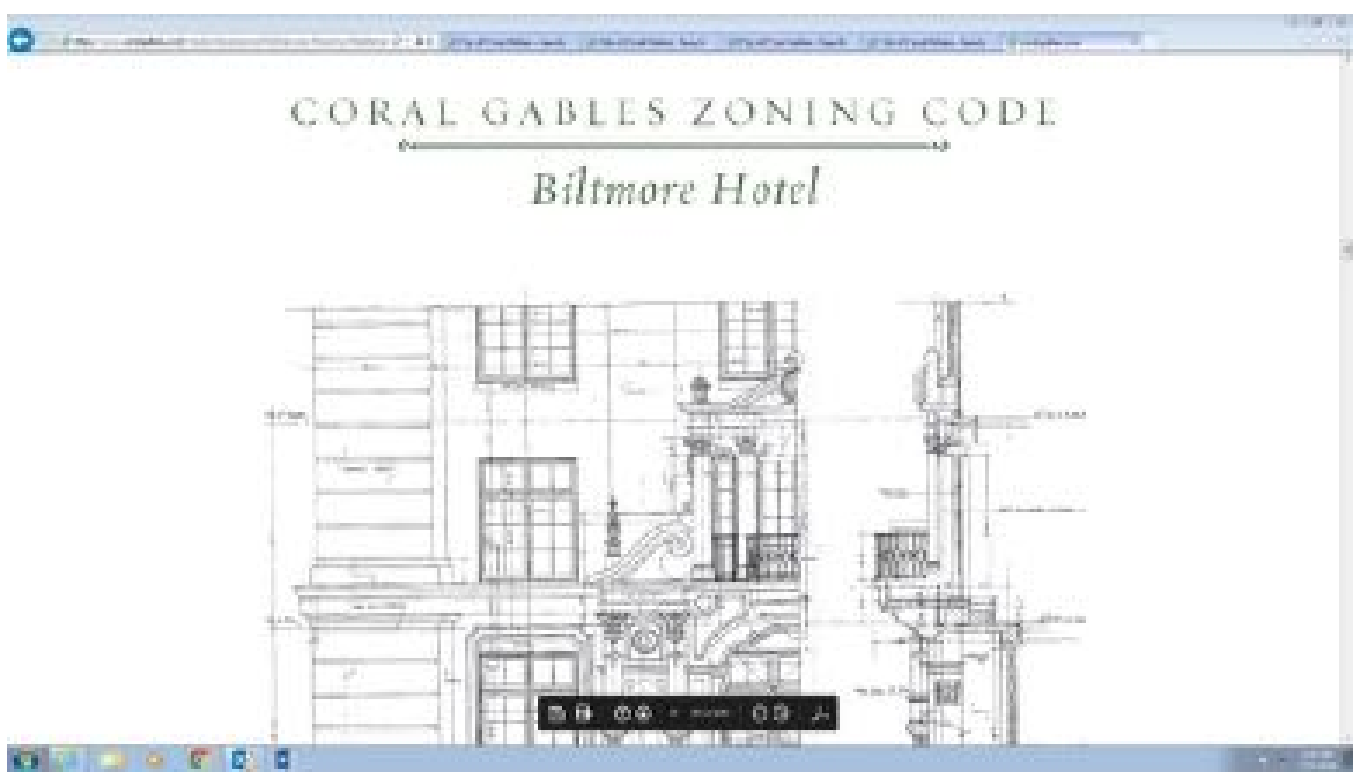

Plate 56. Zoning Code illustration. Source: Coral Gables website.

However, to have this level of information, consensus about aspirational content is needed. Moreover, qualitative information about content has to follow best practices. Collaboration among administrators and academics should be 
encouraged, with the goal of creating tools for the bureaucratic implementation of smart place.

3. Dynamic information and records

Current information should be collected and distributed in real time. Coral Gables uses a variety of sensors and cameras which observe conditions. This idea originated as a public safety program, but it evolved as a best practice for planning and economic development. At present, administrators have more information available that at any previous time. Data must be saved and analized in ways that enhance long-term decisions, with effective measuring and recording. Best practices are still in the development stage, but the topic should provide results in the near future. Plate 57 reproduced the webpage of Coral Gables, which provides access to the :smart city hub":

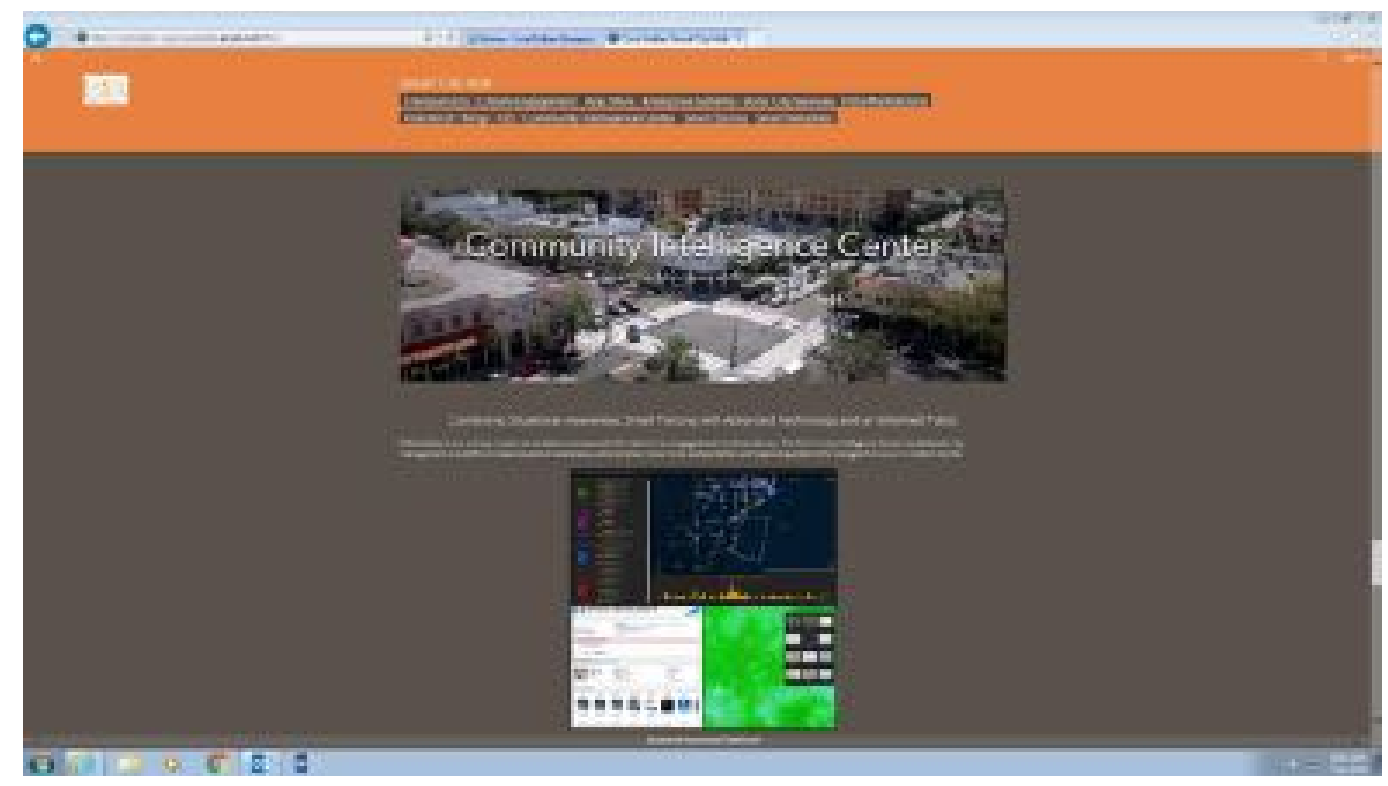

Plate 57. Community intelligence page. Source: Coral Gables website. 
Furthermore, smart tools allow real time monitoring of traffic or events. Current use of these tools is still rudimentary, but future research may lead to additional best practices. Plate 58 is a photograph of the Coral Gables information center, where monitors display video information from street cameras. The information may allow enhanced traffic planning, as part of a general mobility plan.

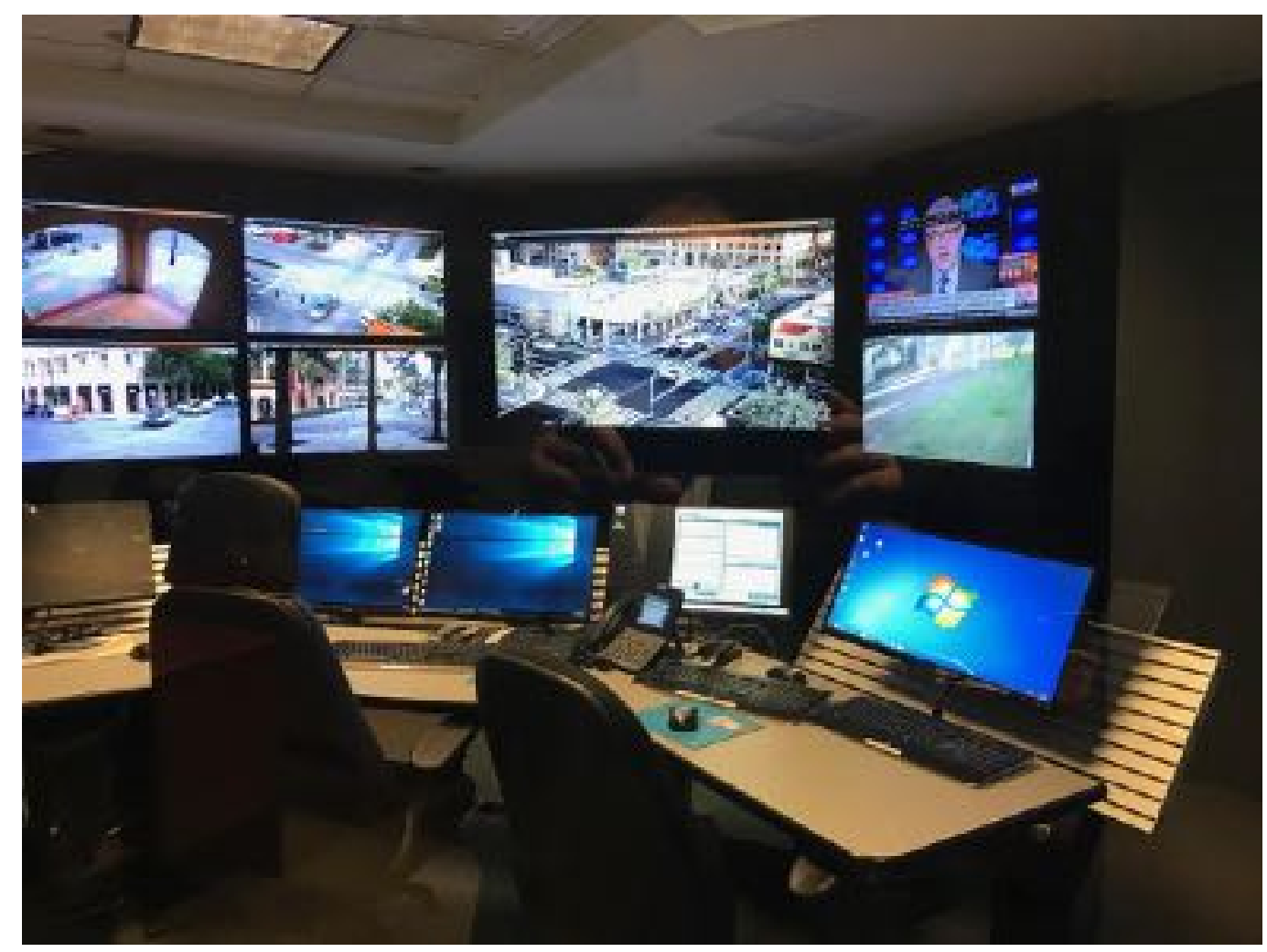

Plate 58. Control office, smart video information. Photograph: Ramon Trias.

Real time data would enhance service management and public safety in the short term. However, the use of real data should expand to subjects related to quality of life. Theory must guide innovation, as collected data has limited value until enhanced bureaucratic processes are adopted, Additional applications will be developed to enhance all aspects of Smart Place with the goal of enhancing local governance. 


\section{Language}

Place should be discussed directly in the context of governance. Research concluded that the last time best practices for design were principally about the content of place was in the 1920's. After conventional planning and zoning was established, form 1926 towards the mid-century, the outcomes of planning and zoning were not directly related to the content of place.

For the past century, buildings and civic spaces were increasingly regulated through inflexible abstractions, loosely linked to real estate priorities such as total square footage and impacts on neighbors. Only in exceptional cases, such as the Coral Gables Mediterranean bonus program, conventional tools have been used to regulate certain aspects of place.

Although various professional disciplines may have areas of emphasis, the outcome of place should guide democratic and bureaucratic activities of local governance. Zoning reform movements such as New Urbanism have stressed this point. The lexicon of urbanism was an example (Duany and Plater-Zyberk, 1999). Findings from this study were summarized in a glossary of terms, which should be developed further. The following best practices would implement Smart Place:

1. Use the language of place.

Coral Gables zoning language of place has a long history, which dates to the first code adopted in 1930. Plate 59 reproduced current excerpts from the zoning code, in the format of a manual of best practices accessed on the city's website. Language for the implementation of place should expand beyond minimum requirements of law and address content directly. The Coral Gables 
zoning code include aspirational language from its first version and retained many early concepts about content after multiple rewrites in the $20^{\text {th }}$ century. Bureaucratic tools for enhanced zoning language were proposed by reform movements from the late $20^{\text {th }}$ century, such as New Urbanism. Smart strategies open future opportunities for blending language, dynamic data and graphics into effective tools for bureaucracy.

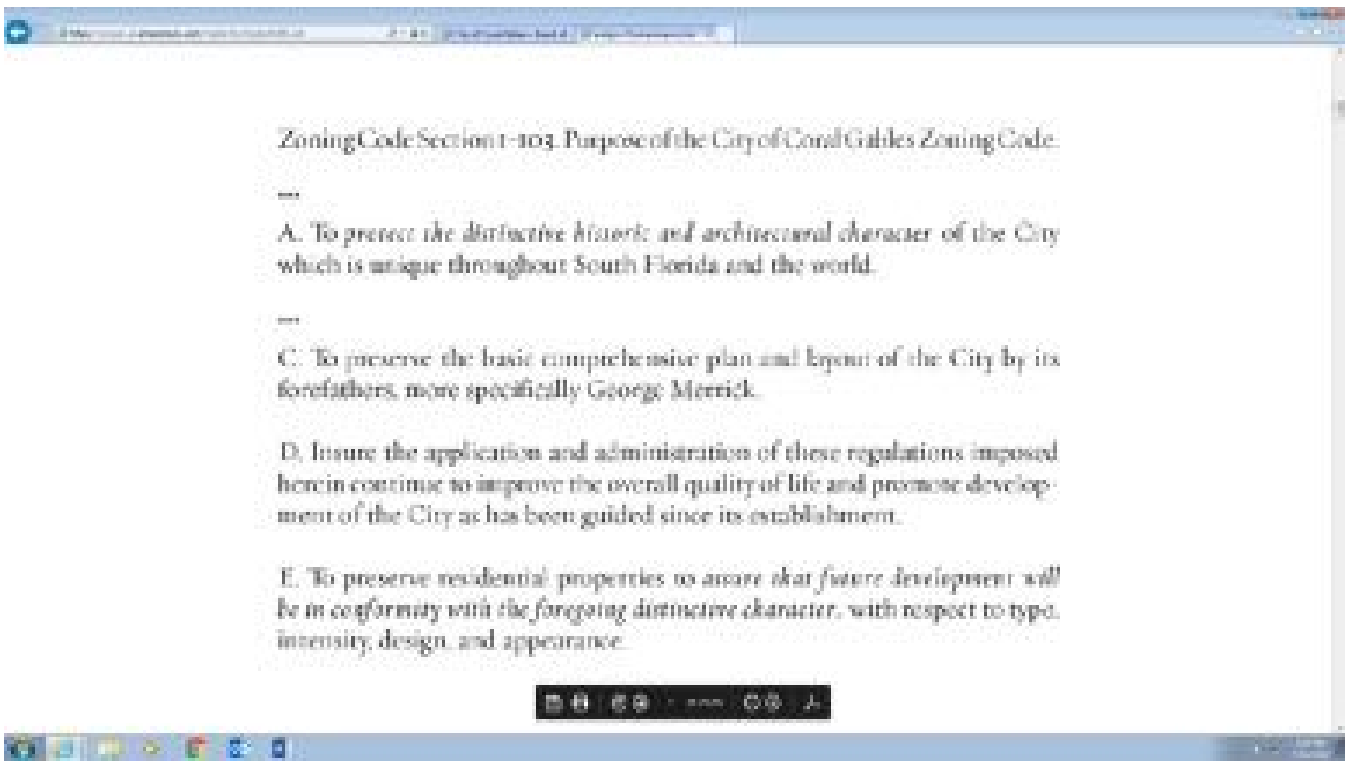

Plate 59. Zoning Code purpose. Source: Coral Gables website.

The glossary section of this study proposed new language for administration.

Such language, upon local calibration, should be used in democratic discussion of place and in local administrative bureaucracy, in the form of zoning codes and related regulations.

\section{Manuals}

Throughout history, treatises and manuals have elevated the quality of professional practice by collecting and promoting content of place. Vitruvius's Ten 
books of Architecture inspired renaissance authors such as Alberti and Palladio. Their publications led to Durand in the early $19^{\text {th }}$ century and folio books of the early $20^{\text {th }}$ century. Smart tools should provide continuity as the repository of aspirational content, with best practices for the $21^{\text {st }}$ century.

Coral Gables, and many other Florida communities such as Fort Pierce, achieved early excellence of place with the assistance of architectural manuals, in the form of reference books on style. Early $20^{\text {th }}$ century manuals were not bureaucratic guidelines, as they discussed both theory and practice with emphasis on education instead of regulation. Architects and builders applied well-researched lessons on typology, aesthetics and construction to their work. Best practices from the 1920's represented a coherent implementation of this approach to design. The convention of the treatise based on content was replaced by conventional planning and zoning based on real estate abstractions.

Folio books of the 1920's were formatted as manuals of specialized aesthetic design. They were intended to be "copied," although adaptation and interpretation would be more accurate descriptions of their practical use. Historically designated buildings throughout American neighborhoods and districts preserve the legacy of this best practice. In 2019 there were 1,173 historically designated properties in Coral Gables. Folio books, the design manuals of the 1920's, made superior design possible as a standard practice.

Several recent manuals have explored New Urbanism theory with the goal of developing best practices. Tachieva (2010) published Sprawl repair manual. The format was a college textbook. It was extensively illustrated with graphics from Duany and 
Plater Zyberk's practice from the 1990's. The manual provided a method for transition from "sprawl to complete communities" (Tachieva, 2010). These terms were language from new urbanism theory. Dover and Massengale (2014) published Street design: the secret to great cities and towns. Civic design is proposed as an alternative to transportation engineering. Criteria for quality infrastructure shifts to place.

The format of contemporary manuals does not have to be a printed book. Smart Place techniques should be developed to provide actionable information. Coral Gables research provided some basic examples, such as Best practices for Board of Architects, which was available digitally on the webpage. The publication followed the example of the folio books of the 1920's in terms of layout and information, but technology allowed frequent updates and universal access.

Best practices should include the preparation of design manuals, calibrated to local aspirational content, and collect user data to verify decisions:

1. Architecture

Best practices for the implementation of content should be described and enforced. Research demonstrated that this was common in the 1920's, when Coral Gables was founded. Qualitative input from experts suggested that content is absent from many discussions or reviews on contemporary architecture. A discussion without content will never lead to a place of quality. Thus, effective implementation of place is directly related to the degree of understanding of the community's aspirational content by design professionals. 
Education for professionals should be understood in terms of best practices. A model may be the folio books of the 1920's, which marked the end of the long history of the treatise. Manuals for best practices may supply educational materials for professionals and restart the practice of the treatise, and standards for review by administrators. The manuals should be understood as works in progress, to be extended with future research. Discussions about content should be resolved with information and data on content. Manuals should be the repository of content calibrated for place.

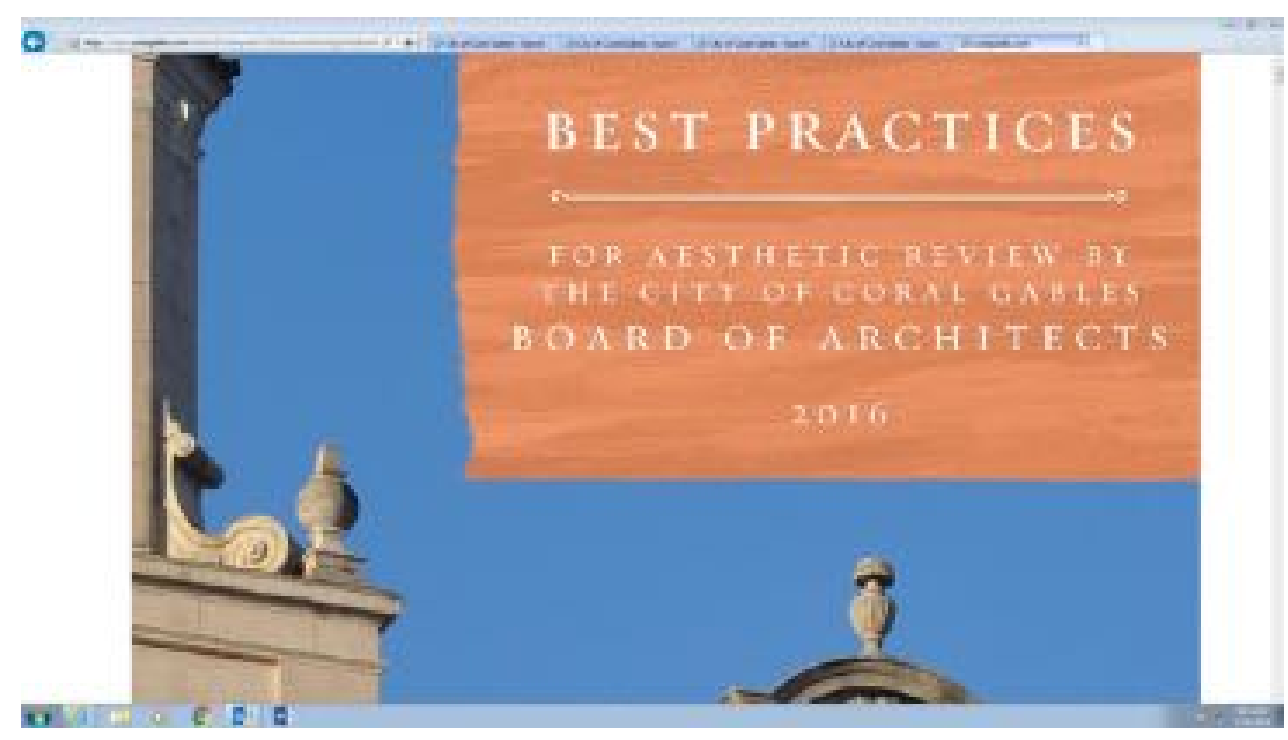

Plate 60. Best Practices Manual, Coral Gables Board of Architects. Source: Coral Gables website.

\section{Street design}

A Public Works design manual, with emphasis on place, should be developed and adopted. Street design may be considered the secret for great communities (Dover, Masssengale, 2014), but antiquated reliance 
automobile design standards has not been phased out in many local governments. Streets must be conceptualized as places, with careful design of pedestrian areas, landscape and the ground level of buildings. Plate 61 illustrated a comprehensive plan for street design in a defined district. Mobility, landscape and future development were discussed comprehensively. Capital projects were described as only one aspect of place, to expand public policy discussions.

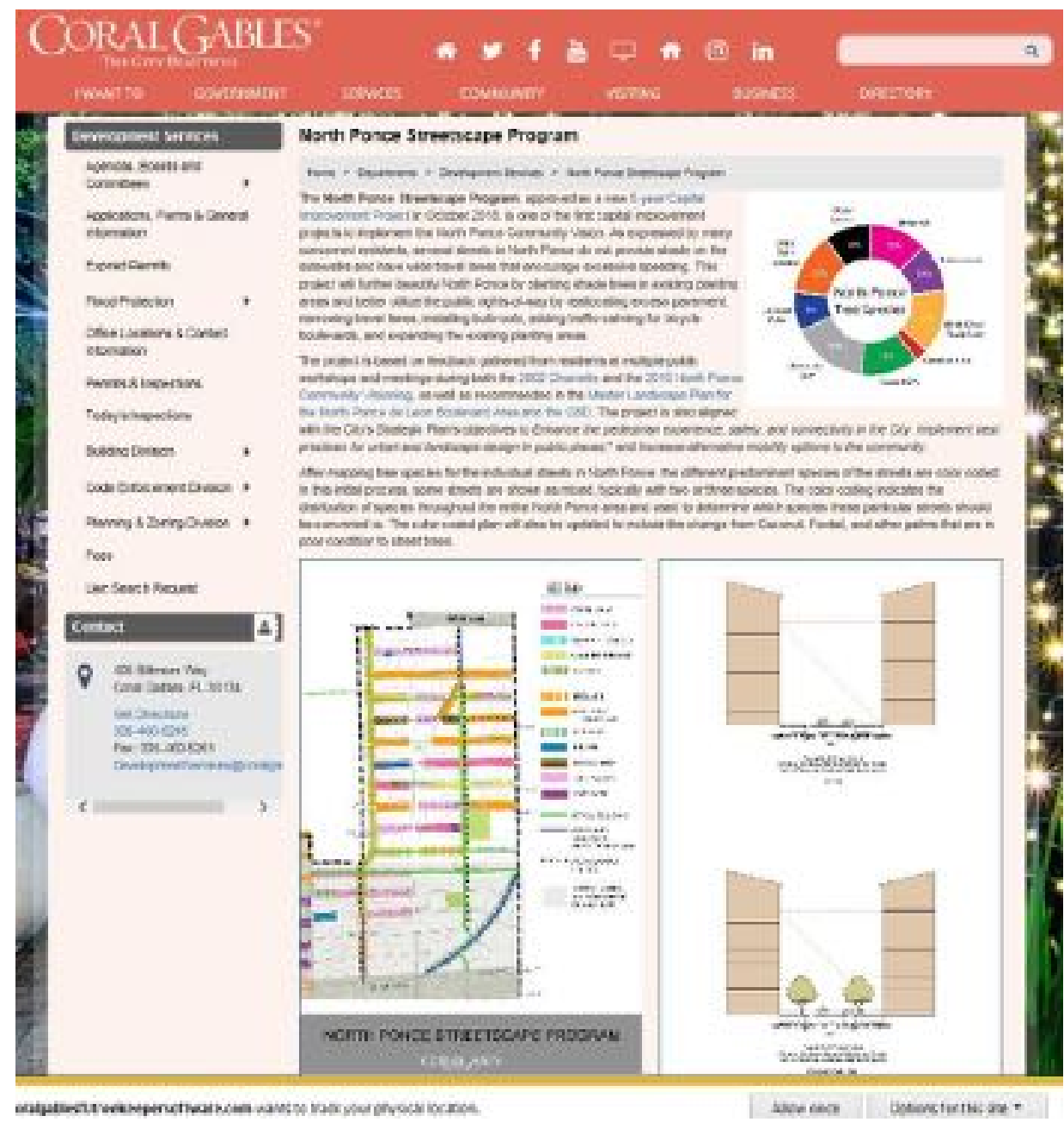

Plate 61. North Ponce capital projects page.

Source: Coral Gables website. 


\section{Civic space}

Plazas and squares should be beautiful and functional. Design manuals would provide aesthetic standards for bureaucracy. Smart tools allow administrators to measure function. Smart place allows an understanding of design and function based on objective data.

Plate 62 recorded pedestrian counts on a public space in Coral Gables, two years after completion. Detailed analysis could be performed on use, time of day and location. The success of implementation strategies could be measured. For example, data on the number of users and the times of highest use would verify the successful aspects of the project, and guide future enhancements.

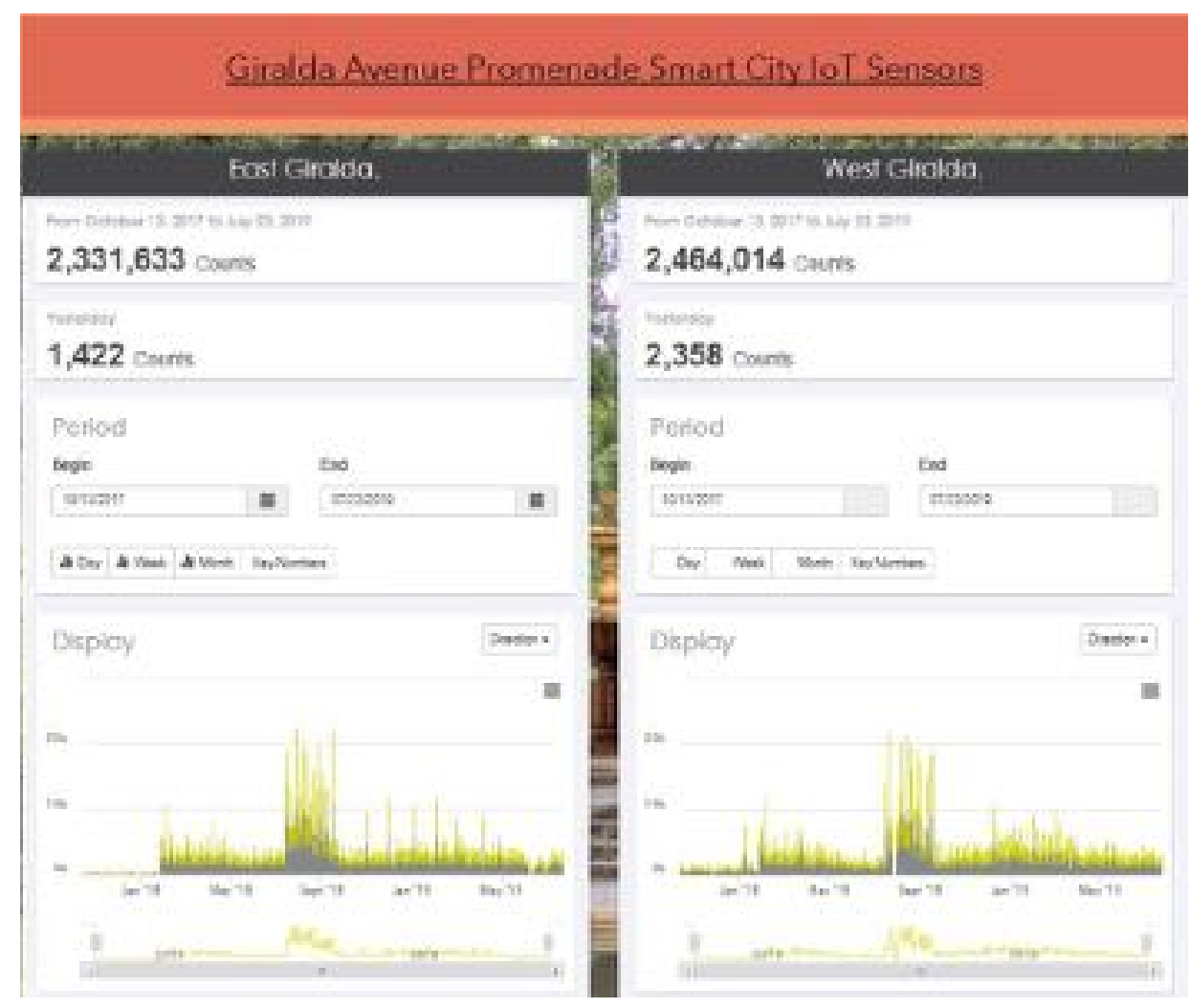

Plate 62. Giralda Plaza pedestrian counts. Source: Coral Gables website. 


\section{Procedures}

Design shapes quality of life, and zoning is the administrative tool that regulates design. Conventional zoning codes limit regulation to rudimentary issues, such as setbacks, height and lot coverage. Limited attention to design has been criticized in recent years by New Urbanism theory and by proponents of form-based codes. Data from Coral Gables demonstrated that a deliberate discussion of design, in terms of aesthetics at all scales of development, would lead to effective regulation, even within the restricted framework of conventional zoning codes and conventional zoning language.

The following best practices are recommended:

1. Zoning must regulate design directly.

Aspirational content should be translated into regulation and distributed for general use. Plate 63 is an image from the Coral Gables website, which highlights aspirational language and eliminates chronology bias through the routine use of images produced at different times, calibrated for the implementation of place.

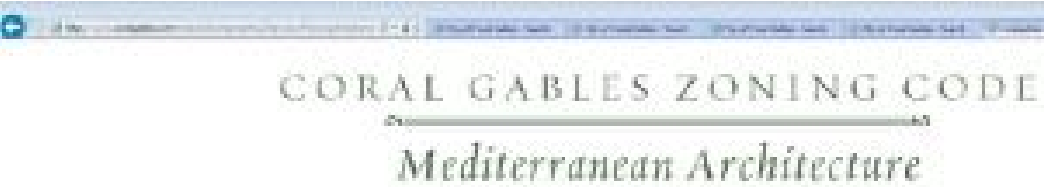

The buldings identified in Scetoon 3-60s of the Zorirg Code represent a rang of urtan comexts, building sales and beiding functiuns that can seve a inspiration for a varicty of Mediterne mean anchitectural poiccs in motern rimes. The

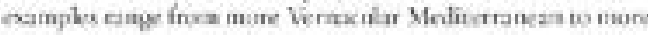
Bewa Aris Mediterracean

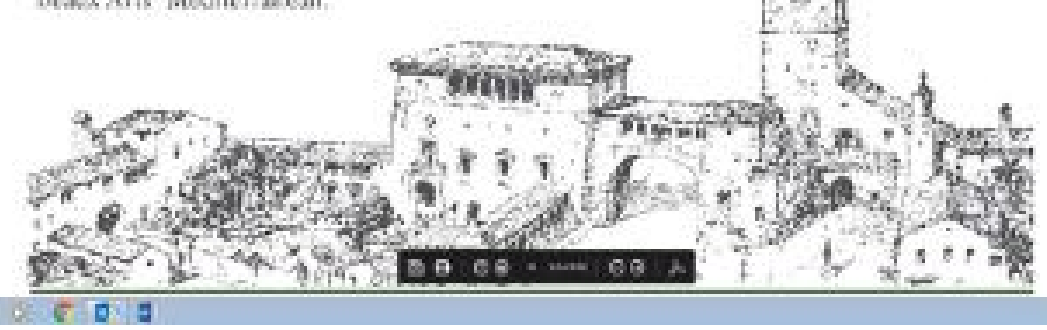


Plate 63. Coral Gables zoning code, Mediterranean architecture. Source: Coral Gables website.

2. Design review must be robust, professional and consistent.

Data and experience from Coral Gables demonstrated the commitment of resources and policy required for an effective design review process. Design review predates incorporation in 1925 and has continued to the present. Although the format has changed through the years, the professional qualifications of the board members and staff have always been high. Design review must be properly funded and supported by policy and regulations. In addition to a robust process, effective design review requires effective content. Findings from Coral Gables suggested that design guidelines may not provide best guidance for content. A lively discussion among professional peers, with direct reference to exemplary precedents, is a superior method of design review.

Moreover, customer satisfaction with a strict process was supported by survey data. In addition, survey findings revealed appreciation and awareness for quality content calibrated to local needs.

The photograph of plate 64 captured the intensity of a typical meeting at the Commission Chambers, with the oil portrait of funder George Merrick on the left. The Board of Architects meeting blends bureaucracy and democracy, as staff review has taken place prior to the meeting, and public discussion supports or expands it. 
Plate 64 recorded one of many meetings on the "Plaza" project, which was discussed in some detail in the Results Chapter's section on the Board of Architects. The project architects had revised the exterior design of one building, to address suggestions from the Board. The members were verifying the aesthetic quality of multiple revisions. Once the Board approved a project, it could be submitted for permits. Then, all the technical trades would review the construction documents for compliance with applicable codes. Once the permit was issued, construction would start.

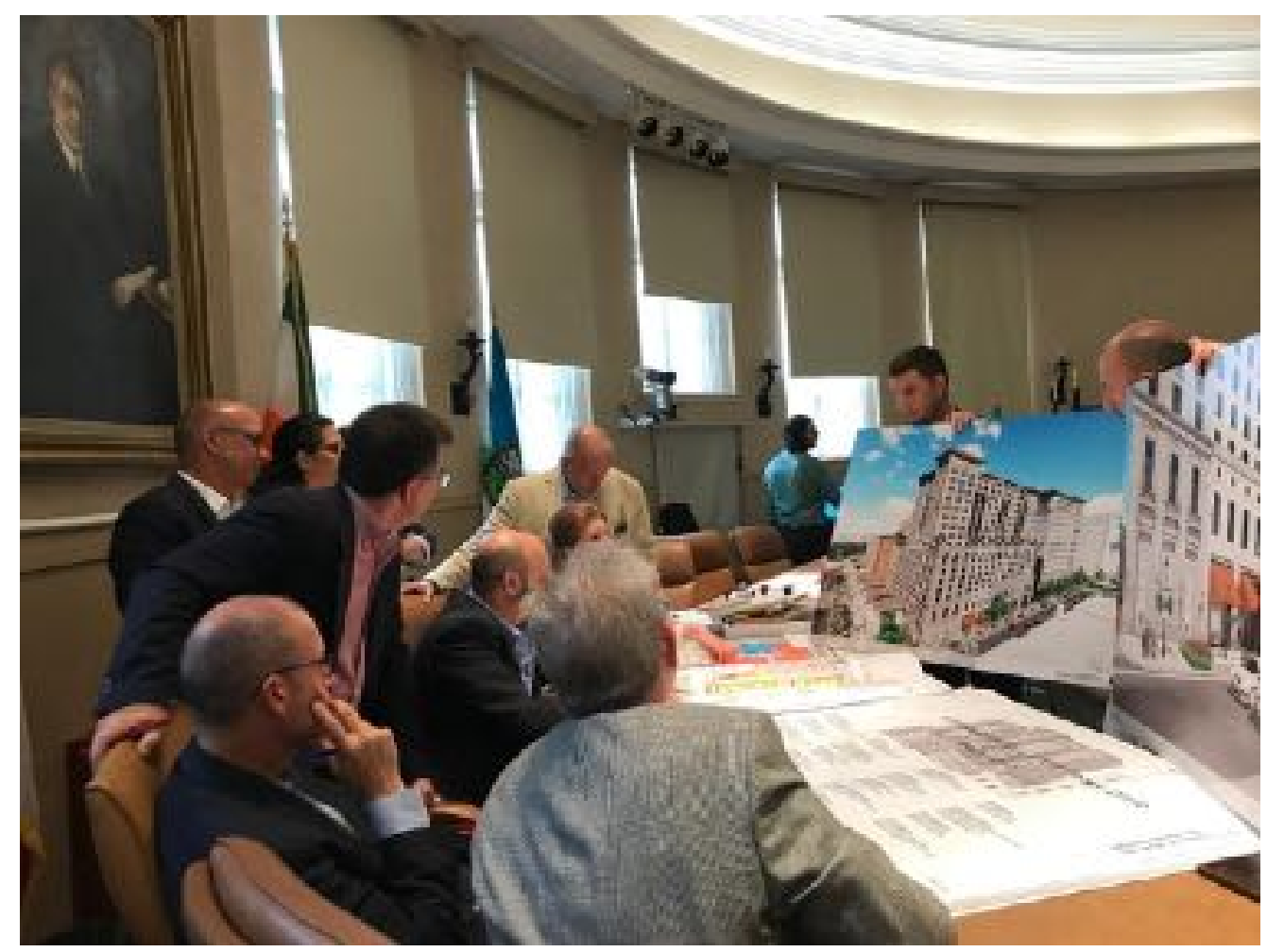

Plate 64. Board of Architects meeting. Photograph: Ramon Trias.

3. Adopt a public platform for electronic plans review.

Bureaucratic comments should be available in real time, with a platform that promoted transparency and cooperation. Conventional plans review caused 
delays and frustration. Although the regulator should remain vigilant, processes could encourage faster and more accurate revisions with enhanced accessibility to comments and submittals. Moreover, smart tools may promote a dynamic design critique during Board of Architects meetings. Technology should increase speed and accuracy for the implementation of content.

Plate 65 was the online portal for the Coral Gables building permit process, which provides a preliminary platform for dynamic design critique. Electronic plan review represents a significant enhancement of bureaucratic procedures, and best practices would be expected in the near future.

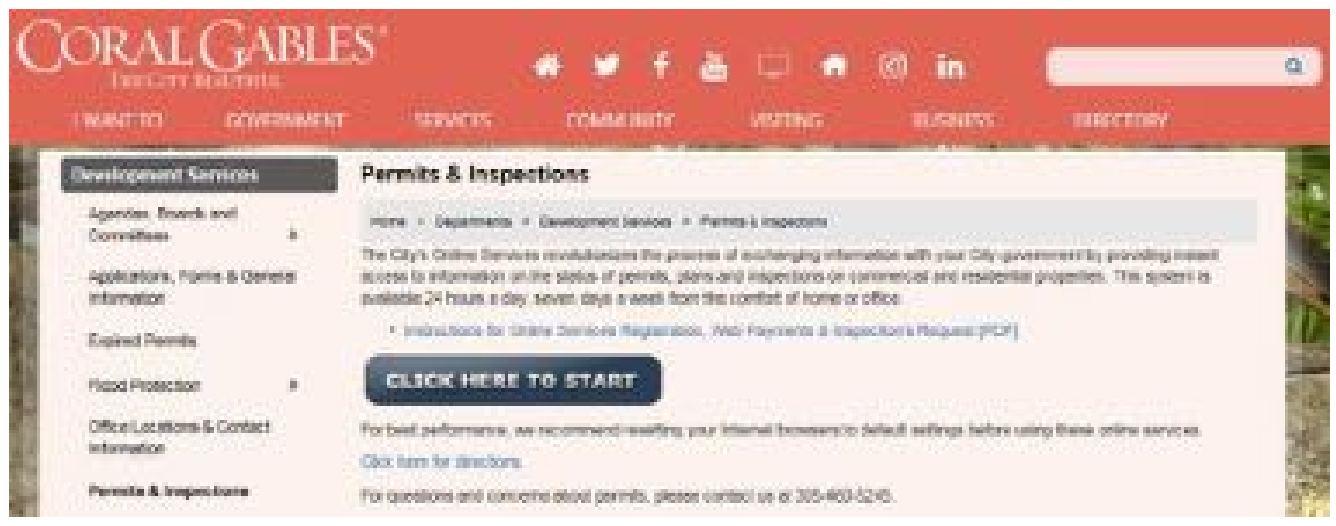

Plate 65. Permit page. Source: Coral Gables website. 


\section{Epilogue}

\section{Coral Gables, 2019}

The brochure was placed in a table, in the second-floor vaulted gallery of City Hall, across from the Commission Chambers. I picked up a copy and recognized every picture and every word, as content of place was common and routine in Coral Gables.

The text mentioned George Merrick, unique architecture, lush landscape and smart city, all important topics of this study. The content of smart place promoted the city as "central and connected" and "resilient and revered." Moreover, the community was "rooted in history and focused on the future."

The text followed conventional branding trends, often repeated by optimistic economic development officials throughout the United States. In the case of Coral Gables, the ideas were true, as they were executed effectively with best practices for almost a century and could be expected to define another hundred years. Plates 66 and 67 reflected aspirational content, as conveyed in 2019.

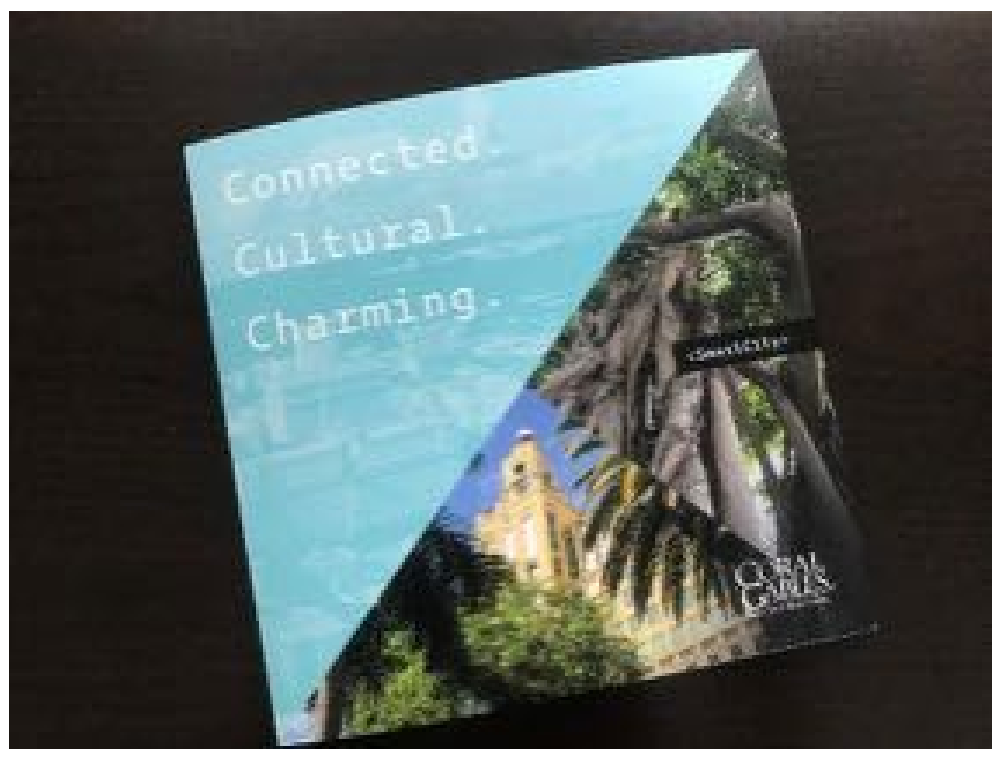

Plate 66. Brochure cover. Source: City of Coral Gables. 


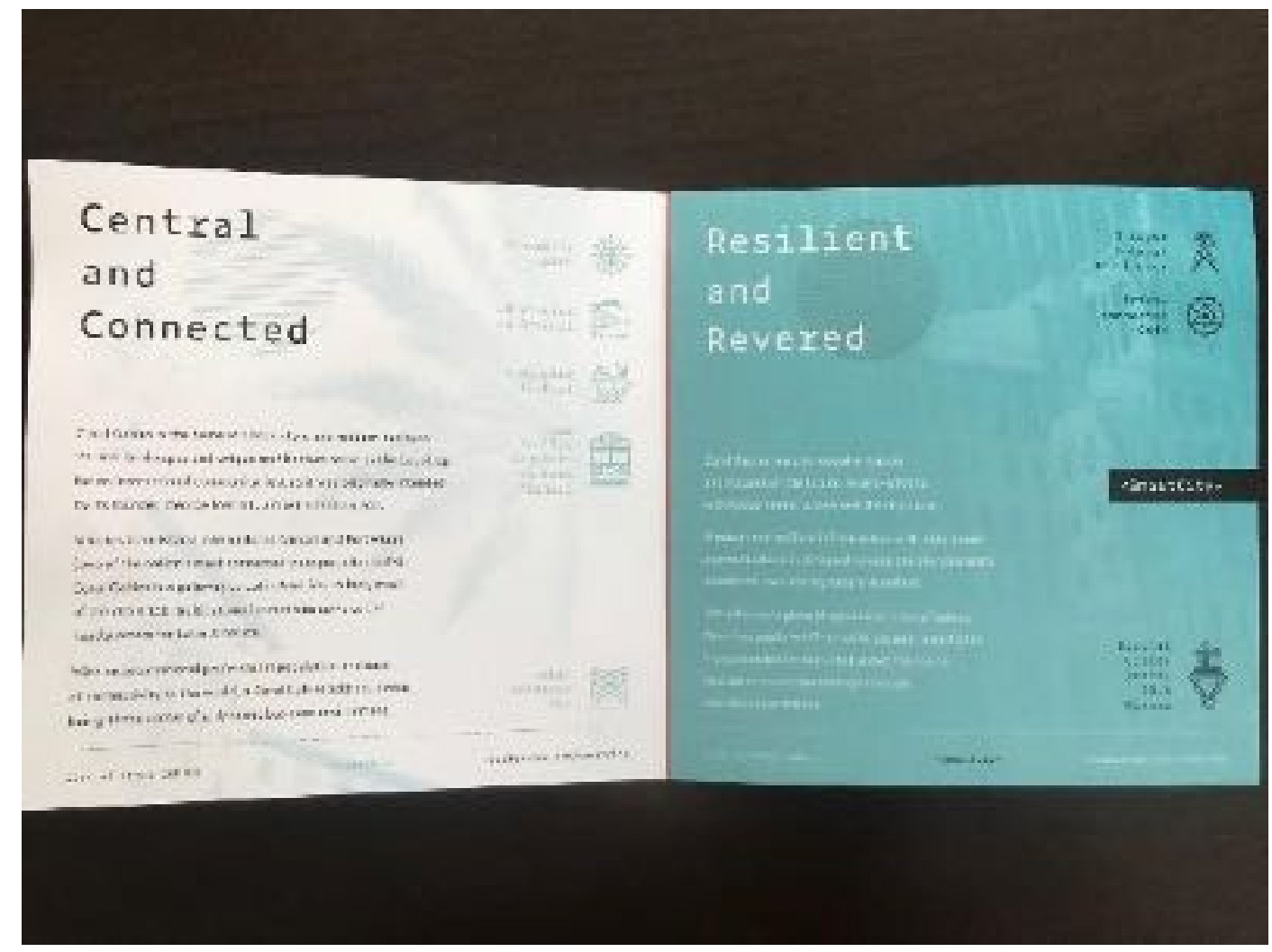

Plate 67. Brochure text. Source: City of Coral Gables.

Branding of aspirational content would facilitate governance and promote business. Ideas about place created value, but not all ideas were equal, nor every branding program would succeed. Branding ideas must emerge from democracy and reflect community vision. Bureaucracy should calibrate the general vision to local needs with actionable tools.

Coral Gables provided data for theory development in this study. As a particular example in a generalized discussion, Coral Gables was at the core of the strengths of the study, but also reflected its limitations. Research on Coral Gables catalogued steps and methods, and also measured the ambitious scope of the task of implementing aspirational content. Prior literature shaped a narrative of place and future research would investigate ways to apply it. Fortunately, the task had become simpler with smart strategies, as all 
information was available. Place as data, without chronology bias, would become the norm of future implementation. But a sense of inevitability was not supported by qualitative or quantitative data. Findings sketched democracy and bureaucracy of place as complex processes in search of actionable content. Furthermore, the study was relatively narrow in scope, and other topics relevant to public administration, such as social or economic issues, were not reviewed. Moreover, public administration invaluable role could be optimized as smart strategies develop, and promote quality place, everywhere. However, early critiques of the manuscript confirmed the initial assumption. Discussion on place was major a gap in the literature. Conventional planning and zoning would be enriched with the perspective of smart place.

\section{Fort Pierce, 2019}

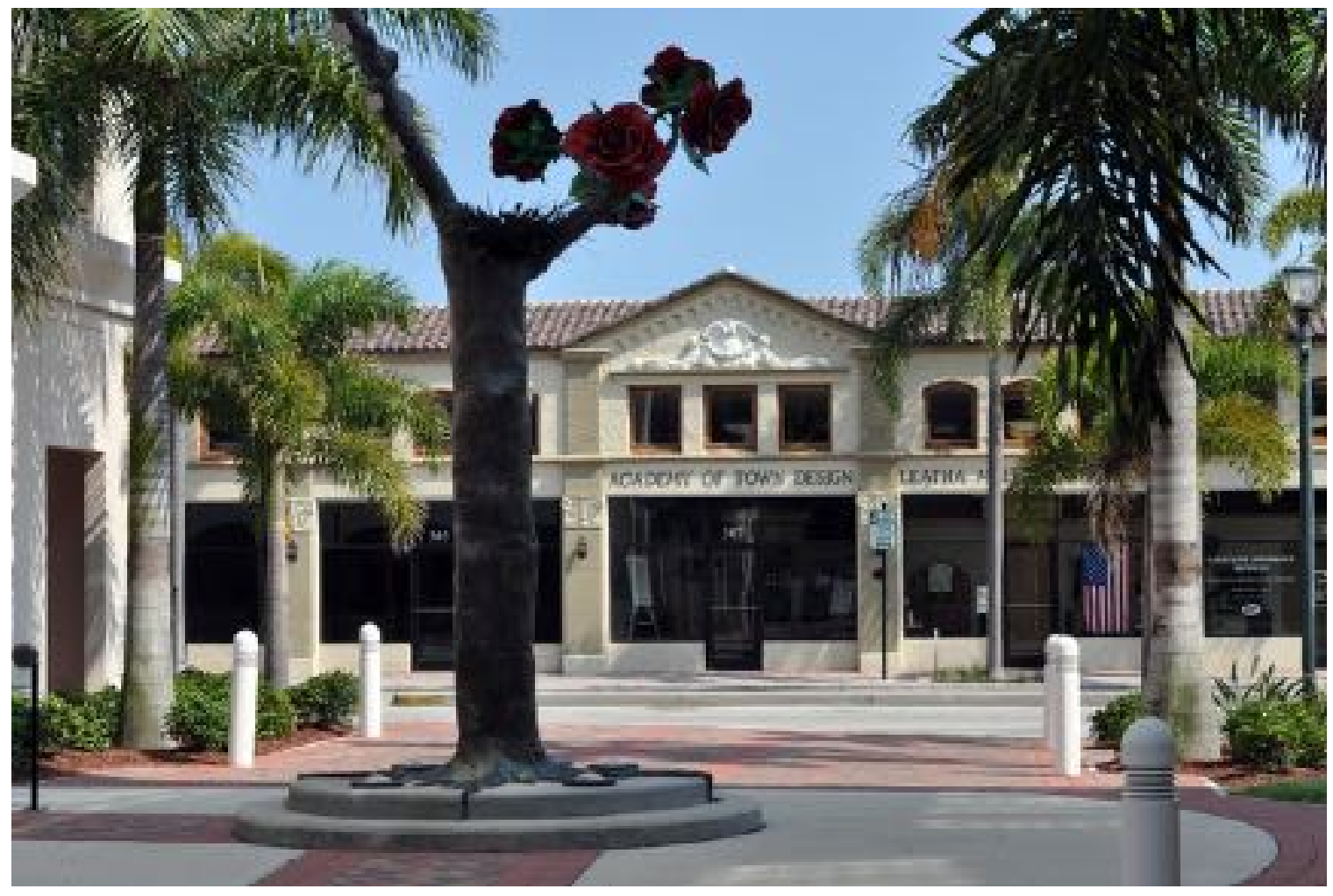

Plate 68. 307 Orange Avenue, Fort Pierce, FL. Photograph: Ramon Trias. 
Flip Gates owned 307 Orange Avenue depicted in plate 68, a building designed by William Hatcher in 1925, where I had my professional office from 2005 to 2012 . The building was designed in the Mediterranean style, as illustrated in folio books from the time. For many years it had been neglected. As I finished this study, I decided to do one final qualitative interview.

"My family constructed this building in 1925, a few years after they moved from West Virginia" Gates explained. 307 Orange Avenue had been owned by the family since construction. Hatcher's original color pencil rendering of the front elevation was hung prominently on a wall. The Mediterranean design was inspired by the folio books he owned in the 1920's. "Restoration in 2005 transformed this side of downtown." Gates followed the same content used by Hatcher, because skillful content is timeless. He recalled with satisfaction the award received at the time from the Florida Trust of Historic Preservation.

The building could have been built in Coral Gables at the same time. The design was also very competent as a commercial building, consistent with New Urbanism theory of the late $20^{\text {th }}$ century. It could be built in a typical town center of the turn of the $21^{\text {st }}$ century. Moreover, the Corinthian capitals were restored in the $21^{\text {st }}$ century by local masons, with acanthus leaf details reproduced in cast concrete.

\section{The Role of Best Practices}

Nothing about 307 Orange Avenue was exceptional. Nothing about Coral Gables was exceptional either, when compared to neighboring local governments in terms of geography or opportunity. Best practices created place and could lead to smart place. 
Quality had been a choice, and the tools for success were known, perhaps forgotten and rediscovered.

Best practices for content determined quality of place. The impact of Hatcher's professional library could be recognized in several buildings: historic city hall, the Raulerson building, my former office. Buildings by other architects, such as the Sunrise Theater and Arcade, faithfully restored in the early 2000's followed comparable aesthetic choices and standards. Downtown Fort Pierce was a well-defined place, known throughout the Treasure Coast of Florida. Coral Gables would be better known and its location in South Florida contributed to its economic growth, but the same content was applied at first, and was supported by consistent practices through the decades. Coral Gables also transformed ideas about place into administrative tools, the main topic of research of this study.

Place had a long history of debate, outside of conventional academic literature. The bureaucratic implementation of place of the Law of the Indies, Ildefos Cerda's research on data and content, Euclid's abstraction of place and late $20^{\text {th }}$ century zoning reform, all identified the role of content for place.

Review of Coral Gables revealed the role of content for governance of smart place. Fort Pierce demonstrated quality place could be a goal everywhere, and suggested strands for future research. Most of these subjects played some role in zoning reform in the late $20^{\text {th }}$ century, but in the $21^{\text {st }}$ century, as smart strategies refocused discussion, a methodical review of content of place would lead tools for enhanced governance. Place and aspirational content may have been overlooked by prior public administration theory, but they had been very relevant to local practice. 


\section{Future Research on Smart Place}

Research proved Smart Place was not in contradiction with historic place. In fact, smart place reaffirmed timeless place, where multiple sequential layers would add value to any future condition.

The true innovation of smart technology was the elimination of chronology bias from data. Moreover, Smart Place promised to replace politics with democracy and promote creativity for bureaucracy. These ideas would transform governance, as best practices from folio books had transformed implementation of place in terms of quality and effectiveness.

Nevertheless, the current study relied on one example, which may provide direction for theory and best practices but cannot answer every relevant research question. The choice of Coral Gables, FL provided valuable information about the history of zoning since the early 1920's and survey data about community engagement from 2018, but it also generated unexpected controversy during the dissertation defense. Prior perceptions about Coral Gables social and economic characteristics interfered with an objective evaluation of some theory ideas. The remedy would be more extensive research along a cross section of diverse communities. However, this approach exceeded the study's research design.

An evident path for future research would be study of other local governments. Moreover, the topic of place could be expanded with commentary on related subjects. Although this study may be interpreted as a critique of some conventions and common topics of public administration literature, it supports the validity of other points of view. The impacts of decision about place can affect social conditions, as some people may be 
included, and other people may be excluded. This is a fundamental question for democracy of place. It also effects quality of life.

The current study emphasized aspirational content, a topic that some scholars may have overlooked in the past, but which may enrich discourse on urban studies, history of cities and local governance. Content may have been dismissed because it is difficult to identify, define and preserve. Even in Coral Gables, where very particular content has often influenced development, research revealed significant debates and disagreements, Content was always fragile. In fact, as experienced staff retired, knowledge of what made place unique was often lost. Best practices cannot depend on people or their recollections and must be made part of bureaucracy.

Additional research on the relationship of policy about town planning and design and equity and justice would advance theory. Public administration has a significant role to play in defining the language of place and implementing well-grounded theory with professional practices. When aspirational content plays a robust role in governance, quality of life prevails.

Future research would explore democracy and bureaucracy of place directly. This study introduced ideas such as aspirational content and Smart Place in a modest and incomplete effort to advance theory within limited research design. The text should be read as initial commentary on elementary concepts that should be expanded beyond the specifics of current data and the bounds of the example of Coral Gables. The conclusion, to be tested by future research, is that content should be neutral, smart strategies should be calibrated to local needs and bureaucracy should implement a spectrum of democratic activities for the enhancement of quality of life for all. 


\section{REFERENCES}

Ackermann, F., Eden, C. (2011). Making strategy: mapping out strategic success, London: Sage.

Ackermann, F., Eden, C., with Brown, I. (2005). The practice of making strategy, London: Sage.

Adams, R. (1929). Thoughts on modern, and other, ornament, Pencil Points, 10-1, 3-16.

Aibar, E., Bijker, W. (1997). Constructing a city: The Cerda plan for the extension of Barcelona, Science, Technology and Human Values, Winter, 1997, 3-30.

Alexander, C. Neis, H., Anninou, A., King, I. (1987). A new theory of urban design, New York, NY: Oxford University Press.

Alexander, C. Ishikawa, S., Silverstein, M., Jacobson, M., Fiksdahl-King, I., Angel, S. (1977). A pattern language, New York, NY: Oxford University Press.

Alexander, C. Neos, H., Anninou, A., King, I. (2004). The nature of order, New York, NY: Oxford University Press.

Alper, C. (1981). Coral Gables City Hall, Historic American Building Survey, FL-363.

Alkadry, M., Blessett, B. (2010). Aloofness or dirty hands? Administrative culpability in the making of the second ghetto, Administrative theory and praxis, 32(4), 532556.

Andrews, R., Boyne, G. A., Law, J., Walker, R. M. (2009). Strategy formulation, strategy content, and performance: an empirical analysis. Public Management Review. 11(1), 1-22.

Anonymous (1923). The domestic architecture of England during the Tudor Period, Boston, MA: The Boston Architectural Club.

Barth, B. (2019). Smart cities or surveillance cities? Planning. March 2019, 16-23.

Barry, B. W. (1986). Strategic planning workbook for nonprofit organizations, St. Paul, MN: Amherst H. Wilder Foundation.

Barzelay, M. (1992). Breaking though the bureaucracy: a new vision of management in government, Berkeley: University of California Press. 
Beauregard, R. (2012). Planning with things, Journal of Planning Education and Research, 32 (2), 182-190.

Benevolo, L. (1971). The origins of modern town planning, Cambridge, MA: MIT Press.

Birch, E. (2001). Practitioners and the art of planning, Journal of Planning Education and Research, 20, 407-422.

Behar, R, Culot, M. (1997). Coral Gables: an American garden city, Paris, Fr: Editions Norma.

Blakeslee, A. (1920). Ornamental details of the Italian renaissance, New York, NY: Architectural Book Publishing Co.

Block, P. (2009). Community: the structure of belonging, San Francisco: Jossey-Bass.

Boviart, T. (2008). Emergent strategic management and planning mechanisms in complex adaptive systems, Public Management Review, 10(3), 319-340.

Bryson, J. M. (2011). Strategic planning for public and nonprofit organizations, San Francisco: Jossey-Bass.

Bryson, J. M., Alston, F. K. (2011). Creating your strategic plan, San Francisco: JosseyBass.

Bryson, J. M., Anderson, S. R., Alton, F. K. (2011). Implementing and sustaining your strategic plan, San Francisco: Jossey-Bass.

Bryson, J. M., Berry, F. S, Yang, K. (2010). The state of public strategic management research: a selective literature review and set of future directions. American Review of Public Administration, 40(5), 495-521.

Bryson, J. M., Crosby, B. C., Bryson, J. K. (2009). Understanding strategic planning and the formulation and implementation of strategic plans as a way of knowing: the contributions of actor-network theory. International Public Management Journal, 172-207.

Burke, B. (2002). Understanding the law of zoning and land use controls. Newark, NJ: Mathew Bender and Company, Inc. (Lexis).

Button, F. (1921). Contract with George Merrick dated April 18, 1921, Coral Gables, FL: Coral Gables Museum.

Cerda, I. (1867). Teoría general de la urbanización: Reforma y ensanche de Barcelona. Madrid: Imprenta Espanola. 
City of Coral Gables. (1925). Building code. Coral Gables, FL: Municipal publication.

City of Coral Gables. (1930). Zoning ordinance. Coral Gables, FL: Municipal publication.

City of Coral Gables. (1937). Zoning ordinance. Coral Gables, FL: Municipal publication.

City of Coral Gables. (1956). Zoning code. Coral Gables, FL: Municipal publication.

City of Coral Gables. (1956). Zoning ordinance. Coral Gables, FL: Municipal publication

City of Coral Gables. (1966). Zoning Code. Coral Gables, FL: Municipal publication.

City of Coral Gables. (2007). Zoning Code. Coral Gables, FL: Municipal publication.

City of Coral Gables. (2002). Coral Gables charrette report. Coral Gables, FL: Municipal publication.

Caro, R. (1974). The power broker: Robert Moses and the fall of New York. New York, NY: Vintage.

Carson, R. (1966). Miami: 1896-1900. Miami. FL: Tequesta.

Connolly, N. (2004). A world more concrete: real estate and the remaking of Jim Crow South Florida. Chicago, IL: University of Chicago Press.

Coral Gables Museum. (2014). Web site. Coral Gables, FL: Municipal publication.

Davis, G. Parker, C., Straub, D. (2012). Writing the doctoral dissertation: a systematic Approach. Hauppauge, NY: Barron's Educational Series.

Department of Commerce. (1926). A standard state zoning enabling act. Washington, DC: Government printing office.

Doheny, D. (2017). Saving the Biltmore, Tequesta, the journal of HistoryMiami museum, 78, 11-51.

Dover, V., Massengale, J. (2014). Street design: the secret to great cities and towns. Hoboken, NJ: John Wiley and Sons, Inc.

Duany, A., Plater-Zyberk, E., A., Speck, J. (2000). Suburban nation: The rise of sprawl and the decline of the American dream. New York, NY: North Point Press. 
Duany, A., Tallen, E. (2013). Landscape urbanism and its discontents. Gebriola Island, BC, Canada: New Society Publishers.

Duany, A., Speck, J., Lydon, M. (2010). The smart growth manual. New York, NY: McGraw Hill.

Duany, Plater-Zyberk and Co. (1999). The lexicon of the New Urbanism. Miami, FL: Duany, Plater-Zyberk and Co.

Durand, J. N. (1809). Precis de lecons d'architecture donees a l'Ecole royale polytechnique. Paris, France: McGraw Hill.

Ewing, E., Clemente, O. (2013). Measuring urban design: Metrics for livable places, Washington, DC: Island Press.

Estape, F. (2001). Vida y obra de Ildefonso Cerda, Barcelona, Spain: Ediciones Península.

Faber, T. (2019). Coral Gables ... city of the future, Coral Gables Magazine, 6(19), 5698.

Faga, B. (2006). Designing public consensus. Hoboken, NJ: John Wiley and Sons, Inc.

Faga, B. (2014). Formers versus zoners: how and why communities shift to form-based codes (Doctoral Dissertation). Available from Georgia Institute of Technology.

Felton, C. (2016, June 10). Euclid commemorates anniversary of historic zoning case with historic marker dedication. The News-Herald, p. News.

Fletcher, D. (1911). Everglades of Florida: acts, reports, and other papers, state and national, relating to the Everglades of their state of Florida and their reclamation. Washington, DC: Government Printing Office.

Fletcher, B. (1901). A history of architecture on the comparative method, for the student, craftsman and amateur. New York, NY: Charles Scribner's Sons.

Florida, R. (2012). The rise of the creative class (Revised). New York, NY: Basic Books.

Florida, R. (2017). The new urban crisis. New York, NY: Basic Books.

Follet, M. (1923, 2016). The new state. Mansfield Centre, CT: Martino Publishing.

Francis, L. (1925). Comprehensive Dade Co. map featuring the location of beautiful Miami. Miami, FL: City of Miami. 
Gasparini, G. (1991). The law of the Indies, the Spanish-American grid plan: The urban bureaucratic form. The New City, 1 (1) 6-17.

Garde, A., Kim, C., Tsai, O. (2015). Differences Between Miami’s Form-Based Code and Traditional Zoning Code in Integrating Planning Principles. Journal of the American Planning Association, 81(1), 46-66.

Garnett, N. (2013). Redeeming transect zoning. Brooklyn Law Review, 78 (2).

Gee, P. (2014). An introduction to discourse analysis: theory and method. New York, NY: Routledge.

Geddes, N. (1940). Magic motorways. New York, NY: Random House.

Geller, R. (2010). The legality of form-based zoning codes. Journal of Land Use, 26 (1), $35-91$.

George, P., Peterson, T. (1988). Liberty Square: 1933-1987, the origins and evolution of a public housing project. Miami. FL: Tequesta.

Goodsell, C. (2015). The New Case for Bureaucracy. Thousand Oaks, CA: CQ Press.

Hendrick, R. (2003). Strategic planning environment, process, and performance in public agencies: a comparative study of departments in Milwaukee. Journal of Public Administration Research and Theory, 13, 491-519.

Howard, E. (1902, 1946). Garden cities of to-morrow. London, GB: Faber and Faber.

Innes, J. E. (1992). Planning through consensus building: a new view of the comprehensive planning ideal. Journal of the American Planning Association, 62, 460-472.

Jacobs, J. (1961). The death and life of great American cities. New York, NY: Random House.

Jacobs, T. (2019). What is a smart city? Architect. January 2019, 66-91.

Kostof, S. (1999). The city shaped: urban patterns and meaning though history. New York, NY: Thames and Hudson.

Kunstler, J. (1993). The geography of nowhere, New York, NY: Touchstone.

Langendorff, R. (1976). Metropolitan federalism: an evaluation of the Dade experiment in governmental reform. Miami, FL: University of Miami. 
Lennertz, B., Lutzenhiser, A. (2018). The charrette handbook, New York, NY: Taylor and Francis Group.

Le Corbusier. (2007). Towards a new architecture. Los Angeles, CA: Getty Publications.

Lefebvre, H. (1991). The production of space. Malden, MA: Blackwell Publishing.

Leigh, N., Blakely, E. (2013). Planning local economic development. Thousand Oaks, NY: Sage Publications.

Lotz, A. (1991). Metropolitan Dade County: two tier government in action. Boston, MA: Allyn and Bacon.

Lynch, K. (1960). The image of the city. Boston, MA: The MIT press.

Lindblom, C. (1959). The science of muddling through. Public Administration Review, $19,78-88$.

Lyotard, J-F. (1983). The postmodern condition: a report on knowledge. Minneapolis, MN: University of Minnesota Press.

Magonigle, H. (1929). The value of tradition: an address before the architectural league of New York. Pencil Points, 10-1, 17-24.

Meijer, A., Rodriguez, M. (2016). Governing the smart city: a review of the literature on smart urban governance, International Review of Administrative Sciences , 82-2, 392-408.

Meixler, E. (2018). Barcelona's Sagrada Familia church has been under construction for 136 years. That's a lot of unpaid permit fees. Time, October 19, 2018, Time.com.

Millas, A., Uguccioni, E. (2003). Coral Gables, Miami Riviera: an architectural guide. Miami: FL: Dade Heritage Trust.

Miller, H. A. (2012). Governing narratives. Tuscaloosa, AL: The University of Alabama Press.

Mohl, R. (1995). Making the second ghetto in metropolitan Miami 1940-1960. Journal of Urban History, 21(3), 395-427.

Mohl, R. (2001). Urban expressways and the racial restructuring of postwar American cities. Economic History Yearbook, vol.42, 89-104. 
Mumford, L. (1970). The culture of cities: its origins, its transformations and its prospects. New York, NY: Harcourt, Brace, Jovanovich.

Nelessen, A. (1993). Visions for a new American dream. Chicago, IL: American Planning Association.

Neuman, M. (2011). Ildefons Cerda and the future of spatial planning: The network urbanism of a city planning pioneer, Town Planning Review, 82 (2), 117-143.

Office of the City Engineer. (1918). Official plat map. Miami, FL: City of Miami.

Paist, P. (1924). Stucco - Color. National Builder, October 1924, 46-47.

Parks, A. (1987). Miami memoirs: John Sewell. Tulsa, OK: Lion and Thorne, Ltd.

Parks, A. (2006). George Merrick's Coral Gables: where your castles in Spain are made real. Milwaukee, WI: Centennial Press.

Parks, A. (2015). George Merrick: son of the southern wind. Gainesville, FL: University Press of Florida.

Patricios, N. (1994). Building marvelous Miami. Gainesville, FL: University Press of Florida.

Poole, S. (1987). Architectural appearance review regulations and the first amendment: the good, the bad, and the consensus ugly. The Urban Lawyer, 19-2, 287-344.

Roy, J. (1989). The streets of Coral Gables: their names and their meanings. Coral Gables, FL: The University of Miami.

Reporter. (1926, November 12). Phineas Paist, National Figure, Miami Herald.

Reps, J. (1965) The making of urban America, Princeton, NJ: Princeton University Press.

Rodriguez, I., Ammidown, M., Dieterich, E., Wallin, B. (1992). From wilderness to metropolis, Miami, FL: Bayshore Graphics, Inc.

Rojas, J., Rexach, L. (1973). Urbanismo español en América. Madrid, Spain: Editora Nacional.

Rowe, P. (2013). Design thinking, Cambridge, MA: The MIT Press.

Sofen, E. (1963). The Miami metropolitan experiment. Bloomington, IN: Indiana University Press. 
Sovle, W. (1924). Spanish farm houses and minor public buildings. New York, NY: Architectural Book Publishing Co.

Speck, J., (2012). Walkable city: how downtown can save America, one step at a time, New York, NY: Farrar, Strauss, Giroux.

Stern R., Fishman, D., Tilove, J. (2013). Paradise planned: the garden suburb and the Modern City. New York, NY: The Monacelli Press.

Suisman, D. (1993). Plaza Mexicana. Places, 8(3), 4-19.

Tachieva, G. (2010). Sprawl repair manual. Washington, DC: Island Press.

Talen, E. (2009). Designing by the rules: the historical underpinnings of form-based codes. Journal of the American Planning Association, 75(2), 144-160.

Talen, E. (2012). City rules: how regulations affect urban form. Washington, DC: Island Press.

Talen, E. (2013). Zoning against sprawl: the case of form-based codes, Journal of the Urban Design, 18(2), 175-200.

Tocqueville, A. (2003). Democracy in America. London, UK: Penguin Classics.

Treasure Coast Regional Planning Council. (1995). Strategic Regional Policy Plan. Stuart, FL: Treasure Coast Regional Planning Council.

Trias, R., Garcia-Zamor, J. C. (2015). The Seven50 plan and regional governance in southeast Florida. Current Urban Studies, 3(4), 300-312.

Unwin, R. (1994). Town planning in practice. New York, NY: Princeton Architectural Press, Inc.

Van Pelt, J. (1923). Masterpieces of Spanish architecture, Romanesque and allied styles. New York, NY: The Pencil Points Press, Inc.

Volsky, G. (1994). Leading French architect admires Coral Gables'spirit. Coral Gables Gazette, October 10-6, 1997.

Weber, M. (1922, 2011). Bureaucracy. In Shafritz, J. M., Ott, J. S. and Jang, Y. S. (2011) (Ed.), Classics of organization theory. Boston, MA: Wadsworth.

Wilson, W. (1887, 2011). The study of administration. In Shafritz, J. M., Ott, J. S. and Jang, Y. S. (2011) (Ed.), Classics of organization theory. Boston, MA: Wadsworth. 
Wheeland, C. (2004). Empowering the vision: Community-wide strategic planning in Rock Hill. S.C., Lanham, MD: University Press of America.

Whittlesey, A. (1920). The renaissance architecture of central and northern Spain, New York. NY: Architectural Book Publishing Co.

Yerbury, F. R. (1925). Lesser known architecture of Spain. London: Ernest Benn LTD. 


\section{APPENDICES}

$\begin{array}{ll}\text { DOCUMENT } & \text { PAGE }\end{array}$

1. Community Engagement Survey Instrument..................................360

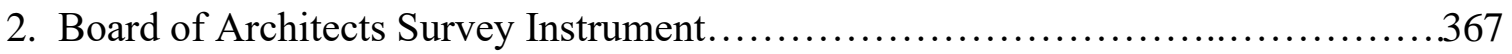




\section{Community ENGAgement SuRver 2018}

Dear Cly ad Corad Cables Anesitemt,

You have been selected to cemplete our 2013 commanty Encspement Survef.

5 prefiere ura enouesta en espho, camuniquese can nosatros al 305.4605202 y sclicte la encucstz comun tarla en espafal $y$ se le enviád per correa.

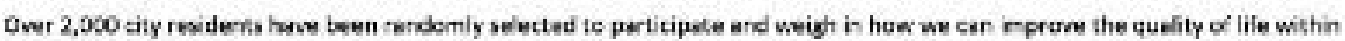
the cry Beateits.

The purpose of the surver is iv:

- Increzce reskant enaremert

- Isentify kef areas thet impset the oualty of lfe within the City of Coral Gabley and Miami-Dade Ceunty

- Colect input for fiszal planning and longterm capital improvemert projects

- Messure setbisctisen and impertanen of bey city servicas

Your responses are contidential. The survey is being consucted by a third-party organization and there are no tracsing codes on the survey or envelopes. If pou have sny questiors regardirg the survey peocess or the survey kself, piesesend sn email to surverposoralgabies.007

Fleuse select one adult within your household to complete the survey and mal t bock by September 12 , 2018 usine the postage Fold ervelcpe provided.

Thark you for toking the time to provide as your valua ble fsedbsdi!

Cathy Swanson-Rivenbark, City Marager

1. How long have wou tived in Corai Gables?

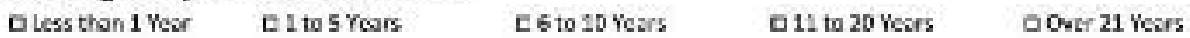

2. What is the aip code of your residence?

$\begin{array}{llll}\square .33133 & \text { 口 } 33134 & \text { 口 } 33135 & \text { 口 } 33146 \\ 033155 & \text { 0 } 33156 & \text { a } 33157 & \text { 口 }\end{array}$

3. Are you a full-time or seasonal residem of Coral Gables?

Crull-Tme Resicent CSessanal Resident

4. Do you awn of rent your residence?

वown a Rert

5. Do you have children under 18 living in your household?

ares $\quad \mathrm{Nn}$

6. What is your age range?

\begin{tabular}{|c|c|c|}
\hline & D 31 to 43 & \\
\hline
\end{tabular}

7. What is your employment status?

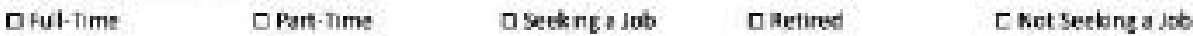

8. What is your total household income?

口icss that $\$$ sok o $\$ 50 k$ to $\$ 100 k$

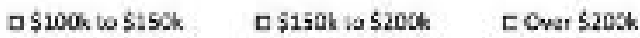

9. What is the hichest degree or level of school you have completed?

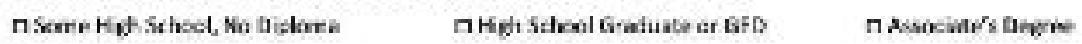

a Bacteler's Degree $\quad$ G Galuate Degre: 


\section{City of Corul Ganifs Community Engagement SUrver 2018}

10. How would you rate the overal quality of itte within the Cry of Coral Gables ONLY? You will be ssked about tounty snd school district services in question 11.

carelisn:

DGood

口Folr

口Poor

DI Don't Know

10a. Place a check next to the top 5 factors that contribute to your rating of the quality of life within the City of Corz: Gables ovir.

\begin{tabular}{|c|c|c|c|c|}
\hline D Seree of Kaizhtertood & E Parks \&. Opan Seases & D Bke Fothe & D Wrilkabilty & acut_ral Offerires \\
\hline O Becreatioral Antholes & r central I sestion & nWabermys & n ronnomy & O bhs \\
\hline a Vouth Servicas & C Senicer Servecse: & DAscess so Hesth Carm & D I res Canofy & a Histent Landmerka \\
\hline a Miss Tratsportitiont & C Qivarsity & DGty Services & - Mediteransin Afdhitecture & a Hamelasures \\
\hline D Pualk Sthools & c shopplng \& Dinring & DTrattic & D Pcpustisn Grewth & aclty Requiationa \\
\hline OPublx surety & CImergency Kesponse & DCost of unve & OProperty Vabie & I New Develogme-t \\
\hline
\end{tabular}

10b. What are the top 4 actions the city sheuld focus on to maintsin or improve the quality to life within the City af Coral Gables DNLY.

1.

2.

4.

\begin{tabular}{|c|c|c|c|c|}
\hline \multicolumn{5}{|c|}{ 11. How would you rate the overall guality of life within Miami-Dade County? } \\
\hline f Excallent & ก Gand & nFair npoar & \multicolumn{2}{|l|}{ n I Den't Knove } \\
\hline \multicolumn{5}{|c|}{$\begin{array}{l}\text { 11a. Place a check next to the top } 5 \text { factors that contribute to your rating of the quality of life within Miamb-Dade County } \\
\text { ONLY. }\end{array}$} \\
\hline a Library System & D Courty Sarrioss & Desocies & o Public Heshth Services & C Horreieseness \\
\hline OSenve of Neighbarthas & D Park 8 Dpen seoces & Dolke Paths & D Wakahitry & c Outurai Cffernes \\
\hline 口Ptereationa Artinitives & DCeniral tuation & D Wolirways & DEconaty & c Jubs \\
\hline a Youth Servioes & Dseniser Services & DAcress to Heslen Care & aTrec Caropr & C Hetoork Landmarke \\
\hline aMass Tranapotation & D Dreersty & D oty Services & D Arshitecture & c Courty Peguatiors \\
\hline aPutlesichseds & nshopping \& Cinrine & nTrafie & In Preulatiren Giremeth & r New Despicpertem \\
\hline aputelicsataty & D Emergerey Respoese & D Costof Laing & DProperty value & L Cther: \\
\hline
\end{tabular}

11b. What are the top 4 actions the city should focus on to maintain or improve the quality of Efe within Miemi-Dade County?

1

2

4.

Fax $x$ of 7 


\section{City of Coral Gables Community Engagement Surver 2018}

12. Place a chedk next to the top 5 community inuestments the City of Coral Gables should focus on over the next 3 to 5 vears to improve the overall cuality of Ife in the City.

arualic Ar.

aCul.ual Eversi \& Vesues

E Giy Ewnts

ㅁ Histeric Landrarks

o Bvergr Coneervotion

a Aecycine Programs

CSes-Level Rece Resilency

口 Ekctrk Wohities

o Puslic Parkne

asdewaks

L Mase Trangporation

口Trolley $\mathbf{5}$ Freebec

口 Parks $\mathbf{B}$ Cpen Spaces

a fecreations fadities

C incl.sion Prograns

Q Traffic Calmine

a Hediney Lordicions

a Bike Paths

c'Waturwas

口Streat Lotiry

nPaice Mrateticn

nfire freeteien

r Maremedic Saroibas

n Disater Proparedrabs

a Codu Enfortament

a Saribliun Servises

c Strest Lightirg

口Onimesusus da Cijy Servicas

Other:

\begin{tabular}{|c|c|c|c|c|c|c|c|c|}
\hline \multicolumn{9}{|c|}{ 13. Dervelepment Services - Rate your satisfactien end impartance for each of the follawing services. } \\
\hline & $\begin{array}{c}\text { Very } \\
\text { Satdeted }\end{array}$ & Settrined & Dimetififed & $\begin{array}{c}\text { Very } \\
\text { Dteastieted }\end{array}$ & $\begin{array}{l}\text { Vert } \\
\text { Impartant }\end{array}$ & Importam & $\begin{array}{l}\text { Somemat } \\
\text { mportamt }\end{array}$ & $\begin{array}{c}\text { Net } \\
\text { Impartant }\end{array}$ \\
\hline $\begin{array}{l}\text { Fublic ed.cution of permitehg } \\
\text { requirements \& processes }\end{array}$ & $\pi$ & $\pi$ & r & 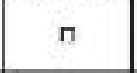 & $n$ & n & $n$ & $\pi$ \\
\hline Buiding permt process & a & E & C & 口 & $\mathrm{E}$ & 口 & a & C \\
\hline Zorire farmis protess & 口 & ㅁ & 工 & $\square$ & 口 & 口 & ㅁ & c \\
\hline Buerd of Nrthtects neview & $\square$ & $\square$ & D & $\square$ & c & व & $\mathbb{0}$ & ㄷ \\
\hline \multirow[t]{2}{*}{ 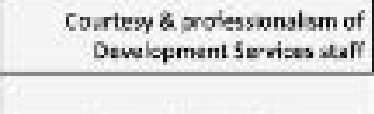 } & 口 & ㅁ & D & $\mathbf{L}$ & $\mathrm{L}$ & $\mathbf{u}$ & $\mathbf{u}$ & ㅁ \\
\hline & \multicolumn{8}{|c|}{ 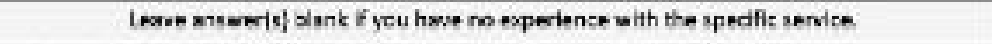 } \\
\hline \multicolumn{9}{|c|}{ 13a. What can the Derelopment Services Department do to better meet or eweced your expectations? } \\
\hline
\end{tabular}

\begin{tabular}{|c|c|c|c|c|c|c|c|c|}
\hline \multicolumn{9}{|c|}{ 14. Development Services Code Enforcement - Rate your satisfaction and Importance for each of the following services. } \\
\hline & $\begin{array}{c}\text { Very } \\
\text { Sensted }\end{array}$ & Sortsfed & Dosoritind & $\begin{array}{c}\text { Vary } \\
\text { Dissetsisted }\end{array}$ & $\begin{array}{c}\text { Wary } \\
\text { Importient }\end{array}$ & Impartant & $\begin{array}{l}\text { Sanembat } \\
\text { Inportant }\end{array}$ & $\begin{array}{c}\text { Not } \\
\text { Importwet }\end{array}$ \\
\hline Oty mode wablendusatinn & ᄃ & D & $\mathbf{D}$ & ᄃ & D & $\mathbf{0}$ & $\mathbf{0}$ & C \\
\hline $\begin{array}{r}\text { Response times \& follow up of Code } \\
\text { Frlorsement Officer }\end{array}$ & ᄃ & $\mathbf{c}$ & $\mathbf{D}$ & c & D & $\mathbf{c}$ & $\mathbf{\square}$ & 다 \\
\hline Appearance of your acightortood & ᄃ & C & D & C & D & 口 & $\mathbf{\square}$ & c \\
\hline $\begin{array}{r}\text { Courtery a profssional bem of } \\
\text { Code Enforcement tatH }\end{array}$ & $r$ & n & $n$ & $\Pi$ & $n$ & $\pi$ & $\pi$ & $\Gamma$ \\
\hline \multicolumn{9}{|c|}{ 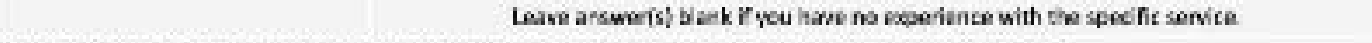 } \\
\hline \multicolumn{9}{|c|}{ 14a. What can the Sode Enforcement Pivision do to better meet or exceed your expectations? } \\
\hline
\end{tabular}

Aetady 
City of Collal Gables Community Engagement Survey 2018

\begin{tabular}{|c|c|c|c|c|c|c|c|c|}
\hline \multicolumn{9}{|c|}{ 15. Police Department - Rate your satistaction and importanoe for each of the follorwing services. } \\
\hline & $\begin{array}{c}\text { very } \\
\text { satisted }\end{array}$ & Sasisted & Desuetilied & $\begin{array}{c}\text { Very } \\
\text { Disiatisted }\end{array}$ & $\begin{array}{l}\text { Very } \\
\text { Impartant }\end{array}$ & inpartent & $\begin{array}{l}\text { Sonewiar } \\
\text { Infortam }\end{array}$ & $\begin{array}{c}\text { Net } \\
\text { Impartint }\end{array}$ \\
\hline $\begin{array}{r}\text { Crime prevention s. public } \\
\text { edusatien }\end{array}$ & ㅁ & $\mathrm{n}$ & $\mathbf{n}$ & ᄃ & n & 口 & 口 & ᄃ \\
\hline Spoodire in my neightertood & 드 & L & D & E & 드 & ㅁ & ㅁ & E \\
\hline $\begin{array}{r}\text { Fee Ing sate in cly ports, retall } \\
\text { detricts \& publie speres }\end{array}$ & 단 & c & ㅁ & c & c & ㅁ & ㅁ & c \\
\hline Neghicerhood 5afeby Ads program & E & D & 口 & E & E & $\mathbf{L}$ & $\mathbf{D}$ & L \\
\hline Polke reszanse ta amergencies & ㅁ & D & $\mathrm{D}$ & E & E & 口 & 口 & 工 \\
\hline $\begin{array}{r}\text { Courtegy \& professionalism of } \\
\text { Foles Department saff }\end{array}$ & ㅁ & $\mathrm{n}$ & $\mathrm{D}$ & E & ㅁ & $\mathbf{n}$ & 口 & E \\
\hline
\end{tabular}

Leave arswe ist blatk ry you have as cxperisnce with one specific service

15a. What can the Pelio Department do to bettar mest ar enceed your enpectations?

\begin{tabular}{|c|c|c|c|c|c|c|c|c|}
\hline & $\begin{array}{l}\text { Very } \\
\text { sadisted }\end{array}$ & Satiefad & Deratiened & $\begin{array}{c}\text { Very } \\
\text { Cicuatisted }\end{array}$ & Iepartant & Inpartant & $\begin{array}{l}\text { Somenitek } \\
\text { Impartamt }\end{array}$ & $\begin{array}{c}\text { Not } \\
\text { Impartant }\end{array}$ \\
\hline Fire presentien A pable edustion & ㅁ & D & $\mathbf{D}$ & ᄃ & C & $\mathbf{0}$ & $\mathbf{0}$ & C \\
\hline $\begin{array}{l}\text { Emergency madiod puble } \\
\text { eduation (CPA) }\end{array}$ & $\mathbf{c}$ & D & D & C & $\mathbf{c}$ & $\mathbf{D}$ & $\mathbf{0}$ & ᄃ \\
\hline Kesponse to ire emergencies & 工 & $\mathbf{C}$ & D & ᄃ & 口 & 口 & 口 & c \\
\hline Aesporse to med ca emerzendes & ㅁ & D & D & ᄃ & C & $\mathbf{0}$ & $\mathbf{0}$ & ᄃ \\
\hline $\begin{array}{l}\text { Courtegy s professicnalem of } \\
\text { fice Department vieff }\end{array}$ & $\mathrm{t}$ & D & 口 & E & $\mathbf{L}$ & $\mathbf{n}$ & $\mathbf{\square}$ & E \\
\hline
\end{tabular}

Leave arswerisf blank ryou hase no experience with the speofic senvice

16a. What can the Fire Department do to better meet or eroesd your cxpectations?

\begin{tabular}{|c|c|c|c|c|c|c|c|c|}
\hline & $\begin{array}{c}\text { Very } \\
\text { Satistind }\end{array}$ & Serisfed & bissetshed & $\begin{array}{c}\text { Very } \\
\text { ahvelafied }\end{array}$ & $\begin{array}{c}\text { Very } \\
\text { Impartant }\end{array}$ & meoran & $\begin{array}{l}\text { Sementat } \\
\text { mpertane }\end{array}$ & $\begin{array}{l}\text { Nat } \\
\text { Inpartant }\end{array}$ \\
\hline $\begin{array}{l}\text { Hurricate preparadraca } \\
\text { a publc edusation }\end{array}$ & ㅁ & D & D & 0 & $\mathbf{0}$ & व & D & $\mathbf{0}$ \\
\hline Furricant tmersency response & 미 & D & D & a & $\mathbf{D}$ & $\mathbf{D}$ & $\mathbf{D}$ & D \\
\hline 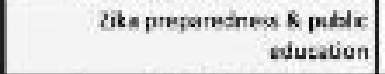 & D & D & D & 口 & $\mathbf{L}$ & $\mathbf{a}$ & 口 & $\mathbf{L}$ \\
\hline $\begin{array}{l}\text { Courber } 4 \text { prolessisnalibm of } \\
\text { Emergency Manapemant saff }\end{array}$ & C & D & D & 0 & D & $\mathbf{a}$ & $\mathbf{D}$ & $\mathbf{0}$ \\
\hline \multicolumn{9}{|c|}{ Leave answer(s) blank if pow have no eaper ence with the ssectic service. } \\
\hline
\end{tabular}

Aetady 


\section{Citr of CORAI GABLES COMMUNITY ENGAGEMENT SURVEY 2018}

\begin{tabular}{|c|c|c|c|c|c|c|c|c|}
\hline \multicolumn{9}{|c|}{ 18. Publir. Works Departmem - Rate your satisfaction and importance for each of the following services. } \\
\hline & $\begin{array}{c}\text { Very } \\
\text { sattefied }\end{array}$ & Sasisted & Dearationted & $\begin{array}{c}\text { Very } \\
\text { Disuatieted }\end{array}$ & $\begin{array}{c}\text { Vey } \\
\text { Impartint }\end{array}$ & Inpartant & $\begin{array}{l}\text { Somewalax } \\
\text { Inportam }\end{array}$ & $\begin{array}{c}\text { Nes } \\
\text { Impertint }\end{array}$ \\
\hline Aewdway oend t ars & 다 & D & 口 & c & ᄃ & 口 & 口 & c \\
\hline Acedury drancegs & 다 & D & D & [ & ᄃ & 口 & ㅁ & [ \\
\hline Mairbenante of publit rightis of way & 다 & c & ㅁ & ᄃ & ᄃ & ㅁ & ㅁ & ᄃ \\
\hline Shest trow trimting 5 , pleting & 다 & c & D & C & ᄃ & 口 & 口 & ᄃ \\
\hline Waterwar condt ons & ㅁ & 口 & ㅁ & F & ᄃ & ㅁ & ㅁ & ᄃ \\
\hline $\begin{array}{l}\text { Courtes/ \& protessionaltsm of } \\
\text { Puelic Works Department esff }\end{array}$ & ㅁ & ㅁ & ㅁ & ᄃ & ㅁ & ㅁ & ㅁ & c \\
\hline \multicolumn{9}{|c|}{ 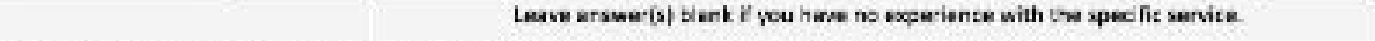 } \\
\hline
\end{tabular}

19. Public Works Sanitation Pivision - Rate your satisfaction pand importanoe for ench of the followine services.

\begin{tabular}{|c|c|c|c|c|c|c|c|c|}
\hline & $\begin{array}{l}\text { Very } \\
\text { Sotiatied }\end{array}$ & Satiafied & Disentiafied & $\begin{array}{c}\text { Very } \\
\text { Ctantiathed }\end{array}$ & $\begin{array}{c}\text { Very } \\
\text { Impartant }\end{array}$ & Imocetant & $\begin{array}{l}\text { Somewhot } \\
\text { Impostant }\end{array}$ & $\underset{\text { Nimpartam }}{\text { Nat }}$ \\
\hline Household gortage service & व & $\square$ & ㄷ & $\mathbf{0}$ & $\mathbf{\square}$ & D & D & $\mathbf{0}$ \\
\hline Balk trash pleservisa & $\pi$ & $\pi$ & $\Gamma$ & $\mathbf{n}$ & $\mathbf{n}$ & $\pi$ & $\mathbf{n}$ & $\pi$ \\
\hline Neryring servioe & व & $\square$ & ז & $\mathbf{0}$ & $\mathbf{0}$ & 0 & 0 & $\mathbf{n}$ \\
\hline Uukt thah put mantensmoe & ] & $\square$ & ᄃ & 口 & 口 & ס & D & 口 \\
\hline 5 ze a deslen of recyding bies & $a$ & 口 & C & $\mathbf{0}$ & 口 & $\mathbf{0}$ & D & $\mathbf{D}$ \\
\hline Reporse to misssd pickups & a & 口 & E & $\mathbf{0}$ & $\mathbf{D}$ & $\mathbf{0}$ & a & $\mathbf{D}$ \\
\hline $\begin{array}{l}\text { Courtegy la proress onal sm of } \\
\text { Saniat en Desisien staff }\end{array}$ & a & a & c & 口 & 口 & a & 口 & 口 \\
\hline
\end{tabular}

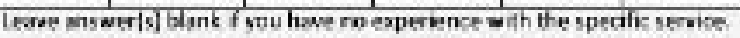

19a. What can the Public Works Sanitation Division do to better meet or exceed your expectations?

\begin{tabular}{|c|c|c|c|c|c|c|c|c|}
\hline \multicolumn{9}{|c|}{ 20. City Events, Arts \& Culture - Rate your satisfaction and Importance for each of the followng services. } \\
\hline & $\begin{array}{c}\text { Vory } \\
\text { Sadsted }\end{array}$ & Seristed & Doretisticd & $\begin{array}{c}\text { Very } \\
\text { Oisuetisted }\end{array}$ & Impertiont & Infortan & $\begin{array}{l}\text { Sonewitat } \\
\text { Importamt }\end{array}$ & $\begin{array}{l}\text { Not } \\
\text { Iepertant }\end{array}$ \\
\hline Art in Fublic Places Program & L & D & D & E & C & 口 & D & E \\
\hline Cut_.ral venues (Cinemas, theaters)] & ㅁ & $\mathrm{E}$ & 口 & 工 & E & 口 & $\mathbf{\square}$ & E \\
\hline 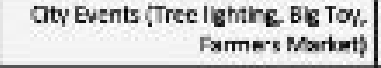 & ㅁ & $\mathrm{D}$ & $\square$ & E & ㅁ. & $\mathrm{n}$ & $\mathrm{n}$ & E \\
\hline Culbural Eosits flam in the Gobles) & 口 & D & D & ᄃ & ㄷ & 口 & 口 & ᄃ \\
\hline $\begin{array}{r}\text { Courtesy a protessknallem of } \\
\text { ment osft }\end{array}$ & ㄷ & D & D & c & ㄷ & $\square$ & $\square$ & c \\
\hline \multicolumn{9}{|c|}{ Leave arswer (s) blankr you have no cxperitnte with the spectic service } \\
\hline
\end{tabular}

Ave 4 at 


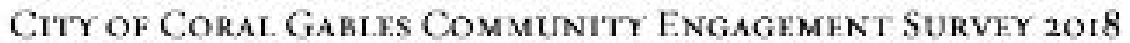

\begin{tabular}{|c|c|c|c|c|c|c|c|c|}
\hline & $\begin{array}{l}\text { Very } \\
\text { satiotind }\end{array}$ & Serisficat & Disiet iffed & $\begin{array}{l}\text { Very } \\
\text { Desatintind }\end{array}$ & $\begin{array}{c}\text { Wery } \\
\text { Impartant }\end{array}$ & Iepertunt & $\begin{array}{l}\text { Sarrematst } \\
\text { importane }\end{array}$ & $\begin{array}{l}\text { Nat } \\
\text { Impartam }\end{array}$ \\
\hline 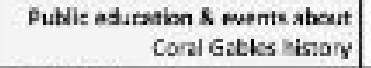 & L & L & D & c & D & [ & D & ם \\
\hline Hestorstion of ovicronumerts & [ & c & D & c & D & c & D & o \\
\hline Deslgevtion of histork hates & 드 & c & D & ᄃ & c & c & D & o \\
\hline Meiriensาce of thstorie prosettes & 다 & c & D & ㅁ & D & c & D & व \\
\hline 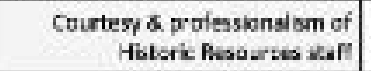 & E & c & ㅁ & c & c & c & ㅁ & a \\
\hline
\end{tabular}

21. What can the Historic Resources Department do to better meet or exceed your eapectations?

\begin{tabular}{|c|c|c|c|c|c|c|c|c|}
\hline \multicolumn{9}{|c|}{ 22. Parks \& Recrestion - Rate you satisfaction and how important for each of the followine services. } \\
\hline & $\begin{array}{l}\text { Why } \\
\text { soristiod }\end{array}$ & Snilinhas & Dherikfined & $\begin{array}{c}\text { Vorr } \\
\text { Oscenisfied }\end{array}$ & $\begin{array}{c}\text { Very } \\
\text { imperesex }\end{array}$ & Impartant & $\begin{array}{l}\text { Someunter: } \\
\text { Inpertant }\end{array}$ & $\begin{array}{c}\text { Not } \\
\text { amperesex }\end{array}$ \\
\hline Astessialtity to resteatiangl fasirias & D & D & $\square$ & D & 0 & c & c & 0 \\
\hline Setaty of reoreabonal fallites & D & D & a & D & a & c & c & 0 \\
\hline Qualry of recreational progams & 口 & 무 & ㅁ & 口 & 므 & E & 工 & 므 \\
\hline Iniksioe rectedt unal proprams & $\mathrm{D}$ & $\square$ & 무 & 口 & ㅁ & ᄃ & 든 & 0 \\
\hline Soi katrestional progrems & D & ㅁ & ㅁ & D & a & ᄃ & ᄃ & 0 \\
\hline $\begin{array}{c}\text { Courtesy \& professisenalian of } \\
\text { Parks B. Recrestion stat' }\end{array}$ & D & $\mathrm{r}$ & $a$ & D & 0 & r & c & 0 \\
\hline \multicolumn{9}{|c|}{ Leave arsower's) blark if pou have no expearierce with the seechic servica. } \\
\hline
\end{tabular}

\begin{tabular}{|c|c|c|c|c|c|c|c|c|}
\hline & $\begin{array}{l}\text { very } \\
\text { surtafied }\end{array}$ & solibfied & Dissikfiod & $\begin{array}{c}\text { Very } \\
\text { Doumtafived }\end{array}$ & $\begin{array}{l}\text { Very } \\
\text { importark }\end{array}$ & Impertint & 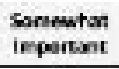 & $\begin{array}{c}\text { Mot } \\
\text { mportant }\end{array}$ \\
\hline Traleproules & ㅁ & 口 & $\square$ & D & a & D & ㅁ & $\square$ \\
\hline Trelley frequanzy & D & $\square$ & a & D & $a$ & D & 0 & 0 \\
\hline $\begin{array}{r}\text { Complimantary downtemil Frosbee } \\
\text { service }\end{array}$ & 0 & 0 & a & 0 & a & 0 & 0 & a \\
\hline Avalability of pusdic perkirg & D & व & a & D & a & 0 & 0 & 0 \\
\hline Raskdervia Perreit Parking Zomas & ㅁ & 口 & a & 口 & a & D & D & a \\
\hline $\begin{array}{c}\text { Courtesy So professioesian of } \\
\text { Porting and Traley stat }\end{array}$ & $\Pi$ & $\Pi$ & त & n & ח & $n$ & $n$ & ח \\
\hline
\end{tabular}

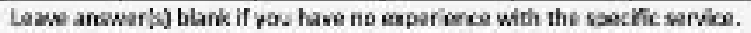

23. What can the Parking o. Trolley Denartment do to better meet or exceed your expectetions? 


\section{City of CoRAL Gables Community Engagement SURVEY 2018}

24. What is your overall satisfaction with how the City communicates with you regarding city news and upcoming events?
DUerysutisfied
ostisfied
oderentirfied
口 Weny niestief ins
口 Bon't Kana

25. What is your preferred laneuapes(s) for City of Coral Gables communications?
ᄃ Endlah
Dspanish
Q Other:

26. During an emergency, like a hurricane, how satisfied are you with how the City communicates important information?
C Verysatisfled
a Sotbried
口 Dssatistiad
a Very Disather
con't knos

27. Place a check neet to your top 3 sources for Clty of Coral Gables news and upcoming events.
c oly wea site
DCLy E-runalutur
c Kewipares:
$\square \mathrm{TV}$
a faceseok
DTwitter
a roernet
L Famly \& Frients
Co morkers
마ogs
C I wing h the Crry Beauthul Magaine
c Ceter:

28. What can the dity of Coral Gables do to better meet or exceed your expectations when commanicatine with you?

29. Would you tell a family member, friend, or co-worher the Clty of Coral Gables \&s a great place to llwe, work and play? Circle a number below ranging from 10 (Nbsolutely) to 1 (Never),
10
7
6
Neutro
43
$\gamma$
1
Absolutely
Never

30. What are rour top 3 favorite places in the City of Coral Gables?

$s$

31. Is there amy reason you would consider moving out of Coral Gables?

32. What question(s] do you wish we would here asked on this strvey?

33. Please provide any other comments and supgestions.

Thank You!

Thank you for completirg this comfidential Community Enezaement Survey and providine vour valuable feedsack. Please use the provided self-addressed envelope to mail your completed survey by September 17, 2018.

Best,

Cathy Swanson-fivenbark, City Manaser

City of Caral Gables 


\section{Gily of tareal Gubles}

\section{Planning and Zoning Customer Satisfaction Survey}

To assist etaff in progesm crhancements, your foodbock is critical.

Please complete this anonymous surwey and place in the bax located at the Counter. Thank you

Are you a: $\square$ Contrsctor $\square$ Resident / liomcowner $\square$ Permit Runner

What is your primary language? II Fnelish 11 spanish $\square$ other

How long have you bean a resident ar contractor doine buxinexs in Coral Gablex?

$\square$ Less 1 year $\square 2$ to 5 vears $\square 6$ to 10 years $\square$ Over 11 years

How many permita have you applied for, includins this application?

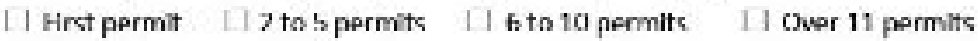

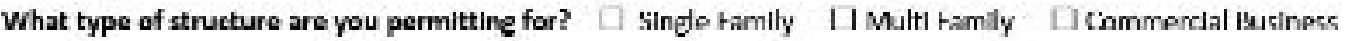

What is the zlp code of your project?

\begin{tabular}{|c|c|c|c|c|c|}
\hline \multicolumn{6}{|c|}{ Please rate your satiafaction with the following: } \\
\hline 7oning Applicatinn Process & $\begin{array}{l}\text { Vory } \\
\text { Satisfied }\end{array}$ & Satistiod & Dessatistled & $\begin{array}{l}\text { Very } \\
\text { Disoatisfied }\end{array}$ & NA \\
\hline Acsess th the permit application & 므 & $\square$ & $\square$ & $\square$ & $\square$ \\
\hline Esso cf complating the sppilication & ㅁ & 口 & $\square$ & ㅁ & ㅁ \\
\hline $\begin{array}{l}\text { Staff Jvalia belity to answer appication } \\
\text { questors }\end{array}$ & $\square$ & $\square$ & $\square$ & $\square$ & $\square$ \\
\hline 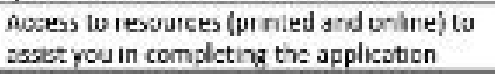 & $\square$ & $\square$ & $\square$ & $\square$ & $\square$ \\
\hline $\begin{array}{l}\text { Connd iscurementa were cledt and } \\
\text { understandable }\end{array}$ & $\square$ & $\square$ & $\square$ & $\square$ & $\square$ \\
\hline \multicolumn{6}{|l|}{ Comments: } \\
\hline Planes Revipw Stafl & $\begin{array}{c}\text { Vary } \\
\text { sulisfied }\end{array}$ & Sutiblied & Dissutiafied & $\begin{array}{c}\text { Vety } \\
\text { Disudinfined }\end{array}$ & NA \\
\hline $\begin{array}{l}\text { 5taff knowkecgesbic about the roning } \\
\text { spalcatlan pmopss }\end{array}$ & $\square$ & $\sqcup$ & $\square$ & $\square$ & $\sqcup$ \\
\hline Staff profeczlersiltem & $\square$ & घ & $\square$ & $\square$ & 口 \\
\hline $\begin{array}{l}\text { Plare renew staff responded timely to your } \\
\text { questurs }\end{array}$ & ᄂ & $\sqcup$ & $\sqcup$ & $\sqcup$ & $\sqcup$ \\
\hline $\begin{array}{l}\text { City deys:tments fother than plenting \& } \\
\text { zening) tamely response to questions }\end{array}$ & $\Gamma$ & $\sqcap$ & $\neg$ & $\Pi$ & $\sqcap$ \\
\hline $\begin{array}{l}\text { Staff pruvided deti, easy to understernd } \\
\text { instructions }\end{array}$ & $\square$ & $\square$ & $\square$ & $\square$ & $\square$ \\
\hline
\end{tabular}




\begin{tabular}{|c|c|c|c|c|c|}
\hline Boord of Architects Process & $\begin{array}{c}\text { Vory } \\
\text { Satistlod }\end{array}$ & 5atisfied & Dissatistiod & $\begin{array}{c}\text { Very } \\
\text { Dissaristipd }\end{array}$ & NA \\
\hline $\begin{array}{l}\text { Zoning staft addsed me what to prepare } \\
\text { for in advarce of the meeting }\end{array}$ & ㄷ & ロ & $\square$ & 口 & $\square$ \\
\hline Heard memiber were respectul & $\square$ & $\square$ & $\square$ & $\square$ & 口 \\
\hline $\begin{array}{l}\text { Wuald metibe reques is informabori weit } \\
\text { ressorable }\end{array}$ & $\square$ & $\square$ & $\square$ & $\square$ & $\square$ \\
\hline $\begin{array}{l}\text { Ucaid mienibers folvwed the rules and } \\
\text { gudelines }\end{array}$ & $\square$ & $\square$ & $\square$ & $\square$ & $\square$ \\
\hline \multicolumn{6}{|l|}{ Comrnents: } \\
\hline Zoninf Code Knowledfe & Very Good & Good & Poor & Very Poor & NA \\
\hline $\begin{array}{l}\text { How would vou iate your unders.anduris of } \\
\text { the zcning requiremente at the "START" of } \\
\text { the applicatian protass? }\end{array}$ & ㄷ & $\square$ & $\square$ & 口 & 口 \\
\hline $\begin{array}{l}\text { How would you rate yaur unjerstanding of } \\
\text { the acnung requirements at the "END" of } \\
\text { the apelikatian prosess? }\end{array}$ & $\square$ & घ & $\square$ & 口 & $\square$ \\
\hline \multicolumn{6}{|l|}{ Comments: } \\
\hline Zoning Requirements & $\begin{array}{l}\text { Strongly } \\
\text { Agree }\end{array}$ & Agree & Disapree & $\begin{array}{l}\text { Stronghly } \\
\text { Dkaggep }\end{array}$ & NA \\
\hline $\begin{array}{l}\text { The Meditcrraresn sochitestural } \\
\text { requirements eantritute to the sity's } \\
\text { oweral teauty. }\end{array}$ & $\square$ & 口 & घ & $\square$ & $\square$ \\
\hline $\begin{array}{l}\text { The criy zerirg zade requirements add to } \\
\text { the Inne-tam ukibn of the dly }\end{array}$ & $\square$ & $\sqcup$ & $\square$ & $\square$ & $\square$ \\
\hline Comments: & & & & & \\
\hline
\end{tabular}

Additional Comments and Suggestions

Thank ynu for campleting the survey. Plate your rempleted survey in the ser ure black bas located at the reanter. 
VITA

\section{RAMON TRIAS}

1991

Master of Architecture

University of Miami, FL

1989

Bachelor of Architecture, Magna cum laude

University of Miami, FL

1989

Bachelor of Arts, Magna cum laude

University of Miami, FL

2012-Present

Assistant Director of Development Services, Planning and Zoning Director of Planning and Zoning

Coral Gables, FL

2007

Visiting Assistant Professor, Architecture

University of Miami, FL

2005-2012

Founder and Principal

Trias and Associates, Town Planning, Architecture, Preservation

2001-2008

Adjunct Professor, Architecture

Indian River State College, Fort Pierce, FL

$1995-2005$

Director of Development

Director of Planning

Fort Pierce, FL

1991-1995

Urban Design Coordinator

Treasure Coast Regional Planning Council

Registered Architect, Florida

National Council of Architecture Registration Boards, certificate

American Institute of Certified Planners, member 